\title{
LA-13638
}

Approved for public release; distribution is unlimited.

\section{A Review of Criticality Accidents}

\section{Revision}


Printing coordination by Jerry Halladay and Guadalupe Archuleta, Group CIC-9

Photocomposition by Wendy Burditt, Group CIC-1

Cover Design by Kelly Parker, Group CIC-1

Cover Illustration: Power and energy traces representative of a typical criticality excursion in solution - from the SILENE experimental report, reference \# 4.

An Affirmative Action/Equal Opportunity Employer

This report was prepared as an account of work sponsored by an agency of the United States Government. Neither The Regents of the University of California, the United States Government nor any agency thereof, nor any of their employees, makes any warranty, express or implied, or assumes any legal liability or responsibility for the accuracy, completeness, or usefulness of any information, apparatus, product, or process disclosed, or represents that its use would not infringe privately owned rights. Reference herein to any specific commercial product, process, or service by trade name, trademark, manufacturer, or otherwise, does not necessarily constitute or imply its endorsement, recommendation, or favoring by The Regents of the Unizersity of California, the United States Government, or any agency thereof. The viezos and opinions of authors expressed herein do not necessarily state or reflect those of The Regents of the University of California, the United States Government, or any agency thereof. Los Alamos National Laboratory strongly supports academic freedom and a researcher's right to publish; as an institution, however, the Laboratory does not endorse the viewpoint of a publication or guarantee its technical correctness. 


\section{DISCLAIMER}

Portions of this document may be illegible in electronic image products. Images are produced from the best available original document. 


\section{A Review of Criticality Accidents}

\section{Revision}

LA-13638

Issued: May 2000

United States Authors:

Thomas P. McLaughlin

Shean P. Monahan

Norman L. Pruvost*

Russian Federation Authors:

Vladimir V. Frolov**

Boris G. Ryazanov ${ }^{\star \star \star}$

Victor I. Sviridov ${ }^{\dagger}$

*Senior Analyst. Galaxy Computer Services, Inc., Santa Fe, NM 87501.

**Lead Researcher. Institute of Physics and Power Engineering (IPPE), Obninsk, Russia 249020.

${ }^{\star \star \star}$ Head of the Nuclear Safety Division. Institute of Physics and Power Engineering (IPPE), Obninsk, Russia 249020.

${ }^{\text {t}} \mathrm{Head}$ of the Nuclear Safety Laboratory. Institute of Physics and Power Engineering (IPPE), Obninsk, Russia 249020.

\section{Los Alamos}

NATIONAL LABORATORY

Los Alamos, New Mexico 87545 



\section{FOREWARD}

We, of the early decades at Pajarito Site, Los Alamos, were near a number of accidental bursts of radiation in the course of critical experiments. In the first of these, the person at the controls exclaimed "a disaster!" With a quarter-mile separation protecting operators, each of these "disasters" proved to be without consequence. Nevertheless, errors that led to them should have been avoided, and accounts of these accidents were disseminated to discourage recurrence.

A serious process criticality accident at Los Alamos was another matter, because protection of operators was supposed to have been provided by criticality safety practices instead of built-in features such as shielding or distance. In this case, publication brought out obscure causes that demanded consideration in the discipline of criticality safety.

The value of publication of both types of accident led William R. Stratton of the Pajarito Group to bring together all available descriptions in his A Review of Criticality Accidents, the linchpin of this account.

Hugh C. Paxton

Los Alamos, NM

August 1999 


\section{PREFACE}

This document is the second revision of A Review of Criticality Accidents. The first was issued as report LA-3611 in 1967 and authored by William R. Stratton. ${ }^{1}$ At that time, he was a staff member in the Critical Experiments Group at Los Alamos and a member of the Atomic Energy Commission's Advisory Committee on Reactor Safeguards. The first revision was published with the same title in 1989 as document NCT-04. ${ }^{2}$ This revision was carried out by David R. Smith, a colleague of Stratton's in the Critical Experiments Group during the 60's and 70's and the Laboratory's Criticality Safety Officer. In 1980, the criticality safety function was removed from the Critical Experiments Group and made a separate entity in the Laboratory's Health and Safety organization with Smith as the first group leader.

With the advent of cooperative research and information exchanges between scientists in the Russian Federation (Russia, R.F.) of the Former Soviet Union and Los Alamos National Laboratory in the early 1990s, discussions began to investigate possible joint work in the field of nuclear criticality safety (to be referred to hereafter as simply "criticality safety"). By 1994, interactions were ongoing between Los Alamos and four Russian sites with criticality safety interests: the Institute of Physics and Power Engineering (IPPE) in Obninsk; the All Russian Scientific Research Institute of Experimental Physics (VNIIEF) in Sarov (formerly Arzamas-16); the All Russian Scientific Research Institute of Technical Physics (VNIITF) in Snezhinsk (formerly Chelyabinsk-70); and the Kurchatov Institute (KI) in Moscow.

Criticality safety staff at IPPE have regulatory oversight responsibility for the four major fissile material production and handling sites where process facility criticality accidents have occurred. These are the Mayak Production Association (Mayak), the Siberian Chemical Combine (Tomsk-7) in Seversk, the Electrostal Machine Building Plant in Electrostal, and the Novosibirsk Chemical Concentrates Plant in Novosibirsk. Thus, criticality safety staff from these four sites were directly involved in the 13 Russian process accidents described herein. The other three institutes, Arzamas-16, Chelyabinsk-70, and the Kurchatov Institute have critical experiment and reactor development capabilities; accidents in this category have occurred at these sites.

This report, planned to be published in both English and Russian language versions, is the fruit of cooperative efforts of criticality safety specialists in both countries. It not only includes all of the Russian criticality accidents, but also revises the US and UK process facility accidents reported in the second edition. The revisions to the US and UK process accident descriptions are mainly expansions of the text to include information that was previously only in reference documents. In a few instances, technical corrections were necessary. The expanded descriptions are provided for the benefit of the broader audience that this document has been attracting over the years.

Finally, as this report was almost to be printed in September 1999, a criticality accident occurred at the JCO fuel processing facility in Japan. Printing was delayed until this most recent accident could be fully understood and documented herein. It is the goal of the authors that with this expanded report, the causes of criticality accidents and their consequences will be better understood and the safety and efficiency of operations with significant quantities of fissile materials will be enhanced. 


\section{ACKNOWLEDGMENTS}

Many people have contributed significantly to the completion of this second revision of A Review of Criticality Accidents. The relative importance of the contribution of each person is not intended by the ordering of names. Each person made a necessary contribution to the final document.

For the Russian accident information:

Gennadiy T. Kirillov-Tomsk-7

Mikhail I. Kuvshinov-Arzamas-16

Dimitri M. Parfanovich-Kurchatov Institute

Aleksandr V. Romanov-Electrostal

Igor G. Smirnov-Arzamas-16

Gennadiy S. Starodubtsev-Mayak

A. P. Suslov-Mayak

Vladimir Teryokhin—Chelyabinsk-70

Aleksandr G. Ustyugov-Novosibirsk

Sergei Vorontsov-Arzamas-16

Isao Takeshita-Japanese Atomic Energy Research Institute

The U.S. authors are indebted to each of the above for answering innumerable questions, often by telephone, at home, late at night in Russia in order to accommodate a mid-morning meeting time in Los Alamos. In particular, we acknowledge that Igor G. Smirnov, Sergei Vorontsov, Mikhail I. Kuvshinov, and Vladimir Teryokhin endured about three hours of "interrogation" one night at one of the Los Alamos authors' homes, and were recompensed only with a meal. On another occasion, after a similar evening of questions and discussion, Gennadiy Starodubtsev agreed to return two evenings later for another four-hour session, each time accepting only a meal as payment. These evening sessions took place after a full day of other business in Los Alamos. Gennadiy Starodubtsev was motivated by a personal desire to contribute to an accurate, complete recounting of the seven Mayak accidents.

Barbara D. Henderson played a key administrative role in keeping the project on track in many regards. She has been involved with the project from the time it was only an ill-defined goal to the final product, a nearly eight-year span.

Charles T. Rombough assisted with this project for more than two years. He has provided seamless transmission of information, text, figures, and photographs, in both English and Russian languages, in addition to producing electronic files of all intermediate drafts.

Nellie Schachowskoj Shropshire and Olga Viddo provided both interpretation and translation services for the many meetings, telephone calls, emails, and intermediate drafts.

Hugh C. Paxton once again, at the young age of 91 years, provided insightful and thoughtprovoking comments on the technical content. He also contributed sharp editorial comments.

David R. Smith provided valuable comments on various drafts, particularly on lessons learned from the accidents.

William R. Stratton provided valuable comments on early drafts of the report. 
Tom Jones was invaluable in generating most of the schematics found in Part I and in Appendix B, under significant time constraints.

Jerry McKamy of the Department of Energy and Chuck Nilsen of the Nuclear Regulatory Commission were instrumental in recognizing the value of and providing financial support for this project. They both also exhibited a vanishing talent by not micromanaging the project, for which the authors are grateful. 


\section{CONTENTS}

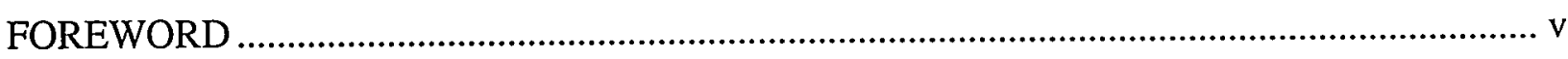

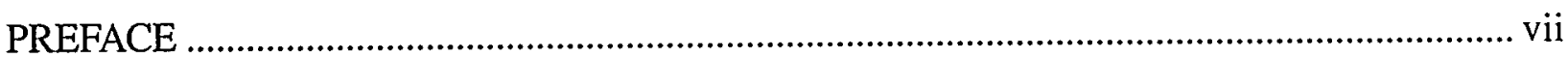

ACKNOWLEDGMENTS ....................................................................................................... ix

TABLE OF CONTENTS .................................................................................................. $\mathrm{xi}$

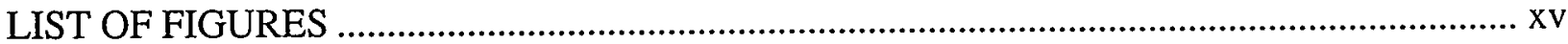

LIST OF TABLES .............................................................................................................. $\mathrm{xix}$

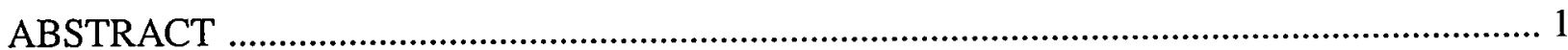

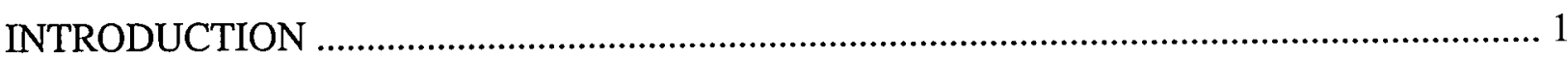

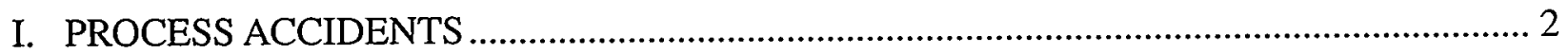

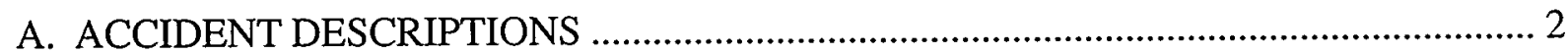

1. Mayak Production Association, 15 March 1953 ............................................................. 7

2. Mayak Production Association, 21 April 1957 ............................................................ 9

3. Mayak Production Association, 2 January 1958 ..................................................... 11

4. Oak Ridge Y-12 Plant, 16 June 1958 ...................................................................... 13

5. Los Alamos Scientific Laboratory, 30 December 1958 ……..................................... 16

6. Idaho Chemical Processing Plant, 16 October 1959 .................................................. 18

7. Mayak Production Association, 5 December 1960 ................................................... 19

8. Idaho Chemical Processing Plant, 25 January 1961 .................................................... 22

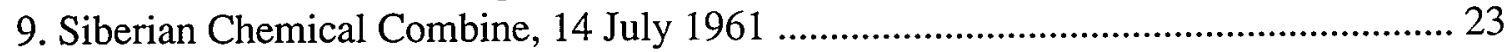

10. Hanford Works, 7 April 1962 ................................................................................ 27

11. Mayak Production Association, 7 September 1962 ..................................................... 28

12. Siberian Chemical Combine, 30 January 1963 ......................................................... 30

13. Siberian Chemical Combine, 2 December 1963 ........................................................ 31

14. United Nuclear Fuels Recovery Plant, 24 July 1964 ..................................................... 33

15. Electrostal Machine Building Plant, 3 November 1965 .............................................. 35

16. Mayak Production Association, 16 December 1965 ..................................................... 37

17. Mayak Production Association, 10 December 1968 .................................................... 40

18. Windscale Works, 24 August 1970 ............................................................................... 43

19. Idaho Chemical Processing Plant, 17 October 1978 .................................................. 45

20. Siberian Chemical Combine, 13 December 1978 ...................................................... 47

21. Novosibirsk Chemical Concentration Plant, 15 May 1997 ......................................... 50

22. JCO Fuel Fabrication Plant, 30 September 1999 ........................................................ 53

B. PHYSICAL AND NEUTRONIC CHARACTERISTICS FOR THE PROCESS FACILITY CRITICALITY ACCIDENTS ……………........................................... 57

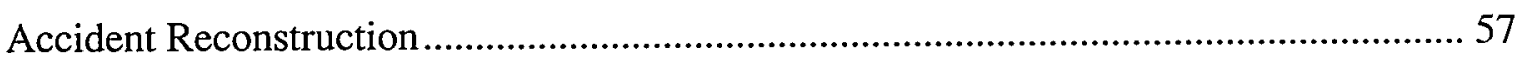

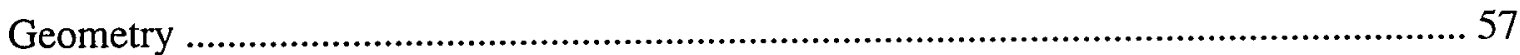

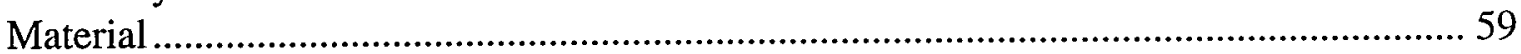

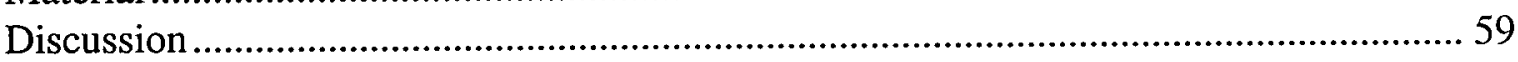

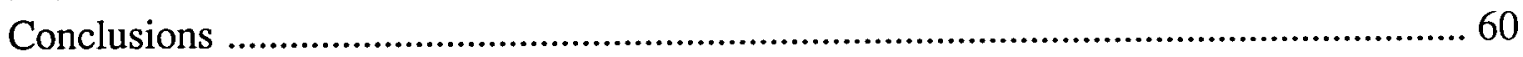

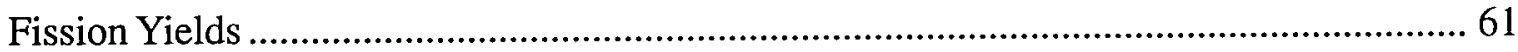




\section{OBSERVATIONS AND LESSONS LEARNED FROM PROCESS CRITICALITY ACCIDENTS}

Observations

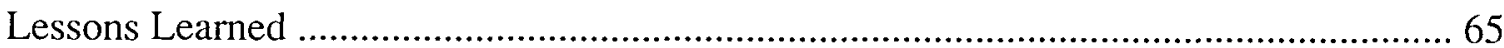

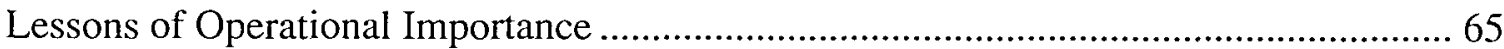

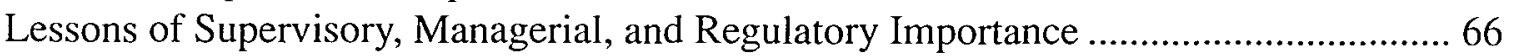

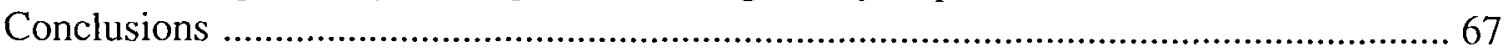

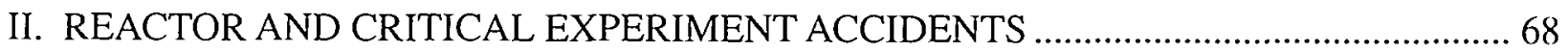

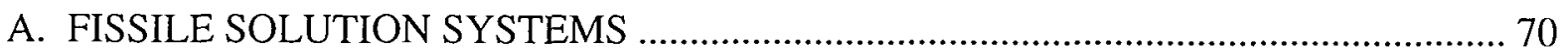

1. Los Alamos Scientific Laboratory, December 1949 ................................................... 70

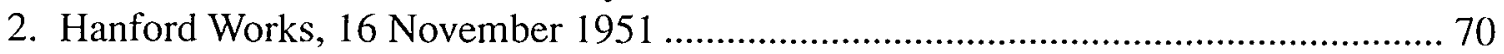

3. Oak Ridge National Laboratory, 26 May 1954 ...................................................... 71

4. Oak Ridge National Laboratory, 1 February 1956 ................................................ 72

5. Oak Ridge National Laboratory, 30 January 1968 .............................................. 73

B. BARE AND REFLECTED METAL ASSEMBLIES ............................................... 74

1. Los Alamos Scientific Laboratory, 21 August 1945 ............................................... 74

2. Los Alamos Scientific Laboratory, 21 May 1946 ................................................... 74

3. Los Alamos Scientific Laboratory, 1 February 1951 ............................................. 77

4. Los Alamos Scientific Laboratory, 18 April 1952 .................................................. 78

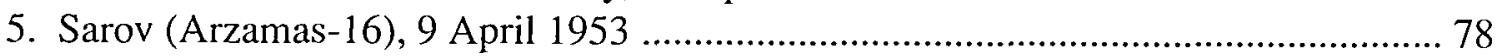

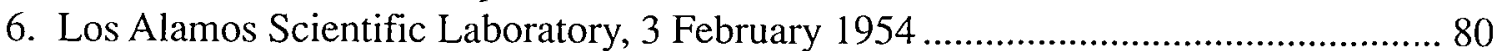

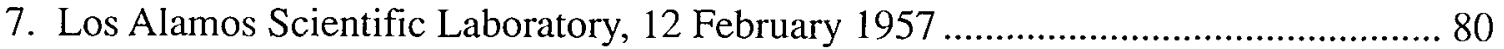

8. Los Alamos Scientific Laboratory, 17 June 1960 ................................................. 83

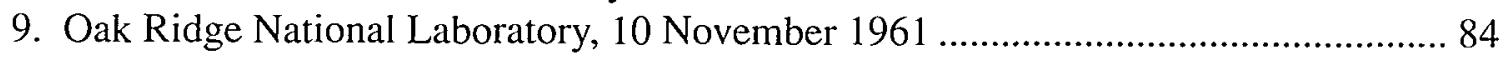

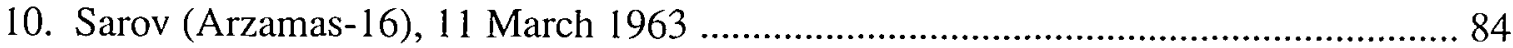

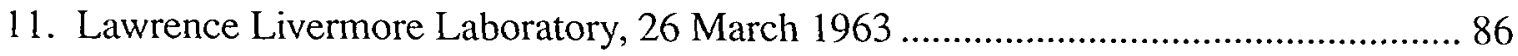

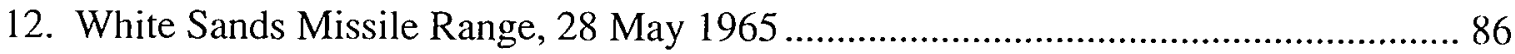

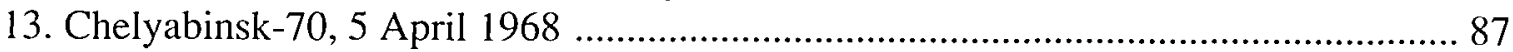

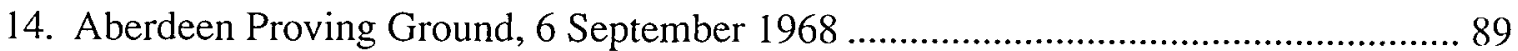

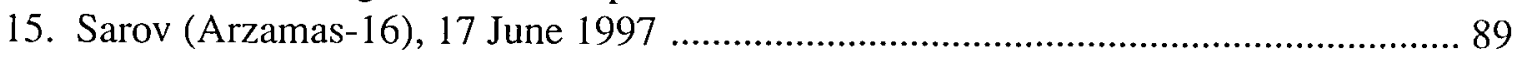

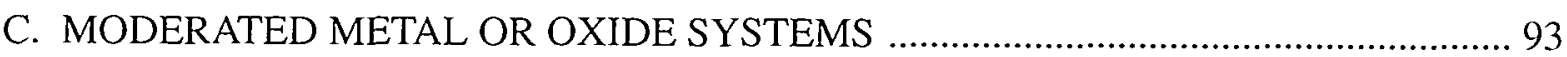

1. Los Alamos Scientific Laboratory, 6 June 1945 .................................................. 93

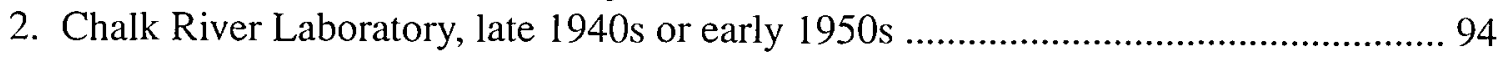

3. Argonne National Laboratory, 2 June 1952 ........................................................... 94

4. Chalk River Laboratory, Atomic Energy of Canada, Ltd., 12 December 1952 ......... 95

5. National Reactor Testing Station, 22 July 1954 ................................................. 95

6. Boris Kidrich Institute, 15 October 1958 ............................................................ 96

7. Centre dÉtudes Nucleaires de Saclay, France, 15 March 1960 ................................ 97

8. National Reactor Testing Station, 3 January 1961 ............................................... 97

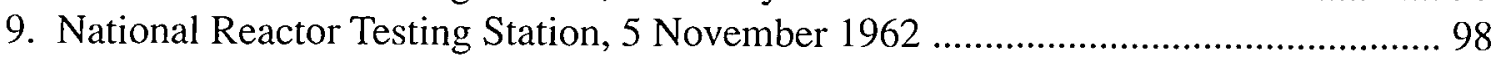

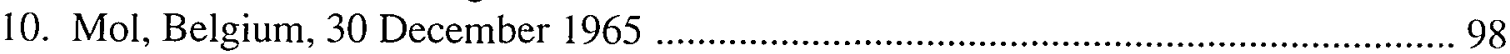

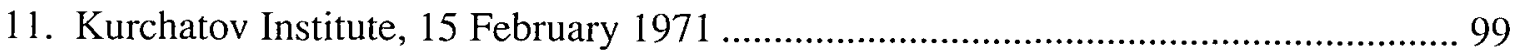

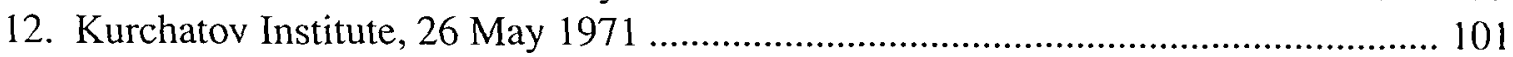

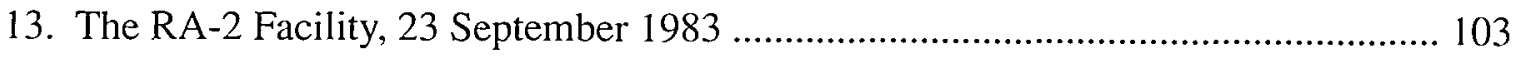




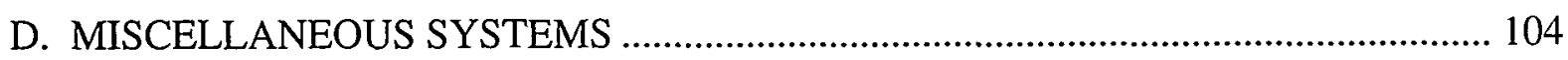

1. Los Alamos Scientific Laboratory, 11 February 1945 ................................................ 104

2. National Reactor Testing Station, 29 November 1955 ............................................ 104

3. Los Alamos Scientific Laboratory, 3 July 1956 ........................................................ 105

4. National Reactor Testing Station, 18 November 1958 ............................................ 106

5. Los Alamos Scientific Laboratory, 11 December 1962 ............................................. 106

III. POWER EXCURSIONS AND QUENCHING MECHANISMS …………………........... 107

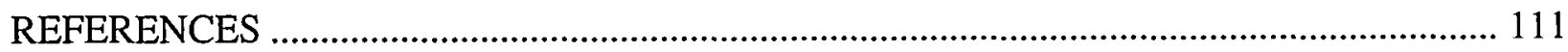

APPENDIX A: GLOSSARY OF NUCLEAR CRITICALITY TERMS ................................... 116

APPENDIX B: EQUIPMENT DIAGRAMS AND TABULAR PHYSICAL AND

YIELD DATA FOR THE 22 PROCESS ACCIDENTS ................................... 120 


\section{FIGURES}

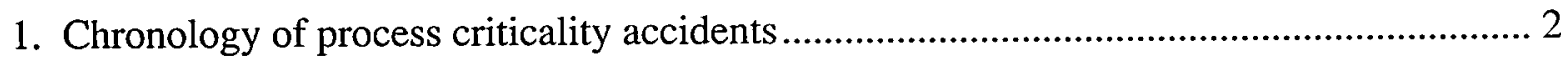

2. Map of the Russian Federation showing the sites of the process criticality accidents, the capital, Moscow, and Obinisk, the location of the regulating authority, IPPE ............. 3

3. Map of the United States showing the sites of the process criticality accidents, and the capital, Washington ..................................................................................................... 4

4. Map of the United Kingdom showing the site of the process criticality accident and the capital, London ........................................................................................................ 5

5. Map of Japan showing the site of the process criticality accident and the

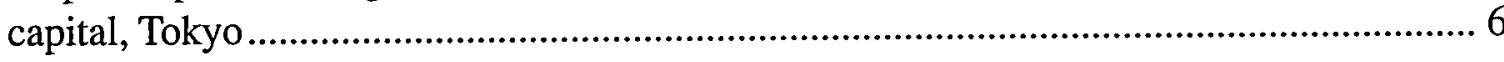

6. Layout of vessels and equipment in the staging area ...................................................... 7

7. Equipment layout for the oxalate precipitation and filtration process .............................. 10

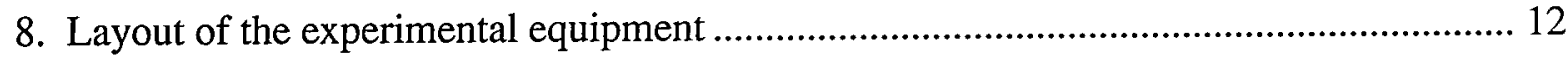

9. Simplified diagram of the $\mathrm{C}-1$ wing vessels and interconnecting piping involved in

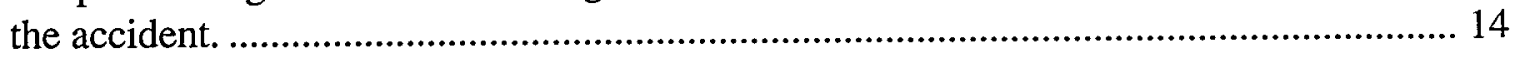

10. Drum in which the 1958 Y-12 process criticality accident occurred ............................... 15

11. Configuration of solutions (aqueous and organic) in the vessel before the accident ....... 16

12. Vessel in which the 1958 Los Alamos process criticality accident occurred ................... 17

13. Layout of vessels in Glovebox 10 and the holding vessel external to the glovebox ........ 19

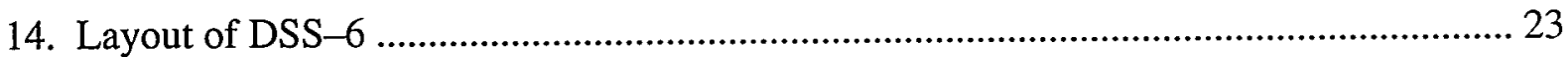

15. Vacuum pump diagram showing oil reservoir (Dimensions are in $\mathrm{mm}$ ) ......................... 24

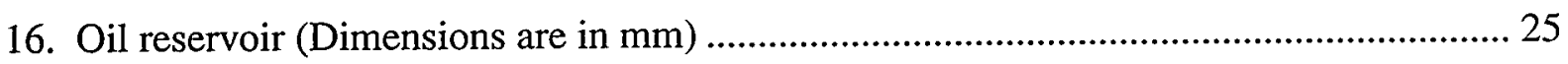

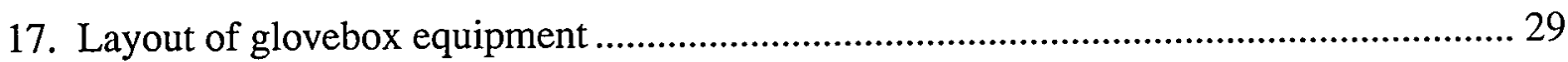

18. Process vessels and material flow diagram. ...................................................................... 30

19. Schematic of vessels showing organic and aqueous solutions (not intended to imply

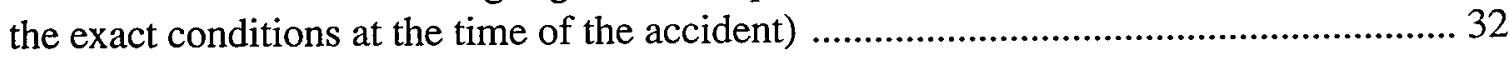

20. Layout of $\mathrm{UF}_{6}$ to uranium oxide conversion equipment and associated vacuum system

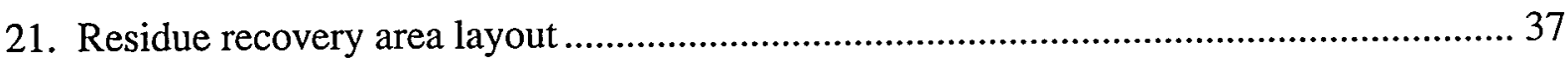

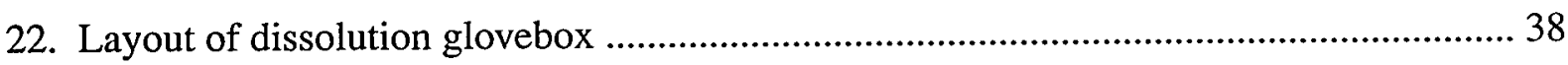

23. Plan view of the tanks involved in the accident ............................................................. 41

24. Elevation view of the tanks involved in the accident ....................................................... 41

25. Process equipment related to the criticality accident ......................................................... 43

26. Solution transfer as reconstructed from the transparent plastic mockup of the transfer vessel. Configuration (B) is the postulated state at the time of the accident 44 
27. First cycle extraction line equipment. The accident occurred in the lower disengagement section of the $\mathrm{H}-100$ column

28. Storage container

29. A simplified layout of Glovebox 13

30. Intended sequence for the transfer of ingots from and to Glovebox 13

31. Actual order of ingot transfers from and to Glovebox 13. The solid lines represent the actions of operator $A$ and the dotted lines the actions of operator $B$

32. Major components of the chemical-etching process

33. Sequence of alarms and duration that the radiation levels exceeded the alarm level $(36 \mathrm{mR} / \mathrm{h})$

34. Authorized and executed procedures 54

35. The precipitation vessel in which the process criticality accident occurred 55

36. The ratio of cylindrical to spherical critical masses of $U(93) \mathrm{O}_{2} \mathrm{~F}_{2}$ solutions, unreflected and with water reflector, as a function of cylinder height to cylinder diameter ratio 59

37. Critical masses of homogeneous water moderated U(93.2) spheres. Solution data appear unless indicated otherwise. The accidents are shown by numbered circles

38. Critical masses of water-reflected spheres of hydrogen-moderated $U(93), U(30.3)$, $\mathrm{U}(5.00), \mathrm{U}(3.00)$, and $\mathrm{U}(2.00)$. The accidents are shown by numbered circles

39. Critcial masses of homogeneous water moderated plutonium spheres. The points suggesting an intermediate curve apply to water reflected $\mathrm{Pu}\left(\mathrm{No}_{3}\right)_{4}$ solution with $1 \mathrm{~N} \mathrm{HNO}_{3}$ and $3.1 \%{ }^{240} \mathrm{Pu}$ content. The accidents are shown by numbered circles

40. The Oak Ridge National Laboratory uranium solution assembly showing the normal and detached positions of the central poison rod.

41. Plutonium sphere partially reflected by tungsten-carbide blocks ................................. 74

42. Configuration of beryllium reflector shells prior to the accident 21 May 1946 ............. 75

43. Calculated fission rate for the $6.2-\mathrm{kg}$ plutonium sphere .......................................... 76

44. Calculated total fissions vs. time for the $6.2-\mathrm{kg}$ plutonium sphere ............................. 76

45. The Los Alamos Scientific Laboratory aquarium assembly machine employed for measurements of critical separation distances .................................................... 77

46. FKBN and assembly involved in the 9 April 1953 accident .................................... 78

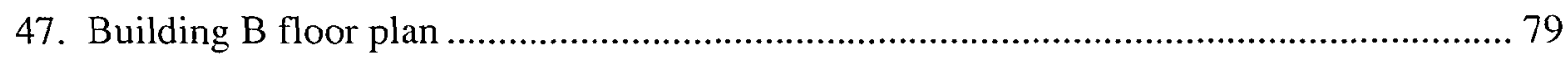

48. The Los Alamos Scientific Laboratory Lady Godiva assembly (unreflected enriched-uranium sphere) in the scrammed configuration

49. Lady Godiva after the excursion of 3 February 1954 82

50. Burst rod and several sections of Lady Godiva showing oxidation and warpage that accompanied the second accident, 12 February 1957 
51. MSKS and assembly involved in the 11 March 1963 accident

52. Building B floor plan

53. Approximate accident configuration of the FKBN vertical lift assembly machine and core

54. FKBN-2M building layout 90

55. FKBN-2M experimental layout 90

56. Accident configuration 91

57. Calculated power history for the accident 92

58. Removal of the main core of the assembly from the lower copper hemishell reflector ... 92

59. The destructive excursion in BORAX, 22 July 1954 96

60. Photograph of the SF-7 control and experimental rooms where the first accident occurred 100

61. Mockup of the accident configuration for the 26 May 1971 accident.... 102

62. The LASL Honeycomb assembly machine. The movable section (right) is in the withdrawn position and the aluminum matrix is only partially loaded

63. Energy model computation of power and energy release vs time. The initial reactivity is $1.2 \$$ above delayed critical. Neutron lifetime values are $10^{-8}, 10^{-6}$, and $10^{-4}$ seconds. The bottom panel shows the corresponding curves of reactivity vs time 108

64. Energy model computation of power vs time. The initial reactivity is $1.0 \$$ above delayed critical. Neutron lifetime values are $10^{-8}, 10^{-6}$, and $10^{-4}$ seconds. The bottom panel shows the corresponding curves of reactivity vs time 
xviii 


\section{TABLES}

1. Contents of Vessels 1 through 7 as Recorded in the Operational Log Before the Accident

2. The Expected Contents of Vessel 18 after the Planned Transfer ........................................ 8

3. The Actual Contents of Vessel 18 at the Time of the Accident. ......................................... 8

4. The Seven Vessels Related to the Reconstruction of the Criticality Accident ................... 20

5. Chronology of Batch Composition Leading to Overloading of Vessel R0 in Glovebox 9 .

6. Analysis of Accident Solution Recovered from Holding Vessel and R3 ......................... 21

7. Results of $\gamma$-Radiation Exposure Rate Measurements at Oil Reservoir ............................ 26

8. Characteristics of the First Three Excursions .................................................................... 52

9. Reconstruction of Accident Geometry and Material Configurations ................................. 58

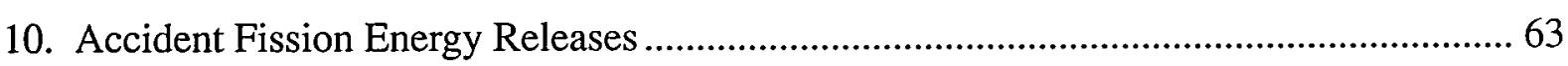

11. Reactor and Critical Experiment Accidents ..................................................................... 68

12. Pitch Versus Critical Number of Rods ..................................................................... 101 


\title{
A REVIEW OF CRITICALITY ACCIDENTS
}

\begin{abstract}
Criticality accidents and the characteristics of prompt power excursions are discussed. Sixty accidental power excursions are reviewed. Sufficient detail is provided to enable the reader to understand the physical situation, the chemistry and material flow, and when available the administrative setting leading up to the time of the accident. Information on the power history, energy release, consequences, and causes are also included when available. For those accidents that occurred in process plants, two new sections have been included in this revision. The first is an analysis and summary of the physical and neutronic features of the chain reacting systems. The second is a compilation of observations and lessons learned. Excursions associated with large power reactors are not included in this report.
\end{abstract}

\section{INTRODUCTION}

This revision of A Review of Criticality Accidents ${ }^{1,2}$ represents a significant expansion of the prior edition with the inclusion of one Japanese and 19 Russian accidents. In the first two parts of this report, 60 criticality accidents are described. These are divided into two categories, those that occurred in process facilities (22), and thus were unexpected, and those that occurred during critical experiments or operations with research reactors (38).

These two categories are based on the following considerations. Process facilities carrying out operations with fissile material avoid criticality accidents through physical and administrative controls. These controls are intended to prevent critical or near-critical configurations from ever occurring in the facility. Operating personnel are usually not technical experts in criticality physics. Under normal working conditions, however, operating personnel can be close to (arm's length from) potentially critical configurations. In contrast, reactor and critical experiment research facilities purposefully plan and achieve near-critical and critical configurations. These operating personnel are usually experts in criticality physics. Although they carry out hands-on operations with fissile material under restrictions similar to those found in process facilities, the planned nearcritical and critical configurations are performed under shielded or remote conditions.

In most cases, the descriptions of the Russian accidents are somewhat lengthier than those that occurred in other countries. This is attributable to the lack of generally available references for the Russian accidents. In other words, the descriptive information in this report is all that is effectively available for these accidents. It has been gleaned from both the original Russian notes and discussions with those who had personal knowledge of the accidents. With the exception of the addition of the six Russian critical experiment accidents, Part II of this report is basically unchanged from that of the second edition.
Although this edition is planned to be available in both English and Russian language versions, decisions had to be made concerning units and terminology, particularly in the English language version. We have attempted to conform to common international usage. However, units as originally reported are sometimes retained for historical accuracy. Also, we have chosen generally understood terminology and avoided terms that might be facility or industry specific. For example, the word "vessel" is used to describe most solution holding containers. Thus "filter vessel" is used instead of "filter boat," a common U.S. chemical industry term.

In Part III, a brief discussion of analytical methods and quenching mechanisms for power excursions is reproduced from the first revision. Two appendices are also new to this revision. Appendix $A$ is a reproduction of LA-1 1627-MS, Glossary of Nuclear Criticality Terms $^{3}$ (supplemented with one additional definition) to assist the reader. In Appendix B diagrams of each of the 22 process vessels in which the accidents took place are shown along with tabular summaries of the system parameters (mass, volume, etc.).

The emphasis of this revision has been threefold. First, it was to include the one Japanese and 19 Russian accidents. Fourteen of these took place in process facilities and six happened during critical experiments and research reactor operations. A second focus of this effort has been to thoroughly review the eight process facility accidents described in the prior revision of this document and their supporting references. This led to some technical corrections and modest expansions of the process descriptions for the benefit of the expanded audience that this report has attracted over the years. Third, two analyses of the 22 process accidents are included. These are (1) physical and neutronic characteristics with an emphasis on understanding systematic features and (2) observations and lessons learned from these accidents. 


\section{PROCESS ACCIDENTS}

The 22 criticality accidents that occurred during process operations are each described in one to several pages. accompanied by schematics and photographs when available. These are the accidents that are directly relevant to process criticality safety. In all cases the level of detail is sufficient to understand the physical conditions. The neutronic, physical, radiologi$\mathrm{cal}$, and human consequences of the accidents are presented. Causes are included for those accidents for which this information was reported in the original documentation or was available from those with first hand knowledge.

As supplements to the descriptions, two new sections have been added to Part I of this revision. The first new section presents the results of simplified reconstructions of the physical and neutronic aspects of each accident. These re-constructions are compared to known conditions for criticality. In addition, the energy releases, both the first spike and the total excursion yield, are discussed with respect to expected values based on data from the SILENE, CRAC, and KEWB experiments. ${ }^{4.5 .6}$ Complementing this section is Appendix $B$ that contains diagrams of the vessels in which the 22 accidents occurred and tables showing the parameters (fissile mass, volume, etc.) of the simplified re-constructions.

In the second new section, observations and lessons learned, extracted from a thorough review of all of the accidents, are presented. This process was necessarily subjective since in many cases there were obvious operator actions that were directly related to the accident, but seldom were the operator's thoughts reported. This summary of lessons learned should prove valuable as a training tool. It may also assist management by providing insight into major risk contributors thus helping to reduce risks and to prevent accidnts.

A chronology of the accidents that occurred in process facilities is provided in Figure 1. Below are listed highlights of these 22 process accidents.

- 21 occurred with the fissile material in solutions or slurries.

- One occurred with metal ingots.

- None occurred with powders.

- 18 occurred in manned, unshielded facilities.

- 9 fatalities resulted.

- 3 survivors had limbs amputated.

- No accidents occurred in transportation.

- No accidents occurred while fissile material was being stored.

- No equipment was damaged.

- Only one accident resulted in measurable fission product contamination (slightly above natural levels) beyond the plant boundary.

- Only one accident resulted in measurable exposures (well below allowable worker annual exposures) to members of the public.

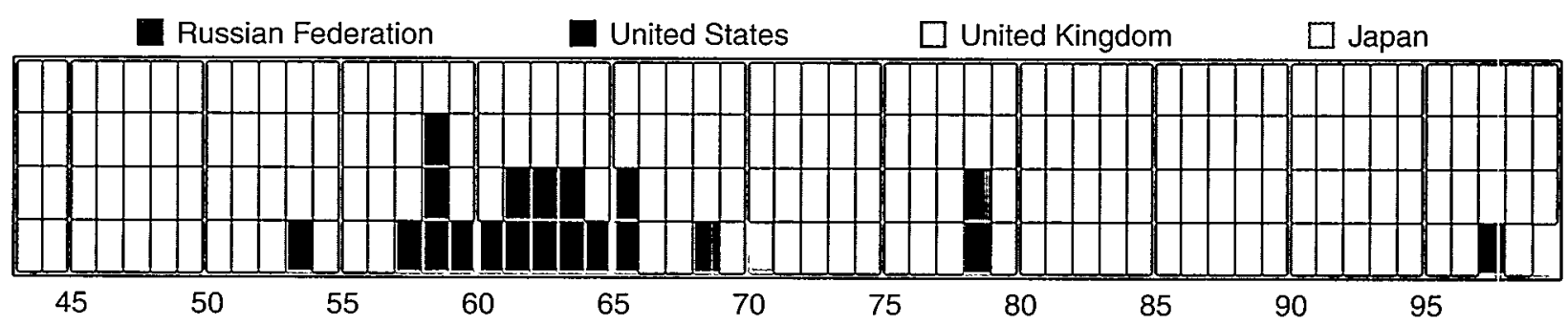

Figure 1. Chronology of process criticality accidents.

\section{A. ACCIDENT DESCRIPTIONS}

The 22 accident descriptions are presented chronologically in this report without regard to country. Figures 2.3,4, and 5 are provided to orient the reader as to the accident locations in the Russian Federation, the United States, the United Kingdom, and Japan, respectively. The capital cities are also included, as well as Obninsk in Russia, where no accidents have occurred but where the Russian coeditors of this report work at the IPPE. The IPPE houses the regulatory body that oversees the four production sites (Mayak, Tomsk-7, Electrostal, and Novosibirsk), where the process accidents occurred. 


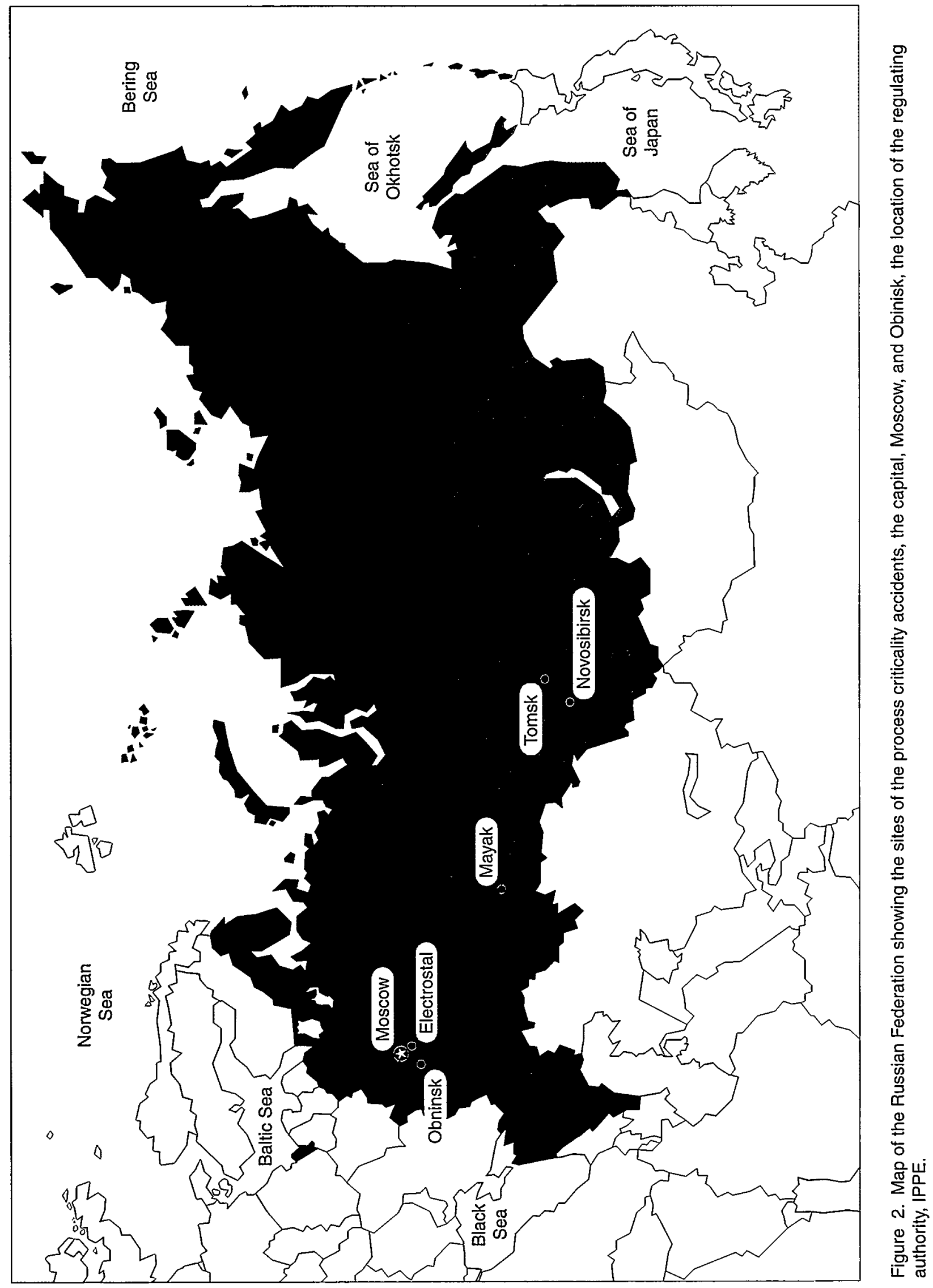




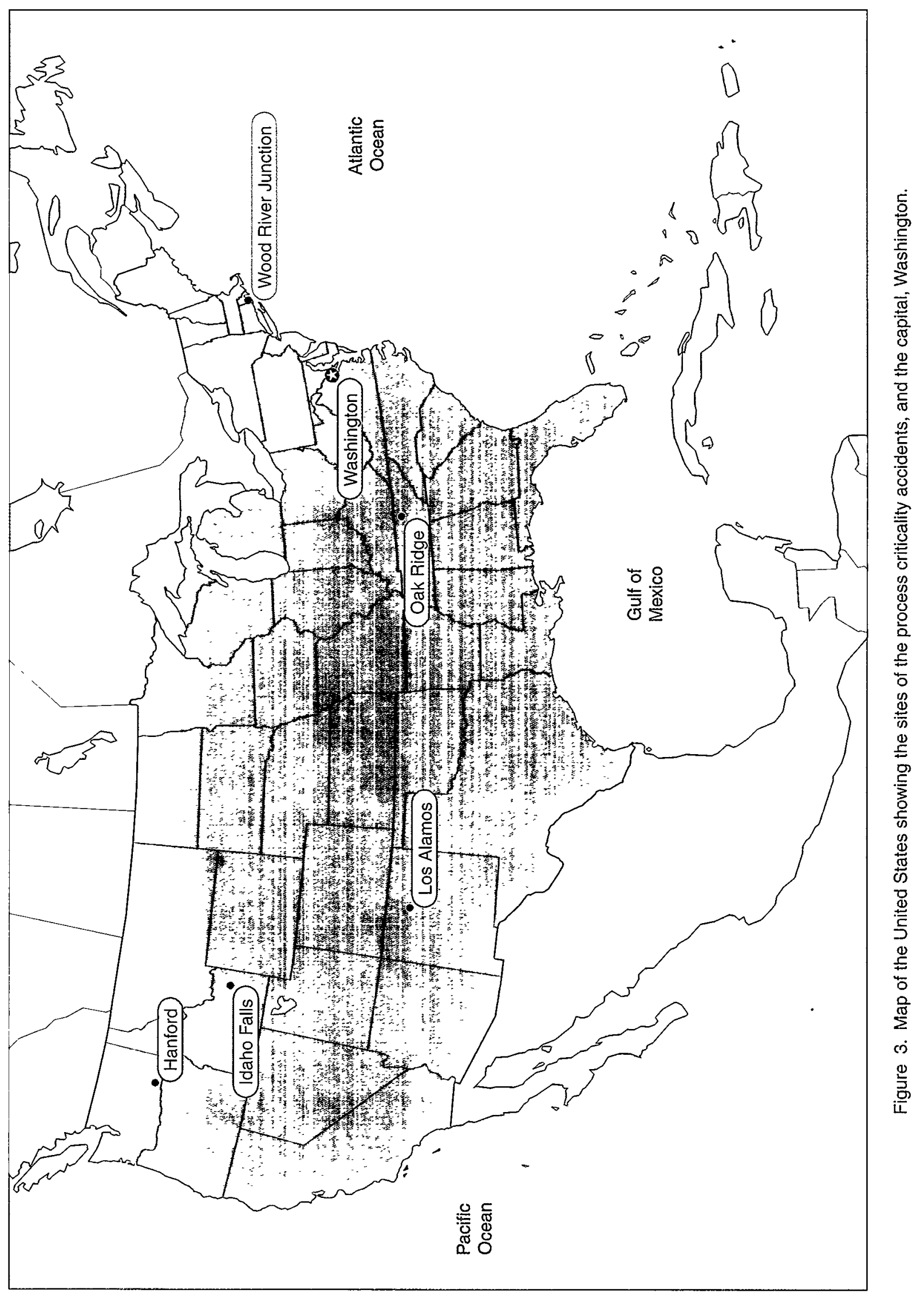




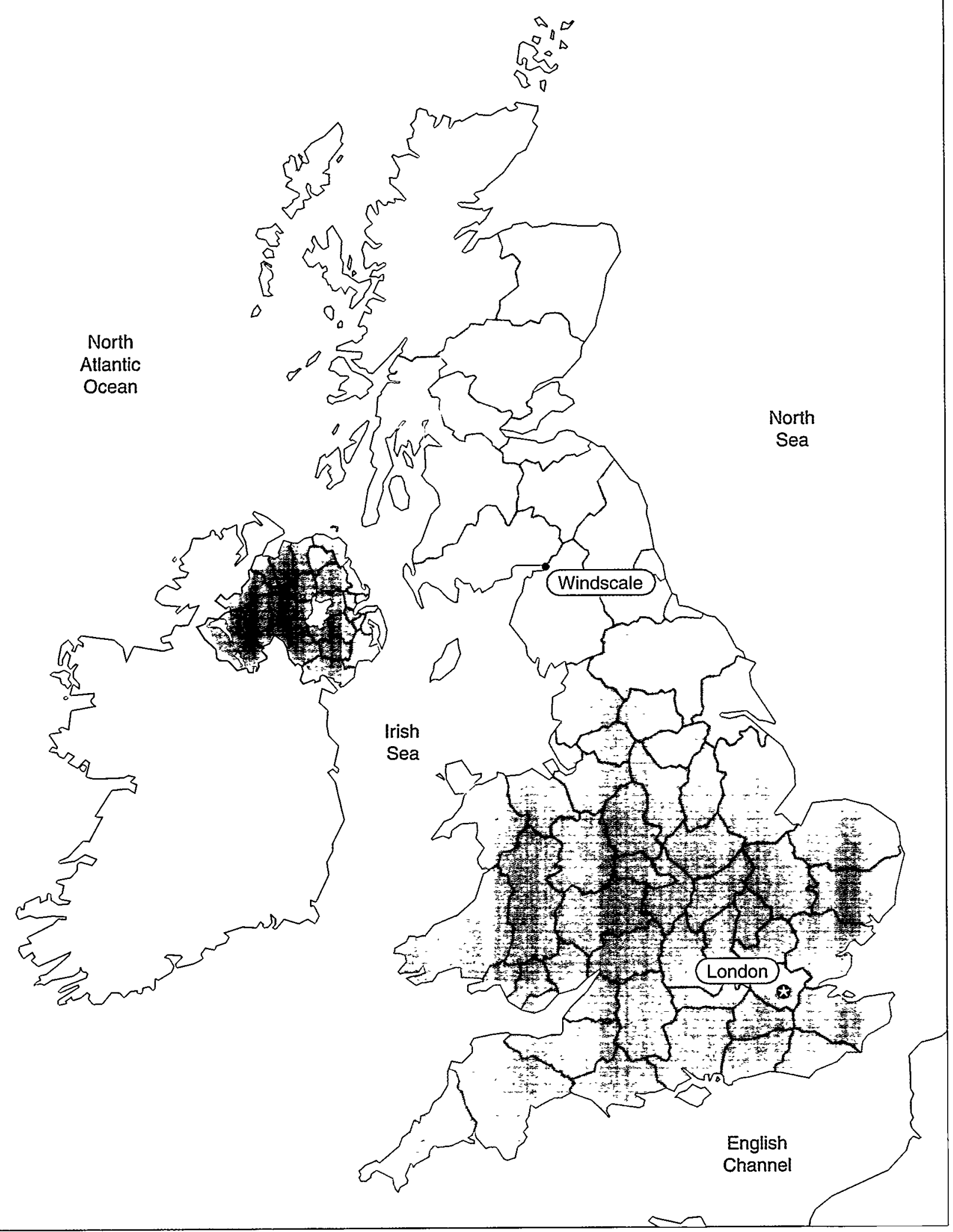

Figure 4. Map of the United Kingdom showing the site of the process criticality accident and the capital, London. 


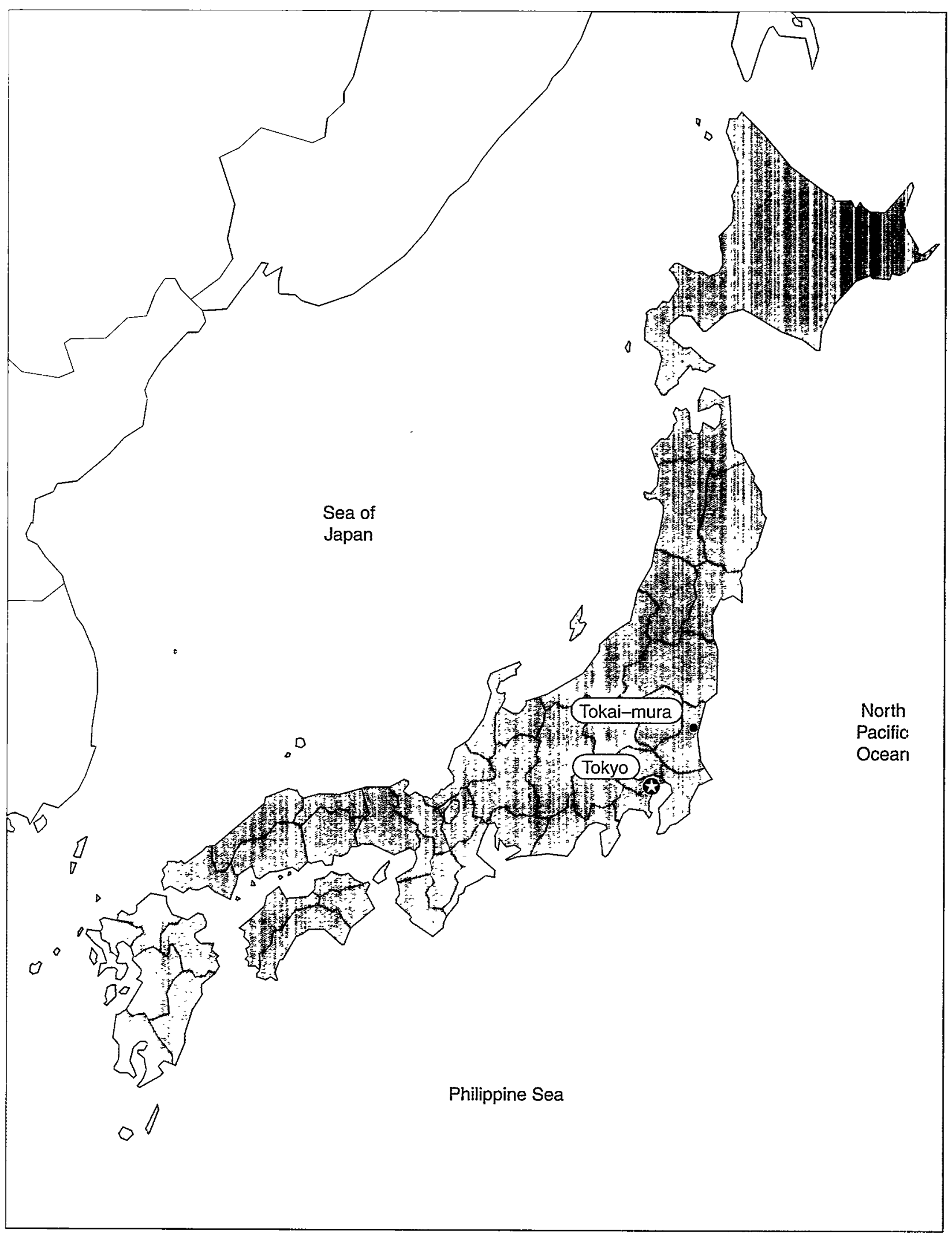

Figure 5. Map of Japan showing the site of the process criticality accident and the capital, Tokyo. 


\section{Mayak Production Association, 15 March 1953}

Plutonium nitrate solution in an interim storage vessel; single excursion; one serious exposure, one significant exposure.

The accident occurred in a plutonium processing building. The plutonium had been recovered from irradiated uranium rods. After separation from the fuel rods, the plutonium in the form of nitrate solution, was put through several purification steps. Operations were performed on 6 hour shifts, 4 shifts per day. The building was not equipped with a criticality alarm system.

Following purification, the plutonium nitrate solution was routed through a staging area before being sent on for further processing. Operations performed within the staging area included mixing, dilution, volume measurement, sampling for plutonium concentration and purity, and interim storage. Plutonium solution that failed purity requirements was returned for further purification. The staging area consisted of a concrete cell and adjacent space located in the corridor outside of the cell. Figure 6 shows the layout of the concrete cell and corridor.

The staging area contained 15 identical short right circular cylindrical stainless steel vessels, each with a unique identification number. The vessels were $400 \mathrm{~mm}$ in diameter and $320 \mathrm{~mm}$ high with the cylindrical axis oriented vertically. The staging area was not equipped with radiation monitoring instruments. Criticality control was implemented by a 500 gram plutonium mass limit per vessel. Criticality safety support consisted of part time effort by a staff physicist. Operators were not trained in criticality safety.

The 15 vessels were separated into 2 linear arrays. The first array containing 7 evenly spaced vessels was located near the back wall of the concrete cell. This array was installed in May 1952 and was supplied with solutions through permanently installed transfer lines. The concrete cell was $3 \mathrm{~m}$ wide, $2 \mathrm{~m}$ deep, and $2.5 \mathrm{~m}$ high. Top surfaces of the vessels were less than $1 \mathrm{~m}$ above the cell floor. Located in front of the array was a vertical, $200 \mathrm{~mm}$ thick cast-iron plate. In addition, a $125 \mathrm{~mm}$ thick cast-iron top plate was located horizontally above the 7 vessels. This plate had cutout holes above each vessel to allow access for making hose connections. Cadmium plates were positioned vertically between the 7 vessels. Procedures required that, for criticality safety purposes, vessels 2,4 , and 6 never contain solution. This constraint was expected to reduce neutronic interaction between the vessels.

The second array containing 8 evenly spaced vessels was located in the corridor outside the concrete cell. This second array was installed after realization that the first array had inadequate capacity for the volume of plutonium solution being processed. Each vessel in the array was individually shielded by approximately $175 \mathrm{~mm}$ of cast-iron on 4 sides and

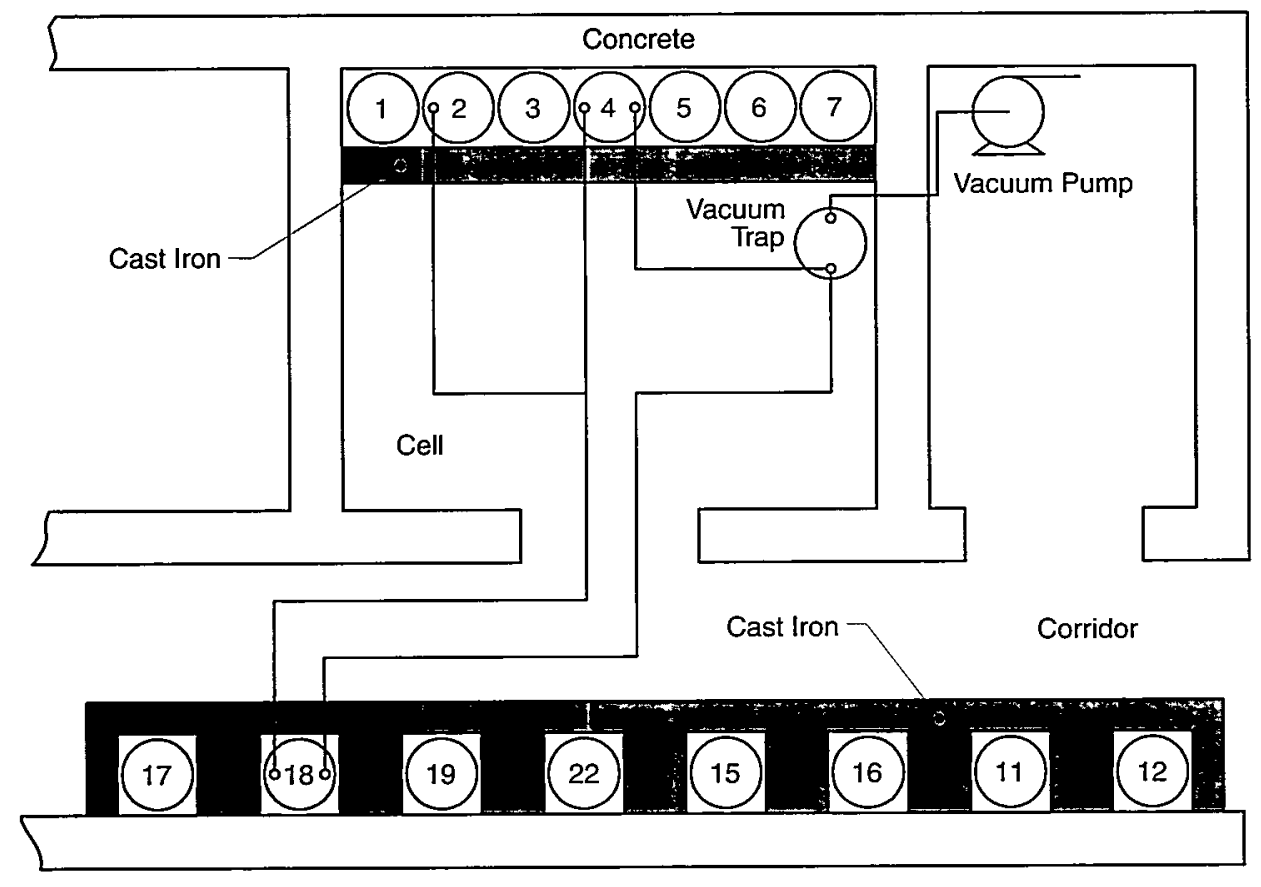

Figure 6. Layout of vessels and equipment in the staging area. 
with the concrete floor and wall on the remaining 2 sides of the vessel. The criticality accident occurred in vessel 18 .

Staging operations involved solutions being transferred between vessels in an array and between arrays. Vacuum transfers between the two arrays were performed by manually connecting hoses up to $7 \mathrm{~m}$ in length. The vacuum system was located in a room adjacent to the concrete cell. To prevent plutonium solution from entering the vacuum system, a vacuum trap. located in the concrete cell, was used. This vacuum trap vessel was made of glass to allow for visual inspection.

Procedures required that written instructions for each shift be reviewed by operating personnel at the beginning of the shift. A team of two or three people performed operations. Procedures also required that shift personnel review the results of solution sampling analysis.

On Sunday, 15 March 1953, the written instructions alerted shift personnel that two transfers of plutonium solution were scheduled to arrive at the vessels in the concrete cell. Table I shows the contents of the seven vessels as recorded in the operational log before the accident. It should be noted that in violation of procedures, vessels 2 and 4 were in use, and the 500 gram mass limit was being ignored. A plan was prepared to receive the first transfer of plutonium solution. The plan specified that the contents of vessels 2 and 4 were to be transferred to vessel 18 , which was located in the second array. The operational $\log$ showed vessel 18 was empty. Based on the values in Table 1 and the assumption that vessel 18 was empty. this transfer would result in vessel 18 having the solution volume and plutonium mass given in Table 2.

Two operators performed the transfer of solution from vessels 2 and 4 to vessel 18 . One operator was positioned next to vessel 18 and the other was in the cell near vessels 2 and 4 . Following completion of the transfers, the operator next to vessel 18 disconnected the hose. Immediately after disconnecting the hose, the operator noticed foaming and violent gas release from the vessel. With his hands the operator also observed that the vessel temperature was elevated well above room temperature. The operator in the cell noticed that solution had accumulated in the glass vacuum trap. The operator in the corridor immediately reconnected the transfer hose to vessel 18. Both operators then decided to transfer the contents of vessel 18 back to vessel 4 . The loss to the vacuum trap during the excursion explains why criticality did not re-occur during this transfer. Water and nitric acid were then added to vessel 4 to dilute and cool the contents. The operators then split the contents of vessel 4 by transferring it to vessels 22 and 12 located in the corridor.
Table 1. Contents of Vessels 1 through 7 as Recorded in the Operational Log Before the Accident.

\begin{tabular}{cccc}
\hline $\begin{array}{c}\text { Vessel } \\
\text { Number }\end{array}$ & $\begin{array}{c}\text { Solution } \\
\text { Volume }(\ell)\end{array}$ & $\begin{array}{c}\text { Pu Mass } \\
(\mathrm{g})\end{array}$ & $\begin{array}{c}\text { Pu Conc. } \\
\left(\mathrm{g} / \ell^{\prime}\right)\end{array}$ \\
\hline 1 & 15.0 & 672.0 & 44.8 \\
2 & 10.0 & 58.0 & 5.8 \\
3 & 15.5 & 567.0 & 36.6 \\
4 & 16.0 & 566.0 & 35.4 \\
5 & 0.0 & 0.0 & 0.0 \\
6 & 0.0 & 0.0 & 0.0 \\
7 & 0.0 & 0.0 & 0.0 \\
Total & 56.5 & 1863.0 & \\
\hline \hline
\end{tabular}

Table 2. The Expected Contents of Vessel 18 after the Planned Transfer.

\begin{tabular}{cccc}
\hline $\begin{array}{c}\text { Vessel } \\
\text { Number }\end{array}$ & $\begin{array}{c}\text { Solution } \\
\text { Volume }(\ell)\end{array}$ & $\begin{array}{c}\text { Pu Mass } \\
(\mathrm{g})\end{array}$ & $\begin{array}{c}\text { Pu Conc. } \\
(\mathrm{g} / \ell)\end{array}$ \\
\hline 18 & 26.0 & 624.0 & 23.8 \\
\hline \hline
\end{tabular}

Neither of the two operators had any training in criticality safety and neither recognized that a criticality accident had occurred. They did not expect that there would be any health effects and they elected to not report their observations. They continued to perform the work of the shift by receiving $15.5 /$ of solution containing $614 \mathrm{~g}$ of plutonium into vessel 5 .

Two days following the accident, 17 March 1953, the operator positioned near vessel 18 at the time of the accident abruptly became ill and requested medical assistance. An investigation was started after the operator reported his illness. The investigation determined that the operational $\log$ at the beginning of the shift on 15 March 1953 was in error (Table 1). The contents of vessel 1 at the beginning of the shift was actually $10 \ell$ of solution containing $448 \mathrm{~g}$ of plutonium, and not $15 \ell$ of solution with $672 \mathrm{~g}$ of plutonium. That is, vessel 1 contained 5 / less solution than was recorded in the operational log. The investigation also determined that the missing $5 \mathrm{f}$ had been transferred into vessel 18 before the beginning of the shift. Table 3 shows the actual contents of vessel 18 at the

Table 3. The Actual Contents of Vessel 18 at the Time of the Accident.

\begin{tabular}{cccc}
\hline $\begin{array}{c}\text { Vessel } \\
\text { Number }\end{array}$ & $\begin{array}{c}\text { Solution } \\
\text { Volume }(\ell)\end{array}$ & $\begin{array}{c}\text { Pu Mass } \\
(\mathrm{g})\end{array}$ & $\begin{array}{c}\text { Pu Conc. } \\
(\mathrm{g} / \ell)\end{array}$ \\
\hline 1 & 5.0 & 224.0 & 44.8 \\
2 & 10.0 & 58.0 & 5.8 \\
4 & 16.0 & 566.0 & 35.4 \\
Total & 31.0 & 842.0 & 27.2 \\
\hline \hline
\end{tabular}


time of the accident. However, the investigation was not able to determine who made the transfer or when it had taken place.

As part of the investigation, both experiments and calculations were performed to estimate the conditions for criticality in vessel 18 . The results determined that $30 \ell$ of solution containing $825 \mathrm{~g}$ of plutonium $(27.5 \mathrm{~g} / \ell)$ would be required for criticality. These values agree closely with the best estimate of the contents of vessel 18 at the time of the accident, $31 \ell$ of solution with $848 \pm 45 \mathrm{~g}$ of plutonium $(27.4 \mathrm{~g} / \ell)$. One contributing cause of the accident was the unrecorded transfer of $5 \ell$ of solution from vessel 1 to vessel 18.

The accidental excursion resulted in approximately $2 \times 10^{17}$ fissions. This estimate was based on a temperature increase of $60^{\circ} \mathrm{C}$ in $31 \ell$ of solution. The $60^{\circ} \mathrm{C}$ temperature rise was based on the coarse observation that the solution following the accident was at or near the boiling temperature. The accident caused no physical damage to any equipment. The operator positioned in the cell received an estimated dose of $100 \mathrm{rad}$. The operator near vessel 18 received an estimated dose of 1,000 rad. He suffered severe radiation sickness and amputation of both legs. He died 35 years after the accident.

Procedures in place before the accident were unambiguous in specifying that vessels 2,4 , and 6 were to never contain solution. The presence of solution in vessels 2 and 4 at the beginning of the shift prior to the accident illustrates that procedures were being violated. The entries in Table 1 also shows that the mass limit of $500 \mathrm{~g}$ per vessel was being violated.

\section{Mayak Production Association, 21 April 1957}

\section{Uranium precipitate, $U(90)$, buildup in a filtrate receiving vessel; excursion history unknown; one fatality, five other significant exposures.}

This accident occurred in a large industrial building housing various operations with highly enriched uranium. Operations were being conducted under the 6 hour shift, 4 shifts per day mode prevalent at Mayak. Rooms typically contained several gloveboxes separated from each other by about two meters and interconnected by various liquid transfer and vacuum lines. The accident took place in a filtrate receiving vessel that was part of batch mode, liquid waste processing and recovery operations.

A layout of the glovebox and its equipment is shown in Figure 7. This was a typical one workstation deep by two workstations wide glovebox. The normal process flow was as follows: the main feed material, impure uranyl nitrate, was generated in upstream U(90) metal purification operations. This, along with oxalic acid, was introduced into the precipitation vessel, which was equipped with a stirrer and an external steam/water heating jacket. A batch would typically contain a few hundred grams of uranium feed in about $10 \ell$ of liquid; concentration was usually in the 30 to $100 \mathrm{~g} \mathrm{U} / \ell$ range. The stirrer operated continuously during the process to prevent the accumulation of oxalate precipitate on the vessel bottom. Precipitation of the uranyl oxalate trihydrate proceeded according to the following reaction:

$$
\mathrm{UO}_{2}\left(\mathrm{NO}_{3}\right)_{2}+\mathrm{H}_{2} \mathrm{C}_{2} \mathrm{O}_{4}+3 \mathrm{H}_{2} \mathrm{O} \rightarrow \mathrm{UO}_{2} \mathrm{C}_{2} \mathrm{O}_{4} \cdot 3 \mathrm{H}_{2} \mathrm{O} \downarrow+2 \mathrm{HNO}_{3}
$$

The oxalate precipitate slurry was then vacuum transferred to a holding tank from which it was drained into a filter vessel. The precipitate containing the uranium was collected on the filter fabric, and the filtrate was pulled through by vacuum and collected in a filtrate receiving vessel, where the accident took place. This vessel was a horizontal cylinder $450 \mathrm{~mm}$ in diameter by $650 \mathrm{~mm}$ in length and had a volume of approximately $100 \ell$. As indicated in the figure, the filtrate was removed through a dip tube and transferred to an adjacent glovebox.

A two tier hierarchy of procedures and requirements was in place at the time. Upper level documents described operations covering large work areas in general terms, while criticality guidance was contained in operating instructions and data sheets posted at each glovebox. Specifics associated with each batch, such as the fissile mass, time, temperature, and responsible operators, were recorded on the data sheets that were retained for one month. Important entries from the data sheets were transcribed to the main shift logs that were retained for one year.

Operational and fissile mass throughput considerations dictated the design and layout of glovebox equipment. Thus, major pieces of equipment were not necessarily of favorable geometry. Limitation of the fissile mass per batch was the primary criticality control throughout the glovebox. The procedure called 


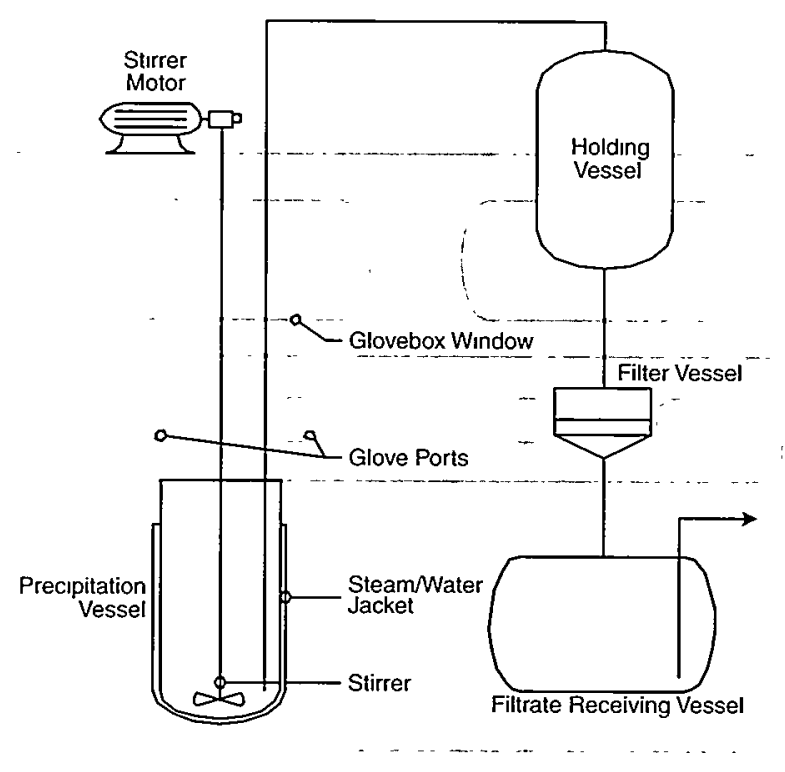

Figure 7. Equipment layout for the oxalate precipitation and filtration process.

for the $U(90)$ mass per batch to be less than $800 \mathrm{~g}$. The fissile mass was determined from the known volume and concentration of the uranyl nitrate. Historically this had resulted in relatively accurate fissile mass control. However, in spite of the fact that the operator followed the available procedures and did not violate criticality controls, there were several factors which contributed to the accumulation of uranium far in excess of that expected:

- The temperature of the precipitating solution was an important process variable, but there was no monitoring device such as a thermocouple. Temperature rise was controlled by the heating time, routinely about 10 minutes; the solution was not brought to boiling. In addition to temperature, the stoichiometry of the solution was important, but control of the uranium concentration was rather imprecise. Therefore the supernatant (the precipitate bearing liquid) that was fed to the filter vessel could have had an elevated temperature and/or acidity, resulting in a higher uranium concentration than anticipated. After the supernatant (now called the filtrate) entered the filtrate receiving vessel it would cool, resulting in additional precipitation of uranyl oxalate trihydrate and its slow accumulation into a hard, thin crust over much of the lower inside of the filtrate receiving vessel.

- While not known for sure, it was suspected that minor defects in the filter fabric might also have contributed to an increased rate of precipitate accumulation in the filtrate vessel. Procedures called for the filter fabric to be replaced based on either visual evidence of defects or unusually high flow rates through the filter.
- Operating instructions required a fissile mass accountability balance between the incoming and product fissile streams. If the difference was less than $5 \%$, then the next batch could be introduced into the glovebox; but if the difference exceeded $5 \%$, then it was required that the vessels be cleaned out. Operating procedures required that these vessels be cleaned out on a specified schedule; however, there was apparently no limitation on the number of batches that could be processed between cleanings if the 5\% threshold was not exceeded. Also, there was no tracking of the fissile mass as it accumulated between cleanings.

- There was no on-line instrumentation for measuring process parameters such as uranium concentration or accumulation in the receiving vessel.

- There was no operationally convenient way to visually inspect the inside of the receiving vessel.

- Finally, a likely major contributor to the accident was a procedural change that had occurred two months before. In an attempt to minimize personnel contamination and process downtime associated with the previous practice of routine physical/mechanical cleaning of the vessels, it was decided that a simple acid flushing of the vessels would be adequate. Two months after the implementation of this procedural change, the accident occurred.

While not a requirement for criticality control, the radiation control personnel routinely checked for uranium buildup with portable gamma-ray instruments from outside of the glovebox. They had not reported any increase in the normal background radiation field before the accident.

The criticality accident occurred during what was thought to be routine vacuum filtration of a batch of uranyl oxalate trihydrate precipitate slurry. Looking though the glovebox window, the operator observed the filter vessel fabric bulge upward, followed by a violent release of gas and ejection of some of the precipitate out of the filter vessel and onto the glovebox floor. The operator instinctively gathered up the precipitate by hand and put it back into the filter vessel. Immediately after (seconds, not minutes), the operator began to feel ill. The release of gas or vapor continued for about 10 minutes, at which time sufficient solution had been ejected from the filtrate receiving vessel into the vacuum trap of an adjacent glovebox to cause the excursion to stop.

There was no criticality alarm system or other means for alerting the operator or nearby personnel that a criticality accident had occurred. Furthermore, the operators had no criticality safety training. Originally, the circumstantial evidence of the gas release in the filter vessel and the sudden sickness of the operator were puzzling to the operational personnel in the room. The fact that a criticality accident had occurred was 
determined by a radiation control person called to the scene. Measurements indicated that an intense gamma radiation field was emanating from the filtrate receiving vessel. These measurements were made about 15 to 20 minutes after the accident. The radiation control person immediately ordered a prompt evacuation of the area.

About 5.5 hours after the event, the exposure rate was measured to be $18 \mathrm{R} / \mathrm{h}$ at a distance of $1.5 \mathrm{~m}$ from the filtrate receiving vessel. It was estimated that this exposure rate corresponded to a fission yield of approximately $1.0 \times 10^{17}$ fissions. Seventeen hours after the accident, measurement of the specific activity of the ${ }^{24} \mathrm{Na}$ in the operator's blood showed $245 \mathrm{~Bq} / \mathrm{cm}^{3}$. Based on analysis done at that time, this activity was consistent with an absorbed whole body dose of about 3,000 rad. The operator died twelve days after the accident.

Five other operators had been in the room at varying distances from the reacting vessel at the time of the accident. They received doses estimated to be upwards of $300 \mathrm{rad}$. All of them suffered from temporary radiation sickness but recovered without apparent long-term health effects.

After dismantling the glovebox and cleaning the various pieces of equipment, a total of $3.06 \mathrm{~kg}$ of ${ }^{235} \mathrm{U}$ was discovered in the filtrate receiving vessel. This material was primarily in two forms: a thin, hard crust, due to long-term buildup, and a flocculent precipitate, the concentration of which decreased with height in the vessel. The accident caused no mechanical damage to this vessel, and the room was not contaminated. The glovebox was taken apart, cleaned, and reassembled with essentially the original equipment. The operation was resumed after just a few days. During the downtime, a radiation meter was installed on the glovebox, operating instructions were revised, and enhanced operator training was implemented.

This accident led to the decision to set up an inplant critical experiment measurement capability to better determine critical parameters for vessels in routine use. The next criticality accident at Mayak on 2 January 1958 involved this critical experiment set up.

\section{Mayak Production Association, 2 January 1958}

\section{Uranyl nitrate solution, $U(90)$, in an experiment vessel; one prompt critical burst; three fatalities one serious exposure.}

This particular accident was unique in that it occurred during operations with a vessel used for inplant critical experiments. However, since the accident occurred well after the cessation of an experiment and during handling operations associated with transferring the fissile solution into favorable geometry bottles, it has been categorized as a process criticality accident.

After the 21 April 1957 accident, it was decided to set up a small-scale experiment capability for measuring the critical parameters of high concentration, highly enriched uranyl nitrate solution. This was deemed necessary in light of the widespread use of unfavorable geometry process vessels, the uncertainties in the critical parameters, and in recognition of two prior criticality accidents at the same plant. Previously, critical vessel dimensions and critical solution concentrations, masses, and volumes were estimated based on calculations, since directly applicable experimental results were unavailable in Russia at that time. The experimental capability was set up in the same building where large volumes of this material were being processed, giving efficient access to the fissile solution.

The small critical experiment setup, shown in Figure 8, was located in a separate room in the main process building. It had only been in operation for two months at the time of the accident. During measurements, the critical experimenters worked at a control panel located a few meters away from the setup and shielded by a $500 \mathrm{~mm}$ thick, water-filled slab tank located $600 \mathrm{~mm}$ from the experiment vessel. There were no criticality alarms installed in the building.

This was the first day of work after the New Year's holiday. While the plant generally ran continuously on four 6-hour shifts daily, there was only one team of critical experimenters. They were working on their first shift of the new year, 13:00 to 19:00. Other plant operators were involved in preparing the fissile solution and in assembling the experimental apparatus, but the critical experiments were performed solely by this dedicated, knowledgeable team.

The prior series of experiments had focused on determining critical parameters for smaller vessels and had been concluded before the end of the year. During the last working days of December the equipment for the next experimental series had been assembled. This was the first experiment conducted with this larger vessel. It was a cylindrical stainless steel vessel, $750 \mathrm{~mm}$ inside diameter, with a wall thickness of 2 to $4 \mathrm{~mm}$, representative of the vessels in common use at the facility. The fissile solution, of known concentrations and volumes, was added from an overhead, graduated cylinder $3 \ell$ in capacity.

The experiment vessel was bolted to a stand and sat atop an $8 \mathrm{~mm}$ thick steel support plate approximately 


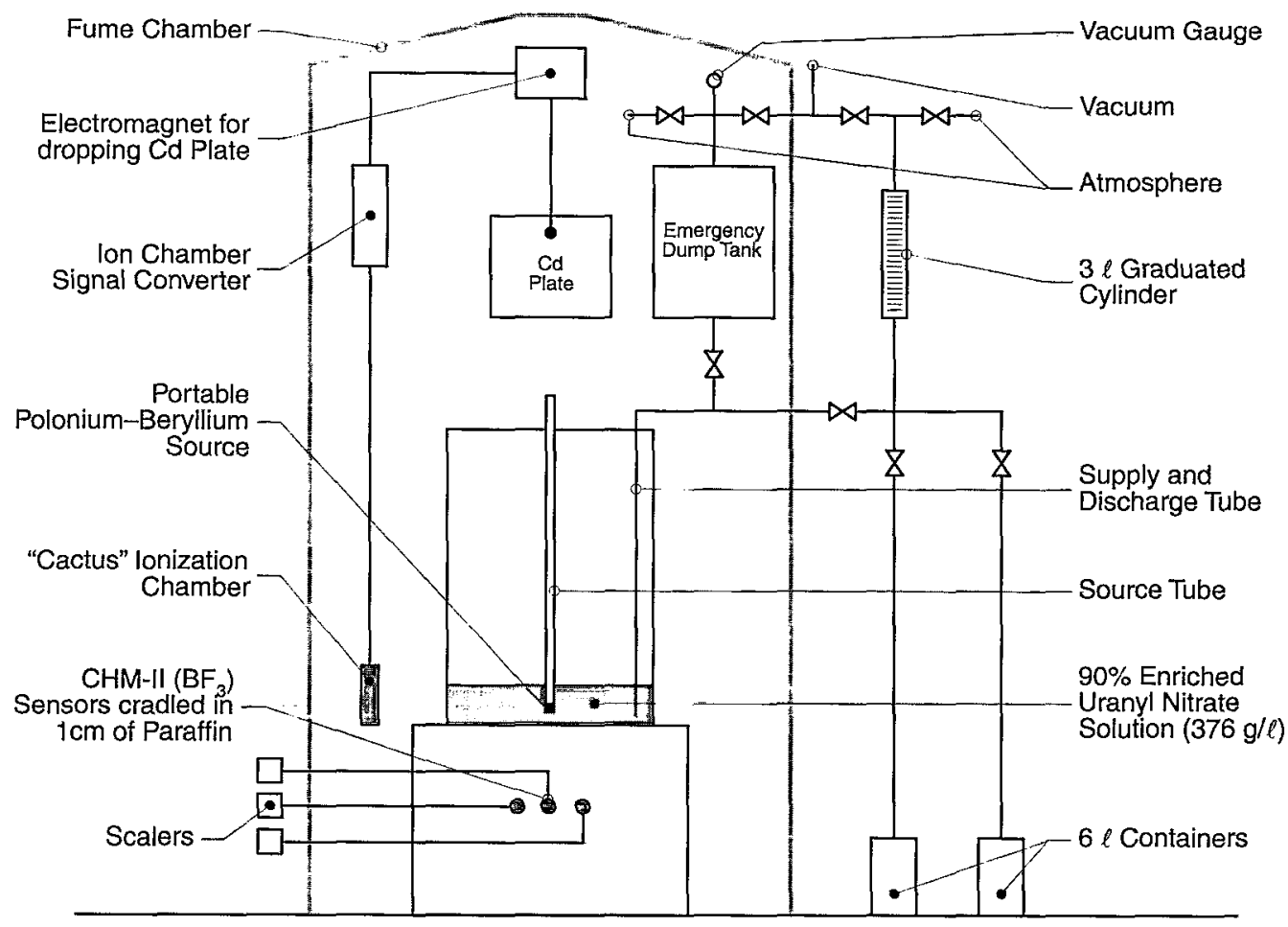

Figure 8. Layout of the experimental equipment.

$0.8 \mathrm{~m}$ above the concrete floor and at least $1.5 \mathrm{~m}$ from any walls. Thus it was without appreciable reflection, approximating many in-plant situations. The vessel capacity was in excess of $400 \ell$, permitting critical states to be measured over a wide range of conditions. A central guide tube accommodated a neutron source, and the leakage neutron flux was monitored with a $\mathrm{BF}_{3}$ proportional counter located beneath the tank. Approach-to-critical measurements employed the standard inverse multiplication technique.

After each experiment was completed, written procedures called for the solution to be drained through a line to favorable geometry 6 liter bottles. This process was to be repeated until the entire experiment vessel had been drained. After filling some of these 6 liter bottles, the experimenters judged the remaining solution volume to be highly subcritical. It was then decided to circumvent the routine, tedious draining process and manually pour the remaining solution of $418 \mathrm{~g} \mathrm{U}(90) / \ell$ from the vessel (there are no records of the molarity of the solution). To accomplish this, the neutron source and its guide tube were removed and then the vessel was unbolted from its stand. Then three of the experimenters manually lifted the vessel and began to move it (in order to directly pour the contents into containers) when the excursion occurred.
They immediately noticed a flash (due to Cherenkov radiation), and simultaneously, fissile solution was violently ejected, reaching the ceiling about $5 \mathrm{~m}$ above. The three experimenters dropped the vessel and, along with a fourth experimenter who was located about $2.5 \mathrm{~m}$ away from the excursion, went immediately to the change room, showered, and were transported to the hospital. The combination of additional reflection from the three experimenters and the change in the geometry of the solution volume was sufficient to cause the system to exceed prompt critical. The small neutron background, estimated at only 100 neutrons per second, apparently also contributed to delayed initiation and thus to increased excursion energetics.

Based on fission product activity in the solution, the single-pulse yield was evaluated to be approximately $2 \times 10^{17}$ fissions. Total neutron and gamma absorbed doses were estimated at $6,000 \pm 2,000 \mathrm{rad}$ for the three who lifted the tank and $600 \mathrm{rad}$ for the coworker at $2.5 \mathrm{~m}$. The three massively exposed workers died in five to six days. The fourth experimenter survived but had acute radiation sickness, followed by continuing health problems. She developed cataracts* and lost sight in both eyes some years later. Due to the severe

*While the likelihood of contracting cataracts is significantly increased for hundreds of rad doses, there is not a direct one-to-one correlation. 
consequences of this accident, the experimental apparatus was disassembled and the critical experiment program at the plant was terminated.

Some of the factors that contributed to the accident are listed below.

- Violation of the procedure that stipulated the complete draining of the experiment solution into 6 liter bottles.

- Unbolting and removing the experiment vessel when it contained solution. This was not specifically permitted in the operating procedure.
- The design of the experiment stand that made it relatively easy to unbolt and remove the experiment vessel.

- The additional reflection provided by the operators and by lowering it closer to the floor.

- The lack of knowledge and awareness of the operators as to the large reactivity changes that can occur with shape changes of solutions having $H / D<1$.

\section{Oak Ridge Y-12 Plant, 16 June $1958^{7,8,9,10}$}

\section{Uranyl nitrate solution, $U(93)$, in a water collection drum; multiple excursions; seven significant exposures.}

This accident occurred in the C-1 Wing of Building 9212 in a process designed to recover enriched uranium, U(93) from various solid wastes. The solid wastes would be dissolved in nitric acid, purified, concentrated, and then converted to uranium tetrafluoride. A similar system, using newer technology, had been installed and was operating in the B-1 Wing of the building. However, because of delays in the startup of $\mathrm{UF}_{4}$ conversion equipment, the solution it produced was being transferred to the $\mathrm{C}-1$ Wing for final conversion.

In the days immediately before the accident, the entire facility (Building 9212) had been shutdown for a fissile material inventory. Due to the complexity of the facility, the inventory required several days, and not all processes were restarted and stopped at the same time. By the day of the accident, production had already resumed in the B-1 Wing but had not in the C-1 Wing.

Figure 9 is a simplified diagram of the C-1 Wing vessels and equipment involved in the accident. The inventory required the disassembly and cleaning of the three, 5 inch (127 mm) diameter vessels * (FSTK 1-2, FSTK 6-1, FSTK 6-2) used to store uranyl nitrate solution. Before resumption of operations, it was necessary to reassemble and to leak test the vessels. This entire process usually required several, 8-hour shifts to complete.

At $\sim 01: 00$ during the shift preceding the accident (23:00 Sunday, 15 June, to 07:00 Monday, 16 June), the $\mathrm{C}-1$ Wing supervisor noted that uranyl nitrate solution was present in a 6 inch $(152 \mathrm{~mm})$ diameter glass standpipe that was part of the $\mathrm{pH}$ adjustment station (Figure 9). He instructed an operator to drain the standpipe. At 05:00, the supervisor again noted uranyl nitrate in the standpipe and questioned the operator as to whether it had been drained earlier. The operator confirmed that it had been, and upon further investigation, they determined that solution was leaking into the standpipe through valve $\mathrm{V}-2$. The valve was closed, and the standpipe was again drained.

At 07:00, on 16 June, the routine shift change occurred and the $\mathrm{C}-1$ Wing supervisor was relieved. Accounts as to whether he informed his replacement of the uranyl nitrate leakage incidents were conflicting, but there was no mention of it in the operating log.

At 08:00 an additional C-1 Wing supervisor arrived. Among other tasks, one of his duties was to oversee the leak checking of the three vessels. The vessels had been cleaned and reassembled the previous week. Furthermore, operations had not resumed in the $\mathrm{C}-\mathrm{I}$ Wing. Because of this information, the supervisor considered it unnecessary to check the vessel level indicator panel or to be concerned about the open or closed condition of any of the vessel valves. The supervisor assigned two operators to leak check the three vessels (which simply involved filling them with water), giving them specific instructions to check valve $\mathrm{V}-1$ because the $\mathrm{B}-1$ Wing had resumed operations.

Unknown to anyone at the time, uranyl nitrate had been leaking from the B-1 Wing through valve V-1 from the early hours of the previous shift until about 13:30, when one of the operators checked it (and by applying pressure completely closed the valve), as instructed by the supervisor. Before this, the uranyl nitrate had been collecting in vessel FSTK 1-2, because valve $\mathrm{V}-3$ had also been open.

Shortly before $14: 00$, the operators completed the leak check of vessels FSTK 6-1 and 6-2, and opened valves $\mathrm{V}-4, \mathrm{~V}-5$, and $\mathrm{V}-11$ to drain the water from these vessels into a 55 gallon (208 $\ell$ ) drum. One of the operators remained near the drum (as was the general practice during leak checking) specifically to monitor the situation for any unusual conditions. Because

\footnotetext{
*The spacing and dimensions of the pipes were such that they could not be made critical for the intended solutions.
} 


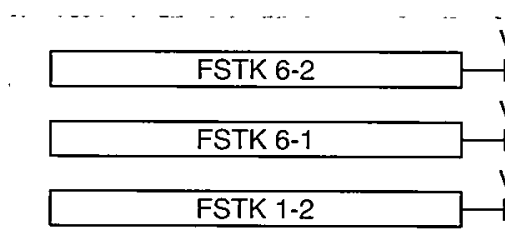

C-1 Wing 5" (127 mm) Storage Vessels
Figure 9. Simplified diagram of the $\mathrm{C}-1$ wing vessels and interconnecting piping involved in the accident.

valve V-3 was already open, and the flow pattern from the three vessels was such that any liquid in vessel FSTK 1-2 would flow into the drum first, the uranyl nitrate solution preceded the water. At approximately 14:05, the operator looked into the drum and noticed yellow-brown fumes rising from the liquid. He stepped away from the drum and within a few seconds saw a blue flash indicating that an excursion had occurred. Almost immediately thereafter, the criticality alarm sounded, and the building was evacuated. Further flow of water increased the uncompensated reactivity for about 11 minutes, then decreased it. The solution became subcritical after about 20 minutes.

Later studies determined that a full 15 minutes elapsed between the time valve V-11 was opened and the system reached the critical point. It is unknown why the operator stationed near the drum (6 years of experience with uranium processing) did not notice the yellow colored uranyl nitrate pouring into the drum.

At the time the system became critical, the solution volume is thought to have been $\sim 56 \ell$ in a cylinder that was $234.5 \mathrm{~mm}$ high and $552 \mathrm{~mm}$ in diameter. The ${ }^{235} \mathrm{U}$ mass at the time was $2.1 \mathrm{~kg}$, with $0.4 \mathrm{~kg}$ being added later, while water was further diluting the system. During the excursion a radiation detection instrument (boron lined ionization chamber, amplifier, and recorder) operating $\sim 430 \mathrm{~m}$ from the accident location was driven off the scale by the radiation intensity. The trace from this detector also shows that about 15 seconds after the initial excursion it was again driven off scale. During the next 2.6 minutes, the trace oscillated an indeterminate number of times. It is possible that the oscillations were decreasing in amplitude, although it cannot be confirmed by examining the trace. This was followed for 18 minutes by a slowly decreasing ramp, about five times above background.

The excursion history can be reconstructed only qualitatively. The most likely source of initiation was

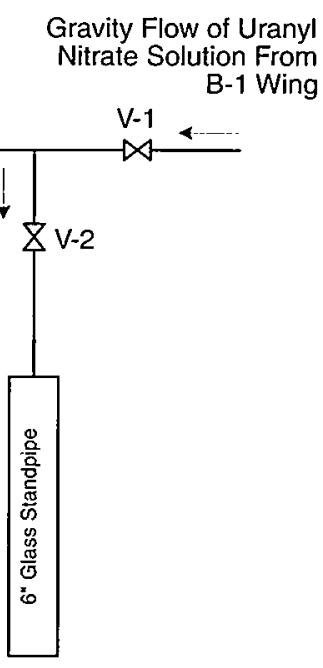

pH Adjustment Station

neutrons from $(\alpha, n)$ with the oxygen in the water. Thus, it is possible that the system reactivity slightly exceeded prompt criticality before the first excursion. The reactivity insertion rate was estimated to be about $17 \% / \mathrm{s}$ at the time. The size of the first spike must have been determined by the reactivity attained when the chain reaction started. Although there is no way to be certain, a reasonable estimate is that the first spike contributed about $6 \times 10^{16}$ fissions of the total yield of $1.3 \times 10^{18}$ fissions. The second excursion, or spike (which also drove the recording pen off the scale), occurred in 15 seconds, a quite reasonable time for existing radiolytic gas bubbles to have left the system. The excursions for the next 2.6 minutes appear to have been no greater than about 1.7 times the average power.

The trace suggests that most of the fissions occurred in the first 2.8 minutes, in which case the average power required to account for the observed yield is about $220 \mathrm{~kW}$. After this, the system probably started to boil, causing a sharp decrease in density and reactivity and reducing the power to a low value for the final 18 minutes.

Figure 10 is a photograph taken of the 55 gallon drum shortly after the accident. There was no damage or contamination. Eight people received significant radiation doses $(461,428,413,341,298,86.5,86.5$, and $28.8 \mathrm{rem}$ ). At least one person owes his life to the fact that prompt and orderly evacuation plans were followed. One person survived 14.5 years, one 17.5 years, the status of one is unknown, and five were alive 29 years after the accident.

Shortly after the accident, a critical experiment was performed at the Oak Ridge National Laboratory (ORNL) that simulated the accident conditions. This was done to provide information about probable radiation exposures received by the people involved in the accident.

The plant was returned to operation within three days. 


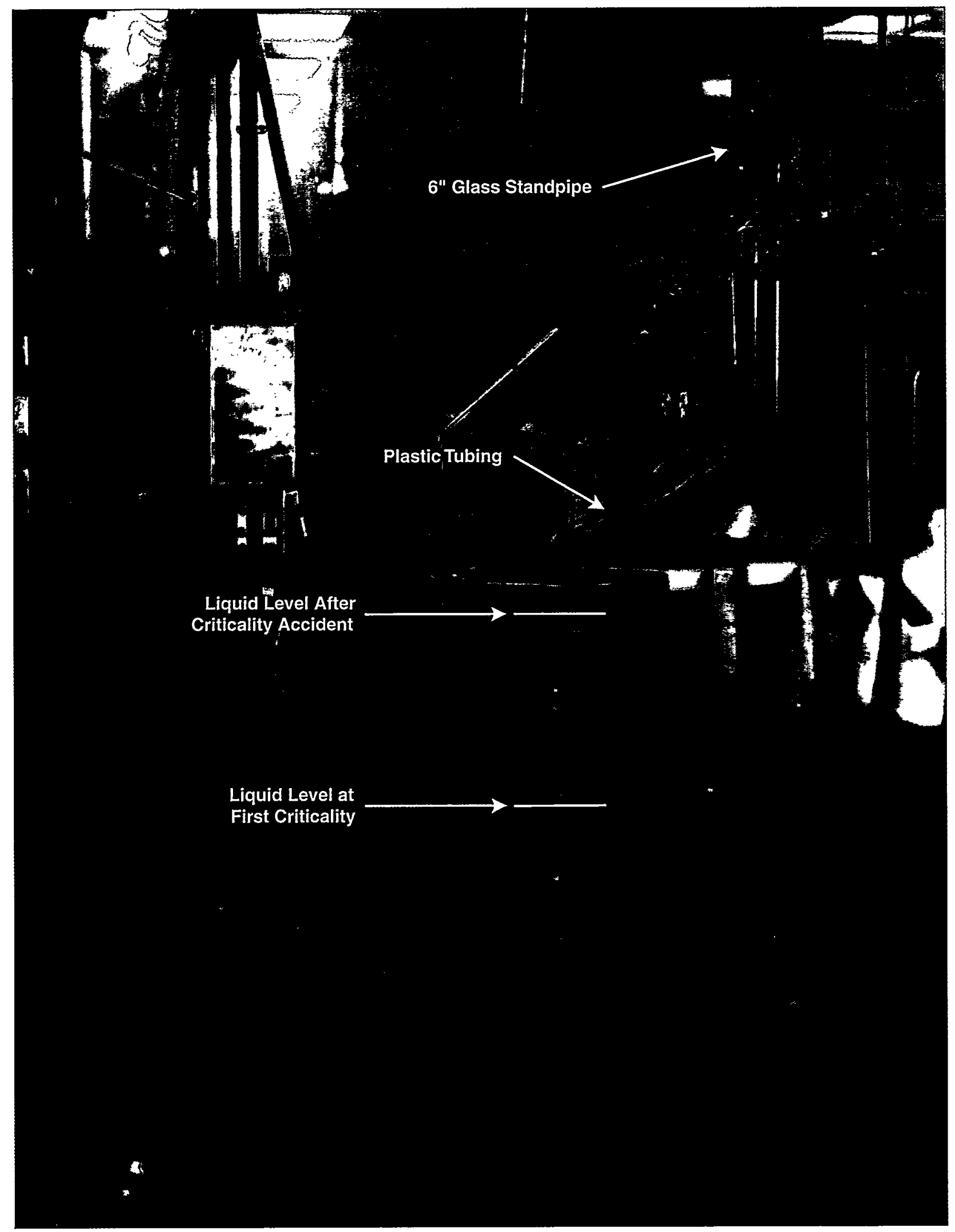

Figure 10 . Drum in which the $1958 \mathrm{Y}-12$ process criticality accident occurred. 


\section{Los Alamos Scientific Laboratory, 30 December $1958^{11,12}$}

Plutonium organic solution in an organic treatment tank; single excursion; one fatality, two significant exposures.

The operations performed at the facility where the accident occurred were those chemical steps used to purify and concentrate plutonium from slag, crucible, and other lean residues that resulted from recovery processes. Typical and expected solutions contained less than $0.1 \mathrm{~g} \mathrm{Pu} / \ell$ and traces of americium. An annual physical inventory was in progress at the time of the accident; thus, the normal flow of process streams into the area was interrupted so that residual materials in all process vessels could be evaluated for plutonium content. This accident occurred at 16:35 near the end of the last workday before the New Year's holiday.

A reconstruction of significant events indicates that unexpected plutonium rich solids, which should have been handled separately, were washed from two vessels into a single large vessel that contained dilute aqueous and organic solutions. After most of the aqueous solution had been removed from this vessel, the remaining approximately $200 \ell$ of material, including nitric acid wash, was transferred to the $1,000 \ell, 1000 \mathrm{~mm}$ diameter, stainless steel tank in which the accident occurred. The tank contained about 295 of a caustic stabilized aqueous organic emulsion, and the added acid is believed to have separated the liquid phases.

The aqueous layer $(330 \ell)$ is estimated to have contained $60 \mathrm{~g}$ of plutonium; the organic layer $(160 \ell)$ contained $3.1 \mathrm{~kg}$ of plutonium (Figure 11). A photograph of the tank is shown in Figure 12. Analyses indicate that this $203 \mathrm{~mm}$ thick layer was perhaps $5 \$$ below delayed criticality and that the critical thickness was $210 \mathrm{~mm}$. When the stirrer was started, the initial action forced solution up the tank wall, displacing the outer portion of the upper layer and thickening the central region. The motion changed the system reactivity from about $5 \$$ subcritical to superprompt critical, and an excursion occurred. None of the $\gamma$-sensitive recording meters within range of the accident showed a definitive trace; they did suggest, however, that there was a single spike. The excursion yield was $1.5 \times 10^{17}$ fissions.

Based on post excursion experiments in a similar geometry vessel, there was no apparent delay between start and full speed of the stirrer, 60 revolutions per minute. After 1 second ( 1 revolution), there was visible movement or disturbance on the surface, and in 2 or 3 seconds the system was in violent agitation. From these observations it can be concluded that the system could have been made critical in about I second; while bubble generation must have been the dominant feedback mechanism for terminating the first spike, the system was permanently driven subcritical by the mixing of the layers. The average plutonium content in the fully mixed solution was $6.8 \mathrm{~g} / \ell$, a value less than the limiting critical concentration for an infinite homogeneous metal-water system.

From these time intervals and the estimate that initially the system was $5 \$$ subcritical, the reactivity insertion rate would have been about $5 \$ / \mathrm{s}$. Using coefficients appropriate for the solution, this insertion rate leads to a spike yield of $2.2 \times 10^{17}$ fissions with the spike completed in 1.65 seconds, that is, 0.45 seconds after prompt criticality was reached. To obtain the observed yield $\left(1.5 \times 10^{17}\right.$ fissions $)$ in a single spike, the reactivity insertion rate would have to be reduced to about $2 \$ / \mathrm{s}$. Because this is inconsistent with the time involved (about 3 seconds before complete mixing), the only alternative is to assume that the rate was somewhat less than $5 \$ / \mathrm{s}$ and that the excursion was terminated in about 3 seconds by the stirring action. One can surmise that the initial action was thickening of the upper layer at the same time reflection was added by the aqueous liquid. This was followed almost immediately by distortion into a less critical, vortex-like shape by the action of the stirring blades and then permanent shutdown due to a uniform concentration of less than $7 \mathrm{~g} / \ell$.

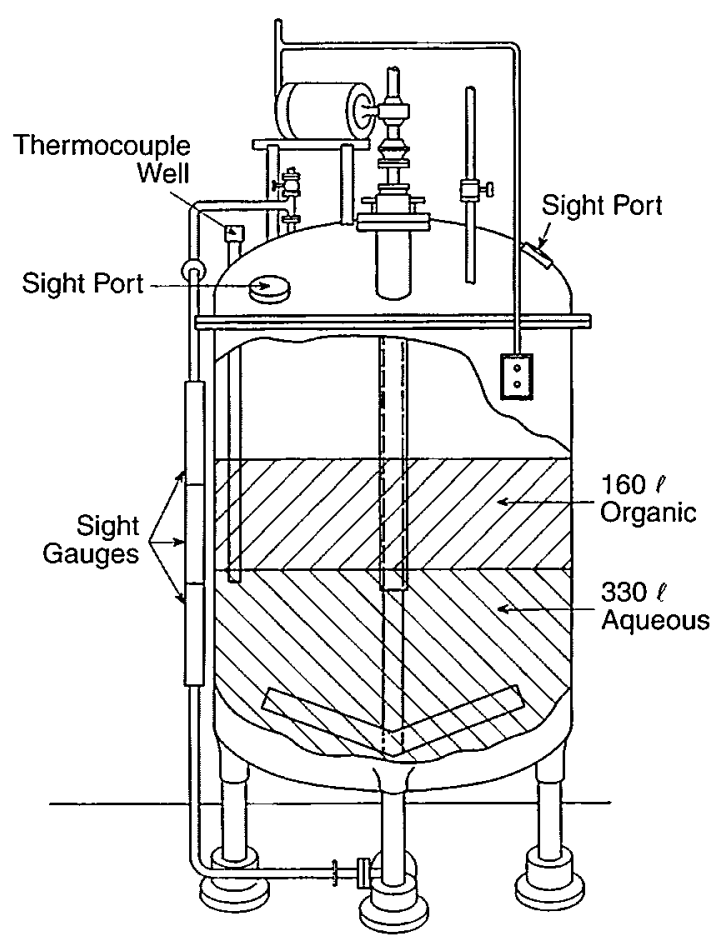

Figure 11. Configuration of solutions (aqueous and organic) in the vessel before the accident. 
The entire plutonium process area had been reviewed by the Laboratory's Nuclear Criticality Safety Committee about a month before the accident. Plans were underway to replace the large-volume process vessels with a bank of more favorable geometry, limited diameter pipe sections (6 inches in diameter by 10 feet long each). Administrative controls that had been used successfully for more than 7 years were considered acceptable for the additional six to eight months that would be required to obtain and install the improved equipment.

Following the accident, procurement of favorable geometry equipment was accelerated and installation was completed before restarting operations. The downtime was about six weeks. To provide enhanced safety, improved techniques for the sampling of solids were implemented and the importance of adherence to procedural controls was emphasized.

The accident resulted in the death, 36 hours later, of the operator who was looking into a sight glass when the motor was turned on. The dose to his upper torso was estimated to have been $12,000 \pm 50 \%$ rem. Two other persons apparently suffered no ill effects after receiving radiation doses of 134 and $53 \mathrm{rem}$. No equipment was contaminated or damaged even though the shock associated with off-axis bubble generation displaced the tank about $10 \mathrm{~mm}$ at its supports.

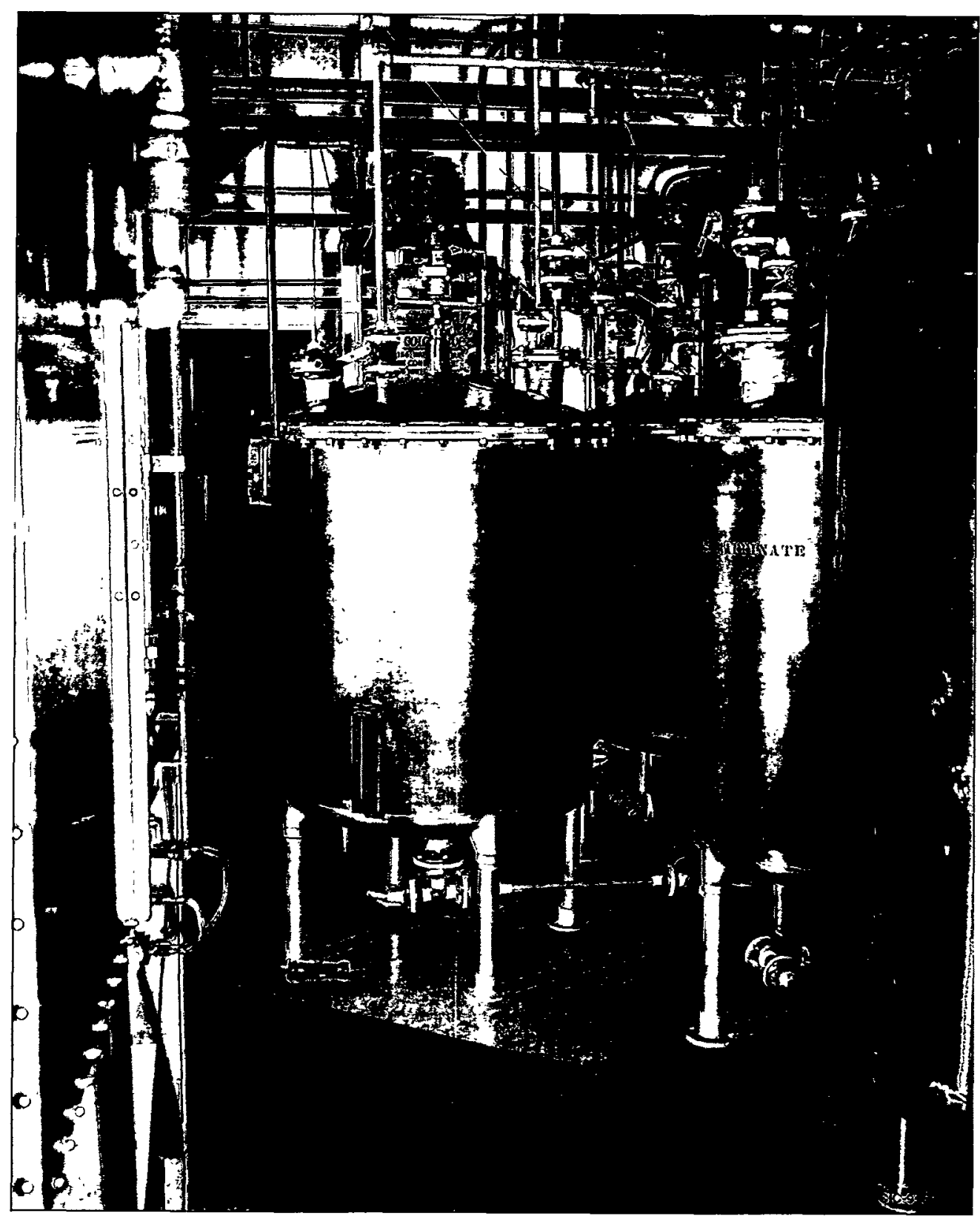

Figure 12. Vessel in which the 1958 Los Alamos process criticality accident occurred. 


\section{Idaho Chemical Processing Plant, 16 October $1959^{13}$}

\section{Uranyl nitrate solution, $U(91)$, in a waste receiving tank; multiple excursions; two significant exposures.}

This accident occurred in a chemical processing plant that accepted, among other items, spent fuel elements from various reactors. The fissile material involved in the accident $(34 \mathrm{~kg}$ of enriched uranium, $\mathrm{U}(91)$, in the form of uranyl nitrate concentrated to about $170 \mathrm{~g} \mathrm{U} / \ell$ ) was stored in a bank of cylindrical vessels with favorable geometry. The initiation of a siphoning action, inadvertently caused by an air sparging operation, resulted in the transfer of about $200 \ell$ of the solution to a $15,400 \ell$ tank containing about $600 \ell$ of water.

Before the accident, a campaign was underway to process stainless steel clad fuels by sulfuric acid dissolution followed by impurity extraction in three pulse columns. Intermediate between the first and second cycle extraction, the solution was stored in two banks of $125 \mathrm{~mm}$ diameter by $3050 \mathrm{~mm}$ long pipe sections, often referred to as pencil tanks. There was a line leading from the interconnected banks of pencil tanks to the 5000 gallon (18900 $\ell$ ) waste receiving tank, but it was purposefully looped $600 \mathrm{~mm}$ above the top of the tanks to avoid any possibility of gravity drain from the pencil tanks to the waste tank. Only deliberate operator actions were thought capable of effecting transfers to the waste tank.

On the day of the accident the operators, following routine written procedures, initiated sparging operations to obtain uniform samples for analysis. While the pressure gauge that indicated the sparge air flow was showing expected pressures from one of the banks, the gauge associated with the other bank was not functioning. There was not another gauge on this bank and the operator proceeded to open the air (sparge) valve until circumstantial evidence indicated that the sparge was operating. However, the air sparge was apparently turned on so forcefully that it caused the liquid to rise about $1,200 \mathrm{~mm}$, from the initial liquid height in the pencil tanks to the top of the loop leading to the waste tank, which initiated a siphoning action.

Although the siphoning rate was 13 liters per minute, it is difficult to relate this directly to the reactivity insertion rate since it also depended on the degree of mixing. The reactivity insertion rate could have been as high as $25 \phi / \mathrm{s}$. Because the $2.73 \mathrm{~m}$ diameter by $2.63 \mathrm{~m}$ long waste receiving tank was lying on its side, the solution configuration approximated a near infinite slab. Waves in the solution could have caused large fluctuations in the system reactivity. After the accident, much of the uranyl nitrate was found crystallized on the inner walls of the tank, and most of the water had evaporated. The resulting excursions generated $4 \times 10^{19}$ fissions, sufficient to boil away nearly half of the $800 \ell$ solution volume that eventually terminated the excursions.

The excursion history is a matter of conjecture. There were only strip chart recordings from continuous air monitors at various distances from the tank. Some of these apparently stopped recording upon being driven to a very high level while those in lower radiation fields (generally farther away) may have been influenced by fission product gases. It is not unreasonable to assume that an initial spike of at least $10^{17}$ fissions was followed by multiple excursions and, finally, by boiling for 15 to 20 minutes. The very large yield is a result of the large volume of the system and the relatively long duration, rather than of the violence of the excursion tank.

Because of thick shielding, none of the personnel received significant prompt gamma or neutron doses. During evacuation of the building, airborne fission products (within the building) resulted in combined beta and gamma doses of 50 rem (one person), 32 rem (one person), and smaller amounts to 17 persons. While the evacuation proceeded relatively rapidly, the general evacuation alarm was never activated; it was a manually activated system. The reason offered was that the accident occurred during the graveyard shift, and the small workforce left their work areas promptly and were all accounted for at the guard station. Afterwards it was acknowledged that local radiation alarms sounded relatively frequently and had somewhat conditioned operators to not evacuate until the second or third separate alarm had sounded.

It was also noted that the normal building egress was used by all personnel; none used the prescribed and clearly marked evacuation route. This led to a bottleneck at the exit point, which could have been severe during the day shift with ten times as many workers present. Thus exposures could probably have been reduced somewhat if immediate evacuation by the proper route had occurred. Equipment involved in the excursion was not damaged.

Several factors were identified by investigating committees as contributing to the accident:

- the operators were not familiar with seldom used equipment, the banks of pencil tanks, and their controlling valves.

- there was no antisiphon device on the line through which the siphoning occurred. It was noted that such devices were installed on routinely used tanks.

- operating procedures were not current nor did they adequately describe required operator actions such as the need for careful adjustment of the air sparge. 


\section{Mayak Production Association, 5 December 1960}

Plutonium carbonate solution in a holding vessel; multiple excursions; insignificant exposures.

This accident occurred in a building where waste solutions were processed for the recovery of plutonium. The recovery consisted of three successive stages of purification, each using oxalate precipitation performed in a batch mode. The operation took place in two gloveboxes located in a 5 by 6 meter room. Procedures called for two operators to control the systems in the room. A criticality alarm system was operational in the building at the time of the accident.

Figure 13 (not to scale) shows the five vessels located in glovebox 10 and the holding vessel located outside but connected directly to vessels inside the glovebox. Table 4 lists the seven vessels related to the reconstruction of the accident, along with their locations, dimensions, and function in the recovery operation. The operation began with a transfer of plutonium nitrate waste solution to vessel $\mathrm{R} 0$ in glovebox 9 where the first purification step was performed. This involved an oxalate precipitation of the plutonium, followed by a decanting of the supernatant liquid containing the impurities as well as some plutonium, and then re-dissolution of the plutonium into a carbonate solution. The end product from R0, the plutonium carbonate solution, was then transferred to either vessel R1 or R2 in glovebox 10 for the second purification (oxalate precipitation, supernatant decanting, re-dissolution) step. Vessels R1 and R2 were identical in dimensions and functions and were operated in parallel to increase productivity. The end product from vessels R1 or R2 (again a plutonium carbonate solution) was then transferred to the holding vessel in preparation for batch transfer to vessel R3 where the last purification step was performed. The product from vessel R3, an oxalate precipitate slurry, was then vacuum transferred to the filter vessel via the transfer vessel. The oxalate precipitate collected by the filter vessel was then sent to another location for calcination.

Vessels R1 and R2 were equipped with transfer lines from $\mathrm{R} 0$ and to the holding vessel. The vessels also had stirrers and openings on top where a funnel could be used to add powdered reagents. The supernatant discharge lines (to vessels where the plutonium was concentrated by boiling and eventually returned to the recovery process) and the liquid chemical reagent supply lines are not shown. The supernatant typically had plutonium concentrations of about $0.1 \mathrm{~g} / \ell$. Both vessels were shielded with $25 \mathrm{~mm}$ of lead. The holding vessel was unshielded and located about $400 \mathrm{~mm}$ above the concrete floor. The holding vessel was equipped with receiving lines from vessels $\mathrm{R} 1$ and $\mathrm{R} 2$, a transfer line to vessel $\mathrm{R} 3$, a vacuum line, and a compressed air line. Vessel R3 had lines and equipment identical to those of vessels R1 and R2. However, in the case of vessel R3, were solutions were received from the holding vessel and then sent out to the transfer vessel. Vessel R3 was also shielded by $25 \mathrm{~mm}$ of lead.

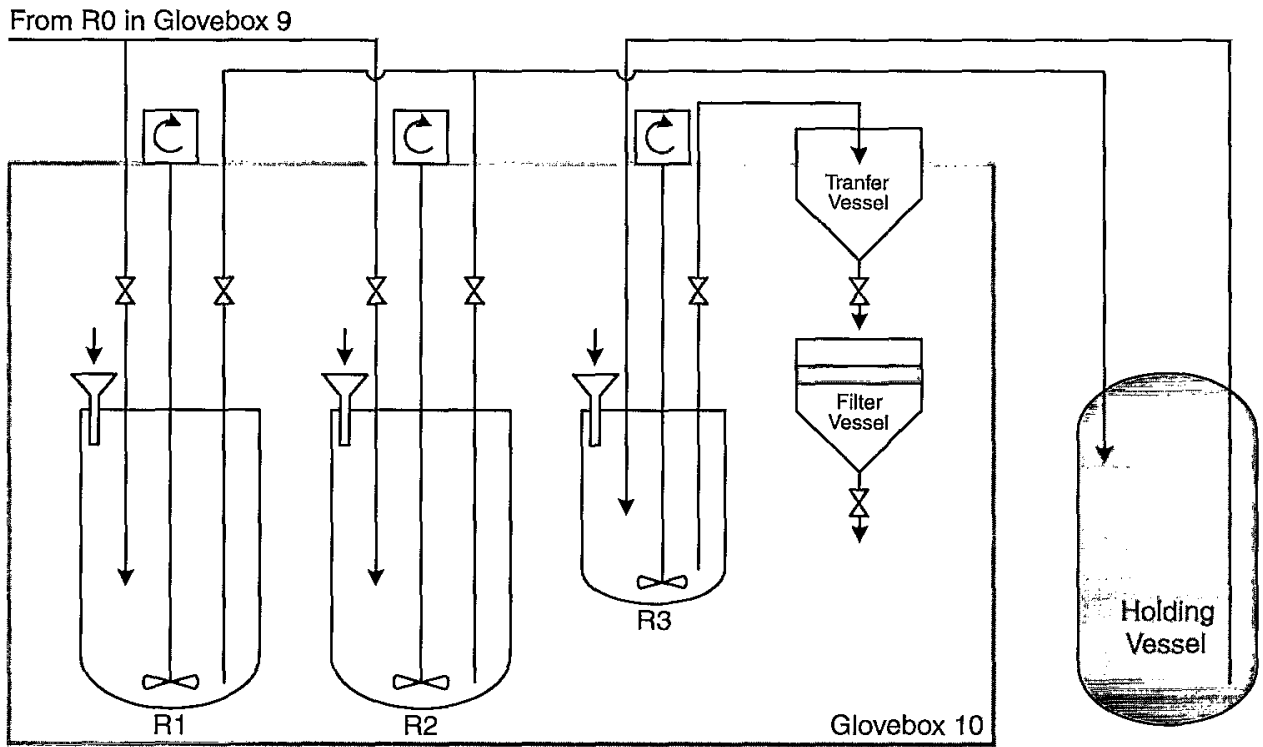

Figure 13. Layout of vessels in Glovebox 10 and the holding vessel external to the glovebox. 
Table 4. The Seven Vessels Related to the Reconstruction of the Criticality Accident.

\begin{tabular}{|c|c|c|c|c|c|}
\hline $\begin{array}{c}\text { Vessel } \\
\text { Designation }^{a}\end{array}$ & $\begin{array}{l}\text { Vessel } \\
\text { Location }\end{array}$ & $\begin{array}{l}\text { Vessel } \\
\text { Diam. } \\
(\mathrm{mm})\end{array}$ & $\begin{array}{l}\text { Vessel } \\
\text { Height } \\
\text { (mm) }\end{array}$ & $\begin{array}{l}\text { Approx. } \\
\text { Vessel Volume } \\
(\ell)\end{array}$ & Vessel Function \\
\hline Ro & $\mathrm{G}-9^{\mathrm{b}}$ & 500 & 900 & 180 & First oxalate precipitation \\
\hline R 1 & $\mathrm{G}-10^{\mathrm{b}}$ & 400 & 500 & 60 & Second oxalate precipitation \\
\hline R2 & $\mathrm{G}-10$ & 400 & 500 & 60 & Second oxalate precipitation \\
\hline Holding Vessel $^{c}$ & $\begin{array}{l}\text { Outside } \\
\text { G-10 }\end{array}$ & 350 & 450 & 40 & $\begin{array}{l}\text { Sample extraction and solution } \\
\text { staging between R1 or R2 and R3 }\end{array}$ \\
\hline R3 & $\mathrm{G}-10$ & 300 & 400 & 27 & Third oxalate precipitation \\
\hline Transfer Vessel & G-10 & 250 & 300 & 15 & $\begin{array}{l}\text { Transfer precipitate from } \mathrm{R} 3 \text { to } \\
\text { filter vessel }\end{array}$ \\
\hline Filter Vessel & $\mathrm{G}-10$ & - & - & 4 & $\begin{array}{l}\text { Collected precipitate while } \\
\text { passing lean solution }\end{array}$ \\
\hline \multicolumn{6}{|c|}{$\begin{array}{l}{ }^{a} \text { All seven had vertical axes of cylindrical symmetry. } \\
{ }^{b} \mathrm{G}-9=\text { Glovebox } 9, \mathrm{G}-10=\text { Glovebox } 10 \\
{ }^{c} \text { Accident location }\end{array}$} \\
\hline
\end{tabular}

At approximately 22:25 on 5 December, an operator working alone in the room initiated a vacuum transfer of carbonate solution from vessel R2 to the holding vessel. Shortly after starting the transfer the operator noticed that one of the criticality alarm system detectors located about $4.5 \mathrm{~m}$ from the holding vessel was sounding intermittently. The detector had a dynamic range of 10 to $3,600 \mathrm{mR} / \mathrm{h}$ and was set to trigger at $110 \mathrm{mR} / \mathrm{h}$. Without stopping the transfer, he left the room to report this observation to the shift supervisor. His decision to leave the room may have saved his life; shortly after his departure the entire alarm system began sounding continuously. All personnel immediately evacuated to an underground tunnel per procedure. Later, radiation safety personnel entered a corridor located about 10 to $15 \mathrm{~m}$ from the room to measure the radiation level. Using a portable PMRIgamma sensing device it was determined that the radiation level exceeded the $18 \mathrm{R} / \mathrm{h}$ upper range of the instrument. Facility managers, the head of the site safety organization, and the site technical specialist arrived at the building about an hour after the criticality alarm sounded.

Following their arrival, the facility managers and the technical specialist began interviewing personnel and reviewing measurements and working documents to locate the site of the accident. They concluded that the accident had occurred in the room with gloveboxes 9 and 10 and that the holding vessel was the most likely location of the accident. Remote readout of the criticality alarm detector located in the room indicated the average radiation level to be in the range of 1.5 to $1.8 \mathrm{R} / \mathrm{h}$. The peak-to-minimum radiation level was oscillating in amplitude by more than a factor of 10 . Using a long pole, personnel placed an integrating dosimeter into the room from the outside corridor during a radiation level minimum. Based on the exposure time, the gamma radiation level about $2 \mathrm{~m}$ from the holding vessel was estimated to be $10 \mathrm{R} /$ $h$. The facility was not equipped with instrumentation that could have automatically recorded the excursion history. In addition, because of the high stress level, personnel did not take the time to manually record the excursion history.

About an hour and a half following the first excursion, the vacuum system in the holding vessel was still switched on. Ordinarily the transfer of solution from R2 to the holding vessel would have been completed in much less than 1.5 hours. One speculated explanation for the continuing excursions was that the vacuum system would cause the transfer of enough solution to initiate an excursion, which would build up pressure sufficient to saturate the vacuum system momentarily interrupting the transfer. Eventually the vacuum system would recover, and more solution from R2 would be transferred leading to another excursion. To test this hypothesis the vacuum system was switched off. Despite this action, the excursions continued.

The next attempt to terminate the excursions took place about $00: 15$ on 6 December. Three operators entered the room during a period of low radiation levels. They closed the holding vessel's vacuum system and R2 transfer line valves. They then opened the holding vessel's compressed air supply and the transfer valves to vessel R3. These tasks were accomplished in about 10 to 12 seconds. During this episode, the average radiation level in the room was about $1.8 \mathrm{R} / \mathrm{h}$. A hand held PMR-1 instrument measured about $14 \mathrm{R} / \mathrm{h}$ in the vicinity of the holding vessel. The vacuum system was then switched on and $5 \ell$ of solution were transferred from the holding vessel to vessel $\mathrm{R} 3$. This action terminated the excursions. The transfer was limited to $5 \ell$ to prevent a criticality accident from occurring in vessel R3. 
During the next shift, radiation safety supervisors decided that the room could be reentered since the remote readout of the criticality alarm system detector measured a radiation level of less than $0.15 \mathrm{R} / \mathrm{h}$. Working from special instructions, three operators entered the room. Consciously limiting their time in the room and using three $20 \ell$ bottles, they were able to remove the $5 \ell$ of solution in R3 and make two transfers of 6 and $8 \ell$ from the holding vessel. The three $20 \ell$ bottles were placed in a specially designated storage location with the contents eventually being returned to the recovery process.

An investigation was carried out to reconstruct the events leading up to the accident. The investigation determined that the accident occurred because the mass limits per batch in vessel R0 had been exceeded. Table 5 presents the chronology leading up to the overloaded batch in vessel $R 0$.

Nitric waste solutions deposited in vessel R0 typically had a plutonium concentration of a few grams per liter. Criticality safety for the entire operation relied entirely on the mass limit for vessel R0. This mass limit was $400 \mathrm{~g}$ of plutonium. As can be seen in Table 5, the mass limit was exceeded on 2 December when the third batch of waste solution arrived at R0. Following the fourth transfer of solution on 3 December, vessel R0 contained a total of $682 \mathrm{~g}$ of plutonium. However, the shift production engineer deliberately changed the R0 vessel log to show only $400 \mathrm{~g}$ in the vessel. On 4 December the oxalate precipitate in vessel R0 was dissolved and transferred in the form of plutonium carbonate solution to an empty vessel, R2, in glovebox 10 . The same shift production engineer then violated procedures again by transferring an additional $30 \ell$ of carbonate solution to R2. This latter transfer contained $115 \mathrm{~g}$ of plutonium. Consequently vessel R2 contained a total of $798 \mathrm{~g}$ of plutonium in a little less than $50 \ell$ of solution in the early evening of 5 December. The plutonium in R2 was then precipitated with approximately $15 \mathrm{~g}$ of plutonium discharged with the supernatant. The precipitate was again dissolved, and the carbonate solution was transferred to the holding vessel, leading to the criticality accident.
Following the accident, the vacuum system trap, the holding vessel, and vessels R2 and R3 were carefully flushed. The flushing of the holding vessel resulted in $40 \ell$ of discharge which contained $180 \mathrm{~g}$ of plutonium. The contents of the three $20 \ell$ bottles which had collected the contents of the holding vessel and vessel R3 were analyzed. Table 6 presents the results of these analyses.

Table 6. Analysis of Accident Solution Recovered from Holding Vessel and R3.

\begin{tabular}{cccc}
\hline $\begin{array}{c}\text { Bottle } \\
\text { Number }\end{array}$ & $\begin{array}{c}\text { Volume } \\
(\ell)\end{array}$ & $\begin{array}{c}\text { Plutonium } \\
\text { Conc. }(\mathrm{g} / \ell)\end{array}$ & $\begin{array}{c}\text { Plutonium } \\
\text { Mass }(\mathrm{g})\end{array}$ \\
\hline 1 & 5 & 39.4 & 197.0 \\
2 & 6 & 37.7 & 226.0 \\
3 & 8 & 36.4 & 291.0 \\
Total & 19 & & 714.0 \\
\hline \hline
\end{tabular}

To reconstruct the volume and plutonium mass that were in the holding vessel at the time of the accident, the $714 \mathrm{~g}$ from Table 6 were combined with the $180 \mathrm{~g}$ from the holding vessel flush to obtain $894 \mathrm{~g}$ of plutonium in $19 \ell$ of solution and precipitate. The flushing of vessel R3 resuited in $10 \ell$ of flush containing $43 \mathrm{~g}$ of plutonium recovered from non-dissolved precipitate. The total mass of plutonium recovered from all the vessels plus the three $20 \ell$ bottles was $1003 \mathrm{~g}$, suggesting that $66 \mathrm{~g}$ was held up in vessel R2.

During the accident and the subsequent cleanup phase, five individuals received doses in the range 0.24 rem to about $2.0 \mathrm{rem}$. There was no contamination or damage to any of the equipment. Following the accident, the holding vessel was immediately replaced with a favorable geometry vessel. The total fission yield was estimated to be about $2.5 \times 10^{17}$ fissions.

Table 5. Chronology of Batch Composition Leading to Overloading of Vessel R0 in Glovebox 9.

\begin{tabular}{cccccc}
\hline Date & $\begin{array}{c}\text { Volume } \\
(\ell)\end{array}$ & $\begin{array}{c}\text { Concentration } \\
(\mathbf{g ~ P u} / \ell)\end{array}$ & $\begin{array}{c}\text { Pu Transferred } \\
(\mathbf{g})\end{array}$ & $\begin{array}{c}\text { Pu Discharged } \\
(\mathbf{g})\end{array}$ & $\begin{array}{c}\text { Running total of } \\
\text { Plutonium in R0 }(\mathrm{g})\end{array}$ \\
\hline 1 Dec & 160 & 1.67 & 267 & 51.0 & $267-51=216$ \\
$2 \mathrm{Dec}$ & 80 & 2.20 & 176 & 21.0 & $216+176-21=371$ \\
$2 \mathrm{Dec}$ & 100 & 3.28 & 328 & 39.0 & $371+328-39=660$ \\
$3 \mathrm{Dec}$ & 80 & 0.58 & 46 & 24.0 & $660+46-24=682$ \\
\hline \hline
\end{tabular}




\section{Idaho Chemical Processing Plant, 25 January 1961 $14,15,16,17$}

Uranyl nitrate solution, $U(90)$, in a vapor disengagement vessel; multiple excursions; insignificant exposures.

This accident occurred in the main process building, CPP 601 , in H-cell. where fission products were chemically separated from dissolved spent fuel. The uranium was then concentrated via evaporation. Operations were conducted 24 hours per day on three 8-hour shifts. The accident happened at 09:50 after a routine shift change at $08: 00$. This was only the fifth day of operation following a shutdown that had lasted nearly a year.

The accident took place in the upper disengagement head of the $\mathrm{H}-110$ product evaporator. This was a vertical cylindrical vessel of about $600 \mathrm{~mm}$ diameter and more than a meter tall, which was above a $130 \mathrm{~mm}$ diameter favorable geometry section. In spite of an overflow line located just below the disengagement head to preclude significant amounts of solution from reaching it. concentrated uranyl nitrate solution, about $200 \mathrm{~g} \mathrm{U}(90) / \ell$, was apparently rapidly ejected up into this unfavorable geometry section.

There were several conjectured causes of the solution entering the disengagement head, which were discussed in the accident investigating committee's reports. ${ }^{14.15}$ The most probable cause was thought to have been a bubble of high pressure air (residuum from an earlier line unplugging operation) inadvertently forcing a large fraction of the available $40 \ell$ of uranyl nitrate solution in the $130 \mathrm{~mm}$ pipe section up into the vapor disengagement cylinder. Neither the exact fissile volume (and thus uranium mass) nor the geometry at the time of the spike is known; they can only be conjectured and bounded. It was certain that the excursion occurred in the head and was reported to be of short duration, a few minutes or less. The total number of fissions was estimated to be $6 \times 10^{17}$ with an uncertainty of $25 \%$.

There was no instrument readout to give a direct indication of the excursion history. Recordings from remote detectors such as continuous air monitors were all that were available from which to infer the time evolution of the excursion. Inspection of these strip chart recordings along with knowledge of their locations led to inconclusive, and, in the case of one strip chart, unexplainable findings. A subsequent American Nuclear Society (ANS) paper ${ }^{15}$ on a method for estimating the energy yield of criticality excursions shows an initial spike of $6 \times 10^{16}$ and a total yield of $6 \times 10^{17}$. The source of these values could not be determined. Experimental data from the $\mathrm{CRAC}^{5}$ series of prompt critical excursions coupled with the knowledge of the bounds on the volume of liquid involved in this accident support the values in the ANS paper. One final source of guidance as to the likely first spike yield is a private communication from Dr. D. L. Hetrick in which he concludes that a value of $6 \times 10^{16}$ seems the most reasonable. ${ }^{17}$

Radiation alarms sounded throughout the process areas, apparently from the prompt gamma-rays associated with the fission spike. All employees evacuated promptly, and there were only minimal doses ( $<60 \mathrm{mrem}$ ) caused by airborne fission products after personnel left the building. A team of operating and health physics personnel reentered the building 20 minutes after the excursion and shut down all process equipment. As radiation levels had quickly returned to normal and there was no indication of any contamination within the manned areas, management authorized the workers to return to the plant at 14:45. No equipment was damaged.

Several items were noted in the reports of the accident investigation committees as contributing causes. These included (1) poor communications, particularly oral messages between operators as to the positions of valves; (2) unfamiliarity of personnel with the equipment after such a long shutdown; and (3) relatively poor operating condition of the equipment. 


\section{Siberian Chemical Combine, 14 July 1961}

Uranitum hexafluoride, $U(22.6)$, accumulation in a vacuum pump oil reservoir; two excursions; one significant exposure.

This accident occurred at a gaseous diffusion uranium enrichment facility. The enrichment process was a continuous, 24 hour operation. The end product was uranium hexafluoride $\left(\mathrm{UF}_{6}\right)$ enriched to various levels depending on the final reactor fuel to be produced.

The initial $\mathrm{UF}_{6}$ sublimation, introduction into the cascade, intermediate purification, and its final desublimation to the solid phase (in cylinders) was conducted in desublimation/sublimation stages (DSS). DSS-6 (Figure 14), occupied a large room (7.2 by $18 \mathrm{~m}$ ) and was an intermediate purification stage (the enrichment was $22.6 \%$ by weight at this point in the cascade). This stage was used to remove contaminants such as air and excess hydrogen fluoride (HF) from the $\mathrm{UF}_{6}$. This process was accomplished by

1. continuously diverting a portion of the $\mathrm{UF}_{6}$ cascade stream to DSS -6 ,

2. desublimating the $\mathrm{UF}_{6}$ at temperatures between -60 to $-80^{\circ} \mathrm{C}$ in the 5 main cylinders and in the 3 intermediate cylinders,

3. condensing excess $\mathrm{HF}$ at a temperature of about $-180^{\circ} \mathrm{C}$ in the 2 sedimentation vessels,

4. drawing off the impurities, followed by

5. sublimation and reintroduction of the $\mathrm{UF}_{6}$ into the diffusion cascade.
During normal operations, most of the $\mathrm{UF}_{6}$ desublimated in the main and intermediate cylinders. The HF, containing only trace amounts of $\mathrm{UF}_{6}$, passed on and collected in the $2 \mathrm{HF}$ sedimentation vessels. The air and any other non-condensable impurities were collected downstream in a bank of 5 holding vessels, about $4,500 \ell$ in capacity each. The contents of these holding vessels were then transferred to the gas purification equipment by the action of a vacuum pump (Figure 15) that used oil as its working fluid. About once every 15 days, it was necessary to replace the oil because accumulation of $\mathrm{UF}_{6}$ caused an increase in density (from 0.9 to $~ 0.92$, with a concentration of $\sim 20 \mathrm{~g} \mathrm{U} / \ell$ ) reducing the pump's efficiency. While clearly having some criticality safety significance, this replacement schedule was motivated primarily by operational considerations.

Both the main and intermediate cylinders were cooled by liquid nitrogen flowing through a coil embedded in iron-shot filled jackets surrounding the cylinders. When there was an adequate supply of liquid nitrogen, its flow was actuated automatically by a signal from thermal transducers (resistance thermometers). However, when in short supply, liquid nitrogen was fed manually from portable dewars. The sublimation (heating) cycle was activated automatically by a pressure sensor in the $\mathrm{UF}_{6}$ accumulation vessel.

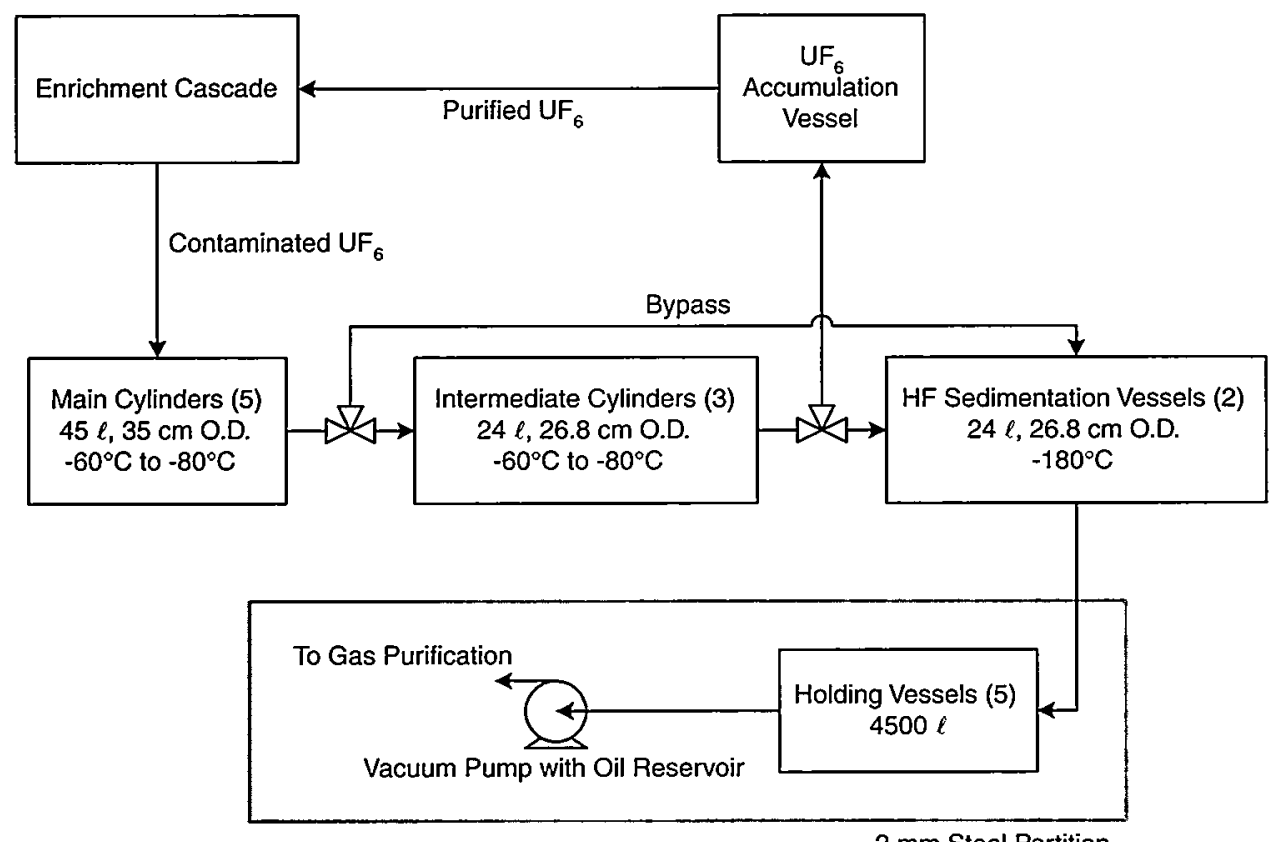

Figure 14. Layout of DSS-6. 


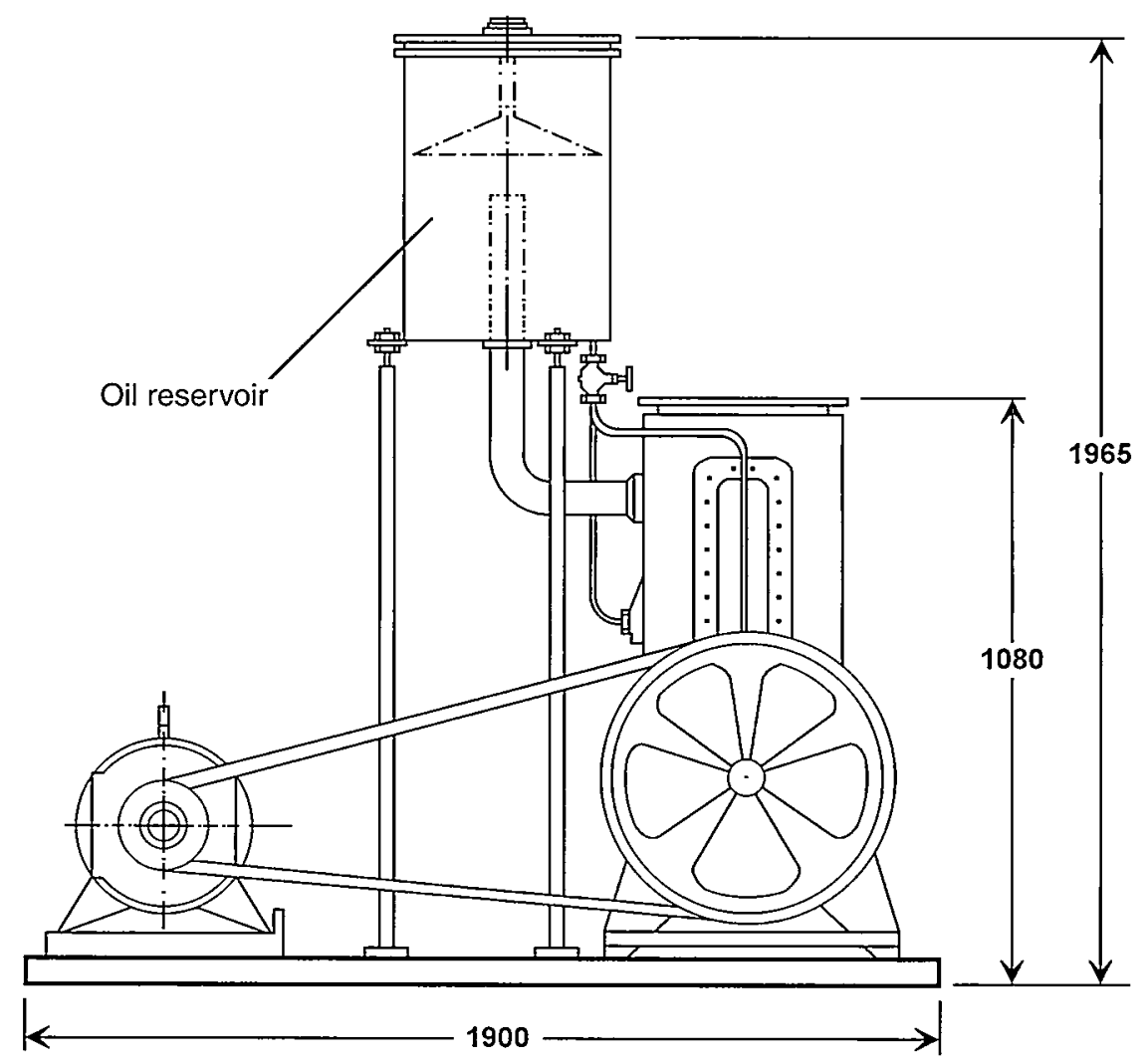

Figure 15. Vacuum pump diagram showing oil reservoir (Dimensions are in $\mathrm{mm}$ ).

On 1 July 1961, equipment breakdowns at the liquid nitrogen production facility decreased its output by $50 \%$. greatly reducing the available supply to the enrichment facility. The following day, operating procedures were changed to require that the 5 main cylinders be charged with liquid nitrogen manually. Furthermore, and in violation of procedures, the cooling of the 3 intermediate cylinders was discontinued entirely. These events and actions resulted in a large increase in the rate and amount of $\mathrm{UF}_{6}$ passing through the holding vessels and accumulating in the vacuum pump oil.

On 10 July, a regulator air leak in the enrichment cascade resulted in the need to divert a greater than normal fraction of the $\mathrm{UF}_{6}$ stream to DSS-6 for purification. On 14 July at $04: 45$, a high radiation alarm sounded in the room housing the main DSS-6 equipment. Unknown to any one at the time, this activation of the alarm was the result of the first criticality excursion occurring in the vacuum pump oil reservoir. Per procedure, the operator ceased operations and summoned the radiation control officer in charge to determine the cause of the alarm. The radiation control officer determined that the average exposure rate in the room was $\sim 9 \mathrm{mR} / \mathrm{h}$. Although the facility had a criticality alarm system with the detector trip points uniformly set to $7 \mathrm{mR} / \mathrm{h}$. it did not activate as the result of this very small excursion.
The radiation control officer surveyed all the equipment in the room but was unable to locate the source of radiation. The holding vessels and vacuum pump were not surveyed since they were in an adjoining room and were not suspected of having any appreciable uranium holdup. The radiation control officer noted that the exposure rate was decreasing rapidly during his survey, falling to $\sim 0.7 \mathrm{mR} / \mathrm{h}$ after only 10 to 15 minutes. He then authorized the resumption of operations.

At 07:30, the operator turned on the vacuum pump from the central control panel to evacuate the holding vessels. As he approached the equipment $(\sim 0.5 \mathrm{~m})$, to open a valve between the pump and holding vessels, the criticality alarm sounded. The operator reported seeing a flash of light at that instant. He did not open the valve, but did turn off the pump and immediately ran to a telephone (about $200 \mathrm{~m}$ away) to inform a supervisor of the accident. Alarms sounded simultaneously in three adjacent buildings at distances from 160 to $320 \mathrm{~m}$ from DSS-6. The radiation control officer arrived and noted that the gamma radiation exposure rate was about $0.7 \mathrm{mR} / \mathrm{h}$ at $100 \mathrm{~m}$ and increased steadily to about $36 \mathrm{mR} / \mathrm{h}$ adjacent to the building housing DSS -6 . The operator was sent to the hospital. 
The accident investigation determined that the excursions had occurred in the vacuum pump oil reservoir (Figure 16). The gamma exposure rate on contact was measured daily at the midpoint of the oil reservoir for five days using a PMR-1 instrument. Results of these measurements are shown in Table 7. A total of $42.95 \ell$ of oil were drained into $5 \ell$ bottles on 18 and 19 July. Analysis of the oil using the luminescent method indicated a uranium concentration of $173 \mathrm{~g} / \ell$ with an uncertainty of $\pm 30 \%$ to $40 \%$ (the luminescent method involved introducing a liquid luminescing agent into the solution and estimating the concentration from the intensity of the emitted light). The uranium enrichment was uniformly $22.6 \%$ by weight.

The time evolution of the excursions had several unusual features. The $\mathrm{UF}_{6}$ had been accumulating at a normal rate until four days before the accident when a large increase occurred. There was no delay in the initiation of the chain reaction due to the very slow reactivity insertion rate and the relatively large neutron source $\left(\sim 1.3 \times 10^{4} \mathrm{n} / \mathrm{s}\right.$ from $\alpha, n$ reactions $)$. Consequently, the first excursion on 14 July (04:45) was very small and probably did not exceed $2 \times 10^{14}$ fissions. After this excursion terminated, the oil in the reservoir probably remained only slightly subcritical. It should be emphasized that the concentration, solution volume, and material configuration at the time of this burst are not well known. Furthermore, it is not known if the vacuum pump was operating during this first excursion.

When the pump was turned on at 07:30, the oil in the pump's cavities was forced out into the central pipe of the oil reservoir. This sudden injection of oil containing uranium led to the second and much larger excursion. The shutdown of this excursion was due to a combination of temperature rise and radiolytic gas generation, which caused ejection of the oil from this central pipe back into the pump's cavities and the gas purification equipment. As with the first excursion, the

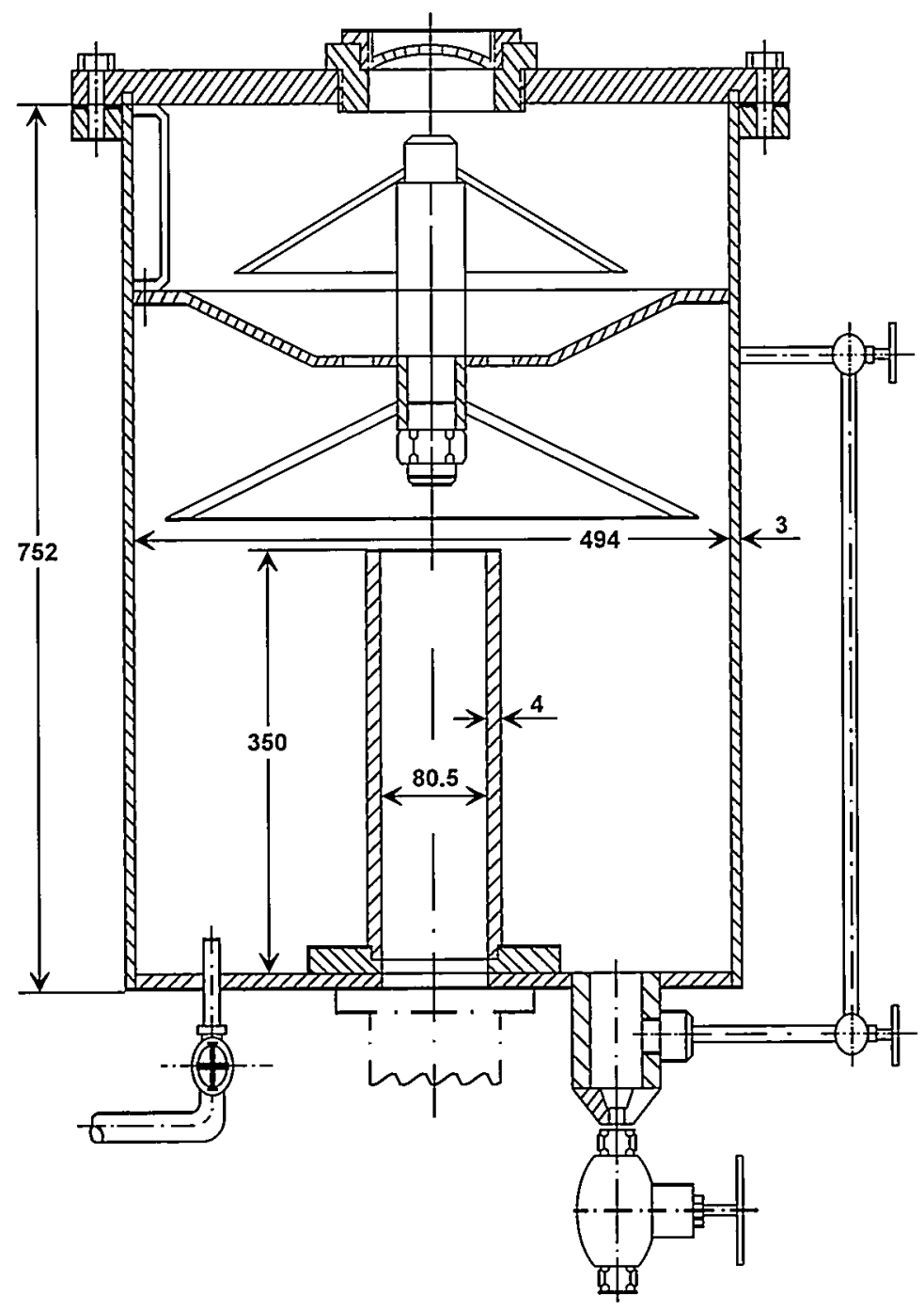

Figure 16. Oil reservoir (Dimensions are in $\mathrm{mm}$ ). 
Table 7. Results of $\gamma$-Radiation Exposure Rate Measurements at Oil Reservoir

\begin{tabular}{ccccc}
\hline $\begin{array}{c}\text { Date } \\
\text { (1961) }\end{array}$ & Time & $\begin{array}{c}\text { Elapsed Time from } \\
\text { Second Excursion } \\
(\text { min) }\end{array}$ & $\begin{array}{c}\text { Exposure } \\
\text { Rate (R/h) }\end{array}$ & Notes \\
\hline 14 July & $12: 00$ & 270 & 36.0 & \\
& $13: 30$ & 360 & 25.2 & \\
& $15: 25$ & 475 & 14.4 & \\
& $17: 30$ & 600 & 14.4 & \\
& $20: 10$ & 760 & 11.2 & \\
15 July & $23: 15$ & 945 & 9.0 & \\
16 July & $12: 00$ & 1710 & 3.6 & \\
& $10: 00$ & 3030 & 1.8 & \\
17 July & $15: 00$ & 3330 & 1.8 & Draining of oil reservoir begun \\
& $11: 00$ & 4530 & 1.1 & Draining of oil reservoir completed \\
18 July & $15: 00$ & 4770 & 1.1 & \\
19 July & $07: 00$ & 5730 & 0.9 & 0.3 \\
\hline \hline
\end{tabular}

exact configuration, concentration, and amount of oil injected into the central pipe of the oil reservoir from the pump are not well known. The total number of fissions for both excursions was estimated by fission product analysis to be about $1.2 \times 10^{15}$.

From 1 July until the accident, the following procedural violations occurred:

1. The temperature recording instruments of the main cylinders were turned off.

2. The main cylinders were cooled by manually pouring the liquid nitrogen directly onto the iron shot and not through the coil as procedure required. This resulted in significant temperature gradients within the main cylinders and, as a consequence, to misleadingly low temperature readings because the thermometer was adjacent to the liquid nitrogen pour point.

3. Cooling of the intermediate cylinders was no longer being performed.

The dose to the operator was estimated to be about $200 \mathrm{rad}$, and only mild radiation sickness symptoms followed. No one else received measurable doses, and there was no equipment damage nor contamination as a result of the accident. 


\section{Hanford Works, 7 April 1962 $18,19,20,21,22$}

Plutonium solution in a transfer vessel; multiple excursions; three significant exposures.

This Recuplex system process plant accident involved: 1) cleaning up the floor of a solvent extraction hood, 2) a product receiver tank that could overflow into the hood, 3) a temporary line running from the hood floor to a transfer tank (about $460 \mathrm{~mm}$ diameter, $69 \ell$ volume), and 4) the apparent improper operation of valves.

The final triggering mechanism cannot be determined because the testimony of witnesses and operators is not in full agreement with the technical findings of the investigating committee. Although other mechanisms cannot be ruled out, there is a plausible course of events. The receiver tank overflowed into the hood, leaving a solution containing about $45 \mathrm{~g} \mathrm{Pu} / \ell$ on the floor and in a sump; the operator, contrary to orders, opened a valve that allowed the solution to be lifted to the transfer tank. The later addition of aqueous solution ( 10 to $30 \ell$ at $0.118 \mathrm{~g} \mathrm{Pu} / \ell$ ) and additional moderation following mixing and/or de-aeration of the contents of the transfer tank led to the excursion.

The total excursion yield in the transfer tank was $8 \times 10^{17}$ fissions, with the initial spike estimated to be no more than $10^{16}$ fissions. Following the spike, the tank was supercritical for 37.5 hours as the power steadily decreased.

Activation of the building criticality alarm system resulted in prompt evacuation. At the time (a Saturday morning), 22 people were in the building, only 3 received significant doses of radiation $(110,43$, and
19 rem). The accident itself caused no damage or contamination but did precipitate final shutdown of the plant. The Recuplex operation had been designed as a pilot plant and only later converted to production. The construction of a new plant had been authorized before the accident occurred.

Response to the accident was unique. A small, remotely controlled, television equipped, robot was used to reconnoiter the building interior, fix precisely the point of the accident (through an attached, highly directional gamma probe), read meters, deposit instrumentation at specified locations, and operate valves on command.

Clayton (1963) ${ }^{19}$ suggested a shutdown mechanism for the accident. A central pipe that entered the bottom of the vessel in which the reaction occurred was found after the accident to contain dibutyl phosphate with a significant loading of plutonium. It is suggested that this started as a layer of tributyl phosphate in carbon tetrachloride on top of the aqueous plutonium solution. The heat and radiation from the fission reaction could have driven off the $\mathrm{CCl}_{4}$ and converted most of the remaining organic to dibutyl phosphate. The denser dibutyl phosphate, having extracted plutonium, could have gone to the bottom of the vessel and into the pipe, where it would contribute little to the system reactivity. As is often the case after an accident, it is difficult to evaluate the validity of this suggestion, but it does appear to provide a consistent explanation. 


\section{Mayak Production Association, 7 September 1962}

Plutonium nitrate solution in a dissolution vessel; three excursions; insignificant exposures.

The accident occurred in a building that housed operations associated with the conversion of plutonium feed material to metal. The metal was subsequently purified by a number of processes and then cast into ingots. In each of these steps, dry residues (typically sand, slag, and crucibles from chip briquetting and casting) that contained recoverable quantities of plutonium were generated. It was during the chemical dissolution of some of these residues in an unfavorable geometry vessel that the accident occurred.

The residues were typically collected, canned, and stored pending chemical treatment to recover the plutonium. There being no practical means to assay individual cans in real time, fissile mass per can was estimated based on historical averages. This average was determined from records of the assay of the solution in which each batch of residues was dissolved. The historical average plutonium content of the residues was about $1 \%$ by weight. The statistical fluctuation of this average was also based on these historical records.

Most cans contained less than $50 \mathrm{~g}$ of plutonium in about $5,000 \mathrm{~g}$ of residue, but occasionally, as a result of operational deficiencies, the plutonium content was significantly in excess of $100 \mathrm{~g}$. All cans, regardless of suspected plutonium content, were stored in the same glovebox awaiting recovery. The criticality mass limit took into account the statistical fluctuation of the fissile mass per dissolution batch; thus, the plutonium feed mass was calculated by multiplying the residue mass by $1 \%$.

The first step in the recovery process was to dissolve the slag and residues in nitric acid. Typically five cans of residue were combined as the feed for a dissolution batch; procedures limited the number of cans to six. The glovebox used for this had two identical dissolution vessels, shown in Figure 17. While not bearing on this accident, it is interesting to note that this glovebox was an early, conservative design; it was made of $8 \mathrm{~mm}$ thick steel and had $50 \mathrm{~mm}$ of lead shielding.

Each dissolution vessel was cylindrical, $450 \mathrm{~mm}$ in diameter and $620 \mathrm{~mm}$ in height and had a capacity of about $100 \ell$. Each was equipped with a stirrer and a 60 $\mathrm{mm}$ thick heating jacket through which hot water was circulated. The vessels were open-topped with movable plates typically covering the openings. Reagents were added through lines and residues were added manually by pouring. Also, each vessel had a solution sampling device that was used to monitor the acidity $(\mathrm{pH})$. During the course of a dissolution run it was important to maintain a specified acidity level; excess acidity was lowered by adding more residue.
During the days just before the accident, research was being conducted on technology for producing metal ingots by reduction smelting briquettes made from metal shavings. After having been returned to service subsequent to repairs, the first charge to dissolution vessel 2 was a residue batch from these smelting operations. This charge was high concentration residue containing $318 \mathrm{~g}$ of plutonium. After the dissolution run, only $11 \mathrm{~g}$ of plutonium was discharged in the nitrate solution. This was a clear sign of a very incomplete dissolution that should have caused operating personnel to postpone charging the next batch into vessel 2 . Nevertheless, the next batch, containing $352 \mathrm{~g}$ of plutonium, was loaded into the vessel.

Because repairs were in progress on liquid transfer systems, only nitric acid was initially added to vessel 2 . Water was added several hours later in violation of the procedure that specified that water be added first. The quantities of these two reagents that were added were also in violation of the procedure. After several hours of mixing, the solution was determined to be acidic.

Further mixing finally resulted in a slightly alkaline $\mathrm{pH}$ measurement. After allowing for the settling of solids, the clear liquid was decanted and sent to a collection tank.

Records are incomplete, but it is likely that during this long dissolution run that additional residue from casting operations was charged to vessel 2 to neutralize the solution. Two subsequent dissolution operations were then performed. After the first of these, the solution was still acidic. During the second, an aqueous ammonia reagent was added which did neutralize the solution. Heating and mixing were then stopped and the solution was allowed to settle. After about 3 hours, at 00:15 on 7 September, the criticality alarm sounded, and personnel promptly evacuated to the predetermined assembly location, an underground tunnel.

Here it was determined (by the absence of blood sodium activation) that no one received a significant dose. The excursion may have fortuitously occurred while the operators were on a work break. A workforce shift change was scheduled for 01:00, but workers for the next shift were not allowed into the facility, and all workers from the prior shift remained on duty. All recovery actions involving the equipment and solution in this glovebox were performed remotely from the shift supervisor's room, approximately $30 \mathrm{~m}$ distant, until the system was put into a safely subcritical state.

Fifteen minutes after the first excursion, unsuccessful attempts were made to remotely open a line and drain vessel 2 . Further attempts at remote recovery included heating and mixing of the solution, temporarily lowering the reactivity of the system. A short while later the 


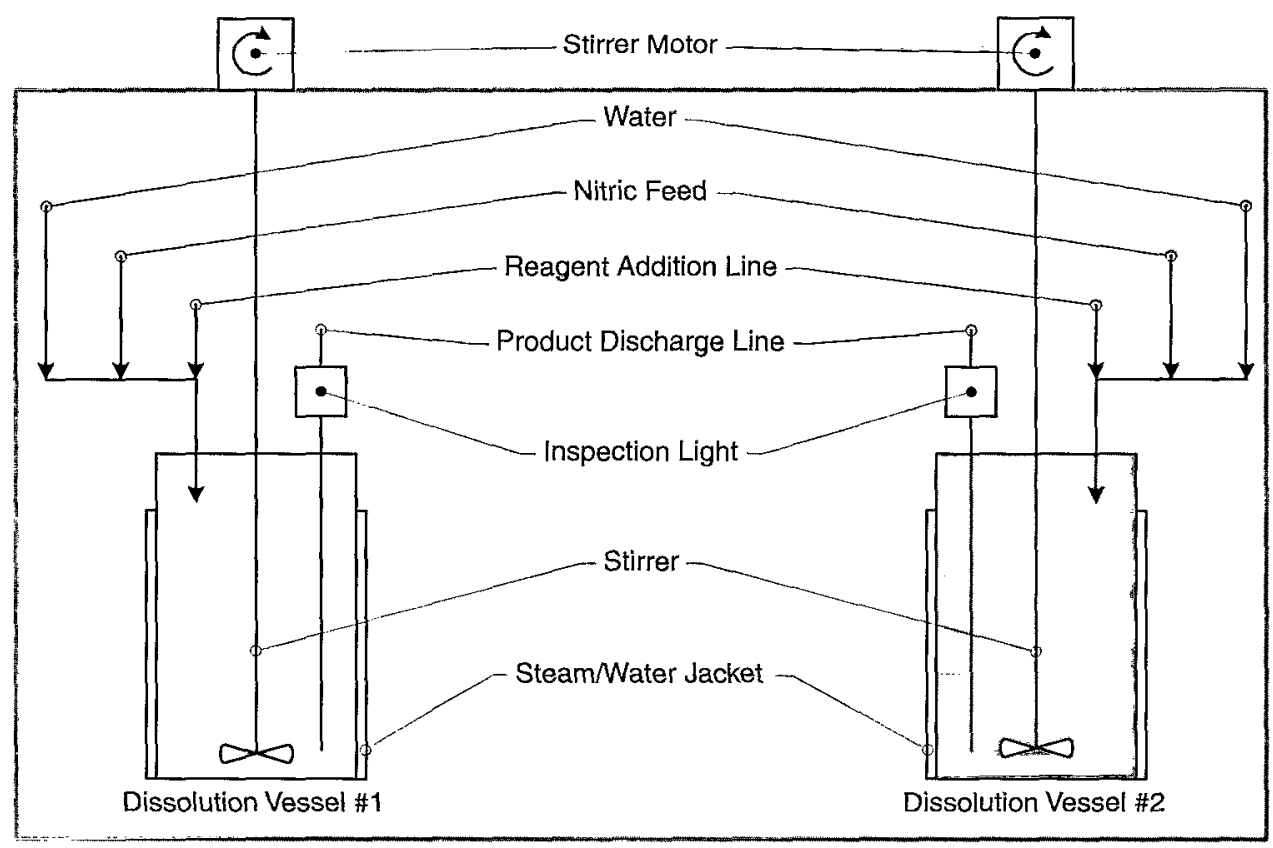

Figure 17. Layout of glovebox equipment.

heater and stirrer were turned off again, leading to a second excursion at 01:10. This was apparently no larger than the first, as it did not trip detectors that had not tripped during the first excursion.

After this second excursion the plant and building managers arrived at the accident site along with the manager of the safety organization and supporting physicists. They then directed further recovery operations. Attempts to remotely drain vessel 2 by various means continued until a third and final excursion occurred at 01:55. Detectors which had not previously tripped (some as far away as $150 \mathrm{~m}$ ) were activated, indicating that this third excursion was the largest. At this time the stirrer and heater were once again turned on (to keep the system subcritical) and left on until the solution could finally be transferred from vessel 2 .

The final draining of the vessel was a two-part process. First, about one-half of the solution in vessel 2 was transferred to an aqueous collection vessel and then from there partitioned into several bottles. This procedure was then repeated with the remaining solution in vessel 2 . All the bottles were stored in an isolated room, and the contents were reprocessed only after the radiation levels decreased to acceptable levels.

The trip level of the criticality alarm detectors was $110 \mathrm{mR} / \mathrm{h}$. They were spaced a maximum of $30 \mathrm{~m}$ apart but were commonly much closer. Fifteen minutes after the first excursion the exposure rate in the vicinity of the glovebox was about $2.2 \mathrm{R} / \mathrm{h}$. Thirty minutes after the third excursion the exposure rate in the vicinity of the glovebox was about $1.8 \mathrm{R} / \mathrm{h}$.

Ultimately it was determined that there had been a total of $1,324 \mathrm{~g}$ of plutonium in the dissolution vessel at the time of the accident. This was about three times the criticality safety limit. The recovered nitric solution contained $933 \mathrm{~g}$ of plutonium and a very rich precipitate was found in the bottom of vessel 2 . It contained $391 \mathrm{~g}$ of plutonium in $660 \mathrm{~g}$ of solids; the remainder was mostly graphite pulp from molds. Using approximate techniques, the energy release for all three excursions was estimated at $2 \times 10^{17}$ fissions. The excursion history was not recorded. There was minor ejection of solution from the vessel onto the glovebox floor, likely from the third excursion.

Several factors contributed to the accident:

- Unfavorable geometry equipment.

- The charging of high grade residues into the dissolution vessel when the criticality controls were based on residues with an average $1 \%$ plutonium content.

- Inadequate isolation of high grade residues from the more common low grade residues in the staging glovebox.

- Unclear and difficult to read labels on the residue cans.

- Procedural violations on the sequence of reagent additions.

- Inadequate supervisory monitoring of operations; inadequate attention to the completion of accountancy documents.

- Lack of real time fissile material accounting instrumentation.

No equipment damage occurred and only a short downtime was needed to clean up the spilled solution. 


\section{Siberian Chemical Combine, 30 January 1963}

\section{Uranyl nitrate solution, $U(90)$, in a collection vessel; multiple excursions; insignificant exposures.}

This accident occurred in a waste recovery line of a uranium metal production building. The waste feed was a dry precipitate. The first step in recovering the uranium was a time-intensive, concentrated nitric acid dissolution process. Two sets of identical equipment were used to increase the throughput and to optimize the process. Figure 18 is a material flow diagram for this process.

The solution was vacuum transferred from the dissolution vessels to the intermediate feed vessels, through a filter vessel, and then finally to the collection vessels. The dissolution and intermediate vessels were $320 \mathrm{~mm}$ in diameter and $520 \mathrm{~mm}$ in height. The collection vessels were $390 \mathrm{~mm}$ in diameter and $500 \mathrm{~mm}$ in height. All of the vessels had curved ends and were about $50 \mathrm{f}$ in volume. Since the process vessels were not favorable geometry, limiting the fissile material mass was the only control used to prevent criticality accidents. Compliance with the mass limit was solely dependent on the reliability of the chemical analysis of the dry precipitate.

Despite the importance of chemical analysis results for implementing the criticality safety mass control, there were two allowed reporting formats:

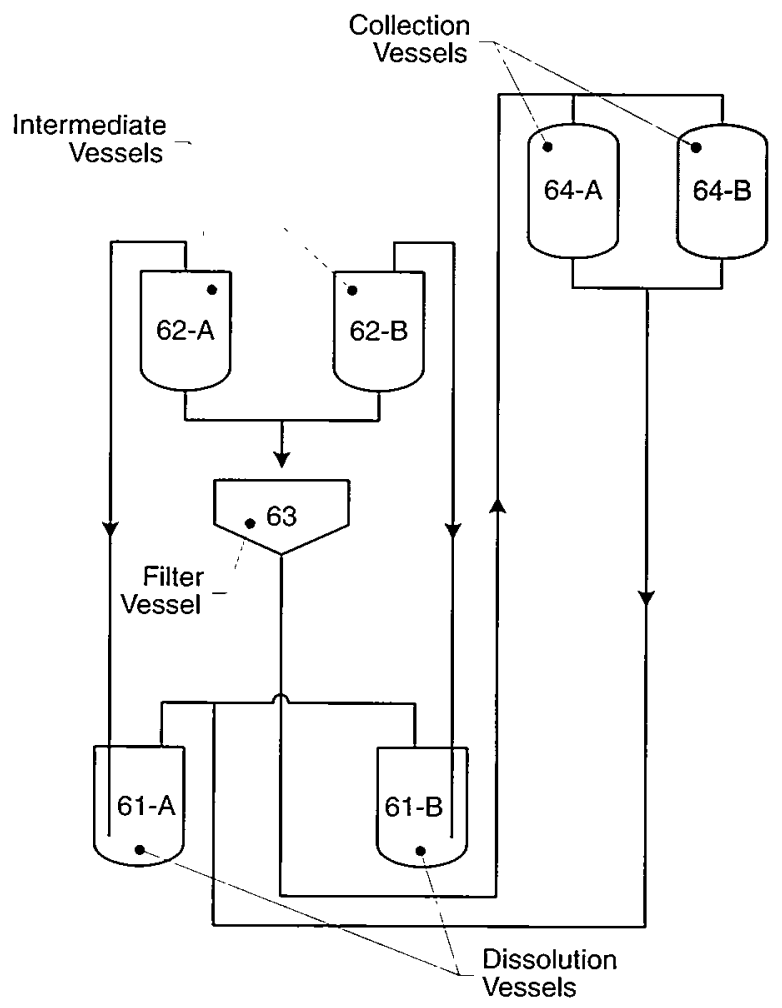

Figure 18. Process vessels and material flow diagram.
1. as grams of uranium per kilogram of precipitate, $\mathrm{g} \mathrm{U}(90) / \mathrm{kg}$, or

2. as a mass fraction, the uranium-to-precipitate mass ratio.

The bulk amount of precipitate to be processed was calculated using the results of the chemical analysis. The precipitate was then weighed before loading into the dissolution vessels.

When dissolving consecutive batches of precipitate, the operational procedure allowed for the recycling of solution with low uranium concentration from the collection vessels, as long as the total mass of uranium in the dissolution vessels did not exceed $400 \mathrm{~g}$. The uranium concentration in the recycled solution was determined by analyzing samples from the collection vessels. This concentration was always reported as grams of uranium per liter ( $\mathrm{g} \mathrm{U} / \%$ ) and was also used for compliance with the criticality safety mass limit.

On 30 January 1963, two waste containers were received at the waste recovery line with the chemical analysis results attached. These results were reported as a mass fraction, approximately 0.18 in this case. The supervisor for the shift erroneously recorded this result in the work orders as $18 \mathrm{~g} \mathrm{U} / \mathrm{kg}$ of dry precipitate (instead of 180). The actual uranium content in this batch of dry precipitate was thus in error and underestimated by a factor of 10 .

Using the erroneous work orders, an operator loaded $2 \mathrm{~kg}$ of precipitate from one container and $5 \mathrm{~kg}$ from another into dissolution vessel 61-A, believing the total uranium content to be $126 \mathrm{~g}$ when it was actually about $1,260 \mathrm{~g}$. Because of a shift change, a different operator completed the dissolution process. The solution was then filtered and transferred to collection vessel 64-A, where a sample was taken to determine the concentration. Later during that same shift, the operator asked for the sample results by telephone. While this normally would have led to the discovery of the original recording error, the laboratory erroneously reported the results for a vessel other than 64-A. By an unfortunate coincidence, this other vessel contained solution with a uranium concentration 10 times lower than that in 64-A, thus reinforcing the operator's expectations.

The supervisor for the second shift, relying on this erroneous information, decided to recycle this supposedly low concentration solution to dissolve the next batch of dry precipitate. This next batch, still subject to the original recording error, contained $\sim 1,255 \mathrm{~g}$ of uranium, about the same as that of the preceding batch. The dry precipitate was loaded into dissolution vessel 61-A and then the solution from collection 
vessel 64-A was added. The dissolution vessel thus had over $2,500 \mathrm{~g}$ of uranium, an amount close to the unreflected critical mass for this diameter vessel. The solution was then filtered in $10 \ell$ batches and transferred to the larger diameter collection vessel 64-B. In the course of this filtering/transfer operation, the solution exceeded the critical height in 64-B, and the first excursion occurred at 18:10 on 30 January 1963 . The criticality alarm system sounded and all personnel evacuated. The $\gamma$-ray detectors were set to activate at $110 \mathrm{mR} / \mathrm{h}$. Several of the personnel were directed to undergo medical assessment.

During approximately the next 10 hours, eight additional excursions occurred, decreasing in power each time. The total number of fissions was estimated to be $7.9 \times 10^{17}$. This was based on a sample analysis that determined the total ${ }^{140} \mathrm{La}$ fission product content after the accident. The shutdown mechanisms for the excursions were

- expansion caused by the formation of radiolytic gas bubbles,

- ejection of some of the solution into the service piping,
- thermal expansion of the solution (decreased density), and

- an increase in the solution temperature, which tended to harden the neutron spectrum.

Each time the solution drained back into the vessel from the service pipes and cooled down another excursion took place. The excursions were terminated on 31 January 1963 at 04:30, when part of the solution was drained from the collection vessel to portable $5 \ell$ containers.

The accident investigation determined that a total of $2,520 \mathrm{~g}$ of uranium in a volume of about $35.5 \ell$ $(\sim 71 \mathrm{~g} / \ell)$ was in the collection vessel at the time of the accident. All of the solution $(35.5 \ell)$ was stored in a concrete shielded room for one year, then reprocessed.

Four people standing at a distance of $10 \mathrm{~m}$ from the collection vessel received radiation doses of 6 to $17 \mathrm{rad}$. No damage occurred to the vessel nor was there any contamination of the surroundings. The process was inoperative for no more than 12 hours.

\section{Siberian Chemical Combine, 2 December 1963}

\section{Uranium organic solution, $U(90)$, in a vacuum system holding vessel; multiple excursions; insignificant exposures.}

This accident occurred in an enriched uranium, $\mathrm{U}(90)$, reprocessing and purification facility. Operations were being conducted on four 6-hour shifts per day. The combination of an unfavorable geometry holding vessel and the unplanned accumulation of much larger than expected quantities of organic solutions led to the accident.

The normal use of the vacuum system routinely resulted in the accumulation of small amounts of solution within the vacuum system as drops and condensate. In addition, occasional operator mistakes resulted in the overflow of process vessels, again resulting in solution entering the vacuum system. In order to protect the vacuum system from the corrosive effects of this solution, and to prevent loss of solution from the process stream, two traps and a holding vessel were installed in the vacuum line. The traps, 696 and 697 in Figure 19, were intended for the collection of solutions that entered the vacuum lines. Holding vessel 694 served as a backup in the event that either of the two traps filled to preset levels. This would result in the automatic draining of some of their solution. All three vessels had straight cylindrical sidewalls of $500 \mathrm{~mm}$ diameter with hemispherical bottoms and a volume of about $100 \ell$. The vessels were spaced about 1.5 meters, surface-to-surface.
Each vessel had a level indicator that was actuated when an electrically conductive solution reached a preset height. For traps 696 and 697, the preset height was only half as high as for vessel 694 . When the level indicator in either 696 or 697 was actuated, the transfer of solution occurred automatically until the level was drawn down (decanted) to the bottom of the dip tube. However, when the level indicator in holding vessel 694 was actuated, its entire contents were drained via the outlet line.

When these vessels were installed, it was believed that only high conductivity aqueous solutions would accumulate in them. However, because organics such as tributylphosphate were transferred in this facility using this same vacuum system, considerable amounts of organic solution were in fact also ending up in these vessels. The very low electrical conductivity of these organic solutions was insufficient to actuate the level indicators.

During typical operations, sufficient quantities of aqueous solutions would accumulate in vessels 696 and 697 , causing the automatic decanting to occur up to four times per day. The elevation difference between the level indicator and the dip tube was slight, thus causing only 1 or $2 \ell$ to be transferred at a time. 


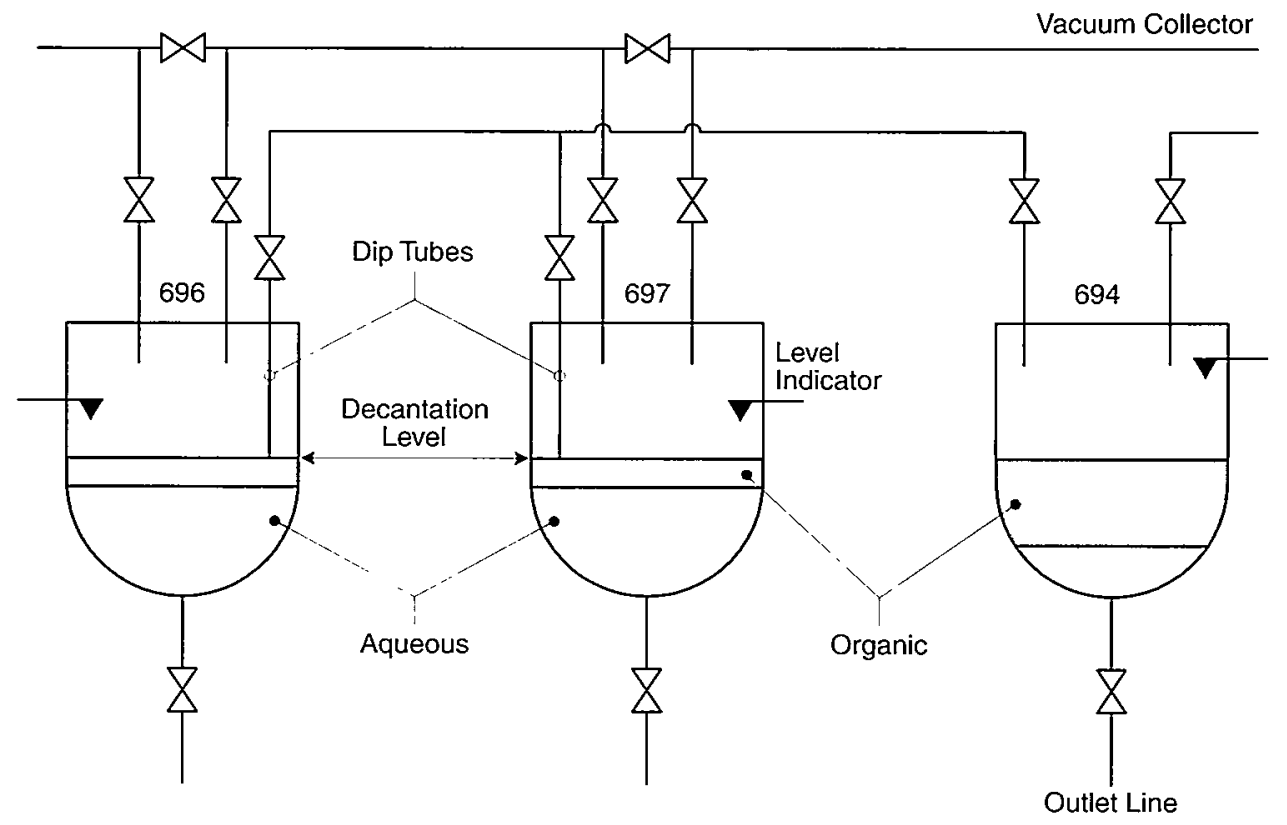

Figure 19. Schematic of vessels showing organic and aqueous solutions (not intended to imply the exact conditions at the time of the accident).

Because the organic solution was much less dense than the aqueous solution, the liquids separated into different layers within the vessels. Since the organic solution did not actuate the level indicators, it could continue to accumulate until the level of aqueous solution was sufficient to trigger a transfer. In addition. as aqueous solution entered the vessels it would temporarily mix with the organic solution. This caused a portion of the fissile material in the aqueous solution to be extracted into the organic layer, thus increasing its fissile material concentration.

These same chemical and physical processes were also occurring in holding vessel 694 . However, because its level indicator was set twice as high, more liquid, and thus a greater amount of high concentration organic. could accumulate undetected. Prior to the accident. holding vessel 694 , in which the excursion occurred, had not been emptied for 8 days. Furthermore. and unknown to operating personnel, the vessel was mostly filled with high concentration organic.

On 2 December 1963 at 23:45, detector 38 tripped, causing the criticality alarm to sound. This detector was in a corridor close to the location of the traps and holding vessel. Operating personnel did not routinely work in this corridor, nor were they present when the alarm sounded. Nevertheless, personnel were evacuated from all building locations near detector 38 . The detectors were gamma sensing, with the trip level set at $110 \mathrm{mR} / \mathrm{h}$. Very quickly, detector 38 's reading in- creased a hundred fold to $11 \mathrm{R} / \mathrm{h}$. Based on subsequent radiation surveys, it was determined that the excursion had occurred in holding vessel 694 .

During the first $\sim 195$ minutes, 11 excursions in total were observed. These were very long, weak excursions with a time between power peaks of about 20 minutes. At 03:45 the following morning, on 3 December, the vacuum system was de-energized by plant personnel. This caused some of the highly concentrated organic that had been ejected into the vacuum system during the excursions to the drain back into vessel 694 . This caused a second series of weaker excursions. The first power peak was similar in magnitude to the first peak of the prior series. This second series lasted until about 08:00 (more than 4 hours). Four excursions, each of decreasing intensity, were observed.

By 15:00 that afternoon, the exposure rates had decreased considerably, at which time $30 \%$ of $10 \%$ cadmium nitrate solution were added to the holding vessel from the top. It was thought that this would be a significant neutron absorber since it was expected that the vessel contained mainly aqueous liquid and intimate mixing would occur naturally. However, the cadmium nitrate solution did not mix with the organic and served only to displace it from the hemispherical bottom of the vessel. Holding vessel 694 had now become slightly subcritical as a result of higher neutron leakage from the organic solution. The 
additional reflection afforded by the added poisoned aqueous solution was apparently insufficient to compensate for this effect.

After addition of the cadmium nitrate solution, a hose was inserted into the holding vessel through a top port to siphon out the solution. Surprisingly, at the very beginning of the siphoning, a sixteenth, and final, excursion occurred. Later, upon consideration of the facts, it was recognized that this last excursion was a result of siphoning from the bottom of the vessel. Even though the draining of the cadmium nitrate decreased reflection, it allowed the organic to assume a more reactive geometry as it reentered the hemispherical bottom of the vessel.

The siphoning action was continued (in spite of the last excursion) until the vessel was drained. Altogether about $65 \ell$ of organic with a uranium concentration of $33 \mathrm{~g} \mathrm{U}(90) / \ell$, corresponding to about $2.14 \mathrm{~kg}$ of $\mathrm{U}(90)$, were removed from holding vessel 694.
During the nearly 16 hours over which the accident took place, the plant operators and supervisors on shift at the beginning of the excursions remained at the facility to assist with recovery operations and to document the events.

The total number of fissions, based on ${ }^{140} \mathrm{La}$ fission product analysis, was estimated to be about $6 \times 10^{16}$. A prompt and efficient evacuation was initiated by the sounding of the criticality alarm system. The largest individual dose received was less than five rem. There was no damage to the equipment or radioactive contamination.

The accident occurred (despite the fact that the vessels were steam cleaned monthly) presumably because of a rather quick and large accumulation of both organic and aqueous solutions. Subsequently, changes were made to the process design and between January and September 1964, large numbers of process vessels were replaced. At the end of this renovation, nearly all of the vessels were of favorable geometry.

\section{United Nuclear Fuels Recovery Plant, 24 July 1964 193,24}

Uranyl nitrate solution, U(93), in a carbonate reagent makeup vessel; two excursions; one fatality, two significant exposures.

This accident occurred in a chemical processing plant at Wood River Junction, Rhode Island, which was designed to recover highly enriched uranium from scrap material left over from the production of fuel elements. The plant operated three, 8-hour shifts, 5 days a week. The scrap material was shipped to the plant as uranyl nitrate solution in 55 gallon $(208 \ell)$ drums, at concentrations ranging from 1 to $5 \mathrm{~g} / \ell$ of uranium. The uranyl nitrate was then purified and concentrated by solvent extraction using tributyl phosphate mixed with kerosene as the organic wash. After the final acid strip, the purified uranyl nitrate solution was bubbled through a column containing a fixed charge of 4 to $6 \ell$ of trichloroethane (TCE). The TCE removed any organic that remained in the solution. The original plant design was based on a predicted life of 6 months to 1 year for a single charge of the TCE.

Typical of the difficulties that should be expected with a new operation (the plant had begun operations on 16 March 1964) a larger amount of organic carryover and a higher retention of uranium reduced the TCE's useful life to approximately 1 week. In early April, therefore, a procedure was developed to remove the uranium from the TCE before discarding it. The very low concentration of uranium in the solution (400 to $800 \mathrm{ppm}$ ) was recovered by washing the TCE with sodium carbonate solution. Originally, the operation was performed by manually shaking or rocking the solution within $5 \mathrm{inch}(127 \mathrm{~mm})$ diameter, $11 \ell$ bottles. This somewhat laborious process was used until 16 July. On that date, because an unusually large amount of contaminated TCE had accumulated, an operator was given permission by his supervisor to use a sodium carbonate makeup vessel to perform this process as long as the uranium content did not exceed $800 \mathrm{ppm}$. The vessel was 18 inches $(457 \mathrm{~mm})$ in diameter and 26.375 inches $(670 \mathrm{~mm}$ ) deep and was located on the third level of a tower housing solvent extraction columns. This new procedure was communicated to one other operator on a different shift. Between 16 and 24 July, these two operators washed 10 to 12 bottles each using the carbonate makeup vessel. It should be noted that the treatment of the TCE by any method was not part of the facility license, and therefore was not approved by the regulating authority.

On the day before the accident, a plant evaporator had failed to operate properly, making it necessary to disassemble it for cleaning. During the cleaning, a plug of uranium nitrate crystals was found in a connecting line. The crystals were dissolved with steam, and the resulting concentrated solution ( $256 \mathrm{~g} \mathrm{U} / \ell$ ) was drained into polyethylene bottles identical to those that normally held the very low concentration TCE solution. All of the bottles containing the high concentration solution were labeled as such. 
On Friday, 24 July, at approximately 18:00 the operator assigned to work the solvent extraction columns asked his supervisor if it was necessary to wash some of the contaminated TCE. Since the contaminated TCE was to be used for rinsing a process column. he was told that washing the TCE was not necessary. Nevertheless, the operator proceeded to locate a bottle of TCE with the intention of washing it, perhaps only to obtain an empty bottle. Unfortunately, the operator mistook one of the bottles containing the high concentration solution for one containing TCE. The bottle was transported to the stairwell leading to the third floor location of the carbonate makeup vessel by cart. and then hand carried the rest of the way. The bottle's label, which correctly characterized the contents as high concentration solution, was found after the accident on the floor near the cart.

After arriving at the third floor, the operator poured the contents of the bottle into the makeup vessel already containing $41 \ell$ of sodium carbonate solution that was being agitated by a stirrer. The critical state was reached when nearly all of the uranium had been transferred. The excursion ( 1.0 to $1.1 \times 10^{17}$ fissions) created a flash of light, splashed about $20 \%$ of the solution out of the vessel and onto the ceiling, walls and operator. The operator who fell to the floor, regained his footing and ran from the area to an emergency building $\sim 180 \mathrm{~m}$ away.

An hour and a half after the excursion, the plant superintendent and shift supervisor entered the building with the intent of draining the vessel. When they reached the third floor, the plant superintendent entered the room and approached the carbonate reagent vessel while the supervisor remained behind in the doorway. The superintendent removed the $11 /$ bottle (still end up in the vessel) and turned off the stirrer. He then exited the room, passing the supervisor and preceding him down the stairs. Unknown to anyone at the time (the alarm was still sounding from the first excursion), the change in geometry, created as the stirrer induced vortex relaxed, apparently added enough reactivity to create a second excursion, or possibly a series of small excursions. The estimated yield of the second excursion was 2 to $3 \times 10^{16}$ fissions and no additional solution was ejected from the vessel. The two men proceeded down to the second and first floors and began to drain the tank through remote valves. When the drain line became clogged with precipitate, the superintendent returned to the vessel, restarted the stirrer, and then rejoined the supervisor who was draining the solution into $\sim 4$ bottles on the first floor.

That the second excursion had occurred was not realized until dose estimates for the superintendent and supervisor were available. The supervisor received $\sim 100 \mathrm{rad}$, while the superintendent received $\sim 60 \mathrm{rad}$. Both doses were much higher than expected and were inconsistent with their reported actions. Only after significant analysis was it realized that the two had been exposed to a second excursion, which most likely occurred just as the superintendent passed the supervisor on the way down the stairs.

The radiation dose to the operator as a result of the initial excursion was estimated to be about 10,000 rad. He died 49 hours later. Other persons in the plant received very minor doses. The investigation determined that there had been $2,820 \mathrm{~g}$ of uranium in $51 \mathrm{f}^{\prime}$ of solution in the makeup vessel at the time of the first excursion. No physical damage was done to the system, although cleanup of the ejected solution was necessary. The total energy release was equivalent to $1.30 \pm 0.25 \times 10^{17}$ fissions. 


\section{Electrostal Machine Building Plant, 3 November 1965}

Uranium oxide slurry, $U(6.5)$, in a vacuum system vessel; single excursion; insignificant exposures.

This accident occurred in Building 242 that housed a production scale operation for the conversion of uranium hexafluoride to uranium oxide. The plant operated on four 6-hour shifts per day. Between 23 September 1964 and 19 October 1965, the facility had been converting $2 \%$ enriched material. However, because of the need to provide fuel for two newly commissioned uranium-graphite power reactors at the Beloyarskaya Nuclear Power Plant, it was necessary to begin processing $6.5 \%$ enrichment material. To perform this change over, the process was shutdown on 19 October 1965. During the following three days, the entire system was thoroughly cleaned out. The conversion process was restarted with the higher enriched material on 22 October 1965 . The criticality accident occurred 12 days later.

Figure 20 is a layout of the Building 242 uranium hexafluoride to uranium oxide conversion system and associated vacuum system. The uranium hexafluoride was burned in a hydrogen-air atmosphere in the conversion hopper. The resulting uranium oxides were collected at the bottom of the conversion hopper and then transferred by vacuum to the accumulation hopper. The vacuum system was then switched off and the oxides were loaded into geometrically favorable $20 \ell$ vessels by gravity. The vessels were then transferred from Building 242 to another location where the oxides underwent defluorination and complete reduction to $\mathrm{UO}_{2}$ in a rotating calcination furnace.

The vacuum system was located one floor level below the conversion system. To prevent oxide from entering the vacuum system, two filters were located in the vacuum line connecting the accumulation hopper to the (liquid ring) vacuum pump. Both the primary and the secondary filters used Lavsan, a fluorinated plastic material woven into a cloth-like fabric. Written procedures required that personnel on each shift open and visually inspect the secondary filter. This inspection was performed to ascertain the level of oxide accumulation and to look for mechanical defects in the Lavsan itself. If the operator was unable to see through the Lavsan of the secondary filter, in addition to replacing it, he was also required to open and visually inspect the primary filter. Procedures also required personnel on each shift to have a sample of the vacuum system water analyzed for uranium content. Sample assay results were usually available about 1.5 hours after the sample was taken. There was no nondestructive assay equipment in place or routinely used to determine if uranium oxide was accumulating in the vacuum system.
The components of the vacuum system were a vacuum pump, a water pump, a vacuum supply vessel (where the accident occurred), and a shell-and-tube heat exchanger. The vacuum supply vessel was a vertical axis, right circular cylinder, with a diameter of $650 \mathrm{~mm}$ and a height of $900 \mathrm{~mm}(\sim 300 \ell)$. The vessel was equipped with a water level glass site gauge.

On 3 November 1965 at 11:10, the criticality accident alarm system sounded in Building 242. All personnel in Building 242 immediately evacuated. The alarm systems of the adjacent buildings did not activate. The facility's chief physicist made the first reentry into Building 242 about 50 minutes after the building had been evacuated. Using a portable gammaray detector, he quickly determined that an accident had occurred in the vacuum supply vessel. At this time he recorded a gamma exposure rate of $3.6 \mathrm{R} / \mathrm{h}$ at a distance of $1.5 \mathrm{~m}$ from the surface of the vessel.

Recovery operations, performed by operations personnel under the direction of a health physicist, were conducted in a manner that minimized the likelihood of causing additional excursions. A long rod

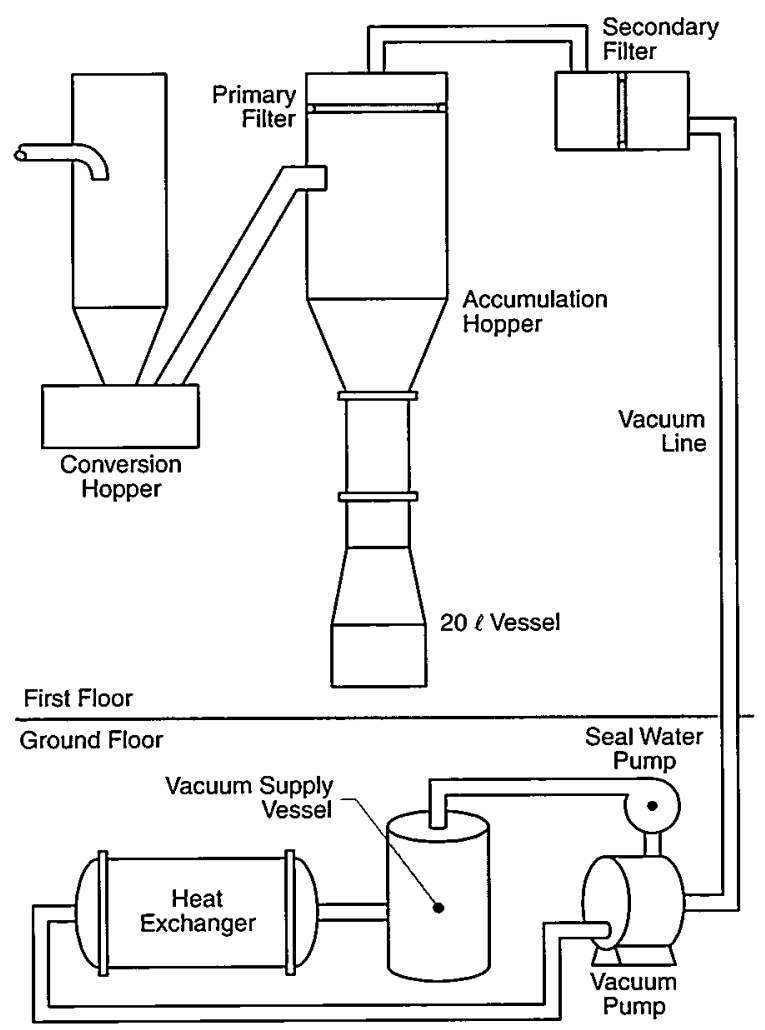

Figure 20. Layout of $\mathrm{UF}_{6}$ to uranium oxide conversion equipment and associated vacuum system. 
was used to break the glass site gauge on the side of the vessel. Geometrically favorable collection trays were positioned so as to collect the draining liquid. The draining operation resulted in the collection of about $60 \%$ of liquid. Analysis showed that the liquid contained $85 \mathrm{~g}$ of uranium per liter or a total of $5.1 \mathrm{~kg}$ of uranium. Eight days after the accident ( 11 November 1965). the vacuum supply vessel was opened and an additional $51 \mathrm{~kg}$ of uranium was recovered. The total material recovered from the vacuum supply vessel was $56.1 \mathrm{~kg}$ of uranium or, at $6.5 \%$ enrichment, about $3.65 \mathrm{~kg}$ of ${ }^{235} \mathrm{U}$. An additional $13.9 \mathrm{~kg}$ of uranium was recovered from the shell-and-tube heat exchanger and connecting lines. The total material recovered was $70 \mathrm{~kg}$ of uranium or about $4.6 \mathrm{~kg}$ of ${ }^{235} \mathrm{U}$.

An investigation was performed to discover the cause of the accident. The investigation team examined the records and confirmed that the Lavsan of the primary and secondary filters had been replaced during the three days that the system was being cleaned ( 19 through 22 October 1965). In addition, $150 \%$ of water had been drained from the vacuum system and replaced with fresh water. During the same period, plans were made to install a third filter between the accumulation hopper and the vacuum pump due to increased criticality safety concerns with the higher enrichment material. However, operations personnel were unable to install the additional filter before the restart of production on 22 October 1965.

The investigation determined that operational mistakes and procedural violations occurred following the restart of production. At the time of the accident. the primary filter was missing. In addition, the secondary filter was not completely secured by the flanges intended to hold it in place. The investigation was not able to determine how long the primary filter had been missing or how long the secondary filter had been leaking. These two operational mistakes allowed uranium oxide from the accumulation hopper to enter the vacuum system. Furthermore, and in violation of procedures, the vacuum system water had not been sampled even a single time since the restart of operations.

Two types of analysis were performed to estimate the total energy released by the accident. The first was based on the $3.6 \mathrm{R} / \mathrm{h}$ exposure rate measurement made $1.5 \mathrm{~m}$ from the vacuum supply vessel about 50 minutes following the accident. Analysis of this information provided an estimate of $5 \times 10^{15}$ total fissions. The second estimate was based on a ${ }^{64} \mathrm{Cu}$ activation analysis of a section of copper wire located about $1.2 \mathrm{~m}$ from the vacuum supply vessel. This resulted in an estimate of $1 \times 10^{16}$ fissions. Both estimates had considerable experimental and computational uncertainties.

Reconstruction of the accident conditions indicated that the onset of the excursion occurred during a slow settling of oxides to the bottom of the vacuum supply vessel. This occurred after the vacuum system was turned off. Initiation was most likely not delayed due to the slow reactivity insertion rate and an inherent neutron source of about 800 neutrons/s that was present in the vacuum supply vessel. The mechanism that terminated the excursion is unknown but could include continued settling of the oxides or expulsion of material into connecting lines. The equipment was not damaged and there was no contamination. A calculation indicated that one person who was about $4.5 \mathrm{~m}$ from the vacuum supply vessel could have received a dose as high as 3.4 rem. 


\section{Mayak Production Association, 16 December 1965}

Uranyl nitrate solution, $U(90)$, in a dissolution vessel; multiple excursions; insignificant exposures.

This accident occurred in a residue recovery area of a metal and fissile solution processing building. The residues being recovered were produced from dissolution, precipitation, and reduction processes. A schematic of the residue recovery area is shown in Figure 21. The residues, which were difficult to dissolve, were first calcined to convert the uranium content, usually less than $1 \%$ by weight, to $\mathrm{U}_{3} \mathrm{O}_{8}$. Residues with abnormally high uranium content, which were occasionally generated (failed castings, cracked crucibles, etc.), were directed by operating procedures to other handling areas subject to special requirements.

The residue dissolution glovebox where the accident occurred had three identical sets of process equipment as shown in Figure 22. Each set was equipped with a cylindrical dissolution vessel, a holding vessel, a filter vessel, and a filtrate receiving vessel. The dissolution vessels had elliptical bottoms, were $100 \ell$ in volume, and $450 \mathrm{~mm}$ in diameter, and were equipped with a pulsating device for mixing, a flat cover plate with a feed hopper, and a pressure relief valve. Heating of the dissolution vessels was accomplished with a $25 \mathrm{~mm}$ thick, steam-water jacket. Solution was moved within the system through a transfer line by drawing vacuum.
The residues were loaded into the dissolution vessel via the feed hopper located on the cover plate. The feed hopper was equipped with a lid that was sealed and locked in place during dissolution. Dissolution was accomplished by adding acid and heating the solution while mixing with the pulsating mixing device. Once dissolution was complete, the resulting solution was vacuum transferred to the holding vessel. The solution was then passed through the filter vessel (to remove non-dissolved solids) to the filtrate receiving vessel.

The day before the accident, 15 December 1965, a shift supervisor instructed an operator to calcine residue batch 1726 (uranium content greater than 1\%) in a glovebox with furnaces intended only for the processing of residues with less than $1 \%$ uranium content. This was a direct violation of the criticality safety rules. After calcination, batch 1726 was sampled, and before the results of the analysis had been obtained, was transferred to another glovebox already storing multiple batches of residue scheduled for dissolution. The analytical laboratory determined the uranium content of the sample from batch 1726 to be $44 \%$ by weight. This result was recorded in the laboratory sample book but was not transmitted to the recovery wing for recording on the batch's accountability card.

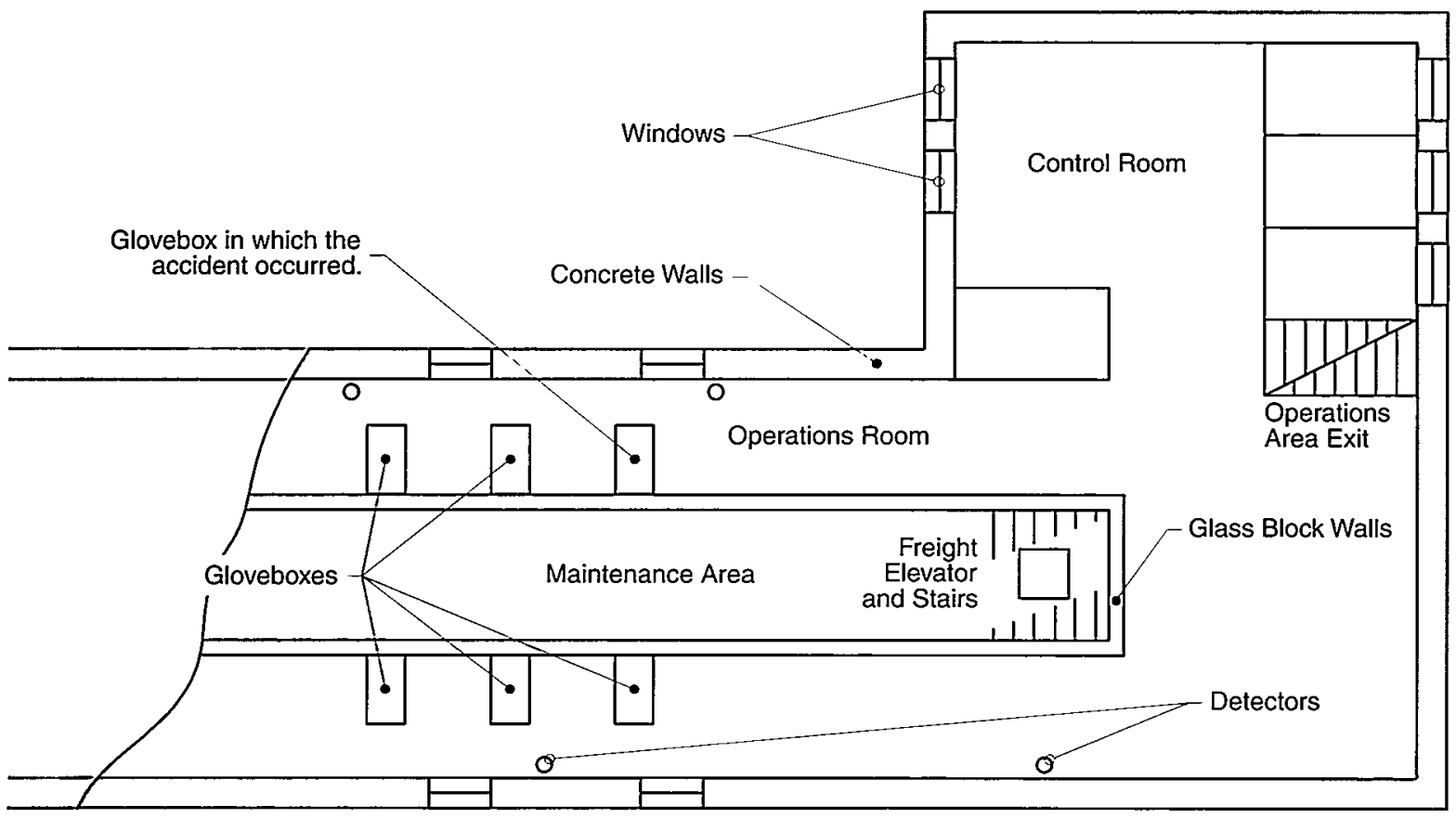

Figure 21. Residue recovery area layout. 


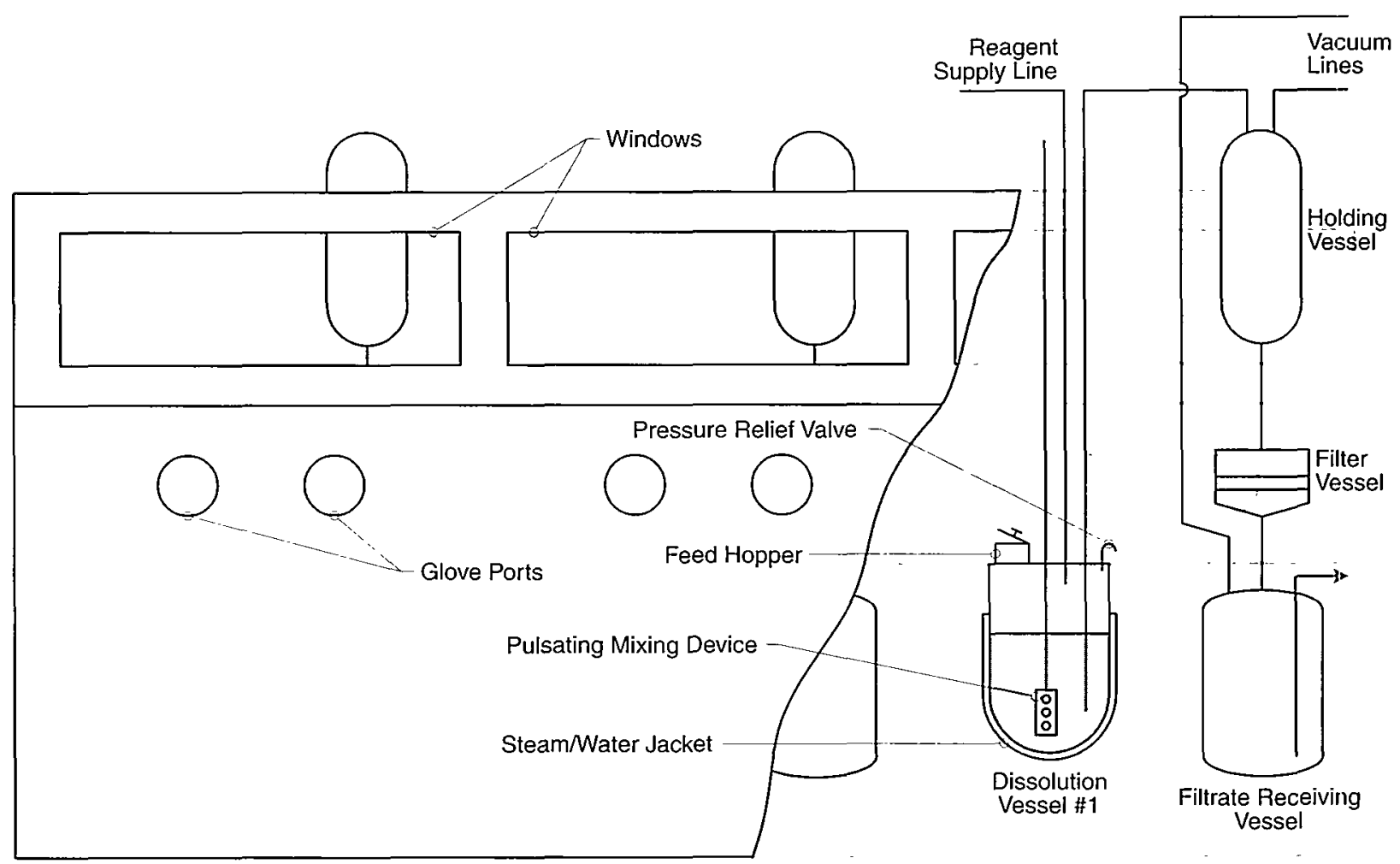

Figure 22. Layout of dissolution glovebox.

Subsequently, an operator preparing the waste batches for dissolution, noticed that the analysis results for batch 1726 were absent and contacted the laboratory by telephone to obtain them. As a result of poor communications, the operator was mistakenly given the assay results for batch 1826 , a batch that was only $0.32 \%$ by weight uranium, $\sim 138$ times smaller than that actually contained in batch 1726 . The operator recorded this result on the accountability card and on the label of the batch 1726 container.

The next day (16 December) $5 \mathrm{~kg}$ from batch 1726 , containing about $2.2 \mathrm{~kg}$ of $\mathrm{U}(90)$, were loaded into dissolution vessel \#1. The criticality mass limit for this vessel was $0.3 \mathrm{~kg}$. The operator, therefore, unknowingly exceeded this limit by more than a factor of 7 . At that same time, dissolution of low uranium content residue was already underway in the two other dissolution vessels.

According to procedure, the dissolution of the waste was to be carried out at $100^{\circ} \mathrm{C}$ for a minimum of 1.5 hours with constant mixing. However, in this case the process was discontinued after only 40 minutes to accommodate the regularly scheduled cleaning of the glovebox before the next shift.
Approximately 10 minutes after the heating and the mixing devices were turned off, the operator, who was cleaning the glovebox at the time, heard the nearest criticality alarm sound for a short time. The operator left the operations area (as per training for the sounding of a single alarm) and went to the central control room to determine the cause of the alarm. When the operator reached the control room, the nearest alarm to the glovebox again sounded. A few seconds thereafter, at $\sim 22: 10$, alarms associated with more distant detectors also began to sound. Eventually, several dozen alarms sounded. As instructed by their emergency training, all personnel evacuated to an underground tunnel. The time-delayed activation of the individual alarms, spaced at different distances from the accident location, indicated that the peak reactivity did not reach prompt critical.

Before the emergency response personnel arrived at $\sim 23: 00$, the dynamics of the system were monitored from another building ( $\sim 50 \mathrm{~m}$ distant) using remote readouts from gamma-ray and neutron sensing instruments. Four additional excursions, separated by about 15 to 20 minutes each, were observed. After the emergency response personnel arrived, it was judged, 
based on a radiation survey, that the central control room (Figure 21 ) could be safely occupied by personnel even during the excursions. Consequently, surveillance and recovery management operations were moved to this location.

Based on interviews with operating personnel, examination of the accountability records and system schematics, and the results of $\gamma$-ray surveys conducted with portable collimated detectors, dissolution vessel 1 or its associated holding vessel was identified as the most likely location of the accident. The surveys indicated that the average exposure rate, 1.5 minutes after an excursion, was $\sim 8 \mathrm{R} / \mathrm{h}$ at a distance of $2 \mathrm{~m}$ from the dissolution glovebox.

After the ninth excursion, cadmium poisoned solution was remotely added to the holding vessel. Despite this action, approximately 20 minutes later a tenth excursion occurred, establishing dissolution vessel I as the site of the accident with a high degree of probability. The removal of the vessel's contents or addition of cadmium poisoned solution were considered to be too dangerous to personnel because either action would have required time intensive manual manipulation of valves located within the glovebox. Instead the emergency response personnel decided to

- remove two gloves from the glovebox ports to gain access,

- unlock and open the feed hopper lid, and

- insert a ball consisting of crumpled up strips of $0.5 \mathrm{~mm}$ thick cadmium foil into the vessel through the feed hopper.

The first two tasks were successfully accomplished by two, specially briefed, experienced operators taking no more than 30 and 60 seconds, respectively, including the time necessary to enter and exit the operations area. The recovery actions were then halted as the radiation level began to rise again indicating that an eleventh excursion was under way. After waiting for a significant decrease in the radiation level, a senior engineer/physicist entered the operations area and loaded the cadmium foil ball into the vessel, taking care to disturb the surface of the solution as little as possible so as not to initiate another excursion. This took about 20 seconds total. As evidenced by the release of a characteristic orange smoke, the cadmium foil began dissolving immediately in the nitric acid. The introduction of the foil terminated the excursions as shown by a steady decrease in the $\gamma$-ray exposure rate measurements. All three of the individuals involved in the recovery actions carried personal dosimeters. No one received doses greater than $0.3 \mathrm{rem}$.

One day after the termination of the accident, the solution was transferred from the dissolution vessel, using temporary piping, to favorable geometry containers. These containers were then sent to a special storage facility and later reprocessed by conventional techniques after the cadmium had been removed.

The total number of fissions for the 11 excursions was estimated from activity measurements to be $\sim 5.5 \times 10^{17}$. The total volume of material in the tank was $28.6 \ell$, and sample analysis indicated that the uranium concentration was $77 \mathrm{~g} / \ell$. Of the personnel in the area at the time of the accident, 17 received doses of 0.1 rem or less, 7 between 0.1 and $0.2 \mathrm{rem}$, and 3 between 0.2 and $0.27 \mathrm{rem}$. The process equipment was not damaged and no contamination occurred. Normal operations were resumed within several days. During the following 2 to 3 years most of the process equipment $(\sim 94 \%)$ was replaced with favorable geometry vessels. 


\section{Mayak Production Association, 10 December 1968}

\section{Plutonium solutions (aqueous and organic) in a 60 liter vessel; three excursions; one fatality, one serious exposure.}

The accident occurred in a building where various chemical and metallurgical operations with plutonium were performed. Operations were conducted on four, 6-hour. shifts per day. The accident occurred on the 19:00 to 01:00 (10-11 December) shift. An unfavorable geometry vessel was being used in an improvised and unapproved operation as a temporary vessel for storing plutonium organic solution. Two independent handling operations with this same vessel and same contents less than one hour apart led to two prompt critical excursions, each one resulting in the severe exposure of a worker. A weak excursion occurred between the two energetic ones, when there were no personnel present.

A small scale research and development operation had been set up in a basement area to investigate the purification properties of various organic extractants. As originally built. the equipment and piping configuration of this research operation precluded these organics from reaching a set of two 1,000 / tanks used for the collection of very lean aqueous solutions $(<\mathrm{lg} \mathrm{Pu} / 6)$ that were also in the basement. Due to a combination of factors (changes to the piping. etc.), organics had inadvertently and unknowingly migrated in significant volume to one of these large aqueous solution tanks in a nearby basement room.

Figures 23 and 24 show plan and elevation views of these tanks. and the other vessels involved in the accident by their location in the basement room. Each tank had an operating volume of 800 /. Each was equipped with neutron detectors located near the bottom to monitor the plutonium concentration and to detect any sediment accumulation.

On 10 December, the 19:00 shift supervisor instructed an operator to sample the contents of tank 2 before transferring it to recovery operations. Since the sampling device was out of order, the sample was taken by lowering a glass vial on a thin line through one of the upper level sensor ports [Figure 24]. The results of the analysis indicated that the plutonium concentration was $\sim 0.6 \mathrm{~g} / 1$. Since the total volume of solution in the tank was $\sim 800$ liters, the total plutonium mass was $\sim 480 \mathrm{~g}$, which exceeded the criticality safety mass limit of $400 \mathrm{~g}$. According to regulations, the shift supervisor then ordered that two additional confirmatory samples be taken.

When taking these additional samples, it was noticed that the solution in both vials was a combination of organic and aqueous solution. The supervisor ordered the decanting of the samples to remove the organic solution before sending the samples for analysis. In fact, two different organic extractants had been used heavily in the nearby research operations since tank 2 had been last cleaned. As a result, a layer of organic solution with properties resulting from the two different extractants had gradually formed on top of the aqueous solution in tank 2 .

The access port of tank 2 was then opened, and the contents were visually inspected. This confirmed the presence of the organic solution layer. Knowing that the downstream equipment was not capable of properly treating organic solution, the supervisor decided to first remove the organic layer and then to transfer a part of the aqueous solution into tank 1 to come into compliance with the mass limits. These decisions were made before the results of the confirmatory sample analyses arrived.

The temporary arrangement of equipment used to remove the organic solution from tank 2 is shown in Figures 23 and 24 . Two reinforced rubber hoses, $1.2 \mathrm{~m}$ in length and $13 \mathrm{~mm}$ in internal diameter, were fixed into the neck of a $20 \%$ glass bottle (usually used for chemical reagents) with a cloth plug. One hose was connected to the vacuum line on tank 1 and the other was lowered into tank 2 through its access port. If the $20 \mathrm{f}$ bottle became full, it was decided that the contents would be poured into a $60 \%$ vessel usually used for the collection of very low concentration wastes before reprocessing. The bottle and vessel were placed on the platform above tanks 1 and 2. The use of these types of temporary, improvised, setups as well as the use of unfavorable geometry vessels were strictly prohibited by existing regulations.

In the presence of and under instructions from the shift supervisor, two operators used the improvised setup to begin decanting the dark brown (indicative of high plutonium concentration) organic solution. The shift supervisor then left to tend to other duties. After having filled the bottle with approximately 17 liters the operators noted that there was still some amount of organic solution remaining in tank 2 . The bottle was then emptied by pouring the contents into the $60 /$ vessel. During the second filling of the bottle, a mixture of aqueous and globules of organic solution were being drawn into the bottle. As a result the operators stopped filling the bottle. One operator then went on to other duties while the other went to the shift supervisor for further instructions.

Under instructions from the supervisor, the second operator resumed the decanting of the solution from tank 2 to the bottle. By carefully adjusting the depth of immersion of the hose from the access port the 


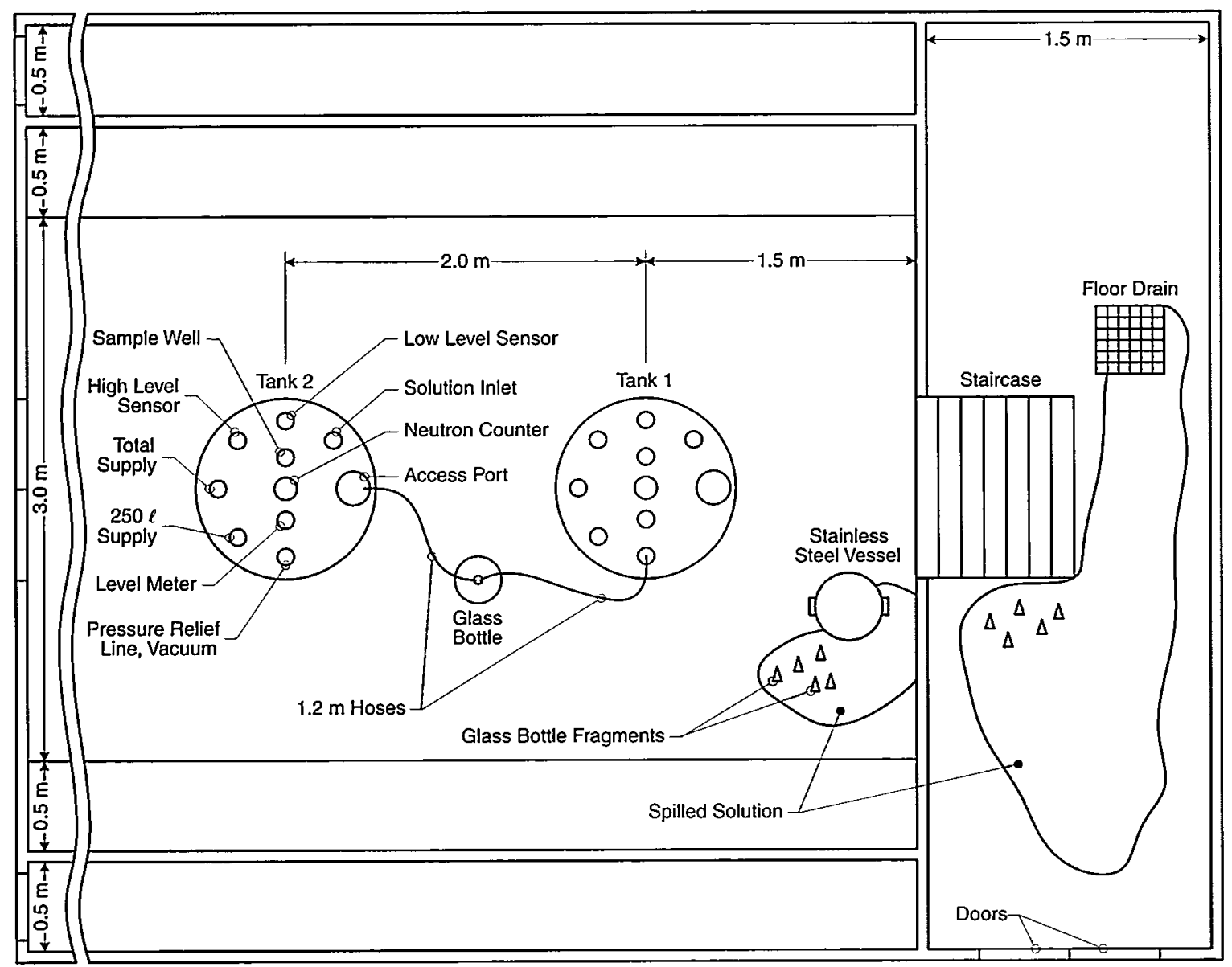

Figure 23. Plan view of the tanks involved in the accident.

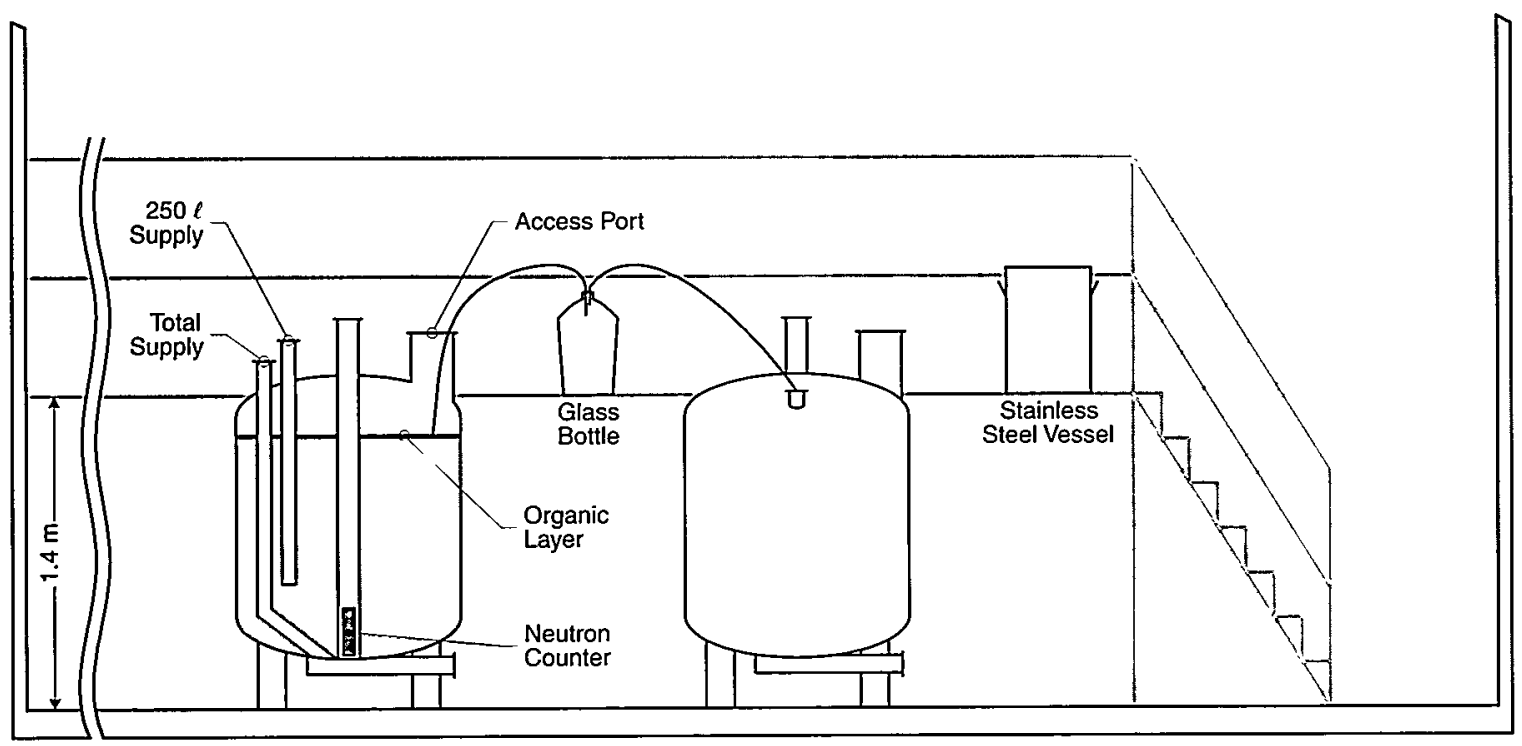

Figure 24. Elevation view of the tanks involved in the accident. 
operator was again able to fill the bottle, this time to nearly $20 \%$. Having disconnected the bottle from the hoses, the operator then poured its contents in the $60 \ell$ vessel for a second time. After almost all of the solution had been poured out of the bottle, the operator saw a flash of light and felt a pulse of heat. Startled. the operator dropped the bottle, ran down the stairs and from the room. The bottle, which had only a small amount of solution remaining, broke, splashing the remaining contents around the base of the $60 \ell$ vessel.

At the instant of the excursion (22:35), the criticality alarm sounded in the room above the tanks. All personnel promptly evacuated to the assigned location (an underground tunnel connecting two adjacent buildings). A similar criticality alarm system in a building approximately $50 \mathrm{~m}$ away also sounded almost immediately thereafter, but only for 3 to 5 seconds. After the first excursion, the radiation control supervisor on duty informed the plant managers of the accident. He then directed the operator to a decontamination and medical facility, collected the dosimeters (film badges) from all personnel, and strictly warned them not to enter the building where the accident had occurred.

A second excursion was recorded at $23: 50$, possibly due to cooling of the solution or the release of gas due to a chemical reaction within the solution. This excursion was clearly weaker than the first as it was detected only by thermal neutron detectors within $15 \mathrm{~m}$ of the accident. It most likely did not attain prompt criticality or lead to the ejection of solution from the vessel. It occurred when all personnel were at the emergency assembly location.

The shift supervisor insisted that the radiation control supervisor permit him to enter the work area where the accident had occurred. The radiation control supervisor resisted, but finally accompanied the shift supervisor back into the building. As they approached the basement room where the accident had occurred, the $\gamma$-radiation levels continued to rise. The radiation control supervisor prohibited the shift supervisor from proceeding. In spite of the prohibition, the shift supervisor deceived the radiation control supervisor into leaving the area and entered the room where the accident had occurred.

The shift supervisor's subsequent actions were not observed by anyone. However, there was evidence that he attempted to either remove the $60 \ell$ vessel from the platform. or to pour its contents down the stairs and into a floor drain that led to a waste receiving tank. (Solution was found on the floor near the drain and around the $60 \ell$ vessel at the top of the stairs.) Whatever his actions, they caused a third excursion, larger than the first two, activating the alarm system in both buildings.
The shift supervisor, covered in Pu organic solution, immediately exited the room and returned to the underground tunnel. The shift supervisor was then sent to the decontamination and medical facility. At 00:45 the site and building managers arrived. Based on an analysis of available documentation, radiation monitor readings, and interviews with personnel, a recovery plan was developed. By 07:00 the solution in the $60 \ell$ vessel had been transferred to several favorable geometry containers. A long handled, large radius of curvature hose and a portable vacuum pump were used to transfer the solution out of the vessel.

Both severely exposed personnel were flown to Moscow for treatment on 11 December. Samples of their blood showed very high ${ }^{24} \mathrm{Na}$ activities. Adjusted to the instant of the exposure, they were 5,000 decays/ $\mathrm{min} / \mathrm{m} \ell\left(83 \mathrm{~Bq} / \mathrm{cm}^{3}\right)$ for the operator and $15,800 \mathrm{de}-$ cays $/ \mathrm{min} / \mathrm{m} \ell\left(263 \mathrm{~Bq} / \mathrm{cm}^{3}\right)$ for the shift supervisor. The operator received an estimated absorbed dose of about 700 rem and the shift supervisor about 2,450 rem. The operator developed acute, severe radiation sickness; both his legs and one hand were amputated. He was still living 31 years after the accident. The shift supervisor died about one month after the accident.

The remaining personnel underwent medical evaluations on the day of the accident. Their dosimeters (film badges) which had just been issued to the personnel on 20 November and 21 November 1968, were used to estimate their doses. The dosimeters indicated that only 6 out of the remaining 27 personnel received doses exceeding $0.1 \mathrm{rem}$. Their doses were estimated to be $1.64 \mathrm{rem}, 0.2 \mathrm{rem}$, and four with less than $0.15 \mathrm{rem}$. The operator's dosimeter was overexposed, and the shift supervisor's dosimeter, taken by the radiation control supervisor after the first excursion, indicated a dose 0.44 rem.

Altogether, $19.14 \ell$ of solution were recovered from the $60 \ell$ vessel. This was a mixture containing $12.83 /$ of organic solution with a plutonium concentration of $55 \mathrm{~g} / \ell$ and $6.31 \ell$ of aqueous solution with a plutonium concentration of $0.5 \mathrm{~g} / \ell$. Therefore, the plutonium mass that remained in the $60 \ell$ vessel after the last excursion was about 709 grams. The volume of organic solution and plutonium mass spilled or ejected from the vessel could only be estimated as $16 \ell$ and 880 grams, respectively.

The number of fissions in the two prompt critical excursions was estimated from (1) the doses received by the operator and shift supervisor and (2) the measured exposure rate from fission product gamma-rays ( $1.5 \mathrm{mR} / \mathrm{s}$ at $3 \mathrm{~m}$ from the vessel, 1 hour after the last excursion). The number of fissions in the first excursion was estimated at $3 \times 10^{16}$, and in the last excursion about $10^{17}$ fissions. The vessels containing the solution were placed in an isolated room until the radiation levels decayed to an acceptable level, at which time the solution was reprocessed. 
The investigation identified several contributing factors to the accident:

- The shift supervisor's decision to take actions that were improvised, unauthorized, and against all regulations, to recover from the plutonium mass limit excess in tank 2.

- Changes to the original piping system that had precluded organic solution transfers to the aqueous solution tanks. As a result of these changes, organic solution could be sent to these tanks in three different ways. These included, (1) the operation of cer- tain valves out of the proper sequence, (2) through the vacuum and vent lines in the event of stop-valve failures, and (3) through the purposeful transfer of aqueous solution containing held up organic solution from the extraction facility

- A transfer from tank 1 to tank 2 of about $10 \ell$ solution with an unknown plutonium content on 10 December 1968 between 07:00 and 13:00.

The small scale organic solution research and development operation was discontinued in this building as a result of the accident.

\section{Windscale Works, 24 August $1970^{25,26,27}$}

\section{Plutonium organic solution in a transfer vessel; one excursion; insignificant exposures.}

This criticality accident is one of the more interesting and complex because of the intricate configurations involved. The plant was used to recover plutonium from miscellaneous scrap, and the processes used were thought to be subject to very effective controls. Recovery operations started with a dissolver charge of about $300 \mathrm{~g}$ of plutonium. Following dissolution, the supernatant was transferred through a filter to a conditioner vessel, where the concentration was adjusted to between 6 and $7 \mathrm{~g} \mathrm{Pu} / \ell$, less than the minimum critical concentration.

The solution was vacuum lifted from the conditioner to a transfer vessel (Figure 25). When the transfer was completed, the vacuum was broken and the transfer vessel contents were allowed to drain into a constant volume feeder that supplied a favorable geometry, pulsed, solvent extraction column. The connection from the transfer vessel to the constant volume feeder was through a trap 25 feet $(7.6 \mathrm{~m})$ in depth, that prevented any potential backflow and thus controlled contamination.

The excursion occurred on completion of the transfer of a $50 \ell$ batch of solution from the conditioner to the transfer vessel. The small size $\left(10^{15}\right.$ fissions) and brief duration (less than $10 \mathrm{~s}$ ) of the excursion precluded the termination of the excursion

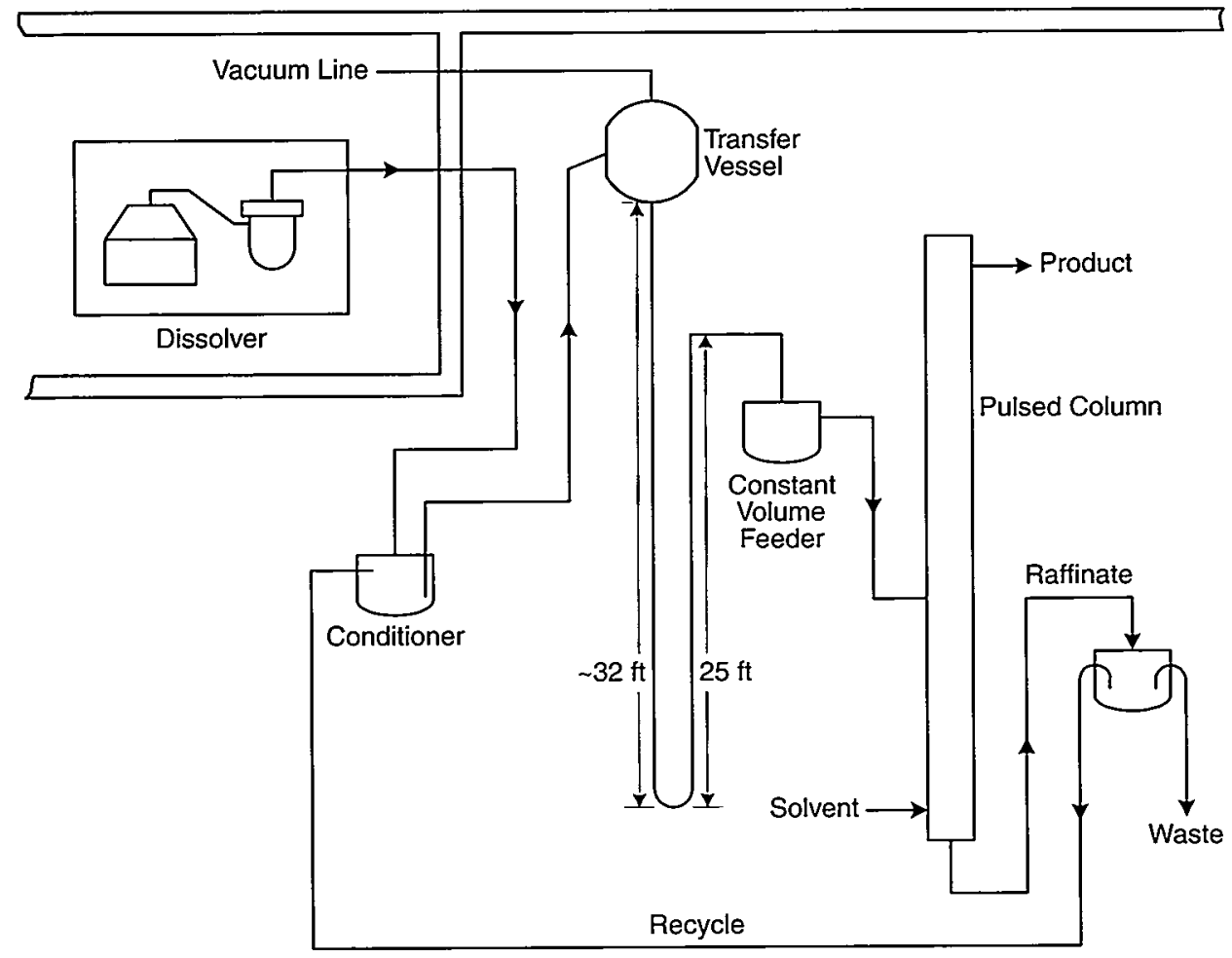

Figure 25. Process equipment related to the criticality accident. 
due to any energy based shutdown mechanism. Radiation measurements indicated that the excursion occurred in the transfer vessel, but the solution from the conditioner was too lean to sustain criticality, and the total quantity of plutonium in the batch $(300 \mathrm{~g})$ was about $50 \%$ of the minimum critical mass. Thus, it was feared that the transfer vessel might contain large quantities of solids, perhaps tens of kilograms and that any disturbance of the system might cause another, possibly much larger. excursion.

A 6 inch ( $150 \mathrm{~mm})$ diameter hole was cut through the concrete roof, and the vacuum line to the transfer vessel was opened. The interior of the transfer vessel was inspected with a fiber-optics system (developed specifically for this recovery operation) and was found to contain liquid. A small diameter plastic line was inserted into the vessel and $2.5 \%$ aliquots were siphoned to a collection point in an adjacent building. Inspection of the liquid revealed tributyl phosphate and kerosene with a specific gravity of 0.96 that contained $55 \mathrm{~g} \mathrm{Pu} / 1$. Aqueous solution from the conditioner had a specific gravity of 1.3 . A column 25 feet $(7.6 \mathrm{~m})$ in height of aqueous solution in one arm of the trap was sufficient to balance approximately 33.8 feet $(10.3 \mathrm{~m})$ of solvent in the other arm. Thus any solvent introduced into the transfer vessel was held in the arm and could accumulate until the volume of solvent corresponded to a height of 33.8 feet $(10.3 \mathrm{~m})$ above the bottom of the trap. Some $39 \%$, containing about $2.15 \mathrm{~kg} \mathrm{Pu}$. were present. Degradation of the solvent indicated it had been trapped in the transfer vessel for several months and perhaps for as long as 2 years.

Each time a batch of aqueous solution was processed through the transfer vessel, the organic extractant would strip some plutonium from the aqueous solution. With each transfer, the plutonium concentration in the tributyl phosphate and kerosene increased. The operation that resulted in the excursion probably added about $30 \mathrm{~g}$ of plutonium to the solvent. Periodic plant cleanout by flushing nitric acid through the system presumably reduced the plutonium concentration in the trapped solvent. Thus, the concentration
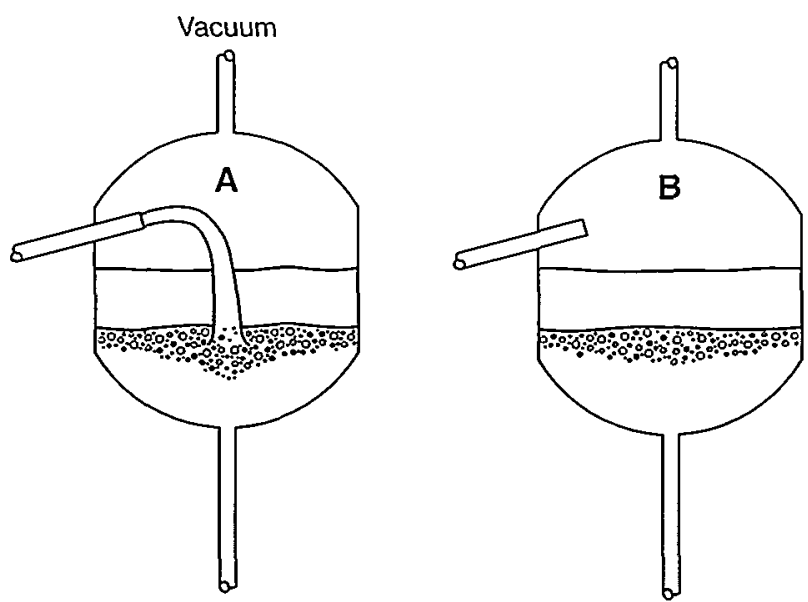

may have been slowly increased, then been abruptly reduced. Several such cycles could have been repeated before the system achieved criticality. The drain rate of the transfer vessel was not sufficient to account for the brief duration of the excursion.

A transparent plastic mockup of the transfer vessel was used to observe the configuration of the liquids during transfer. The situation existing during the transfer is shown in Figure 26A. Rich organic $(55 \mathrm{~g} / \mathrm{f})$ is floating on top of lean aqueous solution ( 6 to $7 \mathrm{~g} / /^{\prime}$ ). The aqueous solution stream pouring into the center of the vessel provides a region of low reactivity. Between the organic and aqueous is a region of mixed phases, about 3 inches $(7.6 \mathrm{~cm})$ thick near the axis of the vessel. This configuration is subcritical.

Just after completion of the transfer (Figure 26B) the central plug of aqueous solution has disappeared, the region of mixed phases is still present, and the configuration has reached the state of maximum reactivity. Separation of the two phases occurs within a few seconds of completing the transfer (Figure 26C). Monte Carlo calculations have indicated that the reactivity of Figure $26 \mathrm{~B}$ is about $5 \$$ greater than that of Figure $26 \mathrm{~A}$ and about 10 to $15 \$$ greater than Figure 26C.

Apparently, there was sufficient time between nitric acid washes for the plutonium concentration to increase until the system became slightly supercritical at the conclusion of a transfer, tripping the criticality alarms.

Two people were in the plant at the time of the accident. One received an estimated dose of $2 \mathrm{rad}$, the other less than 1 rad.

This excursion illustrates the subtle ways in which accidents can occur during solution processing. Although the deep trap was considered a safety feature for the control of contamination, it contributed directly to the criticality accident. The difficulty of understanding what had happened, even after it was known in which vessel the excursion occurred, is an excellent example of the impracticability inherent in attempting to calculate criticality accident probabilities for specific processes.

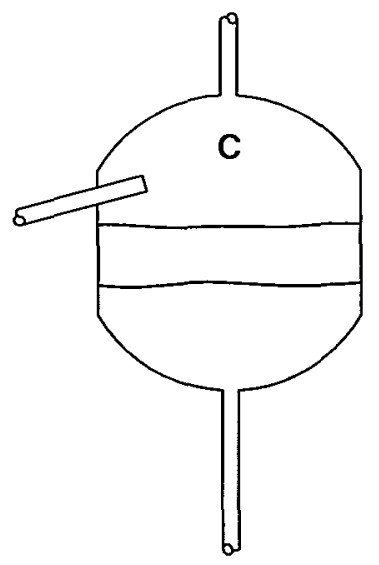

Figure 26. Solution transfer as reconstructed from the transparent plastic mockup of the transfer vessel. Configuration $(B)$ is the postulated state at the time of the accident. 


\section{Idaho Chemical Processing Plant, 17 October $1978^{28,29,101}$}

\section{Uranyl nitrate solution, $U(82)$, in a lower disengagement section of a scrubbing column; excursion history unknown; insignificant exposures.}

The accident occurred in a shielded operation of a fuel reprocessing plant in which solutions from the dissolution of irradiated reactor fuel were processed by solvent extraction to remove fission products and recover the enriched uranium.

In the solvent extraction process, immiscible aqueous and organic streams counter-flow through columns while in intimate contact and, through control of chemistry, material is transferred from one stream to the other. A string of perforated plates along the axes of the columns was driven up and down forming a "pulsed column" that increased the effectiveness of contact between the two streams. The large diameter regions at the top and bottom of the columns were disengagement sections where the aqueous and organic streams separated.

In this particular system (Figure 27), less dense organic (a mixture of tributyl phosphate and kerosene) was fed into the bottom of the G-111 column while an aqueous stream containing the uranium and fission products was fed into the top. As the streams passed through the pulsed column, uranium was extracted from the aqueous stream by the organic with fission products remaining in the aqueous stream. The aqueous stream containing fission products was sampled from the bottom of the G-111 column to verify compliance with uranium discard limits before being sent to waste storage tanks. The organic product stream (containing about $1 \mathrm{~g} \mathrm{U} / \ell$ ) from the top of the G-111 was fed into a second column, $\mathrm{H}-100$, at the bottom of its lower disengagement section.

In $\mathrm{H}-100$, the organic product was contacted by a clean aqueous stream (fed into the top) to scrub out residual fission products. The aqueous stream was buffered with aluminum nitrate to a concentration of 0.75 molar to prevent significant transfer of uranium from the organic stream to the aqueous stream. In normal operation, a small amount of uranium (about $0.15 \mathrm{~g} / \ell$ ) would be taken up by the aqueous stream, which was, therefore, fed back and blended with the aqueous recovery feed going into $\mathrm{G}-111$. The organic stream from $\mathrm{H}-100$, normally about $0.9 \mathrm{~g} \mathrm{U} / \ell$, went on to a third column, where the uranium was stripped from the organic by 0.005 molar nitric acid. The output of the stripping column then went to mixer settlers where additional purification took place. Still further downstream, the uranium solution went to an evaporator where it was concentrated to permit efficient recovery of the uranium.

Several factors contributed to this accident. The water valve on the aluminum nitrate make-up tank (PM-106) used for the preparation of the aqueous feed for the scrubbing column, $\mathrm{H}-100$, had been leaking for about a month prior to the accident. Over time, this leak caused a dilution of the feed solution from $0.75 \mathrm{M}$ to $0.08 \mathrm{M}$. The $13,400 \ell$ make-up tank was equipped with a density alarm that would have indicated the discrepancy, but the alarm was inoperable. A density alarm was scheduled to be installed on the $3,000 \ell$ process feed tank (PM-107) that was filled, as necessary, from the make-up tank, but this had not been done. The make-up tank was instrumented with a strip-chart recorder showing the solution level in the tank. However, the leak into the tank was so slow that the change in level would have not have been discernible unless several days worth of the chart was analyzed. To complicate matters, the chart recorder had run out of paper on 29 September and it was not replaced until after the accident. Furthermore, procedures that required the taking of samples from the feed tank, PM-107, to confirm the density, were not being followed.

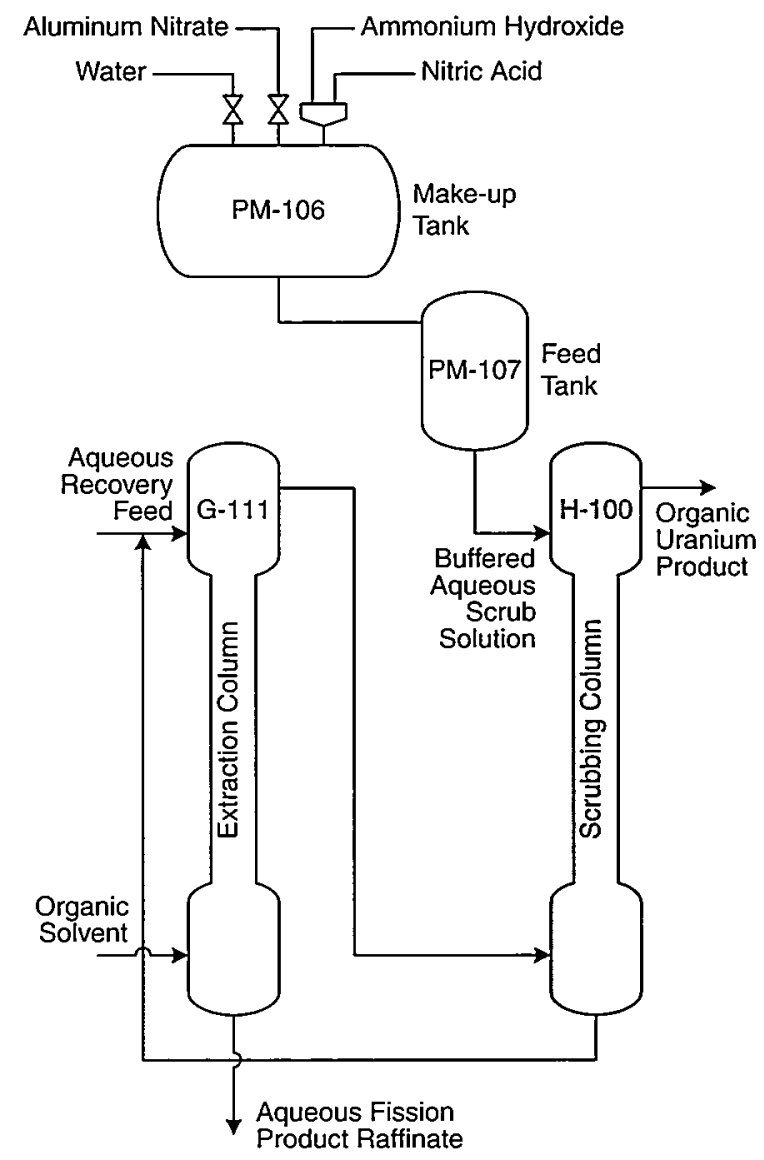

Figure 27. First cycle extraction line equipment. The accident occurred in the lower disengagement section of the $\mathrm{H}-100$ column. 
The out-of-specification aqueous feed to the $\mathrm{H}-100$ scrubbing column caused it to operate as a stripper rather than as a scrubber. Some of the enriched uranium was removed from the $\mathrm{H}-100$ column organic and recycled into the input of $\mathrm{G}-111$. This partially closed loop resulted in a steady increase in the uranium inventory in the two columns. Each time diluted solution was added to the feed tank from the make-up tank, the aluminum nitrate concentration in the feed was further reduced and stripping became more effective until the excursion occurred.

Analyses of the aqueous feed for column $\mathrm{H}-100$ (feed tank PM-107) showed the proper concentration of $0.7 \mathrm{M}$ aluminum nitrate on 15 September 1978. Samples taken on 27 September and 18 October (the day after the accident) had concentrations of $0.47 \mathrm{M}$ and $0.084 \mathrm{M}$, respectively. Concentrations of aluminum nitrate less than $0.5 \mathrm{M}$ would allow some stripping of uranium from the organic, and the final aluminum nitrate concentration would result in almost all of the uranium being stripped from the organic.

The feed tank (PM-107) was filled with aluminum nitrate solution from the make-up tank (PM-106) at about 18:30, on 17 October. At approximately 20:00, the process operator was having difficulty in controlling the $\mathrm{H}-100$ column. During his efforts to maintain proper operation, he reduced the system pressure causing an increased aqueous flow from $\mathrm{H}-100$ back to G-111. At approximately 20:40, a plant stack radiation monitor alarmed, probably because of fission products in the plant stack gases. Shortly after this alarm, several other alarms activated and the plant stack monitor gave a full-scale reading. The shift supervisor and the health physicist went outside the building and detected radiation levels up to $100 \mathrm{mrem} / \mathrm{h}$. At 21:03, the shift supervisor ordered the building evacuated, and by 21:06 an orderly evacuation had been completed. Road blocks were established and management was notified.

It is probable that as the uranium inventory in the bottom of $\mathrm{H}-100$ increased the system achieved the delayed critical state, then became slightly supercritical. As the power increased, the temperature rose compensating for the reactivity introduced by the additional uranium. This process would continue as long as the uranium addition was slow and until the reduced pressure on the column permitted more rapid addition of uranium and a sharp increase in reactivity. The system is thought to have approached prompt criticality, at which time the rate of power increase would have been determined by the neutron lifetime (on the order of milliseconds).

Prior to evacuating, the process operator shut off all feed to the first cycle extraction process, but did not stop the pulsation of the columns. The continuation of the pulse action after the feed was turned off probably led to better mixing of the solution in the bottom section of $\mathrm{H}-100$ and terminated the excursion. Later analysis showed that the excursion had occurred in the lower disengagement section of the $\mathrm{H}-100$ column. Records indicate the reaction rate increased very slowly until late in the sequence, when a sharp rise in power occurred. The uranium inventory in Column $\mathrm{H}-$ 100 was estimated to have been about $10 \mathrm{~kg}$, compared with slightly less than $1 \mathrm{~kg}$ during normal operation. The total number of fissions during the excursion was estimated to be $2.7 \times 10^{18}$.

Several factors contributed to this accident.

- The water valve on the aluminum nitrate make-up tank (PM-106) used for preparation of the aqueous had been leaking for about a month prior to the accident.

- Significantly more solution had been transferred from the make-tank to the feed tank than should have been available (because of the leak). This was not noticed by any of the plant staff.

- The chart recorder for the make-up tank that would have shown the solution level had run out of paper weeks earlier. The paper was not replaced until after the accident.

- The density recorder and alarm on the aluminum nitrate feed tank, PM-107, had not been installed even though it appeared on the controlled drawings of the plant.

- The operating procedure that required sampling before transfer between the aluminum nitrate make-up and feed tanks was not followed. Furthermore the procedure actually used on the process floor was an older out-of-date version that did not contain this requirement.

- In the two years preceding the accident, the experience level of the operators had decreased dramatically.

- The safety analysis prepared in 1974 identified the criticality risk if the aluminum nitrate scrub feed were to become dilute, but incorrecly assumed that stoppage of the scrub feed was also necessary. The evaluation process had been excessively focused on the physics of subcriticality and not on risk assessment.

There were no significant personnel exposures and no damage to process equipment. As a direct result of this event, the plant suffered an extended and expensive shutdown. Operating procedures were reviewed in detail and revised as appropriate. Increased emphasis was given to plant maintenance and operator training. An extensive and highly instrumented plant protection system involving redundant sensors and redundant automatic safety controls was installed. The importance of maintenance of safety related equipment and the need for adherence to well developed operating procedures were reemphasized by this accident. 


\section{Siberian Chemical Combine, 13 December 1978}

\section{Plutonium metal ingots in a storage container; single excursion; one serious exposure, seven significant}

exposures.

Various operations with $\alpha$-phase plutonium metal ingots were performed in Building 901, Department 1, of this plant. There were 16 interconnected gloveboxes manned by a total of 7 operators. Although the operators were trained on all of the individual operations, each would be assigned only a particular subset at the beginning of each shift. By written procedure, it was not allowed for an operator to deviate from his assigned tasks even if the deviation involved assisting others with their tasks.

Transfer and temporary storage of the ingots within the gloveboxes was accomplished using cylindrical storage containers designed specifically for this purpose. The containers were lined with a $0.5 \mathrm{~mm}$ thick cadmium layer and had a $30 \mathrm{~mm}$ thick shell of polyethylene encased in a stainless steel sleeve (Figure 28). The design decreased the neutron interaction for a planar array to such a degree that it was not necessary to control the number or storage arrangement of the containers within any of the gloveboxes.

The ingots were produced from a direct oxide reduction process and were in the shape of a frustum of a cone. The dimensions of the ingots are no longer

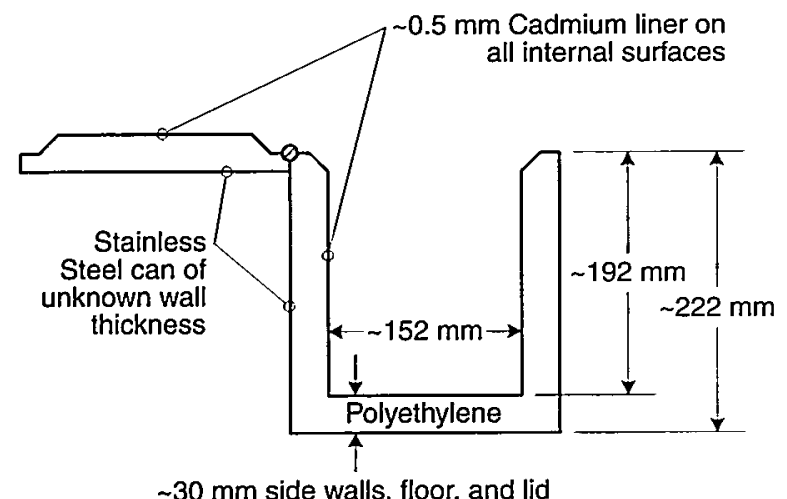

Figure 28. Storage container. known. Depending on the origin of the feed material the upper mass limit of an ingot was either $2 \mathrm{~kg}$ (waste recovery, precipitation/calcination) or $4 \mathrm{~kg}$ (relatively pure oxide). The general administrative limit for the storage containers in this building allowed up to 2 ingots totaling $4 \mathrm{~kg}$ or less. However, the size of the container did not preclude the possibility of loading multiple ingots to levels in excess of a critical mass. It was assumed that the operating personnel, because of their proficiency and discipline, would not make gross errors (more than twice the administrative limit) in loading the containers or ignore the safety limits.

Glovebox 13 , where the criticality accident took place, consisted of three workstations, (1391-A, 1391-B, and 1392, see Figure 29) and was connected to gloveboxes 12 and 6 by a pass-through port and conveyor, respectively. All of the ingots produced at the plant passed through this glovebox operation. For these particular workstations, the administrative limit for the containers was even stricter, allowing only one ingot regardless of its mass. Workstation 1391-A was used for extracting drill samples (up to $0.1 \mathrm{~g}$ ) for chemical analysis of the impurities. The ingots were weighed in workstation 1391-B, where the samples were also temporarily stored. Workstation 1392 was used for measuring the dimensions of the ingots. Within the workstations the ingots were removed and returned to their original containers one at a time. The workstations were equipped with pass-through ports in the connecting walls, gloveports, and $50 \mathrm{~mm}$ thick leaded glass windows. The front of the workstation had a $30 \mathrm{~mm}$ thick lead shield to reduce the $\gamma$-radiation from the plutonium.

At the beginning of the shift on 13 December 1978, three containers were in workstation 1391-B, and four containers were in workstation 1392, each with one ingot. The ingots are numbered sequentially in Figure 29 for the purpose of the discussion that follows. Although the containers are depicted as being linearly arranged, in actuality the containers holding ingots 4 and 5 were behind those with ingots 6 and 7 , making visual inspection of the contents more difficult

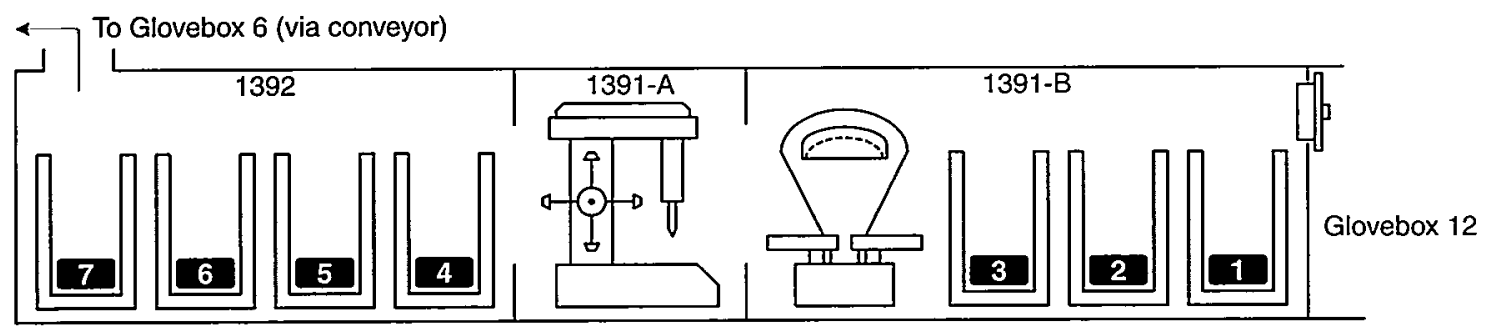

Figure 29. A simplified layout of Glovebox 13. 
than implied by the figure. At the time of the accident, processing of six of the ingots had been completed, and only ingot 3 needed to remain in 1391-B. According to the shift instructions, Operator $A$ was to

1. transfer the six processed ingots to glovebox 6 , and to

2. transfer four ingots from glovebox 6 and two from glovebox 12 to glovebox 13 for processing.

The intended order of ingot transfers, as specified in the shift instructions, is illustrated in Figure 30. The actual order of ingot transfer is shown in Figure 31, Frames 1 through 6. Operator A transferred two ingots, 6 and 7, from workstation 1392 to glovebox 6 . These ingots were replaced in workstation 1392 by two ingots, 8 and 9, from glovebox 6 . Both of these actions were in accordance with the shift instructions.

Motivated by production pressures to conduct the ingot transfers as soon as practical, Operator A (without authorization and in violation of procedures) requested Operator B to assist him. Operator A then instructed Operator B to transfer ingots 1 and 2 to glovebox 6 and to reload their containers with ingots 10 and 11 from glovebox 12. However, Operator B, who was not working from written instructions, instead transferred ingot 3 into the container already holding ingot 4 , violating the container administrative limit. Operator B then transferred ingot 10 from glovebox 12 to the container that previously held ingot 3 within 1391-B.

Operator A, who had left the area to perform other tasks, then returned and resumed the work as per the shift instructions, assuming, but not confirming, that Operator B had performed the tasks requested. Operator $A$ then transferred ingots 1 and 2, believing them to be ingots 10 and 11 , into the same container already holding ingots 3 and 4 (data on the individual ingots as to size and mass are not well known). The actions of Operator A, even if the container in 1392 had been empty, were also a direct violation of the container administrative limit. Frames 5 and 6 of Figure 32 show these transfers.

While placing the fourth ingot, 1 (mass less than $2 \mathrm{~kg}$ ), into the container, Operator A experienced an instantaneous and significant rise in the temperature near his hands and arms and saw a flash of light. The excursion was immediately terminated due to thermal expansion and the removal or ejection of ingot 1 . The total mass of the four ingots was $10.68 \mathrm{~kg}$. At the same instant, the criticality alarm sounded in two buildings, 901 and 925 , causing all personnel to evacuate. The alarm system detectors were G-M tubes with activation thresholds of $110 \mathrm{mR} / \mathrm{h}$.

After the alarm systems had sounded, Operator A removed two of the three remaining ingots from the container, moving one into workstation 1391-A, and the other into 1391-B. During the investigation, the operator could not clearly recall if he had instinctively removed his hand while still holding the fourth ingot or if it had been forcefully ejected as the result of a sudden thermal expansion brought on by the rapid energy release.

Plutonium samples were taken from each of the four ingots and analyzed for ${ }^{140} \mathrm{La}$ content using gamma-ray spectrometry. From this the number of fissions in this single excursion was estimated to be $3 \times 10^{15}$. Operator A received an estimated total body dose of $250 \mathrm{rad}$, and more than 2,000 rad to his arms and hands, necessitating amputation up to the elbows. Later his eyesight also became impaired. Seven other people located at various distances from glovebox 13 received doses between 5 and $60 \mathrm{rad}$, with the predominant contribution being from fast neutrons. The equipment was not damaged and no contamination resulted.
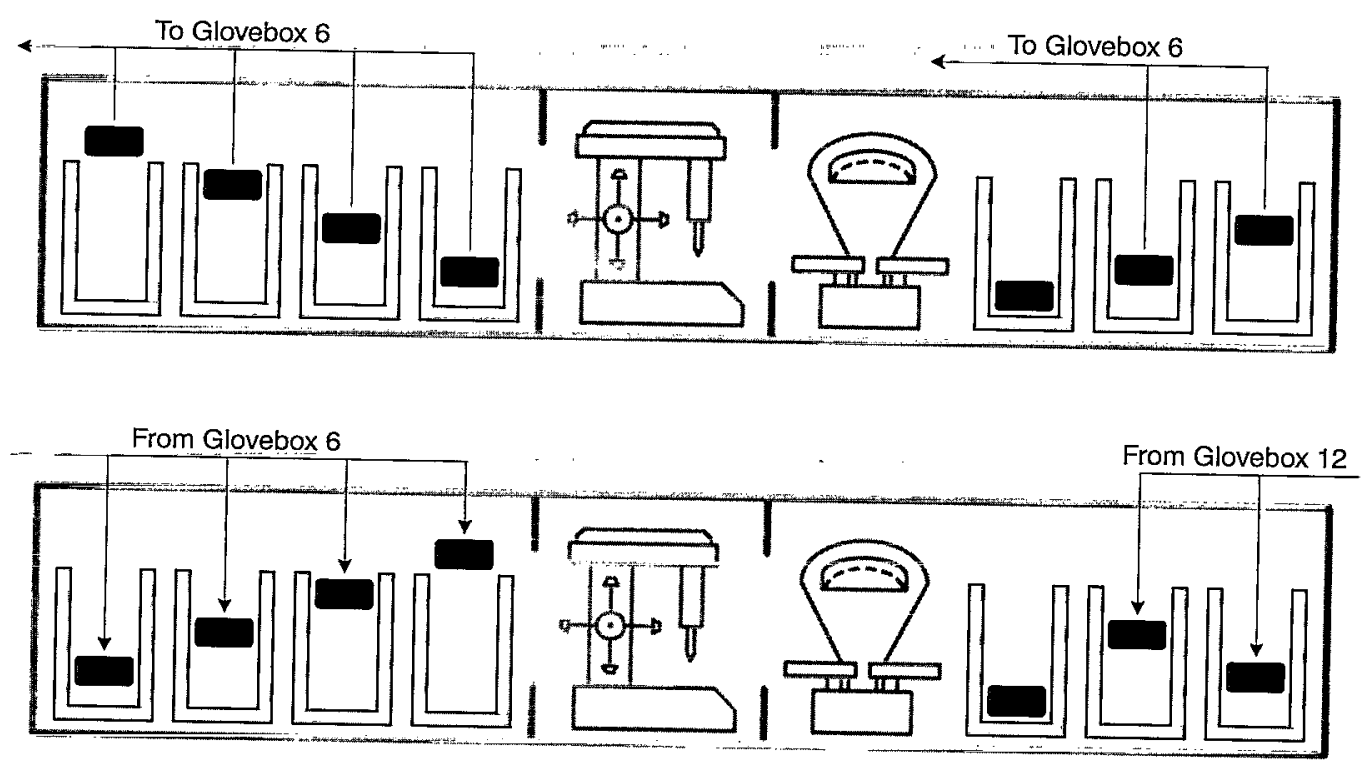

Figure 30. Intended sequence for the transfer of ingots from and to Glovebox 13. 


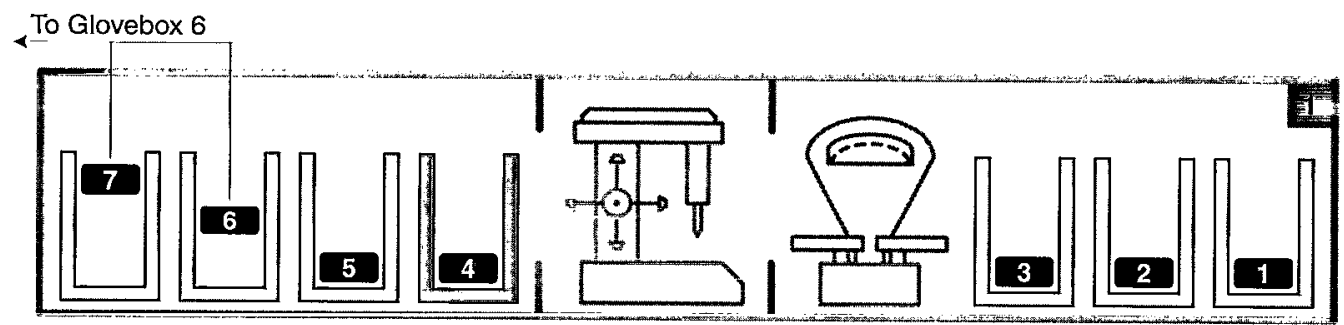

From Glovebox 6
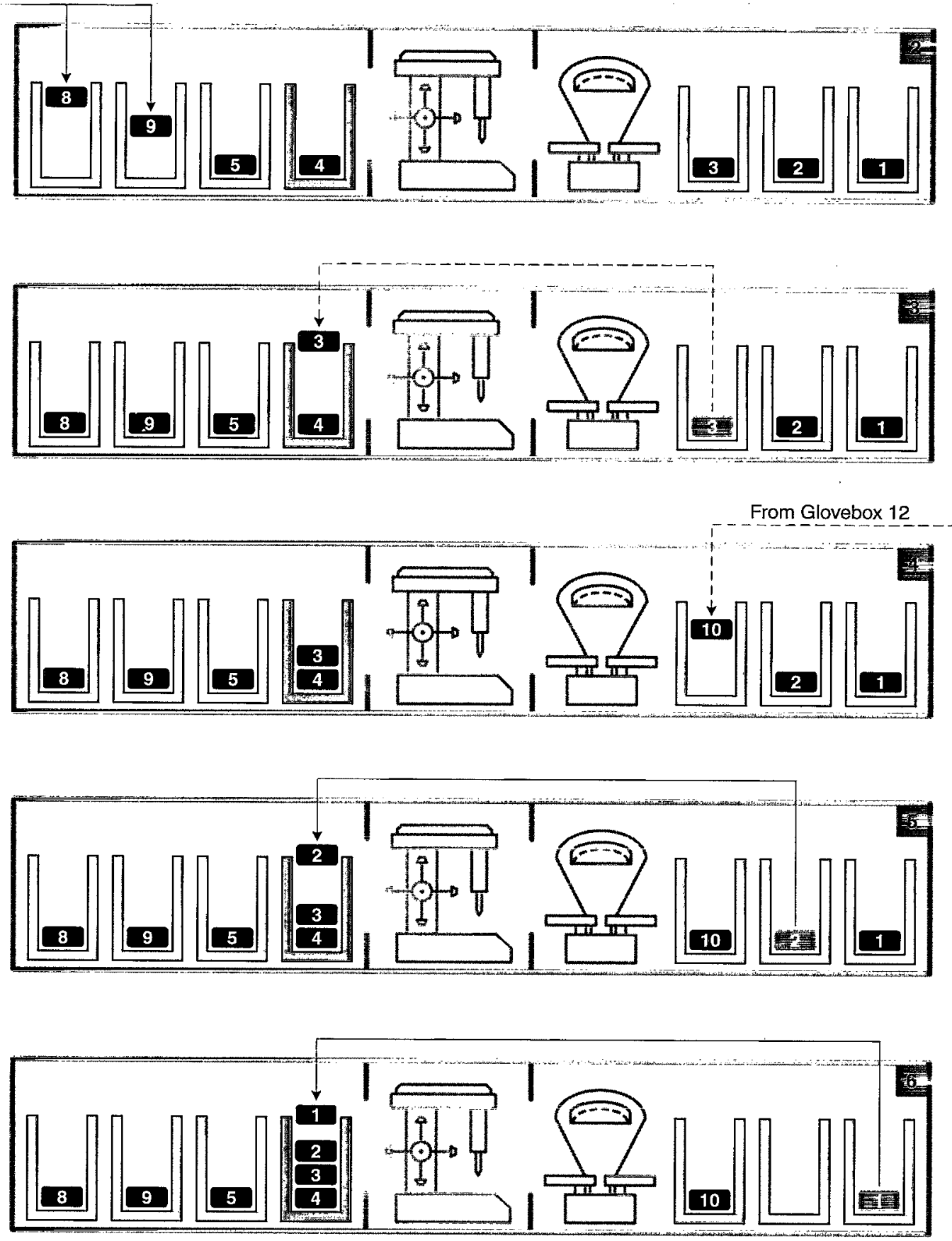

Figure 31. Actual order of ingot transfers from and to Glovebox 13. The solid lines represent the actions of operator $\mathrm{A}$ and the dotted lines the actions of operator B. 


\title{
21. Novosibirsk Chemical Concentration Plant, 15 May 1997
}

\author{
Uranium oxide slurry and crust, $U(70)$, in the lower regions of two parallel vessels; multiple excursions; \\ insignificant exposures.
}

This accident occurred in Building 17 where highly enriched $\mathrm{U}(90)$ fuel rods were fabricated from $\mathrm{UO}_{2}$ and aluminum. using the powder metallurgy method. The final process prior to placing a rod into its aluminum cladding was chemical etching. The objective of this operation was to remove microscopic defects on the rod surfaces to ensure tight contact between the rod and its cladding. The major components of the process equipment are shown in Figure 32.

The etching process involved consecutively immersing a batch of rods into three separate vessels filled with sodium hydroxide (alkali), water, and nitric acid, respectively. As a result of a chemical reaction with the sodium hydroxide. some of the aluminum particles on the surface of the rods formed the precipitates. $\mathrm{NaAlO}_{3}$ and $\mathrm{Al}(\mathrm{OH})_{3}$. The etching process leached a small fraction of the uranium dioxide from the rods which was also deposited on the bottom of the alkali vessel. The rods were then washed in the second vessel with water to remove as much alkali as possible. In the final vessel of nitric acid, any traces of alkali were neutralized and the rods were etched to their final size by dissolving $\mathrm{UO}_{2}$ particles from their surfaces.

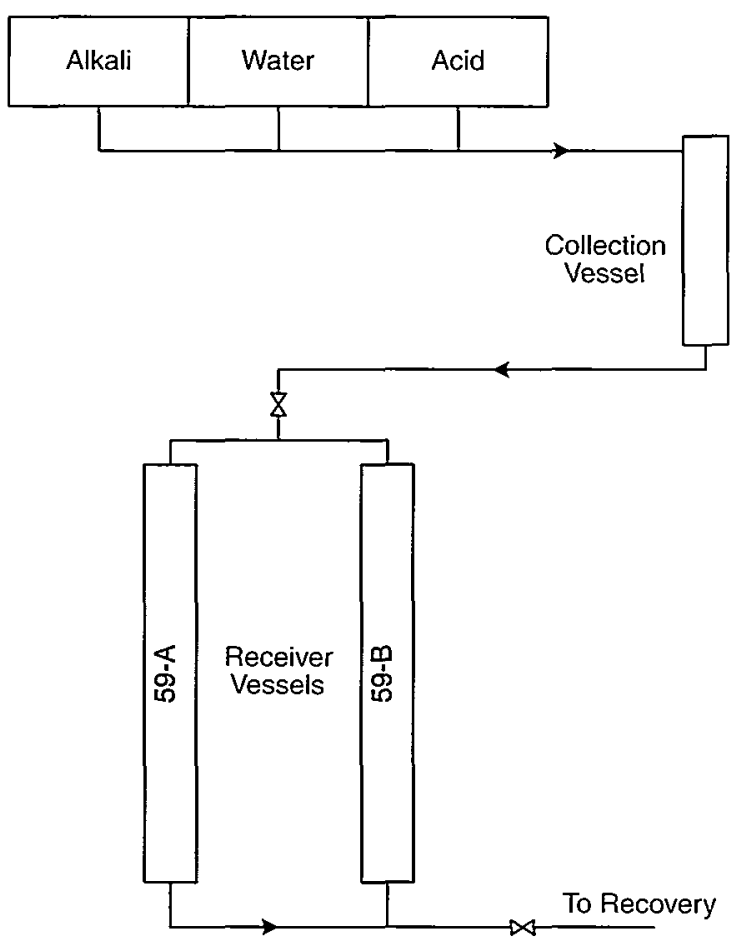

Figure 32. Major components of the chemical-etching process.
Once the etching process with one batch of rods was completed, the contents from all three immersion vessels was gravity drained to a $130 \mathrm{~mm}$ diameter cylindrical collection vessel. As the collection vessel filled, the etching solution was pumped to receiver vessels $59-A$ and $59-B$ through a $64 \mathrm{~mm}$ diameter pipe that was about $100 \mathrm{~m}$ in length. Eventually, the etching solution would be transferred from the receiver vessels to the uranium recovery section of the building.

The etching process had been standardized 13 years before the criticality accident. During this 13 year period, the controlled parameters were the number of rods per batch, the temperature, the concentration of the reagents, and the duration of the immersion operations. Uranium content in the etching solutions was not measured. In fact, since all of the equipment, with the exception of the immersion vessels, was of favorable geometry (according to design and records), there was no capability within the building to determine the uranium content of the etching solutions. Precipitate formation and uranium deposition in the service piping was also not monitored.

In 1996 a solid $\mathrm{UO}_{2}$ deposit was discovered in the collection vessel when it was opened and inspected. The $5.5 \mathrm{~kg}$ deposit (uranium mass fraction of $\sim 69 \%$ ) was gradually removed by dissolving it with nitric acid. Analyses showed that the deposit had been forming for over 10 years since it contained some uranium enriched to only $36 \%$ by weight. Uranium enriched to $36 \%$ by weight had not been processed since around 1986 when a switch to $U(90)$ was made.

Despite the discovery of this deposit, the logical search for similar deposits in the service piping and in the receiver vessels was not initiated, primarily because the criticality safety limits for those components did not include requirements to monitor for uranium accumulation. In fact, for the purposes of the annual material inventory, the entire building was designated as one fissile material balance area. Therefore, the small fraction of uranium being deposited in the receiver vessels per batch of rods went unnoticed because of the large size of the fissile material balance area.

The receiver vessels were of slab geometry, with common inlet and outlet lines for the transfer of solutions. Each vessel was $3.5 \mathrm{~m}$ in height and $2 \mathrm{~m}$ in length, with a design thickness of $100 \mathrm{~mm}$ and an operating volume of $\sim 650 \ell$. Both vessels were made from $4 \mathrm{~mm}$ thick stainless steel. The distance between the vessels was $0.8 \mathrm{~m}$, and they were mounted $\sim 0.75 \mathrm{~m}$ above the concrete floor. Dimensional control of the thickness was provided by internal steel rods welded 
on a $0.4 \mathrm{~m}$ square pitch grid. The bottom of the vessels were sloped $\sim 20$ degrees toward the drain. Steel sheets were placed at $140 \mathrm{~mm}$ from the outside surfaces $(3.5 \mathrm{~m} \times 2 \mathrm{~m})$ to preclude close reflection.

When the vessels were installed they had been approved for use with uranium enriched to a maximum of $36 \%$. However, the nuclear regulatory authority had not been consulted when the change to the higher enrichment, $U(90)$, was implemented.

At 10:00, Thursday 15 May 1997, after completing the etching of a batch of rods, an operator drained the etching solutions from the immersion vessels into the collection vessel. A pump was then turned on for about 15 minutes to transfer the etching solutions to the receiver vessels.

At 10:55, the criticality alarm system, which included 12 monitoring stations," sounded in Building 17, and personnel promptly evacuated. Emergency response personnel arrived, and health physicists began an assessment of the radiation levels both inside and outside of the building.

Based on exposure rate measurements made with portable instruments, the accident location was determined to be receiver vessels 59-A and 59-B located on the ground floor. Twenty-five minutes after the alarm had sounded, the exposure rate $0.5 \mathrm{~m}$ from the receiver vessels was $\sim 10 \mathrm{R} / \mathrm{h}$.

As a recovery action, it was decided to pump borated solution into the receiver vessels using the same system for transferring the etching solutions. A natural boron solution was prepared by mixing $20 \mathrm{~kg}$ of dry boric acid with water. The borated solution was first introduced into the collection vessel and then transferred through the normal piping to the receiver vessels. After transferring the borated solution, the receiver vessels were almost completely filled; the remaining free volume in each vessel was about $30 \ell$.

Despite this action, the alarms once again sounded at 18:50 that same day, indicating that a second excursion had occurred. This was followed by a third excursion at 22:05, and a fourth and fifth at 02:27 and 07:10 on 16 May.

After additional analysis of the situation, it was decided to alter the manner in which solution was fed into the receiver vessels. A method of producing a forced circulation of a highly concentrated solution of lithium chloride was implemented. Lithium chloride was chosen rather than boric acid because of its much higher solubility. To ensure the safety of the personnel involved, injection of lithium chloride was delayed until after the sixth excursion took place at 13:00. At
14:00, the forced circulation of the lithium chloride solution was begun and the system was driven permanently subcritical.

After several hours of circulation and intensive mixing of the solution, it was sampled for chemical analysis. The results of the analysis showed the following concentrations:

$$
\begin{aligned}
& \text { Uranium } 6 \mathrm{~g} / \ell, \\
& \text { Lithium } 6 \mathrm{~g} / \ell, \\
& \text { Boron } 0.5 \mathrm{~g} / \ell,
\end{aligned}
$$

and an overall solution $\mathrm{pH}$ between 9 and 11 .

Given this concentration of uranium and a total solution volume of $\sim 1,300 \ell$ in the two receiver vessels, the uranium mass was estimated to be $\sim 7.8 \mathrm{~kg}$. This result was at odds with design calculations that indicated a minimum critical mass in excess of $100 \mathrm{~kg}$ of ${ }^{235} \mathrm{U}$ at concentrations well above $50 \mathrm{~g} / \ell$ for this two vessel system. It was conjectured that this discrepancy could be explained either by the differences between the design and actual thickness of the receiver vessels or by additional uranium deposits within the vessels. The investigation proceeded to examine both possibilities.

The possibility that the receiver vessels contained additional uranium in the form of deposits was reinforced by filtering solution samples during the circulation process. The pure solution that passed through the filter had a uranium concentration of only $\sim 0.3 \mathrm{~g} / \ell$, i.e., 20 times smaller than before filtration. Therefore, the well mixed $6 \mathrm{~g} / \ell$ solution was more accurately characterized as a slurry of $\mathrm{UO}_{2}$ particles, rather than a true solution. Periodic draining of the tanks would have left behind a wet paste of precipitates that may have hardened over time.

A portable, collimated detector was then used to determine the distribution of the uranium in the receiver vessels by measuring the fission product gamma-rays. In order to decrease the background, $12 \mathrm{~mm}$ thick lead shielding was placed between the receiver vessels. As a result of gamma scanning of the vessels' lateral surfaces, it was determined that the uranium was located almost exclusively in the bottom regions of both vessels, distributed similarly, and covering about $1 \mathrm{~m}^{2}$ in area. Furthermore, the uranium mass of the deposit in vessel 59-A was about 2.8 times greater than that in vessel 59-B.

On 20 May, the cleaning of the receiver vessels was begun. The tanks were first drained and $\mathrm{UO}_{2}$ particles were filtered out and dissolved in favorable geometry vessels using nitric acid. Remaining in the vessels, as

*Each monitoring station was equipped with three plastic scintillator gamma-ray detectors. Each station was designed to alarm if any two detectors exceeded the trip point of $\sim 36 \mathrm{mR} / \mathrm{h}$. 
had been conjectured, was solidified $\left(\sim 2 \mathrm{~g} / \mathrm{cm}^{3}\right)$ crust containing uranium. This crust was dissolved directly in the vessels again using nitric acid. The uranyl nitrate solutions that were produced were transferred to favorable geometry vessels and placed in storage. A second $\gamma$-scanning of the vessels on 29 May confirmed that as much of the deposits as practical had been removed. The total mass of uranium recovered was $\sim 24.4 \mathrm{~kg}$ at an average enrichment of $70 \%$ by weight.

To determine the actual thickness of the receiver vessels, a large device capable of measuring the distance between two opposite, external surface points with a margin of error of $\sim 3 \%$ was constructed. A complete characterization of the thickness of both receiver vessels was then generated. At several points, the internal thickness was determined to be $132 \mathrm{~mm}$, i.e.. $\sim 32 \%$ greater than the design thickness. On the average, the internal thickness in the region of the deposits was $\sim 17 \%$ greater than the design thickness, or about $117 \mathrm{~mm}$, a factor that clearly reduced the criticality safety margin. The location of the solid crust was closely correlated with the deformed regions.

Before the first excursion, uranium was present in both receiver vessels in three forms, the solid crust, the unknown density $\mathrm{UO}_{2}$ particle slurry, and the low concentration solution. Transfer of etching solutions into and out of the receiver vessels occurred up to 300 times a year. The crust and slurry that consisted of a mixture of uranium dioxide, aluminum hydroxide, and other particulates had accumulated gradually over many years. This, coupled with the deformation of the vessels. ultimately resulted in the criticality accident.

The dynamics of the excursions were estimated by analyzing the response of the various alarm system detectors and by analysis of the ${ }^{140} \mathrm{La}$ and ${ }^{235} \mathrm{U}$ in samples of the $\mathrm{UO}_{2}$ particles taken on 20 May. The detectors were located at 12 monitoring stations.

However, during the excursions, at most only three of the monitoring stations alarmed, indicating very low peak power for each excursion. These three stations were located on the ground, first, and second floors directly above one another. From the central control room, health physicists documented the sequence of excursions, the response of the detectors, and the length of time that the detector alarm threshold $(36 \mathrm{mR} / \mathrm{h})$ was exceeded (Figure 33$)$.

Using known distances, the thickness of the floors and ceilings, and prompt gamma-ray attenuation coefficients for concrete, power doubling times $\left(T_{1 / 2}\right)$ and uncompensated excessive reactivity estimates $(\phi)$ for the first three excursions were made. The ratio ( $f$ ) of the total number of fissions to those that occurred in the first excursion was also estimated. These results are shown in Table 8.

Positive reactivity was introduced into the system as the concentration of the $\mathrm{UO}_{2}$ slurry increased under gravity. After each excursion, the system was driven subcritical as radiolytic gas generation decreased the density of the system. The absolute value of these

\section{Table 8. Characteristics of the First Three Excursions}

\begin{tabular}{lccc}
\hline & \multicolumn{3}{c}{ Excursion } \\
\hline Parameter & 1 & 2 & 3 \\
$\mathrm{~T}_{12}(\mathrm{sec})$ & 1.5 & 77 & 147 \\
$\varnothing$ & 67 & 9 & 5 \\
$\mathrm{f}$ & 1.000 & 0.130 & 0.075 \\
\hline \hline
\end{tabular}
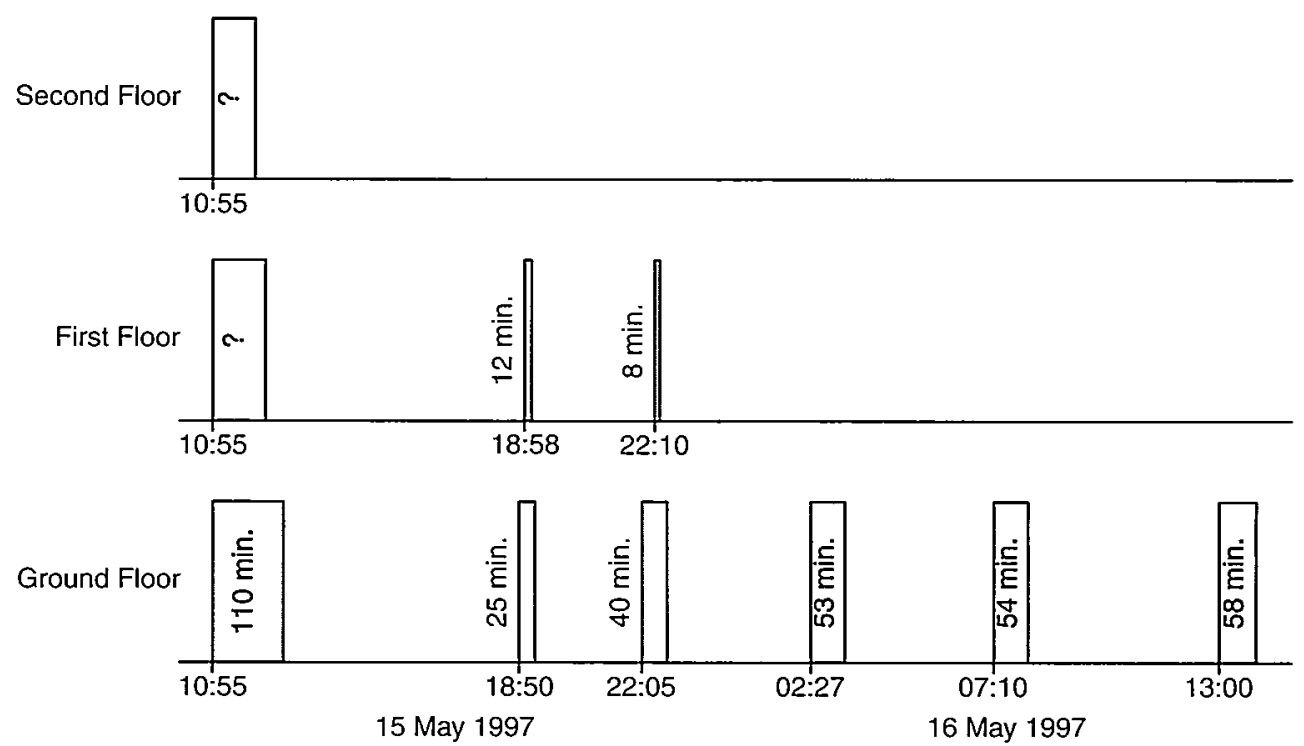

Figure 33. Sequence of alarms and duration that the radiation levels exceeded the alarm level $(36 \mathrm{mR} / \mathrm{h})$. 
competing reactivity effects proved to decrease with each additional excursion. After the fifth excursion, the system achieved a quasi-stationary state, which if not terminated artificially, could have persisted for an indefinite time.

Based on ${ }^{140}$ La activity, the total number of fissions in the two receiver vessels was estimated to be $\sim 5.5 \times 10^{15}$. The number of fissions for each excursion were then calculated to be

- $4.3 \times 10^{15}$,

- $5.6 \times 10^{14}$,

- $3.2 \times 10^{14}$, and

- $\sim 10^{14}$ for each of excursions 4 through 6 .
No contamination occurred and doses to personnel were insignificant. The collective dose for the closest 20 people did not exceed $0.4 \mathrm{rem}$. The equipment was not damaged, although the facility remained shutdown for about three months. The cause of the deformation of the receiver vessels was not known, but it was suspected that it occurred gradually over many years. The vessels were replaced, and a regular monitoring program for both uranium accumulation and vessel integrity was instituted.

\title{
22. JCO Fuel Fabrication Plant, 30 September 1999
}

\author{
Uranyl nitrate solution, $U(18.8)$, in a precipitation vessel; multiple excursions; two fatalities, one significant \\ exposure.
}

The accident occurred in the Fuel Conversion Test Building at the JCO company site in Toki-mura, Ibarakin prefecture, Japan. The building housed equipment to produce either uranium dioxide powder or uranyl nitrate solution from source materials such as uranium hexafluoride or $\mathrm{U}_{3} \mathrm{O}_{8}$. This building was one of three on site that was licensed to operate with fissile materials. The other two housed large-scale production equipment for the conversion of $\mathrm{UF}_{6}$ to $\mathrm{UO}_{2}$ for commercial light water reactors and handled only uranium enriched to $5 \%$ or less. The Fuel Conversion Test Building was much smaller, and was used only infrequently for special projects. It was authorized to handle uranium in enrichments up to $20 \%$. At the time of the accident, U(18.8) fuel processing was underway, with the product intended for the Joyo experimental breeder reactor at the Oarai site of the Japan Nuclear Cycle Development Institute (JNC). The small size ( $300 \times 500$ meters) and inner-city location of the JCO Tokai site contributed to a unique aspect of this accident; this was the first process criticality accident in which measurable exposures occurred to off-site personnel (members of the public).

The operation required the preparation of about $16.8 \mathrm{~kg}$ of $\mathrm{U}(18.8)$ as $370 \mathrm{~g} / \mathrm{l}$ uranyl nitrate that was to be shipped, as solution, offsite for the subsequent manufacture of reactor fuel. The process was being performed in separate batches to comply with the criticality controls. Procedures specified different uranium mass limits for different enrichment ranges. For the 16 to $20 \%$ range the limit was $2.4 \mathrm{~kg}$ uranium. A simplified depiction of the main process equipment and material flow for preparing and packaging the uranyl nitrate, as specified in the license between the JCO Company and the federal government, is shown in Figure 34-A.

Three operators had begun the task on 29 September, the day prior to the accident, but were operating according to the procedure indicated in Figure 34-B. There were basically two deviations from the licenseauthorized procedure that were associated with the actual operations. First, the company procedure that the operators were to have followed, specified that the dissolution step was to be conducted in open, 10-liter, stainless steel buckets instead of the dissolution vessel indicated. This change was known to have saved about one hour in dissolution time.

The much more serious procedural departure, however, was the transfer of the nitrate solution into the unfavorable geometry precipitation vessel instead of the prescribed, favorable geometry columns. This deviation was apparently motivated by the difficulty of filling the product containers from the storage columns. The drain cock below the columns was only about $10 \mathrm{~cm}$ above the floor. The precipitation vessel had not only a stirrer to assure a uniform product but greatly facilitated the filling of the product containers.

On 29 September the operators completed the dissolution of four, $2.4 \mathrm{~kg}$ batches. The solution was first transferred to a five liter flask and then hand poured through a funnel into the precipitation vessel. The precipitation vessel was $450 \mathrm{~mm}$ diameter by $610 \mathrm{~mm}$ high with a capacity of about 100 liters. Figure 35 is a photograph of the actual precipitation vessel, interconnected piping, ports through which materials could be added, and the stairs on which one 
A Authorized Procedure
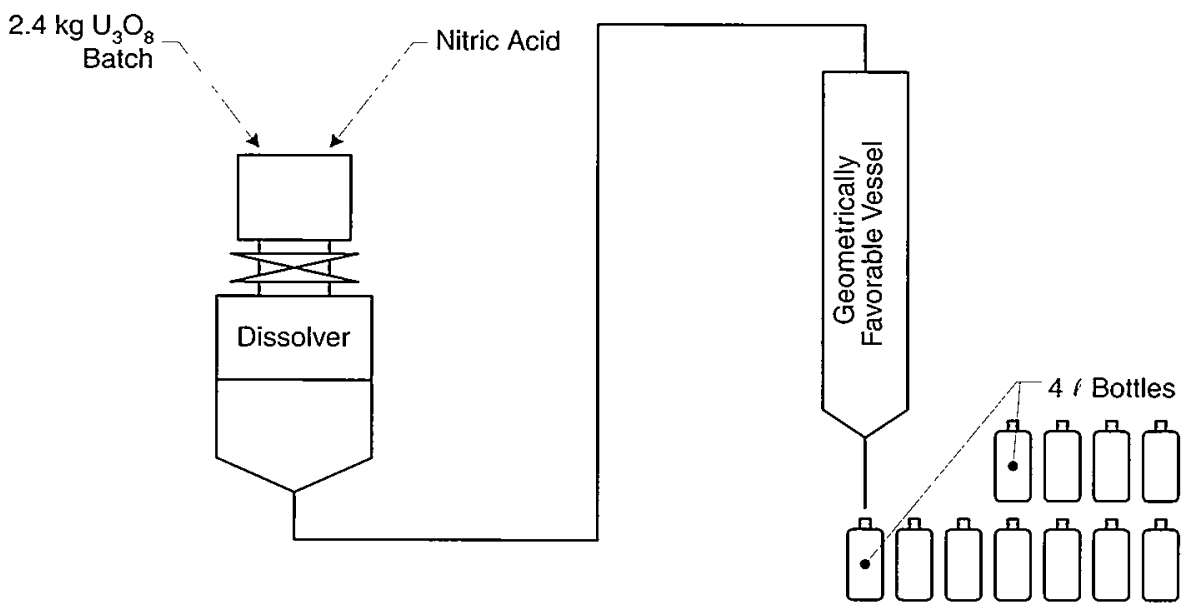

Product Solution $\mathrm{UO}_{2}\left(\mathrm{NO}_{3}\right)_{2}$

B Executed Procedure

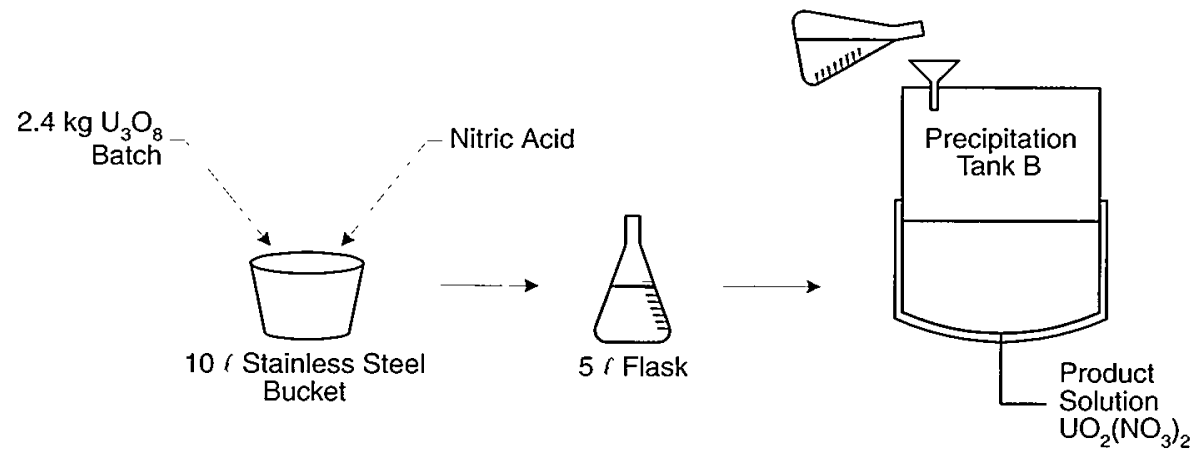

Figure 34. Authorized and executed procedures.

operator stood to pour the solution. The second operator stood on the floor and held the funnel. Completion of the four batches concluded the threeperson team's work for that day.

The next day, 30 September, the three operators began dissolving the final three batches that would be required to complete the job. After transferring batches five and six, the pouring of the seventh batch was begun around 10:35. Almost at the end of the pour ( $183 \mathrm{~g}$ of uranium were recovered from the flask) the gamma alarms sounded in this building and in the two nearby commercial fuel buildings. Workers evacuated from all buildings according to prescribed plans and proceeded to the muster area on site. At this location, gamma ray dose rates far above background were detected and it was suspected that a criticality accident had occurred and was ongoing.

The muster location was then moved to a more remote part of the plant site where dose rates were near to background values. The excursion continued for nearly twenty hours before it was terminated by deliberate actions authorized and directed by govern- ment officials. During this time there were several noteworthy aspects of this accident. First, the JCO Company was not prepared to respond to a criticality accident - the gamma alarms were not part of a criticality accident alarm system. In fact, the license agreement stated that a criticality accident was not a credible event. Thus expertise and neutron detectors had to be brought in from nearby nuclear facilities. Various monitoring devices at the facility as well as the nearby Japan Atomic Energy Research Institute (JAERI), recorded the excursion history. These showed, after a large initial spike, that the power level quasi-stabilized, dropping gradually by about a factor of two over the first $\sim 17$ hours.

About 4.5 hours after the start of the accident, radiation readings taken at the site boundary nearest to a residential house and a commercial establishment showed combined neutron and gamma ray dose rates of about $5 \mathrm{mSv} / \mathrm{hour}$. At this time the Mayor of Tokaimura recommended that residents living within a $350 \mathrm{~m}$ radius of the $\mathrm{JCO}$ plant evacuate to more remote locations. After 12 hours, local, Ibaraki-ken, govern- 


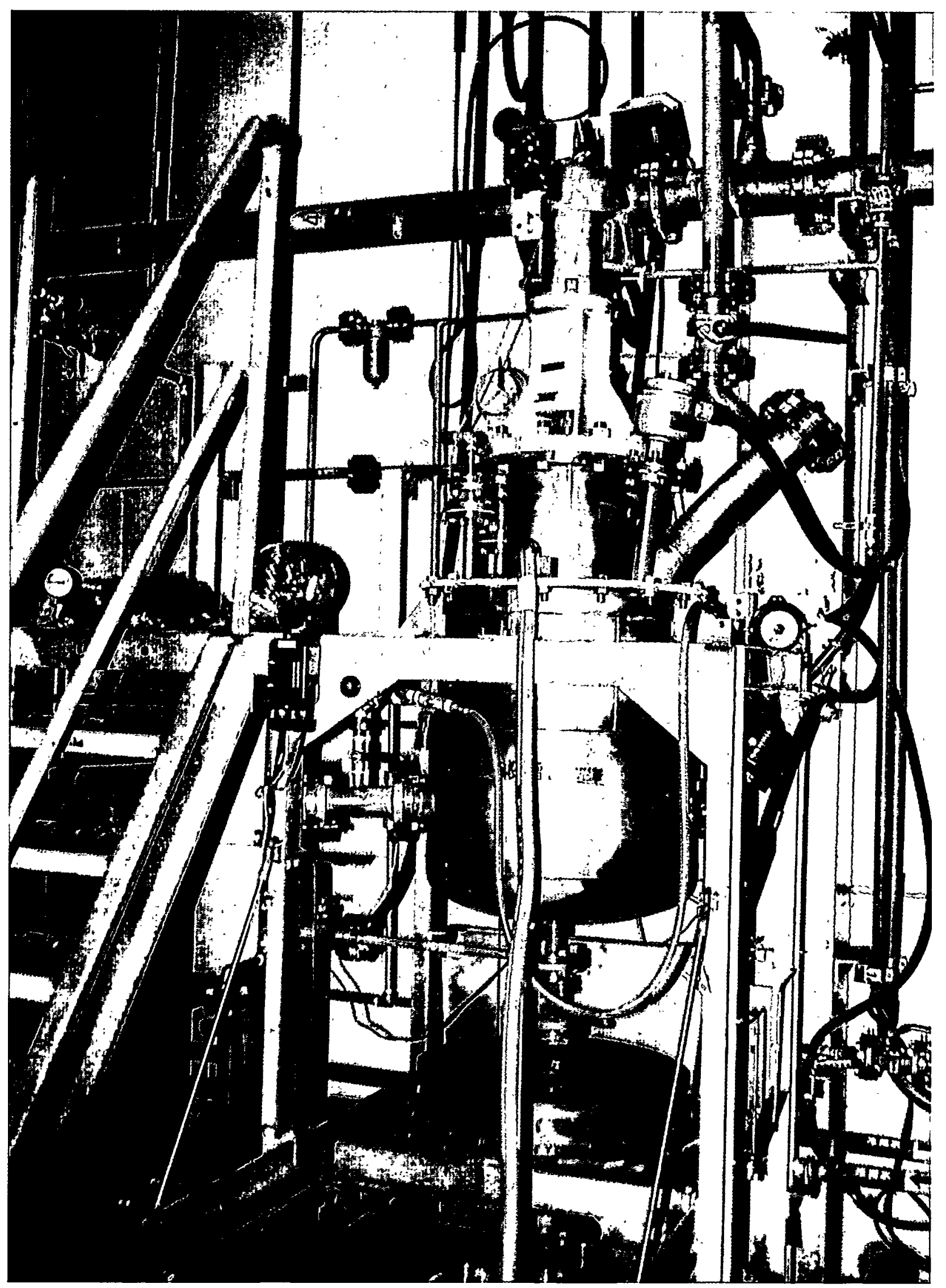

Figure 35. The precipitation vessel in which the process criticality accident occurred. 
ment authorities, recommended that residents within a $10 \mathrm{~km}$ radius of the plant remain indoors because of measurable airborne fission product activity.

Shortly after midnight, plans were carried out to attempt to terminate the excursion. It was decided to drain the cooling water from the jacket surrounding the lower half of the precipitation vessel in the recognition that this might remove sufficient reactivity to cause subcriticality. Several teams of three operators each were sent, one at a time, to accomplish this job. The piping that fed the jacket was accessible from immediately outside the building, but it was difficult to disassemble and the workers were limited to exposures of less than 0.1 Sv each.

When the piping was finally opened at about 17 hours into the accident, not all the water drained from the jacket. This was determined from the various monitoring devices that showed a power drop of about a factor of four and then a leveling off again, indicating that the excursion was not terminated. Complete removal of the water from the jacket was eventually accomplished by forcing argon gas through the piping, again, without entering the building. This led to the shutdown of the reaction at about twenty hours. To assure permanent subcriticality, boric acid was added to the precipitation vessel through a long rubber hose.

A few weeks after the accident, allowing for radiation levels to decay, the solution was sampled from the vessel and analyzed. Based on fission product analysis, it was determined that the total yield of the accident was about $2.5 \times 10^{18}$ fissions. While there were no radiation detectors that recorded the details of the first few minutes of the excursion history, the operators" exposures and the neutron detector readings at the JAERI-NAKA site provide strong evidence that the reactivity exceeded prompt critical. Experimental results from simulated criticality accidents in solutions s.3.4 $^{2.3}$ would then support a first spike yield of 4 to $8 \times 10^{16}$ fissions.
The two workers involved in the actual pouring operation were severely overexposed, with estimated doses of 16 to 20 and 6 to $10 \mathrm{GyEq}$ respectively. The third operator was a few meters away at a desk when the accident occurred and received an estimated 1 to $4.5 \mathrm{GyEq}$ dose. All three operators were placed under special medical care. The operator holding the funnel at the time of the accident died 82 days later. The operator pouring the uranyl nitrate died 210 days after the accident. The least exposed operator was released from the hospital three months after the accident.

Factors contributing to the accident, in addition to the stated procedural violations, likely included:

1) a weak understanding by personnel at all levels in $\mathrm{JCO}$ of the factors that influence criticality in a general sense, and specifically, a lack of realization that the 45 liters of solution, while far subcritical in the intended storage tanks, could be supercritical in the unfavorable geometry precipitation vessel;

2) company pressures to operate more efficiently;

3) the mind-set at all levels within JCO and the regulatory authority that a criticality accident was not a credible event; this mind-set resulted in an inadequate review of procedures, plans, equipment layout, human factors, etc. by both the company and the licensing officials.

The Government decided to cancel the license of JCO operations, and the JCO was likely to accept the decision at the time of the printing of this report.

Of the approximately 200 residents who were evacuated from within the $350 \mathrm{~m}$ radius, about $90 \%$ received doses less than $5 \mathrm{mSv}$ and, of the remaining, none received more than $25 \mathrm{mSv}$. While there was measurable contamination from airborne fission products on local plant life, maximum readings were less than $0.01 \mathrm{mSv} / \mathrm{hr}$ and short-lived. 


\section{B. PHYSICAL AND NEUTRONIC CHARACTERISTICS FOR THE PROCESS FACILITY CRITICALITY ACCIDENTS}

In this section, we examine the physical and neutronic characteristics of criticality accidents that have occurred in nuclear processing facilities of the Russian Federation, the United States, the United Kingdom, and Japan. To assess the validity of the accident descriptions, we have compared the physical parameters reported for each accident to the experimentally known conditions for criticality.

\section{Accident Reconstruction}

The geometry and material specifications provided in accident documentation fall far short of qualifying as criticality benchmarks as accepted by the international criticality safety community. ${ }^{33}$ The ability to accurately reconstruct accident configurations is seriously limited by the lack of reported technical detail. For example, in the case of accident 21 , these limitations are so severe that a re-construction was not even attempted. Re-constructions for accidents 1 through 20 and 22 are provided using interpretations of conditions reported for the accident. The re-constructions are intended to estimate the accident configuration corresponding to the critical state. The estimates of the parameters necessary for these re-constructions should not be interpreted as new "facts" to be added into the documentation of the accidents.

Only primary parameters affecting criticality are considered in our estimates-fissile species $\left({ }^{235} \mathrm{U}\right.$ or ${ }^{239} \mathrm{Pu}$ ), fissile density, shape of fissile material, and degree of moderation. Uranium enrichment is also considered in the case of accidents 9, 15, and 22. Examples of parameters missing in the accident reconstructions or ignored as being of secondary importance include the vessel material, the vessel wall thickness, the presence of fissile nuclides other than ${ }^{235} \mathrm{U}$ and ${ }^{239} \mathrm{Pu}$, and the presence of external reflectors near or in contact with the fissile material. The material mixtures were modeled as homogeneous metal-water mixtures, from which the degree of moderation is implied. This was a known over-simplification for a few of the accidents $(2,9,15$, and 21$)$ are known to have had a heterogeneous distribution.

Table 9 presents estimated parameter values for 22 process facility accidents. To the best of our knowledge, these 22 accidents represent a complete listing of events that unambiguously qualify as process facilities accidents in the R. F., the U.S., the U.K., and Japan.

Some explanation of the column headings presented in Table 9 is necessary.
Accident number: The 22 accidents are numbered in chronological order. Chronological order was selected in recognition of the parallel historical time line of technological developments occurring in the four countries.

Site and Date: Short abbreviations for the country in which the accident took place are used: R.F., U.S., and U.K. for those that occurred in the Russian Federation, the United States and the United Kingdom, respectively. The accident date is provided in the day-month-year format.

\section{Geometry}

Vessel Shape: The vessel shape, e.g., cylindrical, vertical axis. Although this designation is accurate for most accidents, some accidents are known to have occurred when the axis of cylindrical symmetry was neither vertical nor horizontal, but rather tilted at some angle from the vertical.

Vessel Volume: Vessel volume denotes the total volume of the vessel.

Fissile Volume: This heading could be more properly described as fissile material volume. It is an estimate of the volume occupied by the fissile material that dominated the neutronic reactivity of the system. In some cases (accidents 5 and 18), fissile material was present in low concentration exterior to this volume. This additional material had a secondary impact on the system reactivity and was therefore ignored. For those accidents that occurred or were modeled with a vertical axis of cylindrical symmetry and the fissile material was in solution or slurry form, an additional parameter, $\mathbf{h} / \mathbf{D}$, is provided. In those cases the fissile material was modeled as a right-circular cylinder (lower case $\mathbf{h}$ designates the height of the cylinder and capital $\mathbf{D}$ designates the diameter of the vessel).

Shape Factor: The shape factor was used to convert actual shape to equivalent spherical shape as a method to compare these 21 accidents in terms of geometrically equivalent spherical systems.

For the 18 accidents where $\mathbf{h} / \mathbf{D}$ is specified, the unreflected curve in Figure $36^{34}$ was used to determine the shape factor. The curve in Figure 36 is based directly on experimental results minimizing dependence on calculations. For the remaining 3 accidents (numbers 2, 6, and 20), buckling or other mathematically simple approximations were used to estimate the shape factor. 


\begin{tabular}{|c|c|c|c|c|c|c|c|c|}
\hline \multicolumn{2}{|r|}{ ACCIDENT } & \multicolumn{4}{|c|}{ GEOMETRY } & \multicolumn{2}{|c|}{ MATERIAL } & \multirow{2}{*}{$\begin{array}{c}\text { Estimated } \\
\text { Spherical } \\
\text { Critical Mass } \\
\text { (kg) }\end{array}$} \\
\hline No. & Site and Date & Vessel Shape & $\begin{array}{c}\text { Vessel } \\
\text { Volume } \\
(\ell)\end{array}$ & $\begin{array}{c}\text { Fissile } \\
\text { Volume } \\
(\ell)\end{array}$ & $\begin{array}{l}\text { Shape } \\
\text { Factor }\end{array}$ & $\begin{array}{l}\text { Fissile Mass } \\
\text { (kg) }\end{array}$ & $\begin{array}{l}\text { Fissile } \\
\text { Density } \\
(\mathrm{g} / \ell)\end{array}$ & \\
\hline 1 & $\begin{array}{c}\text { Mayak (R.F.) } \\
15-03-53\end{array}$ & $\begin{array}{l}\text { cylindrical } \\
\text { vertical axis }\end{array}$ & 40.0 & 31.0 & $\begin{array}{c}1.2 \\
\mathrm{~h} / \mathrm{D}=0.62\end{array}$ & $0.81{ }^{239} \mathrm{Pu}$ & 26.1 & 0.67 \\
\hline 2 & $\begin{array}{c}\text { Mayak (R.F.) } \\
21-04-57\end{array}$ & $\begin{array}{c}\text { cylindrical } \\
\text { horizontal axis }\end{array}$ & 100.0 & 30.0 & 2.8 & $3.066^{235} \mathrm{U}$ & 102.0 & 1.09 \\
\hline 3 & $\begin{array}{c}\text { Mayak (R.F.) } \\
02-01-58\end{array}$ & $\begin{array}{c}\text { cylindrical } \\
\text { vertical axis }\end{array}$ & 442.0 & 58.4 & $\begin{array}{c}4.2 \\
\mathrm{~h} / \mathrm{D}=0.18\end{array}$ & $22.0^{235} \mathrm{U}$ & 376.7 & 5.24 \\
\hline 4 & $\begin{array}{c}Y-12 \text { (U.S.) } \\
16-06-58\end{array}$ & $\begin{array}{l}\text { cylindrical } \\
\text { vertical axis }\end{array}$ & 208.0 & 56.0 & $\begin{array}{c}1.4 \\
\mathrm{~h} / \mathrm{D}=0.42\end{array}$ & $2.10^{235} \mathrm{U}$ & 37.5 & 1.50 \\
\hline 5 & $\begin{array}{l}\text { LASL (U.S.) } \\
30-12-58 \\
\end{array}$ & $\begin{array}{c}\text { cylindrical } \\
\text { vertical axis }\end{array}$ & 982.0 & 160.0 & $\begin{array}{c}3.5 \\
\mathrm{~h} / \mathrm{D}=0.20\end{array}$ & $2.94^{239} \mathrm{Pu}$ & 18.4 & 0.84 \\
\hline 6 & $\begin{array}{l}\text { ICPP (U.S.) } \\
16-10-59\end{array}$ & $\begin{array}{c}\text { cylindrical } \\
\text { horizontal axis }\end{array}$ & $18,900.0$ & 800.0 & 25.0 & $30.9^{235} \mathrm{U}$ & 38.6 & 1.24 \\
\hline 7 & $\begin{array}{c}\text { Mayak (R.F.) } \\
05-12-60\end{array}$ & $\begin{array}{l}\text { cylindrical } \\
\text { vertical axis }\end{array}$ & 40.0 & 19.0 & $\begin{array}{c}1.2 \\
\mathrm{~h} / \mathrm{D}=0.55\end{array}$ & $0.85^{239} \mathrm{Pu}$ & 44.7 & 0.71 \\
\hline 8 & $\begin{array}{l}\text { ICPP (U.S.) } \\
25-01-61\end{array}$ & $\begin{array}{l}\text { cylindrical } \\
\text { vertical axis }\end{array}$ & 461.0 & 40.0 & $\begin{array}{c}2.9 \\
\mathrm{~h} / \mathrm{D}=0.22\end{array}$ & $7.20{ }^{235} \mathrm{U}$ & 180.0 & 2.48 \\
\hline 9 & $\begin{array}{c}\text { Tomsk (R.F.) } \\
14-07-61\end{array}$ & $\begin{array}{l}\text { cylindrical } \\
\text { vertical axis }\end{array}$ & 65.0 & 42.9 & $\begin{array}{c}1.3 \\
\mathrm{~h} / \mathrm{D}=0.47\end{array}$ & $\begin{array}{c}1.688^{235} \mathrm{U} \\
\mathrm{H} /^{235} \mathrm{U} \sim 600\end{array}$ & 39.2 & $\begin{array}{l}1.29 \\
(0.9 \mathrm{refl})\end{array}$ \\
\hline 10 & $\begin{array}{c}\text { Hanford (U.S.) } \\
07-04-62\end{array}$ & $\begin{array}{c}\text { cylindrical } \\
\text { vertical axis }\end{array}$ & 69.0 & 45.0 & $\begin{array}{c}1.2 \\
\mathrm{~h} / \mathrm{D}=0.60\end{array}$ & $1.29^{239} \mathrm{Pu}$ & 28.7 & 1.07 \\
\hline 11 & $\begin{array}{c}\text { Mayak (R.F.) } \\
07-09-62\end{array}$ & $\begin{array}{l}\text { cylindrical } \\
\text { vertical axis }\end{array}$ & 100.0 & 80.0 & $\begin{array}{c}1.2 \\
\mathrm{~h} / \mathrm{D}=1.11\end{array}$ & $1.26{ }^{239} \mathrm{Pu}$ & 15.8 & 1.05 \\
\hline 12 & $\begin{array}{c}\text { Tomsk (R.F.) } \\
30-01-63\end{array}$ & $\begin{array}{c}\text { cylindrical } \\
\text { vertical axis }\end{array}$ & 49.9 & 35.5 & $\begin{array}{c}1.1 \\
\mathrm{~h} / \mathrm{D}=0.62\end{array}$ & $2.27{ }^{235} \mathrm{U}$ & 63.9 & 2.06 \\
\hline 13 & $\begin{array}{c}\text { Tomsk (R.F.) } \\
02-12-63\end{array}$ & $\begin{array}{l}\text { cylindrical } \\
\text { vertical axis }\end{array}$ & 100.0 & 64.8 & $\begin{array}{c}1.4 \\
\mathrm{~h} / \mathrm{D}=0.47\end{array}$ & $1.93{ }^{235} \mathrm{U}$ & 29.8 & 138 \\
\hline 14 & $\begin{array}{c}\text { Wood River (U.S.) } \\
\text { 24-07-64 }\end{array}$ & $\begin{array}{l}\text { cylindrical } \\
\text { vertical axis }\end{array}$ & 103.7 & 41.0 & $\begin{array}{c}1.2 \\
\mathrm{~h} / \mathrm{D}=0.54\end{array}$ & $2.07{ }^{235} \mathrm{U}$ & 50.5 & 1.72 \\
\hline 15 & $\begin{array}{c}\text { Electrostal (R.F.) } \\
03-11-65\end{array}$ & $\begin{array}{l}\text { cylindrical } \\
\text { vertical axis }\end{array}$ & 300.0 & 100.0 & $\begin{array}{c}1.4 \\
\mathrm{~h} / \mathrm{D}=0.46\end{array}$ & $\begin{array}{c}3.655^{235} \mathrm{U} \\
\mathrm{H} /{ }^{235} \mathrm{U} \sim 600\end{array}$ & 36.5 & $\begin{array}{l}2.61 \\
(1.6 \mathrm{refl})\end{array}$ \\
\hline 16 & $\begin{array}{c}\text { Mayak (R.F.) } \\
16-12-65\end{array}$ & $\begin{array}{c}\text { cylindrical } \\
\text { vertical axis }\end{array}$ & 100.0 & 28.6 & $\begin{array}{c}1.2 \\
\mathrm{~h} / \mathrm{D}=0.60\end{array}$ & $1.98{ }^{235} \mathrm{U}$ & 69.2 & 1.65 \\
\hline 17 & $\begin{array}{c}\text { Mayak (R.F.) } \\
10-12-68\end{array}$ & $\begin{array}{l}\text { cylindrical } \\
\text { vertical axis }\end{array}$ & 62.1 & 28.8 & $\begin{array}{c}1.1 \\
\mathrm{~h} / \mathrm{D}=0.70\end{array}$ & $1.50{ }^{239} \mathrm{Pu}$ & 52.1 & 1.36 \\
\hline 18 & $\begin{array}{c}\text { Windscale (U.K.) } \\
24-08-70\end{array}$ & $\begin{array}{l}\text { cylindrical } \\
\text { vertical axis }\end{array}$ & 156.0 & 40.0 & $\begin{array}{c}3.0 \\
\mathrm{~h} / \mathrm{D}=0.22\end{array}$ & $2.07{ }^{239} \mathrm{Pu}$ & 51.8 & 0.69 \\
\hline 19 & $\begin{array}{l}\text { ICPP (U.S.) } \\
17-10-78\end{array}$ & $\begin{array}{l}\text { cylindrical } \\
\text { vertical axis }\end{array}$ & 315.5 & 315.5 & $\begin{array}{c}1.4 \\
\mathrm{~h} / \mathrm{D}=1.75\end{array}$ & $6.08{ }^{235} \mathrm{U}$ & 19.3 & 4.34 \\
\hline 20 & $\begin{array}{c}\text { Tomsk (R.F.) } \\
13-12-78\end{array}$ & $\begin{array}{l}\text { cylindrical } \\
\text { vertical axis }\end{array}$ & 3.2 & 0.54 & 1.1 & $10.1{ }^{239} \mathrm{Pu}$ & $18,700.0$ & 9.18 \\
\hline 21 & $\begin{array}{c}\text { Novosibirsk (R.F.) } \\
15-05-97\end{array}$ & parallel tanks & $\begin{array}{r}700.0 \\
\text { each tank }\end{array}$ & $*$ & $*$ & $17.1{ }^{235} \mathrm{U}$ & $*$ & $*$ \\
\hline 22 & $\begin{array}{c}\text { Tokai-mura (Japan) } \\
30-09-99\end{array}$ & $\begin{array}{l}\text { cylindrical } \\
\text { vertical axis }\end{array}$ & 100.0 & 45.0 & $\begin{array}{c}1.1 \\
\mathrm{~h} / \mathrm{D}=0.6\end{array}$ & $\begin{array}{c}3.122^{235} \mathrm{U} \\
\mathrm{H}^{/ 235} \mathrm{U} \sim 380\end{array}$ & 69.3 & $\begin{array}{l}2.9 \\
(1.9 \mathrm{refl})\end{array}$ \\
\hline
\end{tabular}




\section{Material}

Fissile Mass: Fissile mass is the mass of either ${ }^{235} \mathrm{U}$ or ${ }^{239} \mathrm{Pu}$. Fissile type is designated below the mass entry. Three uranium accidents, 9, 15, and 22 had enrichments of $22.6 \%, 6.5 \%$, and $18.8 \%$ by weight, respectively. For these accidents the fissile mass column also provides the hydrogen to ${ }^{235} \mathrm{U}$ atom ratio. For the plutonium eight accidents with the plutonium was assumed to be $95 \%{ }^{239} \mathrm{Pu}$ by weight.

Fissile Density: Fissile density is the quotient of fissile mass and fissile volume assuming a homogeneous mixture.

Estimated Spherical Critical Mass: Entries in this column represent the spherical critical mass as the quotient of fissile mass and shape factor. These estimated masses are used as the measure of consistency or agreement of the accident re-constructions with established conditions for criticality. For accidents 9,15 , and 22 , the spherical mass was adjusted to a fully water reflected value.

\section{Discussion}

Traditionally, techniques of the type used to generate the estimates presented in Table 9 have been referred to as "back-of-the-envelope" calculations. These calculations are characterized by their mathematical simplicity and their results are better described as estimates when contrasted to results from computer calculations. In some cases these estimates are sufficient and more elaborate computer code calculations are not necessary. These results are characterized as estimates in conformity with Wheeler's First Moral Principle: "Never make a calculation until you know the answer. Make an estimate before every calculation....".36

Figures 37, 38, and 39 are selected and adapted from Los Alamos report LA-10860. ${ }^{34}$ These three figures include points corresponding to fissile density (or atom ratio) and the estimated spherical critical mass for the twenty-one accident re-constructions in Table 9. Figure 38 includes curves for systems with uranium enrichment corresponding

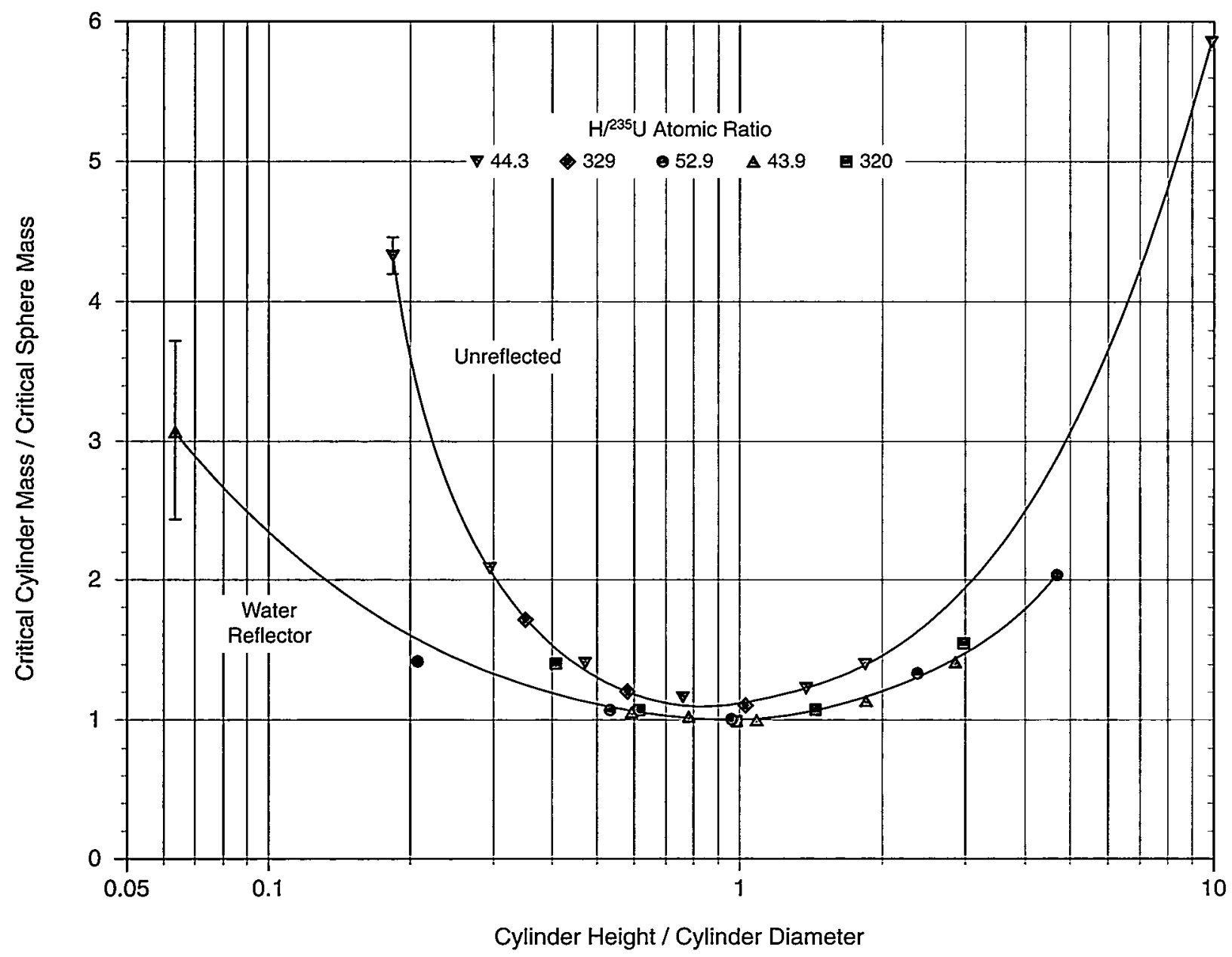

Figure 36. The ratio of cylindrical to spherical critical masses of $\mathrm{U}(93) \mathrm{O}_{2} \mathrm{~F}_{2}$ solutions, unreflected and with water reflector, as a function of cylinder height to cylinder diameter ratio. 
to 2.0,3.0, 5.0, 30.3, and 93.0. Accidents 9, 15, and 22 are superimposed on this figure. Since the curves in Figure 38 are for water reflected systems, these points have been adjusted downward since the actual accidents were relatively unreflected.

Additional adjustments to fissile density and estimated critical spherical mass could be performed. For example, the effects of nitrate absorption and organic versus aqueous base composition could be included in the estimates. Of course, judgment is required as to whether such adjustments are meaningful and whether carrying out such adjustments would lead to estimates in closer agreement with the curves presented in Figures 37, 38, and 39. Such adjustments cannot be justified. The absence of technical detail provided in the accident descriptions prevents meaningful refinement of the estimates. This lack of technical information also precludes any attempt for meaningful, more detailed, neutronic computer modeling.

\section{Conclusions}

Considering the effects of partial reflection and inherent uncertainties in the estimates, it is judged that the position of 18 of the 21 points plotted in Figures 37, 38 , and 39 are sufficient for establishing credible agreement between the reported accident conditions and known conditions for criticality. The estimates for accidents 1,7 , and 9 appear to be somewhat questionable in that more mass than reported in the accident would be required for criticality under the hypothesized unreflected accident conditions. However, accidents 1 and 7, would be in reasonable agreement if the partial reflection present during the accident were taken into account. It should be noted that for these two cases, the "missing" mass is no greater in magnitude than other accident reconstructions (notably, accidents 12,14, and 17) in which the reported mass exceeds the known conditions for criticality. The discrepancy surrounding accident 9 is also consistent with the large reported uncertainty in the amount of mass present. No systematic features are distinguishable that differentiate the R.F., U.S., U.K., and Japanese accidents.

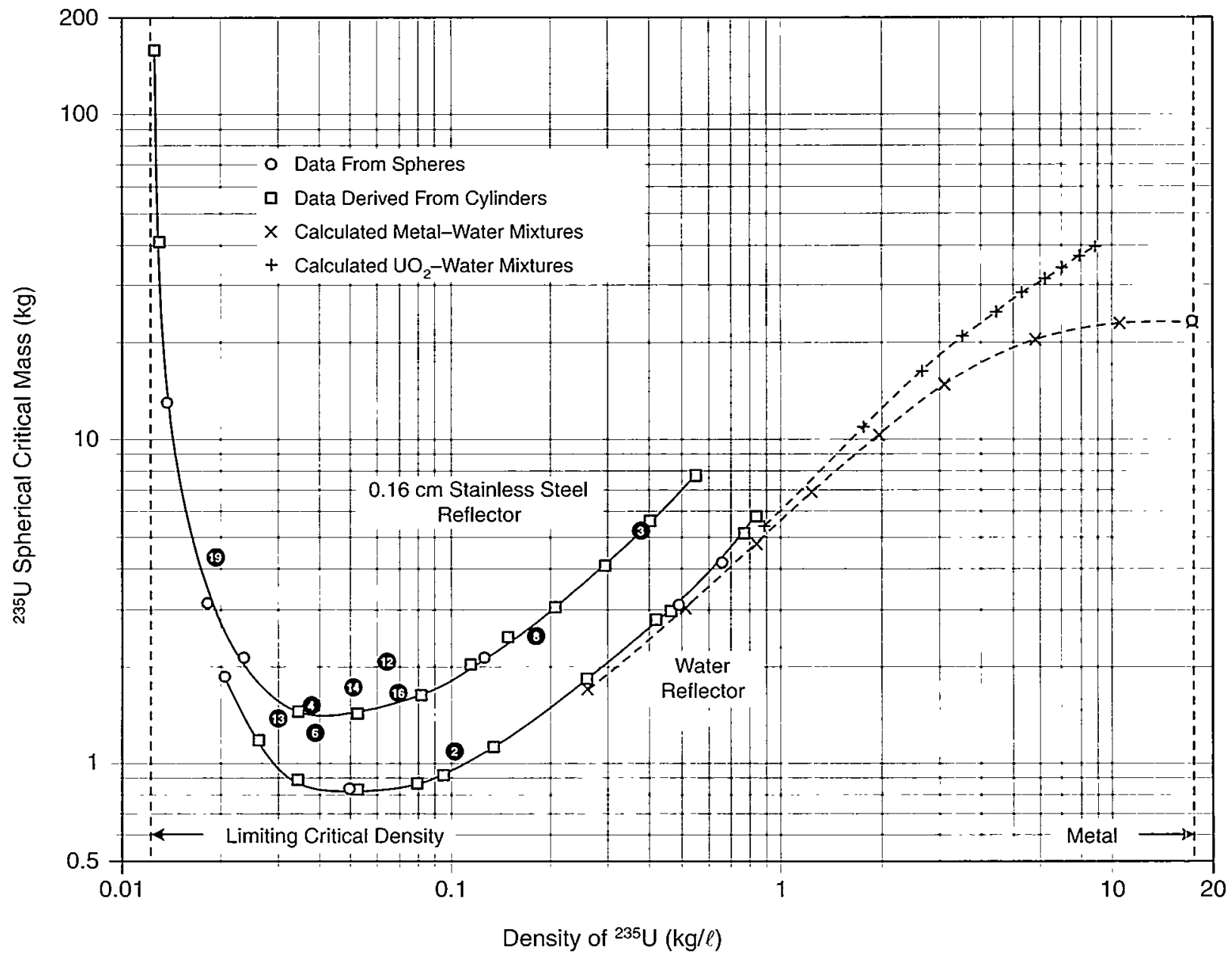

Figure 37. Critical masses of homogeneous water moderated $U(93.2)$ spheres. Solution data appear unless indicated otherwise. The accidents are shown by numbered circles. 


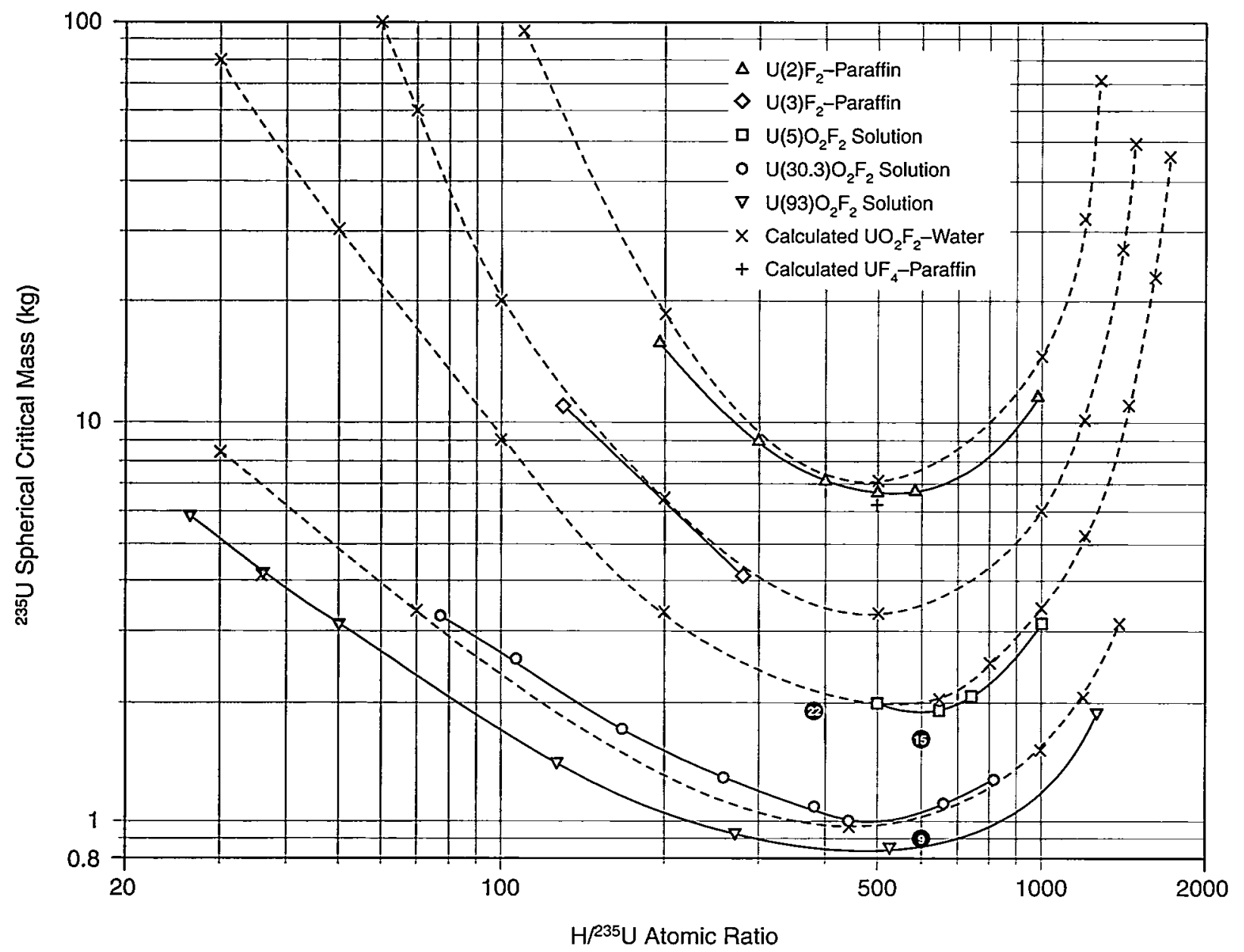

Figure 38. Critical masses of water-reflected spheres of hydrogen-moderated $U(93), U(30.3), U(5.00), U(3.00)$, and $\mathrm{U}(2.00)$. The accidents are shown by numbered circles.

\section{Fission Yields}

Table 10 lists the estimated fission energy releases for the 22 accidents. An attempt has been made to categorize the spike yield in this edition in a manner consistent with the prior two editions of this report and definitions in the appendix. These definitions are repeated here for convenience.

spike (in a prompt power excursion): The initial power pulse of a prompt power excursion, limited by the shutdown mechanism. See excursion, prompt power.

excursion, prompt power: A nuclear excursion as the result of a prompt critical configuration of fissile material. In general, a sharp power spike followed by a plateau that may be interrupted by smaller spikes.

From solution excursion experimental data, such as many of the CRAC ${ }^{4}$ and SILENE $^{3}$ experiments, it is apparent that there is a smooth transition from excursions in which the maximum reactivity did not reach prompt critical to those in which it slightly exceeded prompt critical. There is no significant distinction between the power histories of two excursions, one having a maximum reactivity of $\$ 0.90$ and the other having a maximum reactivity of $\$ 1.10$. They both exhibit an initial spike followed by less energetic, recurring spikes at approximately 10 to 20 second intervals, eventually leading to a quasi-plateau. Only when the maximum reactivity attained is about $\$ 0.50$ or less is the traditional spike not present.

Another result of the CRAC ${ }^{4}$ and SILENE $^{3}$ experiments that can be compared to the accident yields listed in Table 10 is the specific yield of the first excursion, the spike. For experiments with a maximum reactivity of about $\$ 0.50$ or more, the specific yield of the spike was always about $1.0 \times 10^{15}$ fissions per liter except for very fast excursions, those that achieved inverse periods much greater than $100 \mathrm{~s}^{-1}$. For these very fast excursions, specific yields up to several times $10^{15}$ fissions per liter were measured. The accidents for which a spike yield is given in Table 10 are consistent with the specific yields of the CRAC $^{4}$ and SILENE ${ }^{3}$ data in that none exceeded a few times $10^{15}$ fissions per liter. However, there are three reported spike yields 


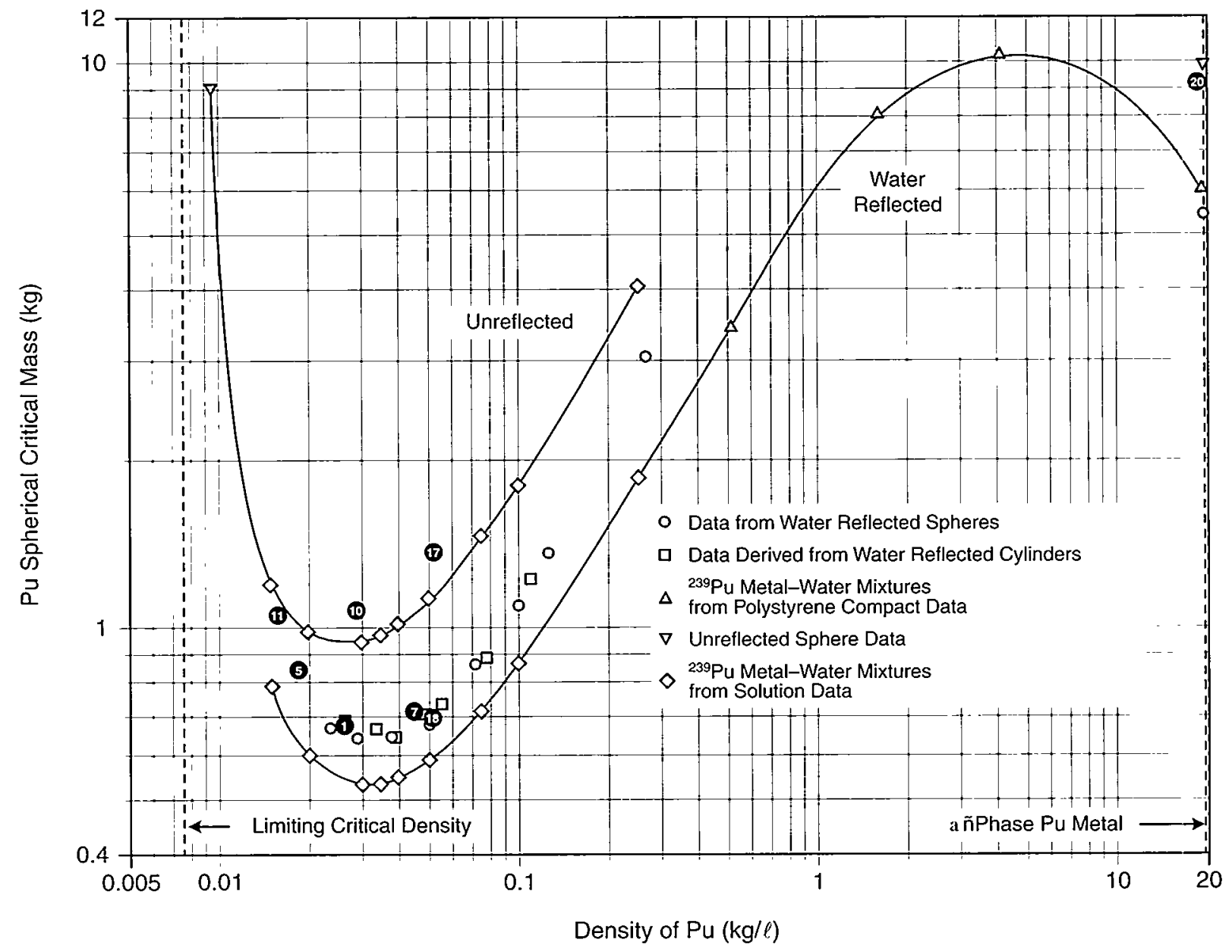

Figure 39. Critcial masses of homogeneous water moderated plutonium spheres. The points suggesting an intermediate curve apply to water reflected $\mathrm{Pu}\left(\mathrm{No}_{3}\right)_{4}$ solution with $1 \mathrm{~N} \mathrm{HNO}_{3}$ and $3.1 \%{ }^{240} \mathrm{Pu}$ content. The accidents are shown by numbered circles.

(Accidents 4.6, and 8) that fall significantly below $10^{15}$ fissions per liter. This indicates either a slow excursion, in which there is not a spike in the classic sense, or simply a yield estimation that was incorrect. There being no compelling evidence for either case, these table entries have been left as they were reported in the prior editions.

About half of the accidents listed in Table 10 indicate that there was no spike yield. This should be interpreted as indicating a slow excursion, i.e., one with a time duration of minutes or longer between power peaks. This definition of slow is consistent with an inverse period of $10 \mathrm{~ms}^{-1}$ or less. Note that accident 20 was a metal system. While there are no plutonium metal experiments to provide a basis for comparison, the two Los Alamos critical experiment accidents with plutonium metal (1945 and 1946) exhibit similar specific spike yields. 


\begin{tabular}{|c|c|c|c|c|c|}
\hline \multicolumn{6}{|c|}{ Table 10. Accident Fission Energy Releases } \\
\hline No. & Site and Date & $\begin{array}{c}\text { First Spike Yield } \\
\left(10^{17} \text { fiss }\right)\end{array}$ & $\begin{array}{c}\text { Fissile Volume } \\
(\ell)\end{array}$ & $\begin{array}{c}\text { Specific Spike Yield } \\
\left(10^{15} \text { fiss } \ell \text { l }\right)\end{array}$ & $\begin{array}{c}\text { Total Yield } \\
\left(\mathbf{1 0}^{17} \text { fiss }\right)\end{array}$ \\
\hline 1 & $\begin{array}{c}\text { Mayak (R.F.) } \\
15-03-53\end{array}$ & unknown & 31.0 & unknown & $\sim 2.0$ \\
\hline 2 & $\begin{array}{c}\text { Mayak (R.F.) } \\
21-04-57\end{array}$ & unknown & 30.0 & unknown & $\sim 1.0$ \\
\hline 3 & $\begin{array}{c}\text { Mayak (R.F.) } \\
02-01-58 \\
\end{array}$ & $\sim 2.0$ & 58.4 & 3.4 & $\sim 2.0$ \\
\hline 4 & $\begin{array}{c}\text { Y-12 (U.S.) } \\
16-06-58\end{array}$ & $\sim 0.1$ & 56.0 & 0.2 & 13.0 \\
\hline 5 & $\begin{array}{c}\text { LASL (U.S.) } \\
30-12-58\end{array}$ & 1.5 & 160.0 & 0.94 & 1.5 \\
\hline 6 & $\begin{array}{c}\text { ICPP (U.S.) } \\
16-10-59 \\
\end{array}$ & $\sim 1.0$ & 800.0 & $\sim 0.1$ & 400.0 \\
\hline 7 & $\begin{array}{c}\text { Mayak (R.F.) } \\
05-12-60\end{array}$ & unknown & 19.0 & unknown & $\sim 2.5$ \\
\hline 8 & $\begin{array}{l}\text { ICPP (U.S.) } \\
25-01-61\end{array}$ & $\sim 0.6$ & 40.0 & 1.5 & 6.0 \\
\hline 9 & $\begin{array}{c}\text { Tomsk (R.F.) } \\
14-07-61\end{array}$ & none & 42.9 & none & 0.12 \\
\hline 10 & $\begin{array}{c}\text { Hanford (U.S.) } \\
07-04-62 \\
\end{array}$ & $\sim 0.1$ & 45.0 & 0.2 & 8.0 \\
\hline 11 & $\begin{array}{c}\text { Mayak (R.F.) } \\
07-09-62\end{array}$ & none & 80.0 & none & $\sim 2.0$ \\
\hline 12 & $\begin{array}{c}\text { Tomsk (R.F.) } \\
30-01-63\end{array}$ & unknown & 35.5 & unknown & 7.9 \\
\hline 13 & $\begin{array}{c}\text { Tomsk (R.F.) } \\
02-12-63 \\
\end{array}$ & none & 64.8 & none & 0.16 \\
\hline 14 & $\begin{array}{c}\text { Wood River (U.S.) } \\
\text { 24-07-64 } \\
\end{array}$ & $\sim 1.0$ & 41.0 & 2.4 & $\sim 1.3$ \\
\hline 15 & $\begin{array}{c}\text { Electrostal (R.F.) } \\
03-11-65 \\
\end{array}$ & none & 100.0 & none & $\sim 0.08$ \\
\hline 16 & $\begin{array}{c}\text { Mayak (R.F.) } \\
16-12-65\end{array}$ & none & 28.6 & none & $\sim 5.5$ \\
\hline 17 & $\begin{array}{c}\text { Mayak (R.F.) } \\
10-12-68\end{array}$ & 0.3 & 28.8 & 1.0 & $\sim 1.3$ \\
\hline 18 & $\begin{array}{l}\text { Windscale (R.F.) } \\
24-08-70\end{array}$ & none & 40.0 & none & 0.01 \\
\hline 19 & $\begin{array}{c}\text { ICPP (U.S.) } \\
17-10-78\end{array}$ & unknown & 315.5 & unknown & 27.0 \\
\hline 20 & $\begin{array}{c}\text { Tomsk (R.F.) } \\
13-12-78 \\
\end{array}$ & 0.03 & 0.54 & 5.6 & 0.03 \\
\hline 21 & $\begin{array}{c}\text { Novosibirsk (R.F.) } \\
15-05-97\end{array}$ & none & * & none & 0.055 \\
\hline 22 & $\begin{array}{c}\text { Tokai-mura (Japan) } \\
30-09-99\end{array}$ & $\sim 0.5$ & 45.0 & 1.1 & 25 \\
\hline
\end{tabular}




\section{OBSERVATIONS AND LESSONS LEARNED FROM PROCESS CRITICALITY ACCIDENTS}

There have now been 22 reported accidents in fissile material process operations. Significant, and often painful. lessons have been learned from these accidents. These lessons are associated with the following design. managerial, and operational attributes: communications; procedures; fissile material accountability and accumulation: vessel geometry and volume; operator knowledge; new restarted, and one-of-a-kind operations: equipment malfunction; and unanticipated movement of solutions. This review has also revealed the actual magnitude and breadth of accident consequences and the value of criticality alarms. While not always readily apparent or emphasized during accident investigations, other significant factors that influence accident risks are: (1) senior management awareness and involvement in safety in general and criticality safety in specific: (2) regulatory agency personnel awareness and involvement; and (3) national and international consensus standards and regulations that are both corporate and governmental.

It is important to note that there have been no accidents that were caused by a single failure. That is, there were always multiple causes for each of the 22 accidents. It is also noteworthy that equipment failure or malfunction was either a minor or a non-contributing factor in all of the accidents.

That lessons have been learned from past criticality accidents is made clear from their time histogram, Figure 1. For about the first decade of operations with significant ${ }^{*}$ quantities of fissile materials, there was not a reported accident. This was likely associated with the relatively small scale of individual operations and the relatively small amounts of fissile material (almost exclusively plutonium and enriched uranium) that was available.

However, between the late 1950s and the middle 1960 s there was about one accident per year in both the R.F. and the U.S. During this time there was a very large increase in the production of fissile material and in the scale of operations at the process sites. Since the middle 1960s, the frequency of accidents dropped by a factor of about 10 , to approximately 1 per 10 years. This drop can be attributed to several factors. First there were significant lessons learned from the earlier accidents such as the need to avoid unfavorable geometry vessels. Secondly, there was a significant increase in management attention to criticality safety, particularly the presence of staff devoted specifically to controlling this hazard. These accidents also prompted those with criticality and operational responsibilities to begin to document critical mass data and operational good practices. The first compilations of data began appearing in the late fifties, and the first national standards in the mid-sixties.

From a review of all the process accidents, we can summarize the findings into two categories: observations and lessons learned. The former are simply facts observed at the time; while the latter are conclusions that can be used to provide safety guidance to enhance future operations. Both categories are discussed in the following sections.

\section{Observations}

The following are factual observations from the 22 reported process accidents with some elaboration as they may apply to the lessons learned.

- The accident frequency rose from zero in the first decade of operations with significant quantities of fissile material to a high of about one per year in both the R.F. and the U.S. during the years around 1960. The frequency then dropped noticeably to about one per ten years and has seemingly remained there. It has been suggested that in the second decade there was a significant increase in both the production of fissile materials and in the scale of operations at process sites, without commensurate attention to criticality safety. Certainly lessons learned from these earlier accidents contributed to the later improved record.

- No accident occurred with fissile material while in storage. This should not be surprising considering the relative simplicity of this operation and the ease of controlling criticality.

- No accident occurred with fissile material while being transported. This should not be surprising given both national and international transport regulations. These regulations specify defense in depth in criticality safety that goes far beyond what would be practical and cost-effective for plant operations.

- No accident resulted in significant radiation consequences beyond the facility site, either to people or to the environment. This reinforces a commonly held contention that criticality accidents are similar to small, bench-top scale, chemical explosions in their personnel and environmental consequences, i.e., they are worker safety issues.

\footnotetext{
"The term "significant" as used here refers to having sufficient fissile material to sustain a chain reaction. The actual quantity of material being processed during the first decade was much less than during subsequent decades.
} 
- Accidents in shielded facilities did not result in radiation doses in excess of current occupational limits or in excess of guidance found in governmental regulations and in national and international standards. In light of this, the appropriateness of emergency evacuation procedures for shielded facilities should be reevaluated.

- No accidents were solely attributed to equipment failure.

- No accidents were attributed to faulty calculations by the criticality analyst.

- Many of the accidents occurred during non-routine operations. However, the number of accidents is too small to draw any strong conclusions.

- Administrative considerations, rather than the severity of the accident, seemed to have determined the length of facility downtime following an accident.

- No new physical phenomena were observed. All of the accidents can be explained by the current knowledge base.

\section{Lessons Learned}

First and perhaps foremost, the human element was not only present but the dominant cause in all of the accidents, as will be discussed in several of the lessons. Second, and not often apparent, there was an element of supervisory, upper-management, and regulatory agency responsibility in all of the accidents. Third, and this follows naturally from the first two, there were multiple causes for every accident. From these 22 accidents the following lessons have criticality safety significance.

In what follows there is not simply a statement of the "lesson", but supporting elaboration. These supporting words were drawn from extensive discussions among the authors and are offered to assist operating and criticality staff in a fuller understanding of the lesson.

\section{Lessons of Operational Importance}

- Unfavorable geometry vessels should be avoided in areas where high-concentration solutions might be present. If unavoidable, they should be subjected to strict controls or poisoned as appropriate to the situation. All but one of the accidents involved fissile material in solutions or slurries (quasi-solutions, but likely heterogeneous and of high concentration). From this, one realizes immediately the importance of favorable geometry (limited dimension), solution handling vessels. When it is judged to be necessary to rely on concentration control associated with the application of large, unpoisoned process vessels, then multiple checks on incoming concentration and redundant monitoring for fissile material accumulation are appropriate, particularly in unshielded operations. In addition, one must not be lulled into complacency because of the near-exclusive use of favorable geometry vessels. This only reduces accident likelihoods, it does not eliminate them. Given sufficient interaction, multiple favorable geometry vessels can always be made critical. Also, failures of favorable geometry vessels can result in accidents. The accident at Novosibirsk in 1997, is perhaps an example of a combination of complacency and vessel failure.

- Important instructions, information, and procedural changes should always be in writing. Failure of communications between operating personnel was a major contributing factor in several accidents. This failure manifested itself in multiple ways. In one accident involving shift work, procedures for the recovery from a process upset were not documented and not passed on to everyone on a subsequent shift; a fatality resulted. Operations should be performed only in accordance with well written, approved, and understood (by the users) procedures, including operating instructions and postings. Two accidents were directly attributable to miscommunication of sample concentrations during telephone transmission of analytical laboratory results. Important data should always be transferred in writing. A fourth accident occurred when improvised operations were underway and oral instructions were misunderstood and unintended actions taken.

- The processes should be familiar and well understood so that abnormal conditions can be recognized. Several accidents were associated with incomplete understanding of abnormal conditions. Had these abnormal conditions been recognized, then controls could have been put in place to prevent the accidents. While these accidents generally occurred in the era before management assigned specialists to assist operating personnel in criticality accident control, the lesson will always be applicable.

- Criticality control should be part of an integrated program that includes fissile material accountability. All piping and equipment associated with fissile material operations should be appropriately monitored to prevent undesired fissile material accumulations. Loss of or inadequate accountability for fissile materials has been associated with several accidents. Sometimes this accountability seemed almost unavoidable when the loss was so gradual that the accountability controls available at the time were not capable of detecting the loss. However, had there been monitoring of piping and vessels through which fissile material routinely passed, or could have credibly passed, then inadvertent accumulations could have been detected. 
Monitoring could take the form of visual inspections, physical cleanings, radiation emission measurements. etc. Criticality control and fissile material accountability are important issues and often mutually supportive.

- Operations personnel should know how to respond to foreseeable equipment malfunctions or their own errors. Hasty and inappropriate responses to process malfunctions have led to more than one accident. This underscores several issues: first. the need for operator understanding of the concept of criticality and of the importance of the particular criticality controls for the process at hand: second, the importance of care and thoroughness in determining credible abnormal conditions for analysis; and third, the importance of having considered responses to unplanned conditions.

- Operations personnel should be trained in the importance of not taking unapproved actions after an initial evacuation. Reentry, except perhaps in lifesaving situations, should be undertaken only after the accident evolution has been technically evaluated, thoroughly understood, and planned actions have been approved. During one accident. unapproved reentry into the accident site and without adequate understanding of the criticality hazard. followed by impulsive actions, led to a loss of life. In a second accident, significant exposures occurred from an ineffective and ill considered reentry and only chance prevented a fatality.

- Readouts of radiation levels in areas where accidents may occur should be considered. Knowledge of radiation levels in evacuated areas has proved valuable in planning recovery actions. Many of the accidents involved power histories that extended from minutes to many hours. In two cases, the accident termination process involved hands on intervention at times of expected minimal exposures. The successes of these interventions were based on detailed knowledge and understanding of the excursion history and its expected behavior.

- Operations involving both organic and aqueous solutions require extra diligence in understanding possible upset conditions if mixing of the phases is credible. Obscure process conditions and unplanned chemistry have led to at least four accidents.

- Operations personnel should be made aware of criticality hazards and be empowered to implement a stop work policy. This awareness should come from a mix of formal and informal training. These include classroom, on-the-job from immediate supervision, and discussions with criticality staff. Lack of understanding of criticality hazards has contributed to several accidents and to exacerbated consequences.

- Operating personnel should be trained to understand the basis for and to adhere to the requirement for always following procedures. Lack of adherence to available procedures, either inadvertently or knowingly, has been a major contributor to several accidents.

- Hardware that is important to criticality control but whose failure or malfunction would not necessarily be apparent to operations personnel, should be used with caution. Operational oversights such as failure to actuate valves per requirements have led to accidents. Duplicate hardware: controls, strict procedural controls with multiple checks on operator actions, and diligent maintenance may be appropriate.

- Criticality alarms and adherence to emergency procedures have saved lives and reduced exposures. Most of the 22 accidents involved excursions that were not terminated after a single burst. Prompt detection and immediate evacuation of personnel within several meters of the accident have been significant in saving lives and limiting exposures.

\section{Lessons of Supervisory, Managerial, and Regulatory Importance}

- Process supervisors should ensure that the operators under their supervision are knowledgeable and capable. Several accidents could have been avoided or the consequences lessened had supervisors been more aware of the routine actions of operators in performing their tasks. It is one thing to have written procedures that are intended to be followed in order to provide for safe operations. It is another that these procedures are understood and being followed as intended. Supervisors might ask themselves periodically, "When was the last time I saw the job being performed properly?"

- Equipment should be designed and configured with ease of operation as a key goal. More than one accident, including the accident in Japan might have been avoided if operators had been provided user-friendly equipment.

- Policies and regulations should encourage selfreporting of process upsets and to err on the side of learning more, not punishing more. At least one accident and attendant fatality were caused by a supervisor's excessive concern for bringing a process back within required limits before it was discovered by management. Improvised operations were performed without accompanying awareness of the criticality hazards. 
- Senior management should be aware of the hazard of accidental criticality and its consequences. Difficult cost-risk-benefit decisions must be made by upper management. There will always be issues of production quotas and timetables, which management must balance against acceptable levels of risk acceptance. Most of the accidents occurred during the peak years of the Cold War, when high production levels were perceived to be of utmost importance. Nevertheless, senior management apparently learned from these accidents and allocated resources for criticality control. The three major expenditures were for criticality specialists dedicated to the support of process operations, favorable geometry and poisoned vessels, in spite of their cost and production drawbacks, and the generation of additional critical mass data. It should be noted that before the first criticality accident in the R.F., nearly all process vessels were of unfavorable geometry in order to maximize production; by 1968 more than $95 \%$ of them had been replaced with favorable geometry vessels.

- Regulations should exist which promote safe and efficient operations. Those who worked in the critical experiment facilities were directly aware of the risks associated with criticality accidents. Some of these people also recognized the need for formal safety guidance to be made available to those who operated process facilities. Accordingly, they, together with process experts, spontaneously set out to develop and document criticality safety guidance for process operations. In the U.S., technical guidance and administrative good practices were codified in a series of documents entitled Nuclear Safety Guide, beginning with the 1957 edition. ${ }^{36}$ Many of these same people then became involved in the development of American national standards and then international standards. Similar actions developed in parallel in other countries, both those that had experienced criticality accidents and those that had managed to work with fissile materials without accidents. The marked decrease in the accident rate by the late 1960 s was probably due to a combina- tion of adherence to these newly codified regulations and guidance and upper management attention to this new hazard.

- Regulators, like process supervisors, should ensure that those they regulate are knowledgeable and capable. While the responsibility for accident prevention must rest first and foremost with those directly in charge of the work, regulatory authorities have a distinct role to play. Similar to the process supervisor, the regulator should also ask questions such as: "When was the last time that I saw the job being performed properly?" and "When was the last time I talked to the process supervisors and became assured that they understood the operations under their control and exhibited a safety conscious behavior and attitude?" At the time of the Wood River Junction accident, 131 days after plant startup, there still had not been a visit by the regulatory authorities. At the time of the 1997 accident, regulatory authorities were not aware of changed criticality limits of the operation even though the change had been made 13 years before.

\section{Conclusions}

Criticality accident risks will not vanish as long as significant quantities of fissile materials exist. However, sufficient knowledge has been gained from planned experiments and from accidents to provide a high degree of confidence that, with appropriate support from senior management, reasonable diligence on the part of criticality staff and operating personnel, and continued adherence to codified fundamental safety principles and guidance, accident likelihoods can be maintained at the current low level or possibly be reduced even further. This will require continued education of future personnel at all levels-regulatory, upper management, supervisory, criticality staff, and operations - on the lessons of the past so that similar accidents will not be repeated.

The following statement, while woven throughout the preceding text is considered worthy of being repeated: All accidents have been dominated by design, managerial, and operational failures. The focus for accident prevention should be on these issues. 


\section{REACTOR AND CRITICAL EXPERIMENT ACCIDENTS}

This section brings out errors that should be avoided in the conduct of reactor experiments and critical experiments. Because criticality is expected, lessons learned from this section do not contribute directly to the discipline of process criticality safety. Of the 38 accidents studied. 5 occurred in what must be categorized as working reactors (the water boiler, Godiva, Dragon. SL-1. and NRX) and 33 occurred in critical facilities where the properties of the assemblies themselves were being investigated.

The major change to Part II of this second revision is the inclusion of six accidents that occurred in the Russian Federation. Four of these involved small uranium or plutonium metal assemblies: two occurred with assemblies involving reactor core mockups.
One minor change in this section is the deletion of what was listed in the prior editions as $I I-D .2$ The U.S.S.R, 1953 or 1954. Based on research of the listed reference and discussions with Russian experts, it has been concluded that the reference was not to a reactor accident but to some other source of personnel radiation exposure.

Some of the reactor and critical experiment accident data are summarized in Table 11 . Where possible and appropriate, the excursion fission energy is divided into that which was created in the spike and that which was in the plateau. For some excursions, almost all fissions were in the plateau; others consisted only of a single spike.

\begin{tabular}{|c|c|c|c|c|c|c|}
\hline Event & Date & Location & Material & Geometry & Damage & $\begin{array}{l}\text { Total } \\
\text { Fissions }\end{array}$ \\
\hline \multicolumn{7}{|c|}{ II-A FISSILE SOLUTION SYSTEMS } \\
\hline 1 & $12-49$ & Los Alamos, NM & $\begin{array}{l}\sim 1 \mathrm{~kg}{ }^{235} \mathrm{U} \text { as uranyl } \\
\text { nitrate }\end{array}$ & $\begin{array}{l}\text { Sphere, graphite } \\
\text { reflected }\end{array}$ & None & $\sim 3 \times 10^{16}$ \\
\hline 2 & $16-11-51$ & Richland, WA & $1.15 \mathrm{~kg} \mathrm{Pu}$ as nitrate & $\begin{array}{l}\text { Bare sphere, } 93 \% \\
\text { filled }\end{array}$ & None & $8 \times 10^{16}$ \\
\hline 3 & $26-05-54$ & Oak Ridge, TN & $\begin{array}{l}18.3 \mathrm{~kg}{ }^{235} \mathrm{U} \text { as uranyl } \\
\text { flouride }\end{array}$ & $\begin{array}{l}\text { Cylindrical } \\
\text { annulus, bare }\end{array}$ & None & $1 \times 10^{17}$ \\
\hline 4 & $01-12-56$ & Oak Ridge, TN & $\begin{array}{l}27.7 \mathrm{~kg}{ }^{235} \mathrm{U} \text { as uranyl } \\
\text { flouride }\end{array}$ & Cylindrical bare & Minor & $1.6 \times 10^{17}$ \\
\hline 5 & $30-01-68$ & Oak Ridge, TN & $0.95 \mathrm{~kg}{ }^{233} \mathrm{U}$ as nitrate & $\begin{array}{l}\text { Sphere, water } \\
\text { reflected }\end{array}$ & $\begin{array}{l}\text { Local } \\
\text { contamination }\end{array}$ & $1.1 \times 10^{16}$ \\
\hline \multicolumn{7}{|c|}{ II-B BARE AND REFLECTED METAL SYSTEMS } \\
\hline 1 & $21-08-45$ & Los Alamos, NM & $6.2 \mathrm{~kg} \delta$-phase Pu & $\begin{array}{l}\text { Sphere with WC } \\
\text { reflector }\end{array}$ & $\begin{array}{l}\text { None (one } \\
\text { fatality) }\end{array}$ & $\sim 1 \times 10^{16}$ \\
\hline 2 & $21-05-46$ & Los Alamos, NM & $6.2 \mathrm{~kg} \delta$-phase $\mathrm{Pu}$ & $\begin{array}{l}\text { Sphere with Be } \\
\text { reflector }\end{array}$ & $\begin{array}{l}\text { None (one } \\
\text { fatality) }\end{array}$ & $\sim 3 \times 10^{15}$ \\
\hline 3 & $1-02-5 I$ & Los Alamos, NM & $62.9 \mathrm{~kg} \mathrm{U}(93)$ metal & $\begin{array}{l}\text { Cylinder and } \\
\text { annulus in water }\end{array}$ & Minor & $\sim 1 \times 10^{17}$ \\
\hline 4 & $18-04-52$ & Los Alamos, NM & $92.4 \mathrm{~kg} \mathrm{U}(93)$ metal & $\begin{array}{l}\text { Cylinder, } \\
\text { unreflected }\end{array}$ & None & $1.5 \times 10^{16}$ \\
\hline 5 & $9-04-53$ & Sarov, R.F. & $\sim 8 \mathrm{~kg} \delta$-phase $\mathrm{Pu}$ & $\begin{array}{l}\text { Sphere with } \\
\text { natural U reflector }\end{array}$ & $\begin{array}{l}\text { Major core } \\
\text { damage }\end{array}$ & $\sim 1 \times 10^{16}$ \\
\hline 6 & $3-02-54$ & Los Alamos, NM & $53 \mathrm{~kg} \mathrm{U}(93)$ metal & $\begin{array}{l}\text { Sphere, } \\
\text { unreflected }\end{array}$ & Minor & $5.6 \times 10^{16}$ \\
\hline 7 & $12-02-57$ & Los Alamos, NM & $54 \mathrm{~kg} \mathrm{U}(93)$ metal & $\begin{array}{l}\text { Sphere, } \\
\text { unreflected }\end{array}$ & Severe & $1.2 \times 10^{17}$ \\
\hline 8 & $17-06-60$ & Los Alamos, NM & $\sim 51 \mathrm{~kg} \mathrm{U}(93)$ metal & $\begin{array}{l}\text { Cylinder with } \mathrm{C} \\
\text { reflector }\end{array}$ & Minor & $6 \times 10^{16}$ \\
\hline 9 & $10-11-61$ & Oak Ridge, TN & $\sim 75 \mathrm{~kg} \mathrm{U}(93)$ metal & Paraffin reflected & None & $\sim 1 \times 10^{16}$ \\
\hline
\end{tabular}




\begin{tabular}{|c|c|c|c|c|c|c|}
\hline Event & Date & Location & Material & Geometry & Damage & $\begin{array}{c}\text { Total } \\
\text { Fissions } \\
\end{array}$ \\
\hline 10 & $11-03-63$ & Sarov, R.F. & $\sim 17.35 \mathrm{~kg} \delta$-phase $\mathrm{Pu}$ & $\begin{array}{l}\text { Sphere with } \mathrm{LiD} \\
\text { reflector }\end{array}$ & None & $\sim 5 \times 10^{15}$ \\
\hline 11 & $26-03-63$ & Livermore, $\mathrm{CA}$ & $47 \mathrm{~kg} \mathrm{U}(93)$ metal & $\begin{array}{l}\text { Cylinder with } \mathrm{Be} \\
\text { reflector }\end{array}$ & Severe & $3.7 \times 10^{17}$ \\
\hline 12 & $28-05-65$ & White Sands, NM & $96 \mathrm{~kg} \mathrm{U}(93)-\mathrm{Mo}$ alloy & $\begin{array}{l}\text { Cylinder, } \\
\text { unreflected }\end{array}$ & Minor & $1.5 \times 10^{17}$ \\
\hline 13 & $5-04-68$ & Chelyabinsk-70, R.F. & $47.7 \mathrm{~kg} \mathrm{U}(90)$ metal & $\begin{array}{l}\text { Sphere with } \\
\text { natural U reflector }\end{array}$ & $\begin{array}{l}\text { None (two } \\
\text { fatalities) }\end{array}$ & $6 \times 10^{16}$ \\
\hline 14 & $6-09-68$ & Aberdeen, MD & $123 \mathrm{~kg} \mathrm{U}(93)-$ Mo alloy & $\begin{array}{l}\text { Cylinder, } \\
\text { unreflected }\end{array}$ & Severe & $6.09 \times 10^{17}$ \\
\hline 15 & $17-06-97$ & Sarov, R.F. & $\sim 44 \mathrm{~kg} \mathrm{U}(90)$ & $\begin{array}{l}\text { Sphere with } \\
\text { copper reflector }\end{array}$ & $\begin{array}{l}\text { None (one } \\
\text { fatality) }\end{array}$ & $\begin{array}{l}\sim 2 \times 10^{17} \text { in one } \\
\text { burst (total } \sim 10^{19}\end{array}$ \\
\hline \multicolumn{7}{|c|}{ II-C MODERATED METAL AND OXIDE SYSTEMS } \\
\hline 1 & $6-06-45$ & Los Alamos, NM & $\begin{array}{l}35.4 \mathrm{~kg} \mathrm{U}(79.2) \text { as } \\
1 / 2 \text {-inch cubes }\end{array}$ & $\begin{array}{l}\text { Water reflected } \\
\text { pseudosphere }\end{array}$ & Minor & $-4 \times 10^{16}$ \\
\hline 2 & $\sim 1950$ & $\begin{array}{l}\text { Chalk River, } \\
\text { Ontario, Canada }\end{array}$ & $\begin{array}{l}\text { Aluminum-clad natural } \\
\text { uranium }\end{array}$ & $\begin{array}{l}\text { Rods in heavy } \\
\text { water moderator }\end{array}$ & Minor & Unknown \\
\hline 3 & $2-06-52$ & $\begin{array}{l}\text { Argonne National } \\
\text { Lab, IL }\end{array}$ & U(93) oxide in plastic & $\begin{array}{l}\text { Fuel elements in } \\
\text { water moderator }\end{array}$ & Severe & $1.22 \times 10^{17}$ \\
\hline 4 & $12-12-52$ & $\begin{array}{l}\text { Chalk River, } \\
\text { Ontario, Canada }\end{array}$ & $\begin{array}{l}\text { Natural uranium fuel } \\
\text { rods }\end{array}$ & $\begin{array}{l}\text { Heavy water } \\
\text { moderated reactor }\end{array}$ & Severe & $1.20 \times 10^{20}$ \\
\hline 5 & $22-07-54$ & $\begin{array}{l}\text { National Reactor } \\
\text { Testing Station, ID }\end{array}$ & $\begin{array}{l}4.16 \mathrm{~kg} \mathrm{U}(93) \text { as } \mathrm{U} / \mathrm{Al} \\
\text { alloy. }\end{array}$ & $\begin{array}{l}\text { Fuel/elements in } \\
\text { water moderator }\end{array}$ & Severe & $4.68 \times 10^{18}$ \\
\hline 6 & $15-10-58$ & Vinca, Yugoslavia & Natural uranium rods & $\begin{array}{l}\text { Fuel rods in heavy } \\
\text { water }\end{array}$ & $\begin{array}{l}\text { None (one } \\
\text { fatality) }\end{array}$ & $\sim 2.6 \times 10^{18}$ \\
\hline 7 & $15-03-60$ & Saclay, France & 2.2 tons $U(1.5)$ as oxide & Fuel rods in water & None & $3 \times 10^{18}$ \\
\hline 8 & $3-01-61$ & $\begin{array}{l}\text { Idaho Reactor } \\
\text { Testing Area, ID }\end{array}$ & $\mathrm{U}(93)$ clad in aluminum & Fuel rods in water & $\begin{array}{l}\text { Severe } \\
\text { (three } \\
\text { fatalities) }\end{array}$ & $4.4 \times 10^{18}$ \\
\hline 9 & $5-11-62$ & $\begin{array}{l}\text { Idaho Reactor } \\
\text { Testing Area, ID }\end{array}$ & $\begin{array}{l}\text { U(93)/Al alloy plates, } \\
\text { Al clad }\end{array}$ & $\begin{array}{l}\text { Fuel elements in } \\
\text { water }\end{array}$ & Severe & $\sim 1 \times 10^{18}$ \\
\hline 10 & $30-12-65$ & Mol, Belgium & U(7) oxide & $\begin{array}{l}\text { Rods in water/ } \\
\text { heavy water }\end{array}$ & None & $\sim 4 \times 10^{17}$ \\
\hline 11 & $15-02-71$ & Kurchatov Institute & $\mathrm{U}(20) \mathrm{O}_{2}$ fuel rods & Be reflected & None & $2 \times 10^{19}$ \\
\hline 12 & $26-05-71$ & Kurchatov Institute & $\mathrm{U}(90) \mathrm{O}_{2}$ fuel rods & Water reflected & $\begin{array}{l}\text { None (two } \\
\text { fatalities) }\end{array}$ & $2 \times 10^{18}$ \\
\hline 13 & $23-09-83$ & $\begin{array}{l}\text { Buenos Aires, } \\
\text { Argentina }\end{array}$ & MTR type fuel elements & Pool type reactor & $\begin{array}{l}\text { None (one } \\
\text { fatality) }\end{array}$ & $\sim 4 \times 10^{17}$ \\
\hline \multicolumn{7}{|c|}{ II-D MISCELLANEOUS SYSTEMS } \\
\hline 1 & $11-02-45$ & Los Alamos, NM & $\begin{array}{l}\text { Uranium hydride in } \\
\text { styrex }\end{array}$ & $\begin{array}{l}\text { The Dragon } \\
\text { assembly }\end{array}$ & Minor & $\sim 6 \times 10^{15}$ \\
\hline 2 & $29-11-55$ & $\begin{array}{l}\text { Argonne National } \\
\text { Laboratory, ID }\end{array}$ & $\begin{array}{l}\text { Enriched uranium in } \\
\mathrm{NaK}\end{array}$ & EBR-1 & Severe & $\sim 4 \times 10^{17}$ \\
\hline 3 & $3-07-56$ & Los Alamos, NM & $\mathrm{U}(93)$ foils in graphite & Honeycomb & None & $3.2 \times 10^{16}$ \\
\hline 4 & $18-11-58$ & $\begin{array}{l}\text { Reactor Testing } \\
\text { Area, ID }\end{array}$ & $\begin{array}{l}\text { Uranium oxide in } \\
\text { nickel-chromium }\end{array}$ & $\begin{array}{l}\text { Aircraft engine } \\
\text { prototype }\end{array}$ & Minor & $2.5 \times 10^{19}$ \\
\hline 5 & $11-12-62$ & Los Alamos, NM & $\begin{array}{l}\text { Large U(93) graphite } \\
\text { cylinder }\end{array}$ & $\begin{array}{l}\text { Cylinder plus } \\
\text { annular reflector }\end{array}$ & None & $\sim 3 \times 10^{16}$ \\
\hline
\end{tabular}




\section{A. FISSILE SOLUTION SYSTEMS}

\section{Los Alamos Scientific Laboratory, December $1949^{37,38}$}

Water boiler reactor; control rods removed by hand; single excursion; insignificant exposure.

This accident occurred when two new control rods (poisons) were being tested in the water boiler reactor. The water boiler was a 12 inch diameter stainless steel spherecontaining $13.6 \%$ of uranyl nitrate. In 1949 it was reflected by thick graphite.

The rods had been installed, and the operator was manually checking their drop times. After several tests of each individual rod (a safe procedure since one rod was sufficient to maintain subcriticality) both rods were pulled, held for about 5 seconds, and then dropped simultaneously. A short time later the rods were again pulled and dropped together.
The removal of the two rods increased the reactivity to about 3 cents over prompt criticality, corresponding to a period of 0.16 seconds. The power probably rose with this period to a very broad peak of 2 or $3 \times 10^{16}$ fissions/s and remained close to this value for about 1.5 seconds. The excursion was not immediately detected because all the instruments were turned off except for a direct reading thermometer that showed a temperature rise of $25^{\circ} \mathrm{C}$, equivalent to a yield of 3 or $4 \times 10^{16}$ fissions.

The operator received a $2.5 \mathrm{rad}$ dose. The reactor was not damaged.

\section{Hanford Works, 16 November $1951^{39}$}

Plutonium solution assembly; cadmium rod removed too rapidly; single excursion; insignificant exposures.

The critical assembly in which the excursion occurred was an aqueous solution of $1.15 \mathrm{~kg}$ of plutonium in the form of plutonium nitrate contained in an unreflected 20 inch diameter aluminum sphere. The purpose of the experimental program was to determine the critical mass of plutonium for various container geometries and solution concentrations. The excursion occurred during the approach to criticality, when the sphere was $93 \%$ full, as a result of withdrawing a remotely controlled, hollow cadmium safety rod in a series of steps with insufficient time between steps. The excursion yield was $8 \times 10^{16}$ fissions, and a small amount of fuel was forced through gaskets at the top of the reactor assembly. Because the gaskets sealed about 18 of air above the fuel level before the accident, pressures considerably in excess of atmospheric must have existed in the assembly during the accident.
The published data suggest that the reactivity insertion rate resulting from the safety rod withdrawal must have been about $4.7 \$ / \mathrm{s}$, which would lead to a fission yield of about twice the observed value if known temperatures and void coefficients of reactivity are used. In this case, however, the action of the scram circuit was sufficiently fast that the cadmium rod most probably contributed to the shutdown of the excursion. A slight reduction in the assumed reactivity insertion rate would lengthen the time, making it even more certain that the excursion was stopped by the falling poison rod.

No personnel were injured in this excursion, although plutonium nitrate solution contaminated the experimental area. The building was successfully decontaminated in a few days, but before cleanup of the test area was completed, a fire occurred and the building was abandoned. 


\section{Oak Ridge National Laboratory, 26 May $1954^{40}$}

Uranium solution assembly, central poison cylinder tilted from proper position; single excursion; insignificant exposures.

The experiment was one of a series in which the critical properties of aqueous solutions in annular cylindrical containers were being investigated. The outer cylinder had a diameter of 10 inches; a cadmium clad inner cylinder was 2 inches in diameter. The system was unreflected and consisted of $55.4 \ell$ water solution of $\mathrm{UO}_{2} \mathrm{~F}_{2}$ solution that contained $18.3 \mathrm{~kg}$ of highly enriched uranium $\left(93 \%{ }^{235} \mathrm{U}\right)$. The excursion occurred while the liquid level was at 40 inches and more solution was being added slowly to approach a delayed critical configuration. The experimental situation before and after the accident is illustrated in Figure 40 . The inner cylinder was essentially a poison rod. When it became detached from its connection at the top and tipped to the side of the outer container, it fell to a less effective position, thus allowing the system reactivity to rise well over prompt criticality and causing a power excursion of $10^{17}$ fissions.

The reconstruction of this accident was most thorough. The tilting of the inner cylinder added reactivity to the system at a rate corresponding to
$3.33 \$ / \mathrm{s}$, which continued well into the prompt critical region. Using known coefficients and generation times, an initial power spike of $5.1 \times 10^{16}$ fissions can be calculated. Since development of the power spike would require only about 0.07 seconds after the system reached prompt criticality $(0.43$ seconds after the cylinder began to tip), the cylinder was still tilting. It is characteristic of such accidents that after an initial spike, the power balances the reactivity insertion rate. For this solution, the required power was a few megawatts, and it must have been fairly constant until the inner cylinder reached its maximum displacement 0.91 seconds after inception of the transient. At this time, the power dropped sharply and when the liquid began to drain, the system became far subcritical.

Because of thick shielding, no one received a radiation dose greater than $0.9 \mathrm{rem}$. Only a few tens of cubic centimeters of solution were displaced from the cylinder; the area was returned to normal experimental use in three days.

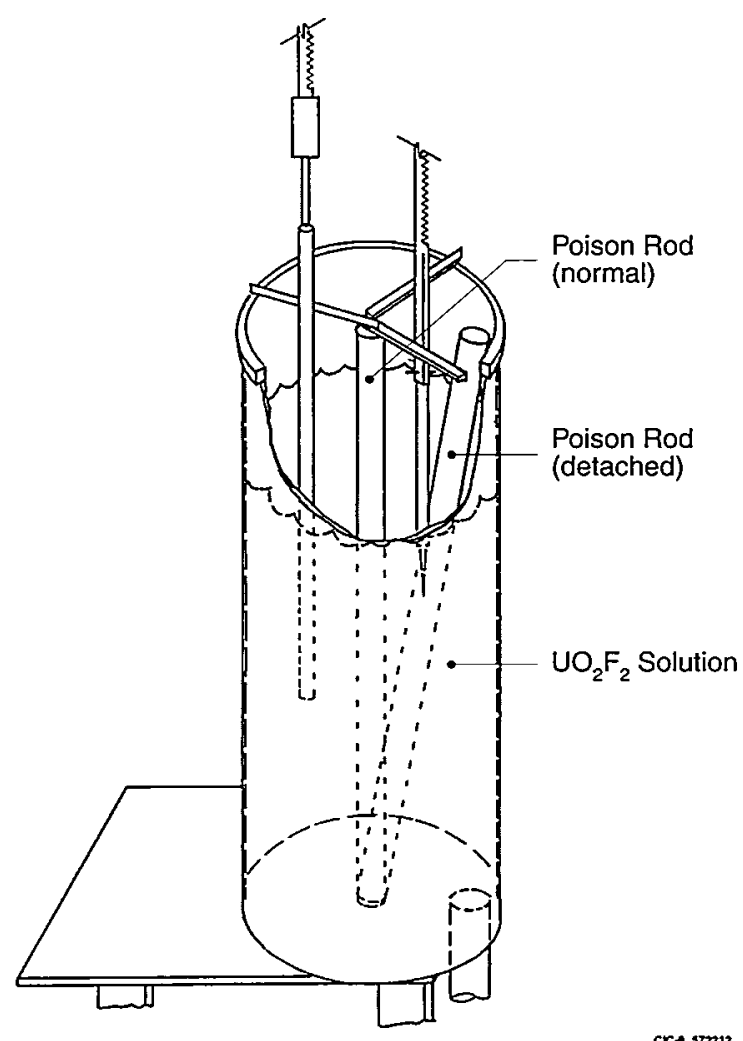

Figure 40. The Oak Ridge National Laboratory uranium solution assembly showing the normal and detached positions of the central poison rod. 


\section{Oak Ridge National Laboratory, 1 February $1956^{40}$}

Uranium solution assembly; wave motion created by falling cadmium sheet; single excursion; insignificant exposures.

In this experiment, certain reactor parameters were being investigated by measuring stable reactor periods. The system was a cylindrical tank $(0.76 \mathrm{~m}$ in diameter $)$ filled to a depth of $130 \mathrm{~mm}$ with $58.9 /$ of $\mathrm{UO}_{2} \mathrm{~F}_{2}$ solution containing $27.7 \mathrm{~kg}$ of ${ }^{235} \mathrm{U}$. Transfer of solution from storage to the test cylinder was achieved by applying air pressure to the storage vessel; flow was controlled by a remotely operated valve in a one-half inch diameter line. With the control switch in the "feed" position, the valve was open and air pressure was applied; with the switch in the "drain" position, the valve was also open, but the air supply was turned off and the storage vessels were vented to the atmosphere. When the switch was in the intermediate "neutral" position, the valve was closed and the storage vessels were vented.

The situation was one in which the solution volume was about $100 \mathrm{~m} /$ less than the critical volume. An increment of solution was added, and the transient period decreased rapidly to approximately 30 seconds, where it seemed to remain constant. Shortly thereafter the fuel control switch was placed in the drain position and the period meter indicated a rapid decrease in period so that the safety devices were actuated almost simultaneously by both manual and instrument signal; the instrument trip point had been set at a 10 second period. Immediately thereafter the excursion occurred. The yield was $1.6 \times 10^{17}$ fissions and, in this case, a considerable volume of solution was forcibly ejected from the cylinder. Post excursion tests showed that if insufficient time were allowed for venting the operating pressure, addition of solution to the reactor could have continued for several seconds after the control switch was placed in the drain position. This addition of solution accounted for the decrease in period that precipitated the scram, but the increment of solution could not have added enough reactivity to account for the excursion.

The reactivity of such shallow, large diameter assemblies is very sensitive to the solution depth but quite insensitive to changes in the diameter. For this system, the estimated difference between delayed criticality and prompt criticality is only $1 \mathrm{~mm}$ of depth. If the effective diameter were reduced to $0.50 \mathrm{~m}$, the depth would have to be increased only $12 \mathrm{~mm}$ to maintain delayed criticality. It is thought that the falling scram, a cadmium sheet slightly deformed at the bottom, set up a wave system that must have converged at least once and created a superprompt critical geometry.

In this case, the analysis was directed to finding what reactivity insertion rate would cause a power spike of the required yield. The analysis was then examined to see if it contradicted any known facts. It was found that a rate of $94 \$ / \mathrm{s}$ was adequate to cause a spike of $8 \mathrm{~ms}$ duration, which would account for the observed yield. The maximum excess reactivity would be about $2 \$$ over prompt criticality; the void volume could be 12 times that of the Oak Ridge National Laboratory 26 May 1954 accident (II-A. 3), thus easily accounting for the splashing of the solution. The void volume that results as microbubbles (caused by disassociation of water by fission fragments) coalesce is discussed in Power Excursions and Quenching Mechanisnis.

A laborious chemical decontamination of the assembly room was required to clean up the ejected solution. Slight mechanical damage was evidenced by distortion of the bottom of the cylinder. The largest radiation dose received was $0.6 \mathrm{rem}$. 


\section{Oak Ridge National Laboratory, 30 January $1968^{41}$}

${ }^{233} U$ solution assembly; reactivity added by air bubble movement; single excursion; insignificant exposures.

Routine critical experiments were underway to determine the critical concentration of an aqueous solution of uranyl nitrate in a thin aluminum sphere (5.84 $\ell$ volume) with a thick water reflector. The uranium contained $97.6 \%{ }^{233} \mathrm{U}$ at a concentration of $167 \mathrm{~g} / \ell$. The solution density was $1.23 \mathrm{~kg} / \ell$.

The solution height in the sphere could be adjusted through the vertical motion of an external $55 \mathrm{~mm}$ diameter cylindrical tank. This adjustment tank was connected to the sphere by a $13 \mathrm{~mm}$ diameter flexible line. The system had achieved criticality, and measurements were being taken to determine incremental reactivity values. Lowering of the adjustment tank did not provide the expected reduction in reactivity. An air bubble was visually observed in the line connecting the adjustment tank to the sphere. In an attempt to remove the bubble, enough solution was drained to the supply reservoir to achieve subcriticality. The adjustment tank was then moved up and down in an effort to dislodge the bubble. The motion was repeated at least twice. At a time when no adjustments were knowingly being made, the reactivity increased rapidly, all shutdown devices functioned, and the radiation alarm sounded.

It is assumed that motion of the air bubble caused the addition of enough solution to the sphere to change the system from subcritical to essentially prompt critical. The yield of the excursion was determined to have been $1.1 \times 10^{16}$ fissions. Approximately $90 \mathrm{~m} \ell$ of solution was expelled from the tank into the water reflector and onto the nearby floor and equipment. The modest cleanup required was accomplished promptly.

Simple modification of the experimental configuration precluded future introductions of air bubbles. 


\section{B. BARE AND REFLECTED METAL ASSEMBLIES}

\section{Los Alamos Scientific Laboratory, 21 August $1945^{37,44}$}

Plutonium core reflected with tungsten carbide; single excursion; one fatality, one significant exposure.

\section{Los Alamos Scientific Laboratory, 21 May $1946^{37,44}$}

Plutonium core reflected with beryllium; one fatality, seven significant exposures.

Two accidental excursions occurred with the same core and were, in several respects, quite similar. The core consisted of two hemispheres of $\delta$-phase plutonium coated with 5 mils of nickel. The total core mass was $6.2 \mathrm{~kg}$; the density was about $15.7 \mathrm{~g} / \mathrm{cm}^{3}$.
In the first accident, a critical assembly was being created by hand stacking $4.4 \mathrm{~kg}$ tungsten carbide bricks around the plutonium core. Figure 41 shows a reenactment ${ }^{*}$ of the configuration with about half of the tungsten blocks in place. The lone experimenter was moving the final brick over the assembly for a total

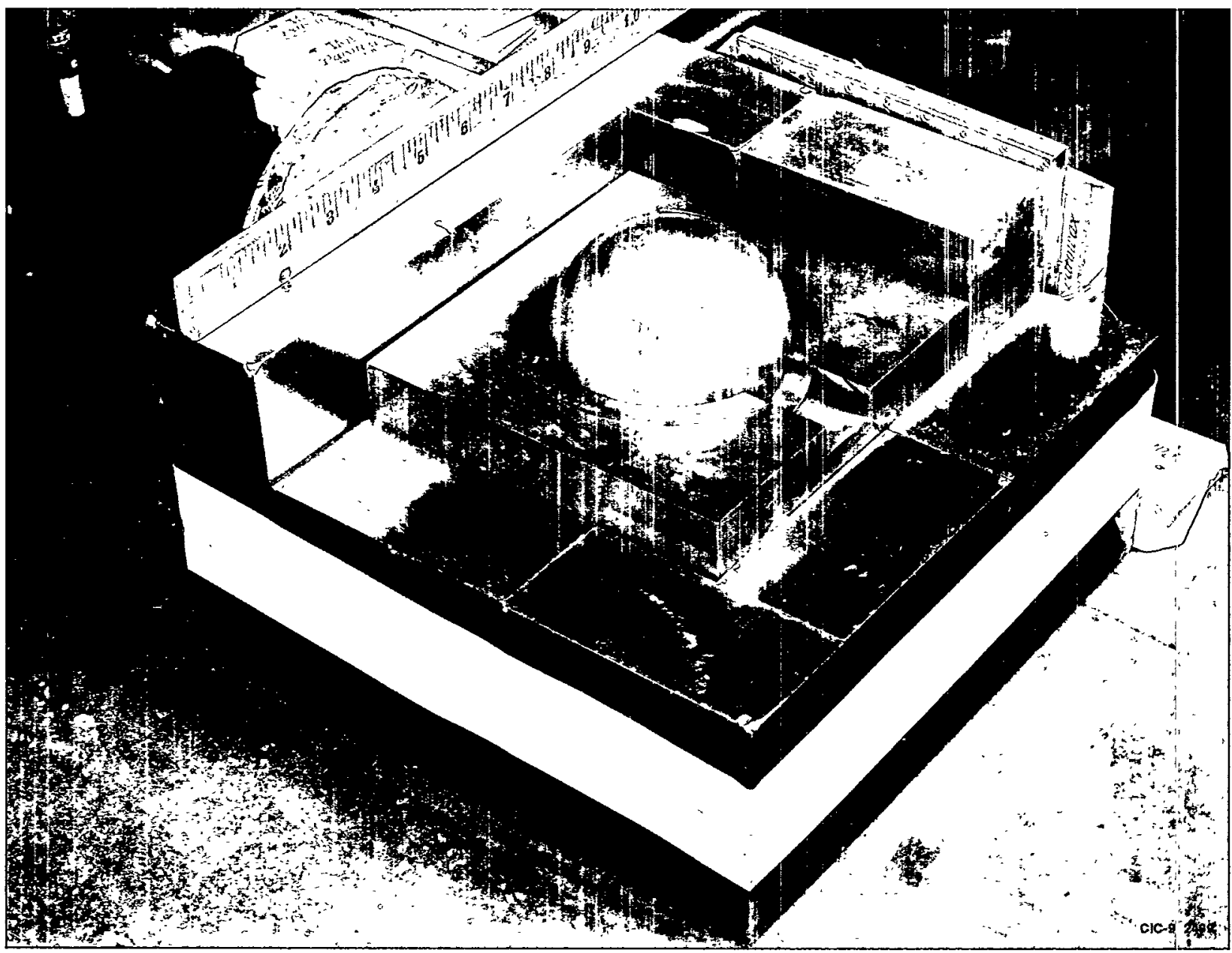

Figure 41. Plutonium sphere partially reflected by tungsten-carbide blocks.

*The Los Alamos National Laboratory archives include some data and comments about a rerun performed 2 October 1945 to determine the radiation dose received in the accident of 21 August 1945 . The yield of the rerun was about $6 \times 10^{15}$ fissions, but the prompt critical state was not reached. The maximum reactivity of the system during this experiment was about $60 \notin$ above delayed criticality. 
reflector of $236 \mathrm{~kg}$ when he noticed from the nearby neutron counters that the addition of this brick would make the assembly supercritical. As he withdrew his hand, the brick slipped and fell onto the center of the assembly, adding sufficient reflection to make the system superprompt critical. A power excursion occurred. He quickly pushed off the final brick and proceeded to unstack the assembly. His dose was estimated as 510 rem from a yield of $10^{16}$ fissions. He died 28 days later.

An Army guard assigned to the building, but not helping with the experiment, received a radiation dose of approximately $50 \mathrm{rem}$. The nickel canning on the plutonium core did not rupture.

In the second accident, the techniques involved in creating a metal critical assembly were being demonstrated to several people. The system consisted of the same plutonium sphere reflected, in this case, by beryllium. The top and final hemispherical beryllium shell was being slowly lowered into place; one edge was touching the lower beryllium hemisphere while the edge $180^{\circ}$ away was resting on the tip of a screwdriver
(Figure 42). The person conducting the demonstration was holding the top shell with his left thumb placed in an opening at the polar point.

The yield of this excursion was $3 \times 10^{15}$ fissions; again, there was no rupture of the nickel canning. The eight people in the room received doses of about 2100 , $360,250,160,110,65,47$, and $37 \mathrm{rem}$. The man who performed the experiment died nine days later.

The results of fission rate calculations in this sphere, as a function of time for several values of excess reactivity, are shown in Figure 43. Figure 44 represents the total number of fissions to be expected as a function of time for the same excess reactivities. These data are applicable to both accidents because the difference in reflector material has only a small effect on the neutron kinetics. In the first excursion, if the excess reactivity did not exceed $15 \notin$, the assembly must have been together for several seconds, which is not unreasonable. In the second event, the experimenter was better prepared to disassemble the material, and it is thought that this was done in a fraction of a second, perhaps $<1 / 2$ second. The known parameters would then be satisfied by an excess reactivity of about $10 \varnothing$.

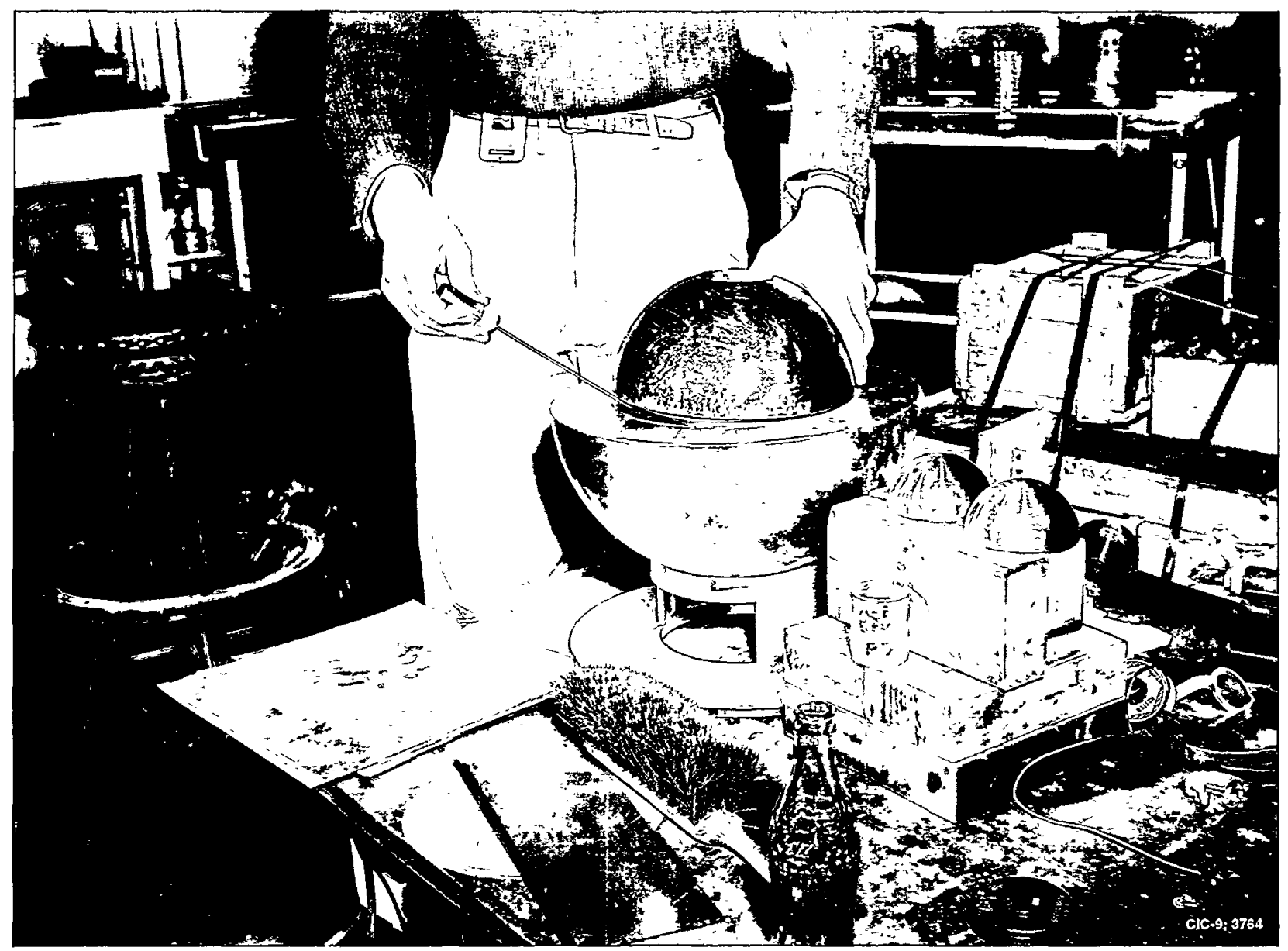

Figure 42. Configuration of beryllium reflector shells prior to the accident 21 May 1946. 


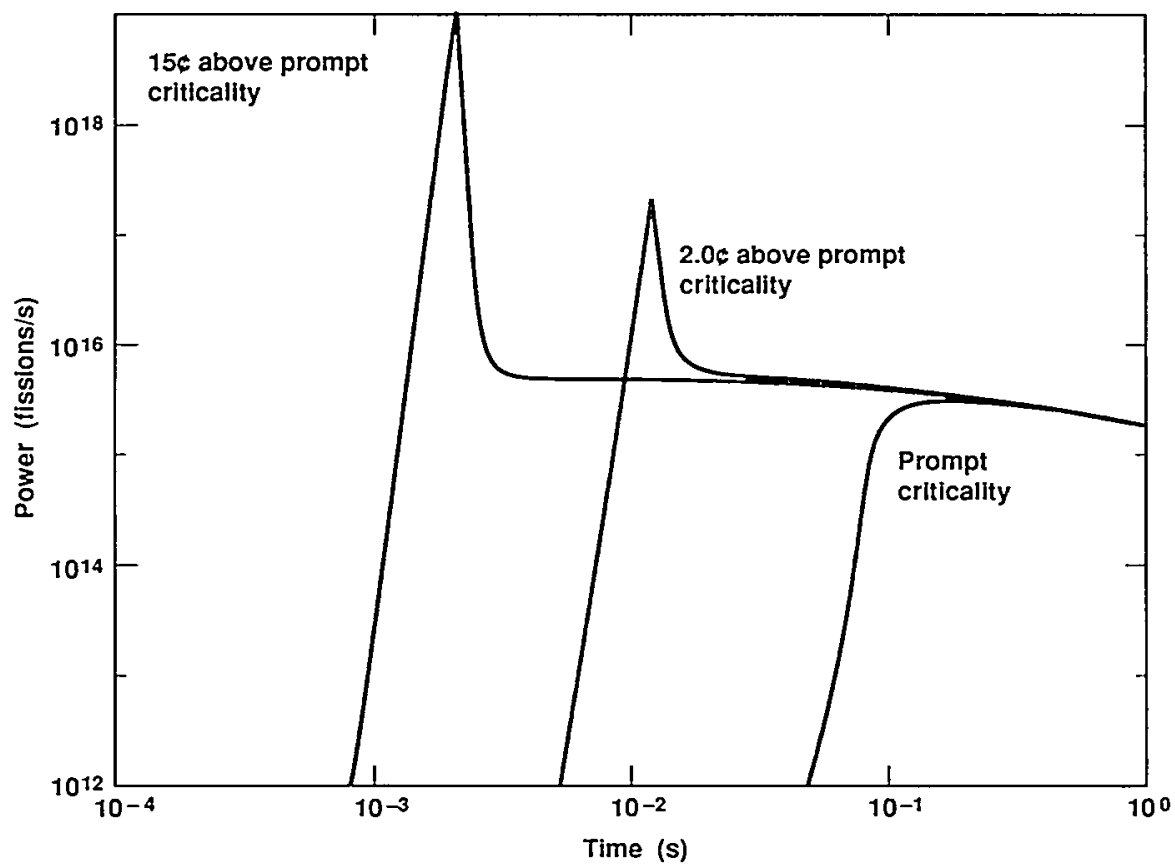

Figure 43. Calculated fission rate for the $6.2-\mathrm{kg}$ plutonium sphere.

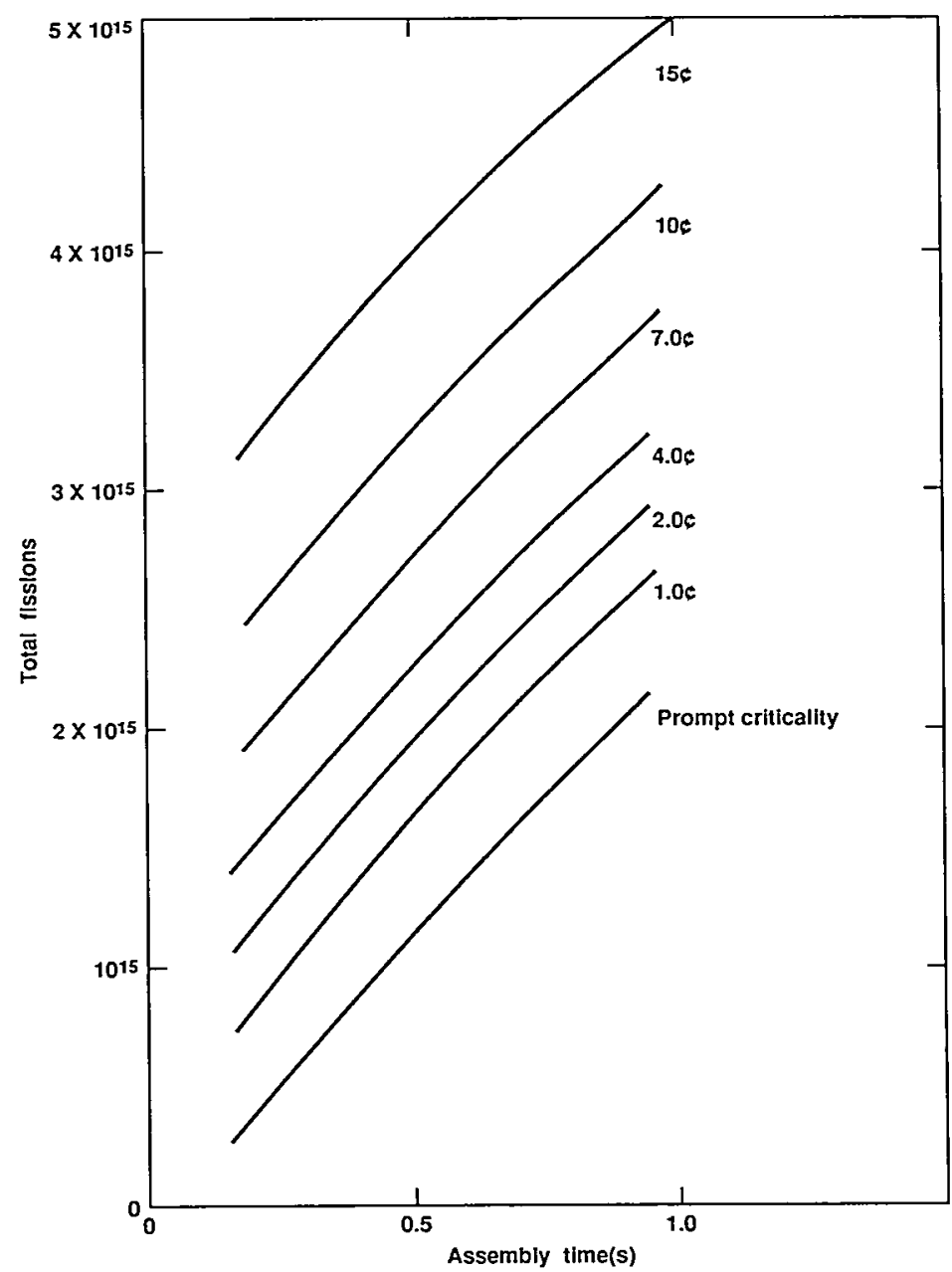

Figure 44. Calculated total fissions vs. time for the $6.2-\mathrm{kg}$ plutonium sphere. 


\section{Los Alamos Scientific Laboratory, 1 February $1951^{42,43,45}$}

Critical separation experiment, two large ${ }^{235} U$ metal masses in water; multiple excursions; insignificant exposures.

A water reflected system was set up in 1949 to obtain the neutron multiplication of a single unit of fissile metal in water. The system had two scram devices. The first, with a quick response, consisted of a pneumatic cylinder that raised the unit out of the water; the second, a slower device, was the draining of the tank. Later, a traveling support was added so that critical separation distances between two units could be determined; a dropping cadmium screen provided an additional scram (Figure 45).

The excursion was precipitated by an experiment that measured the critical separation distance of two enriched uranium masses (each of $93.5 \%{ }^{235} \mathrm{U}$ ) in water: one, a solid cylinder of $24.4 \mathrm{~kg}$ and the other, a hollow cylinder of $38.5 \mathrm{~kg}$. Sheet cadmium 10 mils thick was fastened to the outer surface of the solid cylinder and to the inside surface of the hollow cylinder. A paraffin slug filled the cavity in the hollow cylinder.

At the completion of the critical separation experiment (at a multiplication of 65.5), the assembly was scrammed. The water started draining, the cadmium screen dropped, the solid cylinder (left-hand body in Figure 45) was lifting, and an excursion (later deter- mined to be $10^{17}$ fissions) was made evident by the jamming of neutron counters and the appearance on television of a vapor cloud above the water.

Later reconstruction of the accident showed that the pneumatic tangential scram was the first to be effective and led directly to two types of difficulty. First, the center of reactivity of the left-hand cylinder (Figure 45) proved to be below that of the stationary cylinder; second, the rapid lift through the water created hydrodynamic forces that swung the cylinders closer together. The combination of the two effects was enough to drive the assembly prompt critical and to have maintained at least this much reactivity for 0.2 seconds if the power excursion had not occurred. The first power spike is estimated to have contained $6 \times 10^{15}$ fissions. It is possible that one or more excursions into the prompt region followed because boiling was the primary quenching mechanism.

In this excursion of $10^{17}$ fissions, no radiation doses were received, and no contamination was found in the experimental area. Damage to the uranium consisted of a small amount of oxide flaking and blistering. The experimental area was in use two days later.

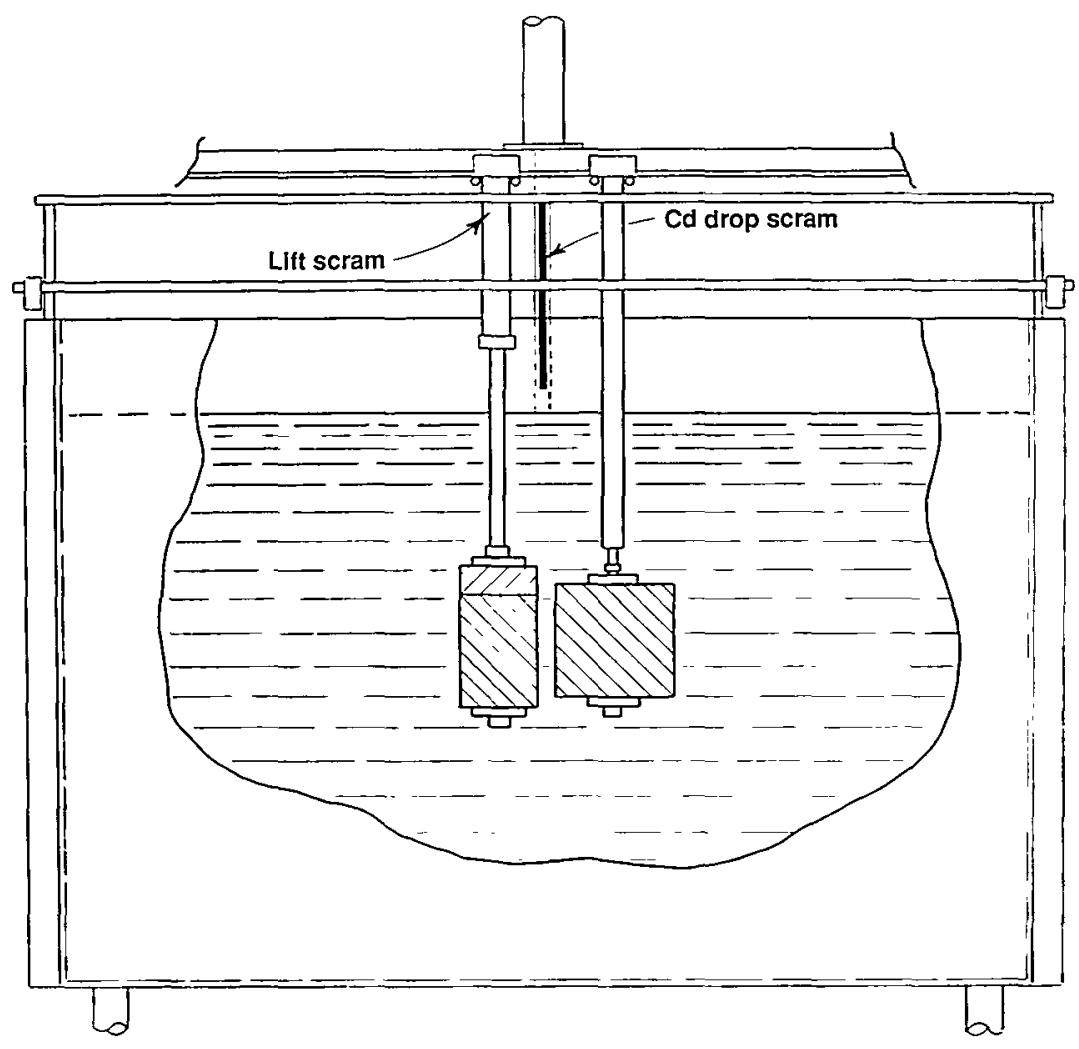

Figure 45. The Los Alamos Scientific Laboratory assembly machine employed for measurements of critical separation distances. 


\title{
4. Los Alamos Scientific Laboratory, 18 April $1952^{44,45}$
}

\author{
Jemima, cylindrical, unreflected ${ }^{2.35} U$ metal assembly; excursion history unknown; insignificant exposures.
}

The system in which the excursion took place was a cylindrical, unreflected, enriched $93 \%{ }^{235} \mathrm{U}$ metal assembly made up of a number of plates, each $267 \mathrm{~mm}$ in diameter and $8 \mathrm{~mm}$ thick.

Complete assembly of the two components had been made previously with six plates in the lower component, but with first three and then four plates in the upper component.

A plot of the reciprocal multiplication versus number of plates, or total uranium, shows clearly that the system should not have been assembled with 11 plates. Nevertheless, such an assembly was attempted following a computational error made independently by two people. Contrary to operating regulations. a graph of the data had not been plotted. The burst yield was $1.5 \times 10^{16}$ fissions.

There is no way to determine the power history experienced by the $92.4 \mathrm{~kg}$ mass without reproducing the experiment. At the time the system was near prompt criticality, the lower component was coasting upward and probably inserting no more than 2 or $3 \$ / \mathrm{s}$, a rate that could cause a power spike of about $10^{15}$ fissions. The power would then stabilize at about $10^{17}$ fissions/s, just enough to compensate for the reactivity insertion rate. Most of the $1.5 \times 10^{16}$ fissions must have occurred in this plateau. The power dropped essentially to zero when the automatic scram system separated the two masses of metal.

During the remotely controlled operation no damage was done to the system, even to the fissile material. None of the personnel received any radiation, and the experimental area was not contaminated. The apparent self terminating property of this excursion stimulated study with Lady Godiva, ${ }^{46,47,48}$ which became a facility for generating large bursts of fission spectrum neutrons in less than $100 \mu \mathrm{s}$.

\section{Sarov (Arzamas-16), 9 April $1953^{49}$}

Plutonium, natural uranium reflected, assembly; single excursion; insignificant exposures.

This accident occurred on 9 April 1953 as an experiment was being conducted on a critical assembly constructed on a vertical split table, FKBN (Figure 46). FKBN. designed and built in 1950, had a hydraulically driven vertical table as its main feature. It was not, however. equipped with a fast acting, gravity driven scram mechanism. FKBN located in Building B (Figure 47), was operated remotely from an adjacent control room.

The critical assembly involved in the accident had an $\sim 100 \mathrm{~mm}$ outside diameter plutonium core (about 8 $\mathrm{kg}$ mass) surrounded by a $300 \mathrm{~mm}$ outside diameter natural uranium reflector. The core was composed of four hemispherical shells (hemishells) of $\delta$-phase plutonium with a thin nickel coating. The core had a $28 \mathrm{~mm}$ diameter central cavity in which a neutron source $\left(\sim 10^{7} \mathrm{n} / \mathrm{s}\right)$ had been placed. The reflector was composed of six nesting hemishells that had a $26 \mathrm{~mm}$ diameter channel at their plane of separation.

The assembly being constructed was separated into two pieces (Figure 46):

1. the upper part on a fixed support consisted of a single natural uranium hemishell, with inner and outer diameters of $120 \mathrm{~mm}$ and $300 \mathrm{~mm}$, respectively; and

2. the lower part, constructed on the table, consisted of three lower natural uranium hemishells, the plutonium core, and two upper natural uranium hemishells.

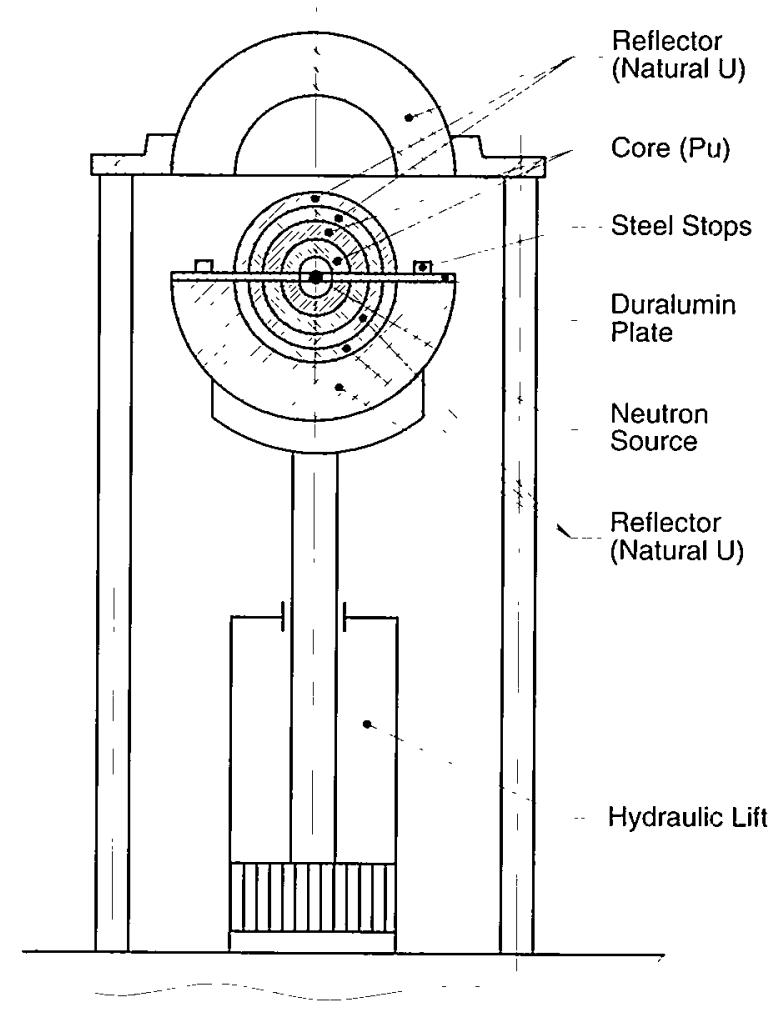

Figure 46. FKBN and assembly involved in the 9 April 1953 accident. 
At the equatorial plane, the two halves were separated by a $5 \mathrm{~mm}$ thick disk of duralumin that had a radial groove into which twenty-four, $80 \mathrm{mg}$ pellets of $\mathrm{U}_{3} \mathrm{O}_{8}\left(90 \%\right.$ enriched in ${ }^{235} \mathrm{U}$ ) were placed. The pellets were used to determine an integrated fission yield for the assembly.

Initially, the distance between the lower and upper parts was $200 \mathrm{~mm}$. The minimal distance the pieces could be brought together depended on the thickness of the steel stops manually installed by the operator. The stops were placed in a horizontal cut in the lower part of the assembly prior to beginning the closure (Figure 46). As the steel stops contacted the upper part of the assembly, the upward movement of the table would automatically cease. The operator would then measure the neutron flux and determine the corresponding state of subcriticality.

The accident on 9 April 1953 was due to an error made by an operator working alone in violation of regulations. The operator mistakenly installed $5 \mathrm{~mm}$ steel stops instead of the $10 \mathrm{~mm}$ required by the experimental plan. This caused an excursion as the assembly was brought together and resulted in a significant release of heat that melted a portion $(\sim 70 \mathrm{~g}$ mass) of the plutonium core. The plutonium flowed out into the horizontal channel in the natural uranium reflector.

The excursion activated an emergency alarm, at which time the operator pushed a button on the control panel and hydraulically lowered the table back down to its original position terminating the excursion. The accident occurred during lunch, when most of the experimental team ( 10 people) was out. About 2 hours afterwards, the experiment supervisor and the operator entered the FKBN experimental cell and performed a visual inspection, during which they received doses of $1.6 \mathrm{rad}$ and $1 \mathrm{rad}$, respectively.

Subsequent inspection of the assembly parts determined that three (of the four) plutonium hemishells had gotten so hot that they fused with the duraluminum disk. Therefore, that portion of the system was shipped to the Chelyabinsk-40 (Mayak) facility for further disassembly.

Analysis of the $\mathrm{U}_{3} \mathrm{O}_{8}$ pellets within the assembly gave an integrated energy release equivalent to about $\sim 1 \times 10^{16}$ fissions. There was no significant contamination within the facility allowing it to be reused for later experiments.

The accident investigation report stated, “...The design of $F K B N$ and its automatic safety features are such that it provides safeguards for only slow changes in reactivity. FKBN is not safeguarded against negligent operation, and therefore per safety regulations operations should be performed only in a manner that would not require any safety system response."

As a result, it was concluded that FKBN did not comply with safe operation requirements for critical assemblies, and it was dismantled. As a replacement, the design was modified several times resulting in the construction by VNIIEF of FKBN-1 (1955), FKBN-2 (1963), FKBN-2M, and others equipped with fast response safety systems. ${ }^{49}$

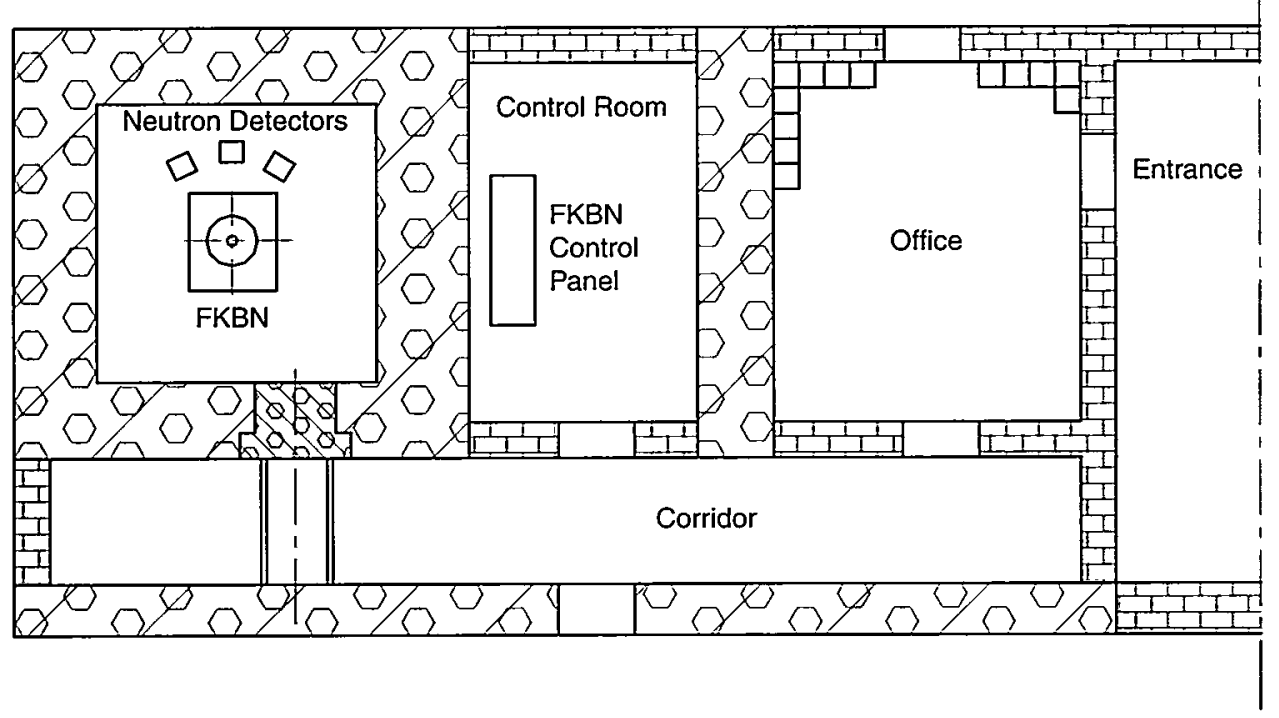

Figure 47. Building B floor plan. 


\title{
6. Los Alamos Scientific Laboratory, 3 February $1954^{42,44,47}$
}

\author{
Lady Godiva reactor; bare ${ }^{235} U$ sphere; control rod incorrectly operated; single excursion; insignificant \\ exposures.
}

\section{Los Alamos Scientific Laboratory, 12 February $1957^{47,48,49,50,51,52}$}

\author{
Lady Godiva reactor; bare ${ }^{235} U$ sphere; added reflection; single excursion; insignificant exposures.
}

These two excursions occurred in the Lady Godiva assembly, an unreflected metal reactor fabricated in three principal sections that when assembled formed a sphere. Figure 48 shows Godiva in the scrammed state. The central section was fixed in position by small tubular steel supports, while the upper and lower sections were retractable by means of pneumatic cylinders, thus providing two independent scram mechanisms. The critical mass was about $54 \mathrm{~kg}$ of uranium enriched to $93.7 \%{ }^{235} \mathrm{U}$. It was operated remotely from a distance of $1 / 4$ mile.

The first accidental excursion occurred during preparations for a scheduled prompt burst, part of a program to measure the parameters associated with excursions. Normally, a burst was initiated by establishing delayed criticality. This was accomplished by adjusting control rods, lifting the top section to reduce reactivity and allow decay of the neutron population, and lowering the top section into position and rapidly inserting a burst rod worth slightly more than $1 \$$.

A power excursion typically creating about $10^{16}$ fissions in $100 \mu \mathrm{s}$ followed; in $40 \mathrm{~ms}$ the system would be scrammed safely. Because the only source of neutrons was spontaneous fission, it was customary to assemble to an excess reactivity of about $70 \phi$ to generate sufficient neutrons to determine the settings for delayed criticality in a reasonable time. This accidental excursion was caused, apparently, because additional reactivity was inserted by error after assembly to $70 \notin$, but before a fission chain started.

The excursion yield was $5.6 \times 10^{16}$ fissions, about six times the yield of the average burst. There was no radiation hazard, contamination, personnel exposures to radiation, or significant damage to the major uranium parts. One piece was slightly warped and required remachining. Several light steel supporting members were bent or broken (Figure 49).

The second accidental excursion occurred during preparations for an experiment in which Godiva was to provide a pulse of fast neutrons. Again, the burst occurred during assembly to establish, in this case, a fiducial point at about $80 \not$ excess reactivity. Control rods were to be adjusted on the basis of this period. The extra reactivity is thought to have been contributed by a large mass of graphite and polyethylene that was to be irradiated. This mass had just been moved close to Godiva, and either the change in reflection was underestimated or the material slumped further toward Godiva.

The burst yield was $1.2 \times 10^{17}$ fissions, about 12 times the standard excursion. The uranium metal was severely oxidized, warped, and apparently had been plastic near the center. The central burst rod was nearly ruptured and, at its center, must have been within $100^{\circ} \mathrm{C}$ of the uranium melting temperature. Figure 50 shows several of the pieces. External damage was limited to the supporting structure; radioactive contamination consisted of oxide scale; cleanup proceeded rapidly. Repair of Lady Godiva was not practical; therefore construction of Godiva I $^{59}$ specifically designed for burst operation, was accelerated. Despite the severity of the excursion, operating personnel received no significant radiation exposures because of the large distance between the reactor and the control room.

The behavior of the Godiva system during superprompt critical power excursions is well understood both experimentally and theoretically. ${ }^{47.51 .52}$ Lady Godiva experienced well over 1,000 safe, controlled bursts. A coupled hydrodynamics-neutronics code describes the behavior of the system adequately.

The first excursion $\left(5.6 \times 10^{16}\right.$ fissions) must have had a period of 6.4 seconds, equivalent to a reactivity excess over prompt criticality of $15 \%$. The excess reactivity of the larger excursion $\left(1.2 \times 10^{17}\right.$ fissions $)$ was $21 \&$ above prompt criticality, corresponding 10 a period of $4.7 \mu \mathrm{s}$.

The fission yield of $1.2 \times 10^{17}$ in the second accident is equivalent to the energy contained in $1.7 \mathrm{lb}$ of high explosive (HE), but the damage was much less than would have been caused by that quantity of HE. The above mentioned code can predict the fraction of fission energy converted to kinetic energy; in this case. only about $1.4 \%$ of the energy, equivalent to 0.024 pounds of $\mathrm{HE}$, was available as kinetic energy to do damage. The damage was consistent with this figure, and it is evident that most of the fission energy was deposited as heat. 


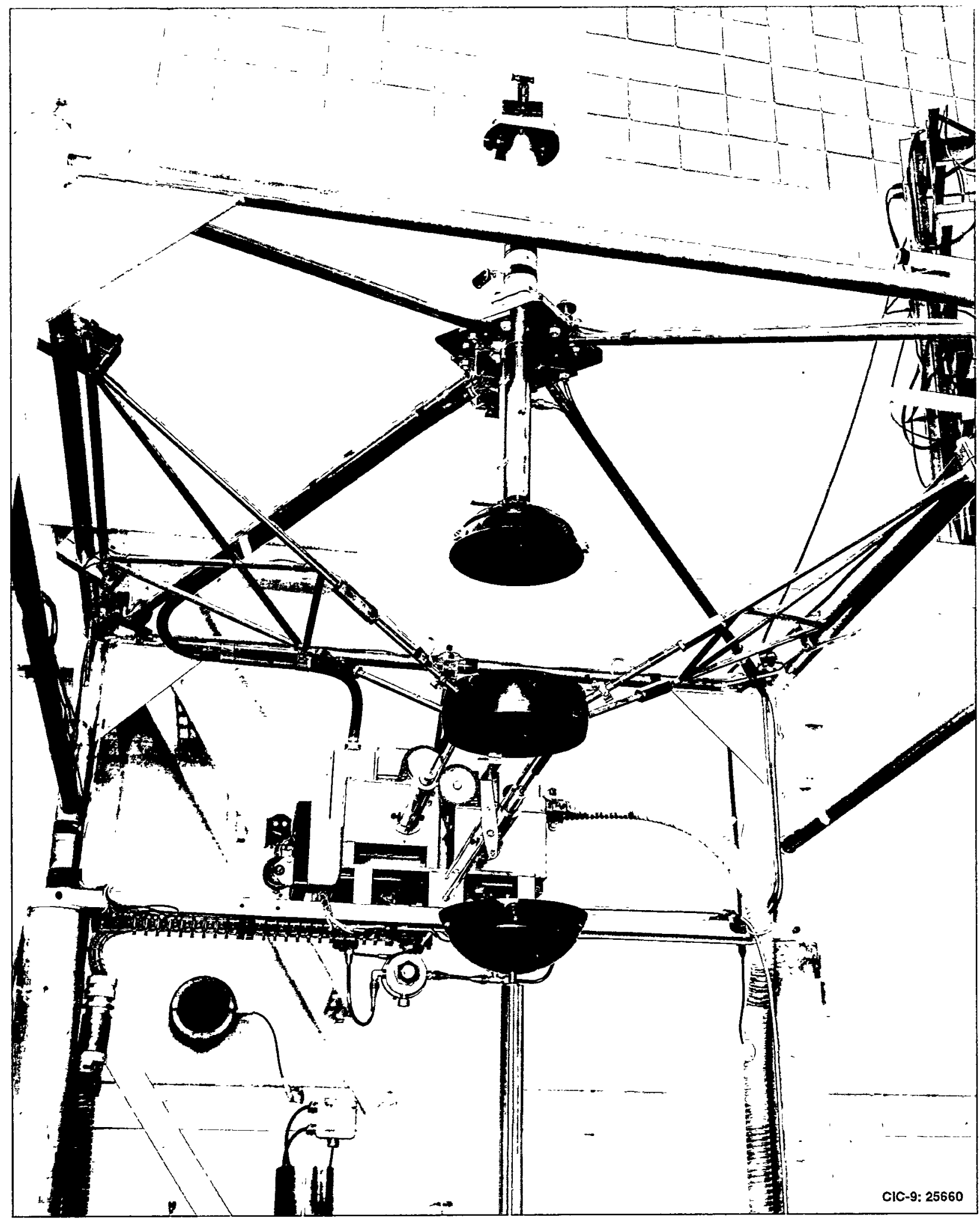

Figure 48. The Los Alamos Scientific Laboratory Lady Godiva assembly (unreflected enriched-uranium sphere) in the scrammed configuration. 


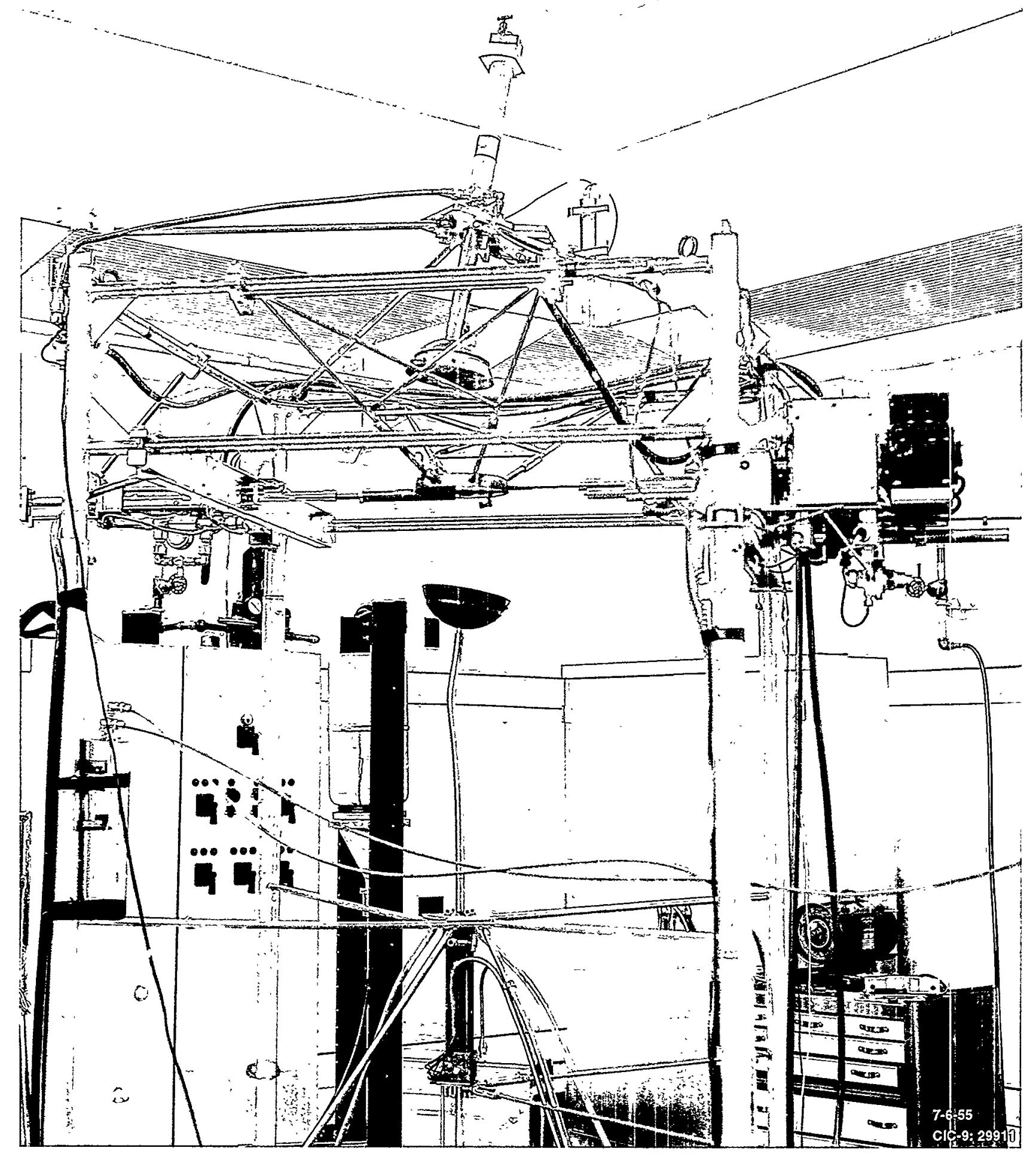

Figure 49. Lady Godiva after the excursion of 3 February 1954. 


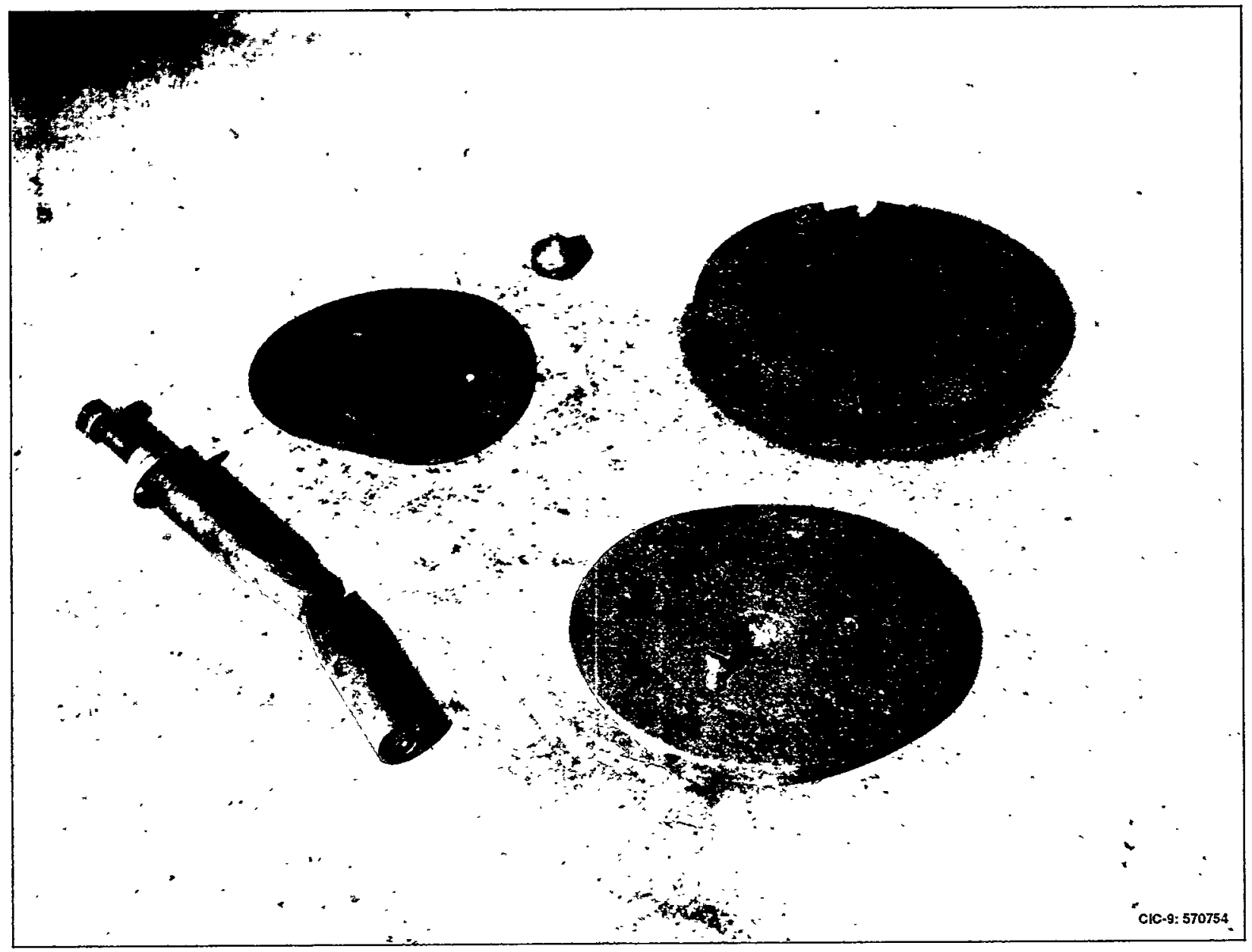

Figure 50. Burst rod and several sections of Lady Godiva showing oxidation and warpage that accompanied the second accident, 12 February 1957.

\section{Los Alamos Scientific Laboratory, 17 June $\mathbf{1 9 6 0}$}

\section{${ }^{235} \mathrm{U}$ metal, graphite reflected, assembly; single excursion; insignificant exposures.}

The critical parameters of highly enriched $\left(93 \%{ }^{235} \mathrm{U}\right)$ uranium metal cylinders in thick graphite (about 9 inches) and near infinite water reflectors were being investigated. In the experiment of interest, an approximate $48 \mathrm{~kg}$ uranium annulus was built up on a cylinder of graphite that, in turn, rested on a hydraulic lift device. This annulus was raised by remote control into a reflector of graphite resting on a stationary steel platform. The system became critical before complete assembly and was scrammed both manually and automatically at about 1 inch from closure. Following the scram signal, the lift dropped rapidly and the system became subcritical, but about one-third of the metal mass stuck in the graphite reflector for a few seconds before falling to the floor. The yield was $6 \times 10^{16}$ fissions; there was no contamination or damage to the fissile metal. Personnel radiation doses were immeasurably small.
This accident was, in many respects, similar to that of Jemima (II-B.4). The reactivity sensitivity of this particular experiment was not measured after the power transient but, when investigators examined similar systems, the reactivity insertion rate probably did not exceed a few dollars per second and the initial spike could have included $10^{15}$ fissions.

The fission yield was very close to that of the first Godiva accident (3 February 1954, $5.6 \times 10^{16}$ fissions), and the two masses are quite comparable. In the earlier case, all of the energy release took place during the power spike and some warping of pieces and damage to supports was seen. In this transient, the metal was undamaged, thus supporting the assertion that the initial power spike was small compared to the total yield. 


\section{Oak Ridge National Laboratory, 10 November $1961^{53}$}

${ }^{235} \mathrm{U}$ metal, paraffin reflected, assembly; single excursion; insignificant exposures.

This power transient in about $75 \mathrm{~kg}$ of highly enriched (about $93 \%{ }^{235} \mathrm{U}$ ) uranium metal reflected with paraffin took place when one portion on a vertical lift machine was approaching the other stationary portion. The experiment was the last of a series during which uranium or paraffin had been added by increments to change the reactivity of the complete system; all previous experiments had been subcritical when fully assembled. In this case, the system became supercritical while the lift was in motion, leading to a yield of between $10^{15}$ and $10^{16}$ fissions.

The closure speed of the lifting device was 16 inches per minute; delayed criticality was later determined to be at a separation distance of 2.7 inches. The sensitivity of the system at this point was
$8.6 \$$ inch. Thus, the reactivity insertion rate was $2.3 \$ / \mathrm{s}$ and a lift slowdown, which became effective at 1.94 inches, did not affect the course of the transient.

The reactivity and power histories must have been similar to those of the Jemima (II-B.4) accident, except that the pertinent scram delay time was only $50 \mathrm{~ms}$ in this case. The initial spike could not have exceeded $10^{15}$ fissions, and the remaining energy must have been created during the subsequent plateau. The appearance of the metal (smooth, no oxide) and the fact that the paraffin did not melt qualitatively confirmed the yield estimate of $10^{15}$ to $10^{16}$ fissions. Personnel radiation doses were trivial, and the laboratory was ready for normal use within 1.5 hours.

\section{Sarov (Arzamas-16), 11 March $1963^{54}$}

Plutonium, lithium deuteride reflected assembly; inadvertent closure; single excursion; two serious exposures.

This accident occurred on 11 March 1963 as modifications and maintenance were being performed on a vertical split machine, MSKS. MSKS (Figure 51) was located within Building B at a reactor site (Figure 52) and was used to perform experiments other than critical approaches. It was limited to assemblies whose shape, composition, maximum subcritical multiplication $(\leq 1,000)$, safe assembly-disassembly procedures, and the contribution of fixtures and equipment in use had already been verified by experiments on the vertical split machine, FKBN-1, located in the same Building B (Figure 52). MSKS was equipped with an automatic gravity driven scram system and closure of an assembly was performed remotely from a control panel behind concrete shielding (Figure 52).

The assembly involved in the accident had a $135 \mathrm{~mm}$ outside diameter plutonium core surrounded by a $\sim 350 \mathrm{~mm}$ outside diameter lithium deuteride reflector (Figure 51). The core was composed of a set of $\delta$-phase plutonium metal hemishells in a thin $(0.1 \mathrm{~mm})$ nickel coating. The core had a $63 \mathrm{~mm}$ central cavity in which a neutron source $\left(\sim 10^{6} \mathrm{n} / \mathrm{s}\right)$ had been placed. The neutron reflector was a set of $\mathrm{LiD}$ hemishells, $107 \mathrm{~mm}$ thick.

On 9 March 1963, the MSKS chief and operations engineer constructed the assembly on MSKS and conducted approach to critical experiments without first performing the required experiments on FKBN-1.

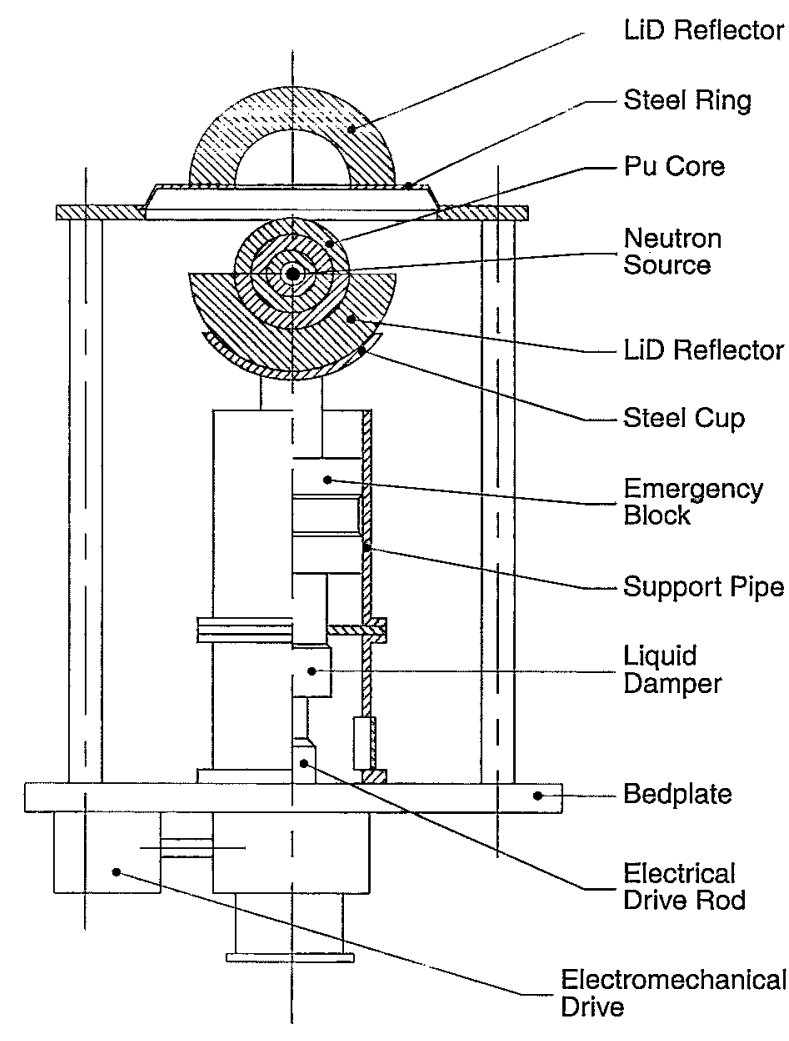

Figure 51. MSKS and assembly involved in the 11 March 1963 accident. 
On 11 March 1963, the facility chief and the operations engineer proceeded with pre-experiment operations with the assembly pieces still in place. The experimentalists attempted to make adjustments to the machinery of MSKS using unauthorized attachments in violation of the operating procedures. As they worked on MSKS adjusting the electromechanical lift mechanism, an excursion occurred. Seeing a flash of light, the experimentalists immediately exited and went to the control room, where the facility chief pushed the control button lowering the table. The automatic scram system did not activate because the detectors to which it was tied were not operating.

The accident was the result of gross violations of the MSKS operating procedures by the facility chief and operations engineer. The excursion was due to the inadvertent closure of the assembly by the experimentalists. As a result of the accident investigation and analysis, it was judged that the assembly had approached or possibly even exceeded the prompt critical state. The number of fissions was estimated to be $\sim 5 \times 10^{15}$ fissions. The nickel clad of the plutonium was not breached and therefore no contamination resulted. MSKS itself was undamaged and remained in long-term service. 54

Since the assembly parts were not damaged, they were used in a special set of experiments to more accurately estimate the exposure to personnel. The facility chief's dose was $\sim 370 \mathrm{rem}$, and the operations engineer received $\sim 550$ rem. Both experienced radiation sickness. The facility chief survived for 26 years, and the operations engineer was still alive 36 years after the accident. Both were immediately taken to a hospital for treatment. Eventually they returned to work at the VNIIEF Physics Division. Four other people working in adjacent area also received doses, although much lower $(\sim 7, \sim 1, \sim 1$, and $\sim 0.02$ rem).

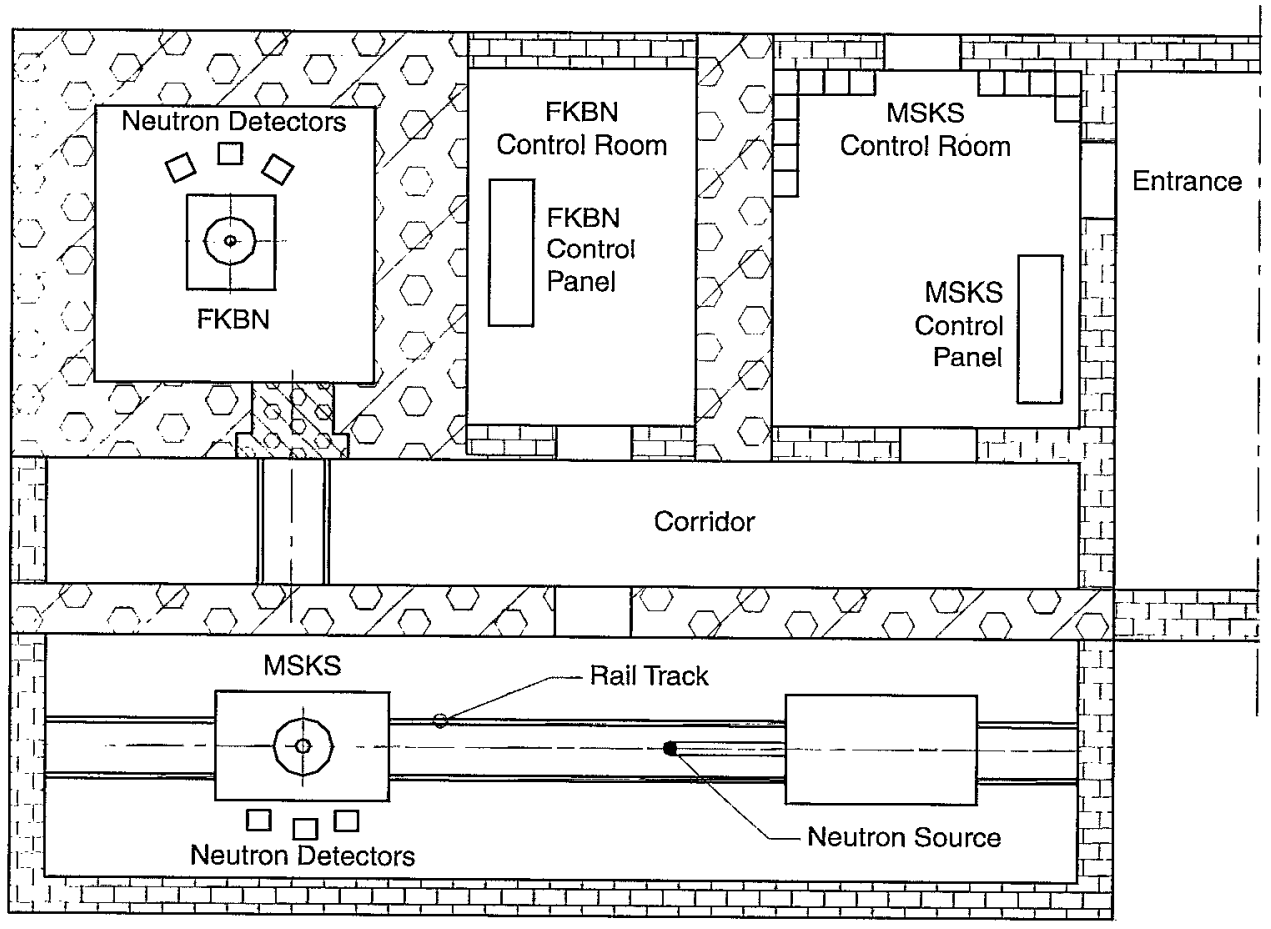

Figure 52. Building B floor plan. 


\title{
11. Lawrence Livermore Laboratory, 26 March $1963^{55}$
}

\author{
${ }^{235} \mathrm{U}$ metal, beryllium reflected, assembly; single excursion; insignificant exposures.
}

The critical assembly consisted of concentric cylinders of highly enriched uranium metal surrounded by a beryllium reflector. The total enriched uranium mass of $47 \mathrm{~kg}$ was divided into two parts with the central core on a lift device and the larger diameter rings with the reflector on a fixed platform. The approach to criticality was to be achieved by lifting the core in a series of steps into the reflected annulus. The experiments were performed in a heavily shielded vault adjacent to the area where the Kukla reactor produced prompt bursts of neutrons.

This step wise assembly procedure was successfully followed for seven multiplication measurements. After the eighth apparently normal assembly, the system suddenly became highly supercritical. An explosive sound was heard, scrams and alarms were actuated, and after a few seconds, the uranium could be seen melting and burning. The yield was later measured at
$3.76 \times 10^{17}$ fissions, but little or no explosive energy was generated. About $15 \mathrm{~kg}$ of uranium burned and about $10 \mathrm{~kg}$ melted and spread over the floor. Dose to personnel in or near the building was low and in no case exceeded $0.12 \mathrm{rem}$. The reactor room was highly contaminated.

The accident is believed to have been caused by the central cylinder of metal on the lift being very slightly off center. When it was lifted into the fixed half, one or more of the metal rings were carried upward. Following the eighth assembly, the system adjusted itself and the rings settled properly around the central core, abruptly increasing the reactivity. The rate is not known nor is the maximum reactivity. The initial spike probably did not exceed $10^{16}$ fissions; most of the energy was generated during a high plateau. Quenching came through thermal expansion and melting.

\section{White Sands Missile Range, 28 May $1965^{56}$}

\section{Unreflected uranium-molybdenum metal fast burst reactor; single excursion; insignificant exposures.}

The success of the Godiva reactor in creating very sharp, intense bursts of near fission spectrum neutrons stimulated the development of several similar reactors for production of pulsed irradiations. One of these was the White Sands Missile Range (located in southern New Mexico in the United States) fast burst reactor, which was composed of $96 \mathrm{~kg}$ of an alloy of highly enriched uranium and $10 \mathrm{wt} \%$ molybdenum. This reactor design was somewhat similar to the Godiva II reactor ${ }^{42}$ - seven rings and a top plate all of which partially enclosed a large central volume that at criticality was filled with a safety block. Two control rods and a burst rod penetrated the rings. The assembly was held together by three metal bolts. Initially, the bolts were stainless steel, but just prior to the accident they were replaced by bolts composed of the uraniummolybdenum alloy, and re-calibration of the reactivity worth of various components was underway. The new worth of the control rods, burst rod, minor components, and the first inch withdrawal of the safety block had been measured.

Further calibration of the safety block seemed to require higher neutron flux than that given by a polonium-beryllium neutron source. To obtain a power of about 1 watt, an interlock was bypassed and the safety block was set into motion inward, approaching a state thought to be known. The excursion took place as the safety block neared the one-half inch. position.

All scrams functioned as designed, but the short period allowed a very high power to be attained, and the excursion was actually terminated by thermal expansion of the metal. The new uranium-molybdenum assembly bolts failed (the heads snapped); the two top rings and minor parts were tossed 5 to 15 feet.

This accident was well instrumented. The minimum period was $9.2 \mu \mathrm{s}$, the maximum reactivity $15 \notin$ above prompt criticality, the reactivity insertion rate $2.2 \mathrm{~S} / \mathrm{s}$, and the burst width $28 \mu \mathrm{s}$. The internal temperature rise of $290^{\circ} \mathrm{C}$ suggested a fission yield of $1.5 \times 10^{17}$, which is only 1.4 times the maximum expected from normal operations.

During this unexpected burst, damage was limited to the failure of the assembly bolts and very slight chipping of the nickel coating of the rings. Personnel radiation doses were immeasurably small. One hour after the excursion the cell was entered and radiation levels were determined to be higher than normal background, but not appreciably higher than those measured after a routine burst. 


\title{
13. Chelyabinsk-70, 5 April $1968^{57,58}$
}

\author{
$U(90)$ metal, natural uranium reflected, assembly; single excursion, two fatalities.
}

The accident occurred on 5 April 1968 at the Russian Federal Nuclear Center (VNITTF) located in the southern Ural mountains between the cities of Ekaterinberg and Chelyabinsk. Criticality experiments began at VNIITF in 1957 using the FKBN vertical lift assembly machine. ${ }^{*}$ FKBN is a Russian acronym for "a physics neutron pile." At that time, intensive work was under way in the development of powerful reactors for studying radiation tolerance. Assembled on the FKBN in particular were a number of critical configurations with a thick reflector and a large internal cavity. This enabled operation in the static and pulsed mode up to several kilowatts. In the case under consideration, research was being conducted on the effect that a spherical polyethylene sample would have on the kinetic characteristics of the reactor system by means of the boiler noise method.

The FKBN assembly machine and system components, as configured at the time of the accident, are shown in Figure 53. The core of the assembly consists of a $U(90)$ spherical metal shell with an internal cavity.

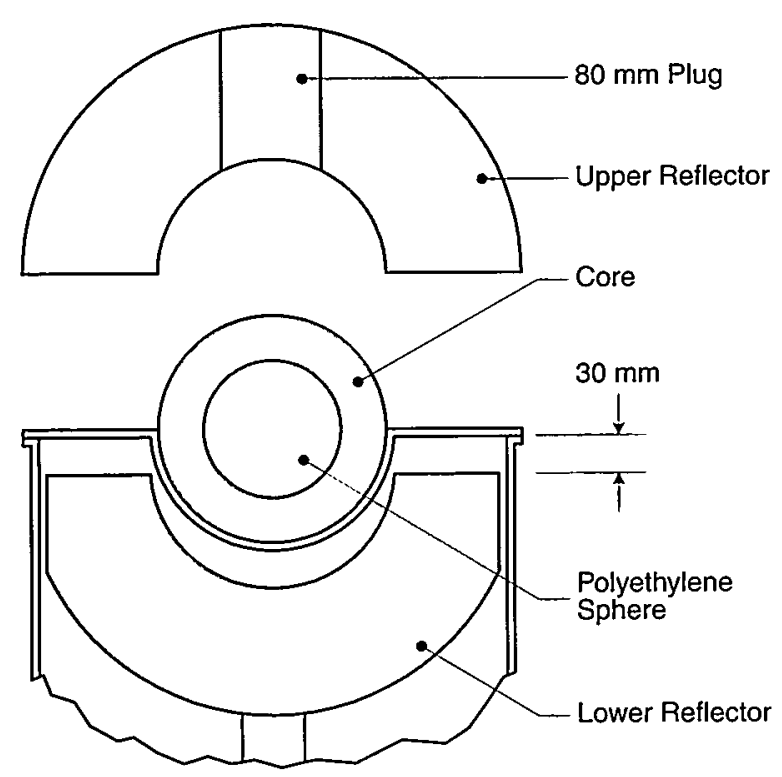

Figure 53. Approximate accident configuration of the FKBN vertical lift assembly machine and core.
The core could be surrounded by a thick, spherical, natural uranium metal reflector. Figure 53 illustrates that the external reflector is split into upper and lower halves. The accidental excursion resulted in the death of two knowledgeable nuclear criticality specialists standing near the assembly at the time of the excursion. A criticality alarm system was not installed at the time of the accident. The upper reflector was natural uranium metal having a total uranium mass of $308 \mathrm{~kg}$. The inside radius was $91.5 \mathrm{~mm}$ and outside radius was $200 \mathrm{~mm}$. The core was a $90 \%$ enriched uranium metal spherical shell having an inside radius of $55 \mathrm{~mm}$ and an outside radius of $91.5 \mathrm{~mm}$. The core uranium mass was $47.7 \mathrm{~kg}$ of uranium or $43.0 \mathrm{~kg}$ of ${ }^{235} \mathrm{U}$. The uranium core was constructed of nested, close fitting, hemispherical components with radii of $55 \mathrm{~mm}$, $67.5 \mathrm{~mm}, 75.5 \mathrm{~mm}, 83.5 \mathrm{~mm}$, and $91.5 \mathrm{~mm}$. A polyethylene sphere had an outside radius of $55 \mathrm{~mm}$. The lower reflector was natural uranium with an inside radius of $91.5 \mathrm{~mm}$ and an outside radius of $200 \mathrm{~mm}$.

The accident occurred on a Friday evening after normal working hours. Earlier that same day an assembly had been constructed on the FKBN machine. Two specialists present for the daytime assembly decided to continue working into the evening in order to complete a second assembly. The evening assembly was to be a repeat of the daytime assembly with one variation-a solid polyethylene sphere was to be inserted into and fill the cavity of the core which was void for the daytime assembly. Using a hand-held controller panel, the senior specialist operated an overhead tackle to lower the upper half of the reflector to make contact with the core (the operation of lowering the upper-half of the reflector could not be carried out under remote control). The junior specialist stood next to the FKBN with both hands on the upper reflector to guide it into place. The accident occurred as the upper half of the reflector was being lowered onto the core and was about to make contact with it. The emergency instrument system was operating and responded after the power level of the excursion reached the kilowatt level. The system dropped the lower half of the reflector, which was sufficient to drive the system deeply subcritical and terminate the excursion.

\footnotetext{
*The prototype of the FKBN was developed and used earlier at the Arzamas-16 research center (VNIIEF). It is mentioned in the reminiscences of A. D. Sakharov. See also proceedings of ICNC'95, Vol. 1, paper 4-44, "Criticality Measurements at VNIITF Review," V. A. Teryokhin, V. D. Pereshogin, Yu. A. Sokolov.
} 
The senior specialist made an error of judgment when he expected the polyethylene sphere to have a small effect on system reactivity. The investigation also established that in addition to the error in judgment, the specialist violated several operational procedures. For the evening assembly, the lower half of the uranium reflector was not positioned $20 \mathrm{~mm}$ above its lower stop as required to ensure an adequate margin of criticality safety for the assembly process. Instead, the lower reflector was positioned $90 \mathrm{~mm}$ above its lower stop which is $30 \mathrm{~mm}$ below its upper stop. The upper stop corresponds to the lower reflector making contact with the lower core. The failure to reposition the lower reflector following the daytime assembly was identified as the primary cause of the accident.

The investigation revealed several additional violations of procedures:

- The instrument system designed to be sensitive enough to alert the specialist that system multiplication was rapidly increasing as they lowered the upper reflector half was not operating. This system had been switched off following the daytime assembly and not switched back on for the evening assembly.

- A third specialist was required to be present in the control room, but the control room was unmanned.

- The assembly required the presence of a health physicist. The health physicist was not present because he was not notified of the evening assembly.

Following the excursion, the two specialists remained conscious and maintained their self-control. They were able to inform administrative officials that the accident had occurred and to place a phone call requesting an ambulance. The senior specialist carried out dose estimates for himself and the junior specialist. The senior specialist made the following entry into his experimental log.

"Eighty-mm diameter plug" was removed.

The gap was $30 \mathrm{~mm}$. Polyethylene was inserted. When moving the shell down a pulse was produced. Safety system was actuated. The operator was at the distance of 0.5 meters away from the shell. The responsible person - at 1.7 meters aw'ay from the overhead-track hoist pendant. There was a flash, a shock, a stream of heat in our faces. The polyethylene contribution exceeded the expected magnitude."
The two criticality safety specialists working with this assembly at the time of the excursion were knowledgeable in neutron physics and the experimental procedures required for criticality measurements. The senior specialist was born in 1929 , joined the facility in 1955, and became qualified to handle fissile material in 1958. The junior specialist was born in 1938 , joined the facility in 1961, and became qualified to handle fissile material in 1962. Both were qualified to carry out the experimental procedures taking place at the time of the accident. At the time of the excursion, the junior specialist was standing approximately $0.5 \mathrm{~m}$ from the assembly axis. The senior specialist was located approximately $1.7 \mathrm{~m}$ away. The junior specialist received an accumulated neutron plus gamma dose in the 20-40-Sv range. The senior specialist received an accumulated neutron plus gamma dose in the 5-10-Sv range. Following the accident, both specialists were taken to the local hospital and then immediately flown to the

Bio-Physics Institute in Moscow. The junior specialist died three days after the excursion. The senior specialist survived for 54 days after the excursion.

The estimated yield of the excursion was $6 \times 10^{16}$ fissions. At the beginning of the excursion, the upper half of the natural uranium reflector was descending on the core at approximately $100 \mathrm{~mm} / \mathrm{s}$, driving the assembly above prompt critical. This closure speed corresponds to a reactivity insertion rate of about $40 \beta / \mathrm{sec}$. A $5.2 \times 10^{6}$ (neutrons per second) ${ }^{238} \mathrm{Pu}$-Be source was located off-center outside of the uranium core of the assembly.

The investigation concluded that although the specialists were highly experienced in working with critical assemblies, it was their overconfidence and haste that resulted in their loss of life. Both specialists had theater tickets for the same evening as the accident. The senior specialist prepared the procedure for the evening assembly disregarding a principle rule for criticality safety which stated: Every unmeasured system is assumed to be critical. The investigation concluded that the accident was caused by "severe violations of safety rules and regulations which occurred due to insufficient control by facility managers and health physics personnel."

\footnotetext{
×This plug was located at the north pole of the upper reflector and passed through the full thickness of the reflector.
} 


\section{Aberdeen Proving Ground, 6 September $1968^{59}$}

Uranium-molybdenum metal fast burst reactor; single excursion; insignificant exposures.

The Army Pulse Radiation Facility Reactor (APRFR), located in Maryland in the United States, was another of the series of Godiva-like reactors. The APRFR design evolved from the Health Physics Research Reactor of the Oak Ridge National Laboratory and was intended to provide large values of neutron flux and fluence.

During pre-operational testing, several minor variations in the reactor configuration were studied in a program to optimize performance. During this testing, an unexpectedly large burst $\left(6.09 \times 10^{17}\right.$ fissions) occurred. It exceeded, by about a factor of three, the maximum burst size the reactor was expected to withstand without damage. Internally the core reached the melting point of the fuel, $1150^{\circ} \mathrm{C}$. The initial period was measured as $9.1 \mu \mathrm{s}$, and the reactivity was estimated to have been about $18 \notin$ above prompt criticality. The planned excess reactivity for this burst was $8.05 \varnothing$, which was expected to result in a burst of $1.68 \times 10^{17}$ fissions.
Post accident analysis indicates that the extra reactivity resulted from a reactor configuration such that the burst rod passed through a reactivity maximum before seating. This condition had not been recognized; apparently on previous operations the burst rod had reached its seated position before the arrival of an initiating neutron. In the absence of a strong neutron source, wait times before an excursion occurs can be long. ${ }^{97}$

Damage was limited to the fuel components of the reactor and included some warping and spalling as well as elongation of bolts. The four central rings fused together at the inner surface and experienced some cracking.

There were no detectable external or airborne radiation hazards and no personnel overexposures.

\section{Sarov (Arzamas-16), 17 June 199749,60,61,62}

\section{$U(90)$ metal, copper reflected, assembly; multiple excursions; one fatality.}

This accident occurred at 10:40 on 17 June 1997 as an experimental assembly was being hand constructed on a vertical split machine, FKBN-2M. FKBN-2M is located in an experimental cell $(12 \mathrm{~m} \times 10 \mathrm{~m} \times 8 \mathrm{~m})$ of a dedicated building (Figure 54 ) at a reactor site. ${ }^{60} \mathrm{~A}$ schematic of FKBN-2M is shown in Figure 55. The lower part of a research assembly is constructed on a table that can be moved vertically up and down using hydraulics, although the table had to be in the up position during construction of an assembly. The upper part is placed on a stand consisting of a ring, upper and lower support, and a carriage that can be moved horizontally and into position over the lower part of the system. Closing of the assembly (by moving the carriage over and the table up) is performed remotely from a control room behind an $\sim 3$ meter thick concrete shielding wall (Figure 54). FKBN-2M is equipped with a fast acting gravity driven scram that automatically causes the table to drop to its down position if the neutron flux exceeds a preset value.
Various sets of nesting fissile (uranium, plutonium) and nonfissile hemishells (steel, copper, polyethylene, etc.), standardized in size, exist to allow for a variety of experimental configurations. Assemblies are constructed by consecutively stacking the hemishells together into the desired configuration.

On 17 June 1997, an experimenter working alone and without having completed the proper paper work (both violations of safety requirements), was constructing an experimental assembly consisting of a core of uranium, $U(90)$ reflected by copper. ${ }^{61,62,63}$ The experimenter was an expert who was confident that he was recreating an assembly that had been the focus of an experiment performed successfully in 1972. He had taken the dimensions for all of the system components from the original 1972 logbook. However, when he copied down the inside and outside dimensions of the copper reflector ( 167 and $205 \mathrm{~mm}$, respectively) he incorrectly recorded the outside dimension as $265 \mathrm{~mm}$. Using this incorrect information, the experimenter had 


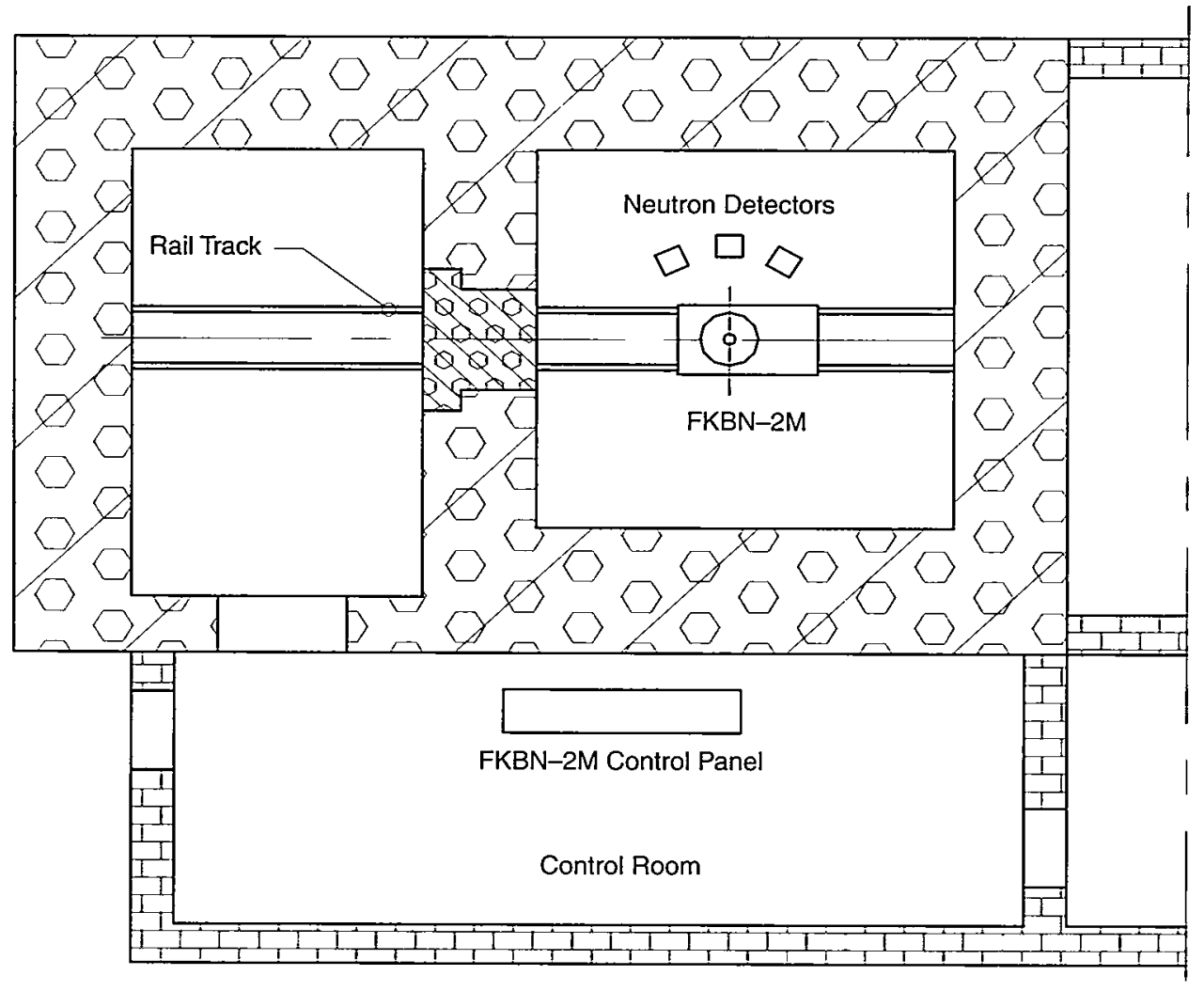

Figure 54. FKBN-2M building layout.

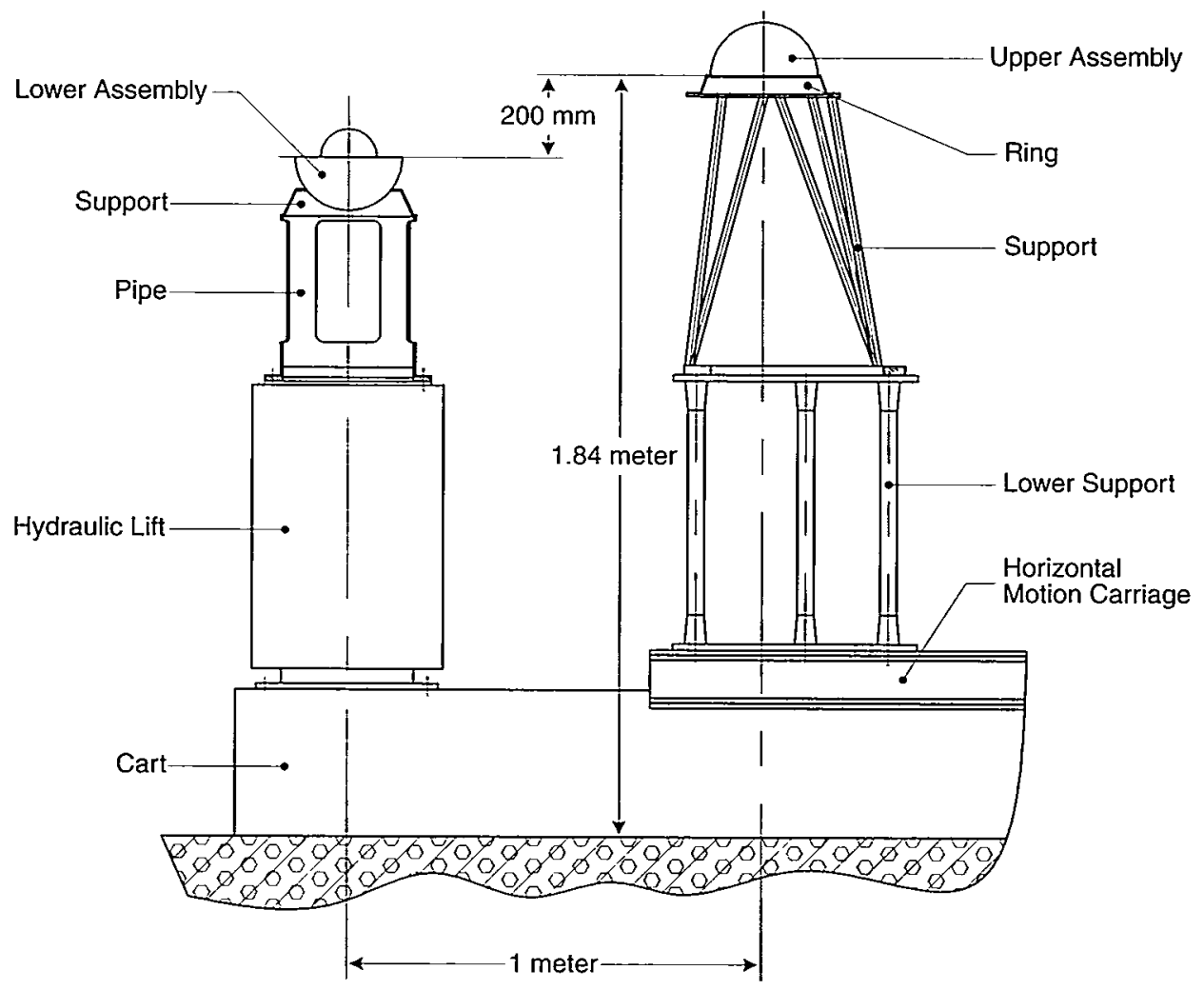

Figure 55. FKBN-2M experimental layout. 
completed the construction of the lower half of the assembly on the table (Figure 56). This lower half consisted of the copper reflector (with an outside diameter of $258 \mathrm{~mm}$ since that was all that was available) and a uranium core ( 9 spherical layers, with an inside diameter of $28 \mathrm{~mm}$ and an outside diameter of $167 \mathrm{~mm})$ with a neutron source $\left(\sim 10^{5} \mathrm{n} / \mathrm{s}\right)$ placed in its center. As he went to position the first upper copper hemishell (with an inside and outside diameters of $167 \mathrm{~mm}$ and $183 \mathrm{~mm}$, respectively) into place it dropped onto the bottom assembly. This led to the initial prompt critical spike and the $\sim 6.5$ day excursion. The automatic scram system activated and dropped the table to its down position ${ }^{60}$ but otherwise had no effect on the supercritical assembly. After the initial fission burst, the assembly eventually reached steady state power conditions.

Seeing a flash of light, the experimenter left the experimental cell, shutting the safety door behind him. He reported the accident to the engineer and attending health physicist who were in the control room at the time. The head of the laboratory and the facility chief were then notified by phone. The facility chief arrived shortly thereafter, at which time the experimenter related the composition and dimensions of the assembly as documented in his logbook. 60

The accident burst conditions were reproduced from measurement of the assembly's neutron flux (19 June 1997) and from computations shown in Figure 57 (these computations were performed by Dr. V. F. Kolesov and Dr. V. Kh. Khoruzhy). The asymptotic power was estimated to be 480 watts, corresponding to an event with an initial excess reactivity $6.5 \notin$ above prompt critical, i.e., $\Delta \mathrm{k}=0.00745$. The initial superprompt critical spike of $\sim 4 \times 10^{15}$ fissions was followed by a subprompt critical excursion lasting 3 to 5 minutes and generating $\sim 2 \times 10^{17}$ fissions. This second excursion was followed by highly damped power oscillations separated by about 40 minute intervals. Several hours afterwards, the assembly power, and the core and reflector temperatures had reached equilibrium levels. The temperature of the uranium core was estimated to have been $865^{\circ} \mathrm{C}$.

The excursion was terminated around 00:45 on 24 June 1997 when a vacuum gripper was used to remove most of the assembly from the stand, leaving only the outermost lower copper hemishell in place. The removed portion of the assembly was placed onto a support stand in the room (Figure 58). All the recovery operations were done remotely.

Later, another two hemishells from the lower reflector were removed, and the system was then separated into two parts and packaged into containers. After the $\gamma$-radiation decreased to allowable levels, it was planned to further disassemble the system (into single components) to restore the damaged coppernickel protective coating on fissile material parts.
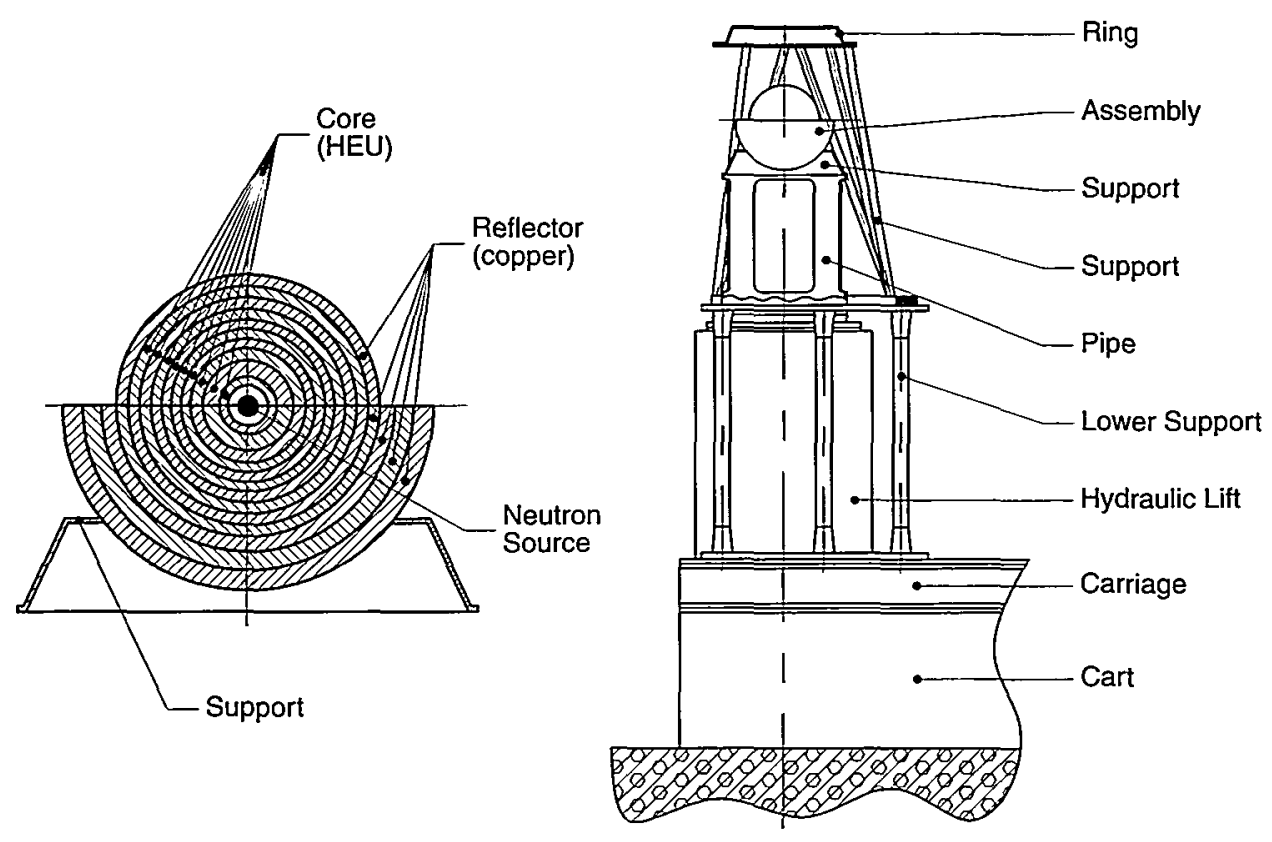

Figure 56. Accident configuration. 
The main cause of the accident was the erroneous judgment of the experimenter as to the state of the experimental assembly he was constructing. The accident resulted in virtually no damage to the machinery or equipment in the facility. The experimental cell was not contaminated. The experimenter received estimated absorbed doses of 4,500 rad from neutrons, and 350 rad from gamma-rays. ${ }^{61,62,63}$ That same day he was transported to a specialized clinic in Moscow, where he died during the night between 19 and 20 June, 1997. No other personnel were injured or received significant exposures. Radiation levels inside the control room and in the vicinity of the building remained at normal levels. The total energy released was estimated to be equivalent to $10^{19}$ fissions. After the accident, experiments with FKBN-2M were stopped to implement safety upgrades to the research operations.

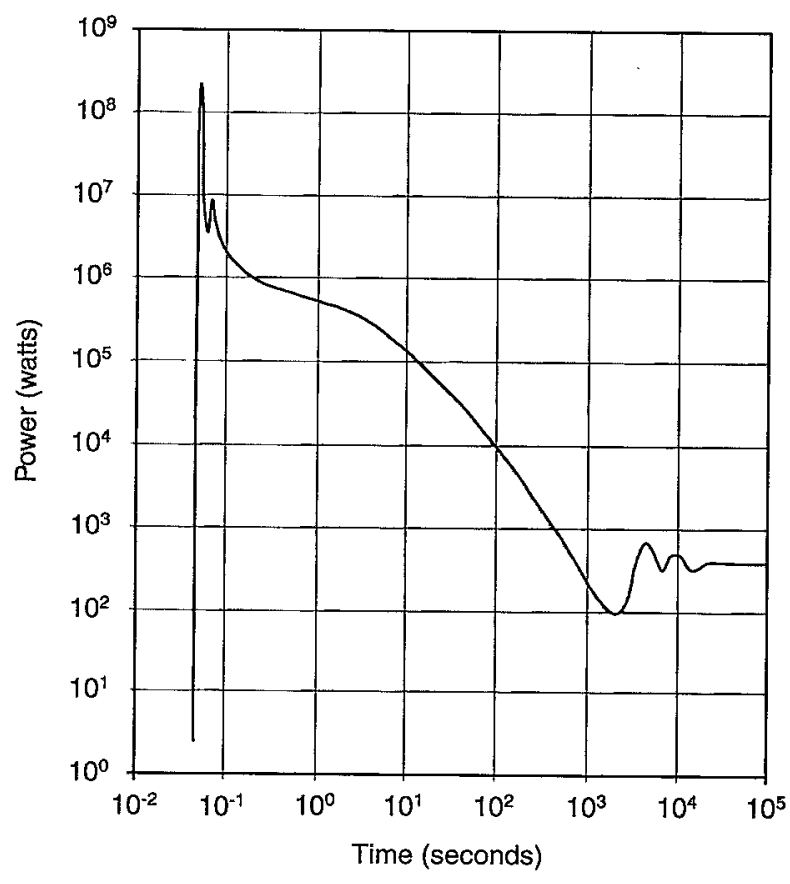

Figure 57. Calculated power history for the accident.

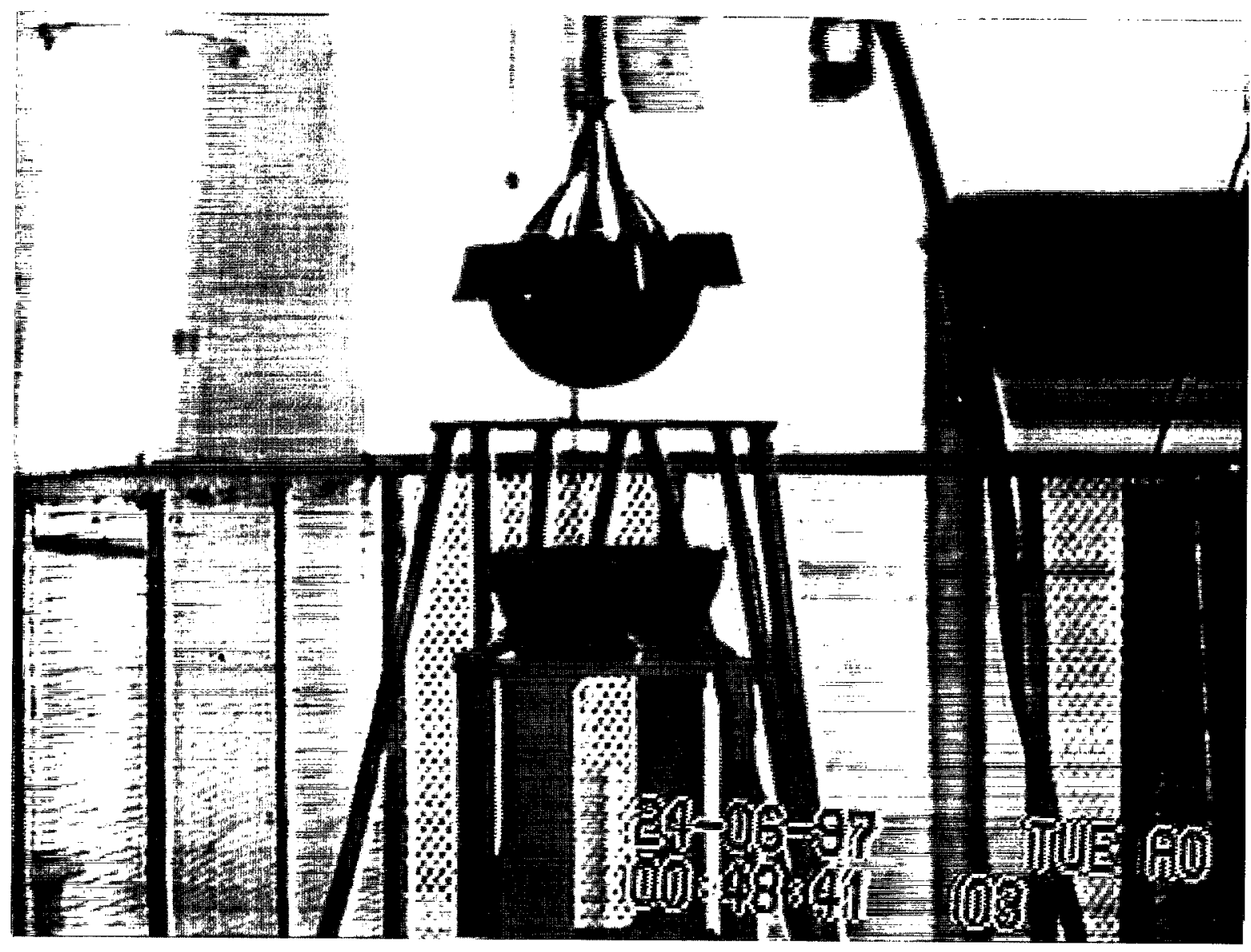

Figure 58. Removal of the main core of the assembly from the lower copper hemishell reflector. 


\section{MODERATED METAL OR OXIDE SYSTEMS}

\section{Los Alamos, New Mexico, 6 June $1945^{37}$}

Pseudosphere of uranium cubes; water reflected; single excursion; 3 significant exposures.

The experiment, designed before the days of remote control, was intended to establish the critical mass of enriched uranium metal surrounded by hydrogenous material. The uranium mass of $35.4 \mathrm{~kg}$ (average enrichment $79.2 \%$ ) was stacked in the form of a pseudosphere constructed of one-half inch cubes and one-half inch. by one-half inch by one inch blocks. The core was in a 6 inch cubical polyethylene box with the void space filled with polyethylene blocks. The whole assembly was placed in a large tank that was then partially filled with water.

Unexpectedly, the assembly became critical before water had completely covered the polyethylene box. The situation was aggravated because no scram device was built into the system and the inlet and drain valves were 15 feet apart. Before the system was reduced to a safely subcritical state 5 or 10 seconds later, a total of 3 to $4 \times 10^{16}$ fissions occurred. This was an energy release sufficient to raise the average temperature of the metal more than $200^{\circ} \mathrm{C}$. Subsequent examination of the polyethylene box showed that it was not watertight. It is probable that water seeped slowly into the uranium assembly as the water level was being raised above the bottom of the box. The additional moderation then caused the supercritical situation that was terminated by boiling of the water within the box and next to the metal cubes.

Calculations have provided some insight into this event. Nesting spherical shells of U(79.2) (thickness of $8 \mathrm{~mm}$ and total mass of $35.4 \mathrm{~kg}$ ) were evaluated with gaps between shells of 0.5 and $1 \mathrm{~mm}$. Adding water to the gaps increased the multiplication factor by 0.04 for the $1 \mathrm{~mm}$ gap, while for the $0.5 \mathrm{~mm}$ case, $\Delta \mathrm{k}$ was found to be about 0.02 . These results apply to the assembly fully reflected by water, where the calculated keff was 1.024 and 1.018 , respectively. The full water reflector was found to be worth about $0.21 \mathrm{in} \mathrm{k}$. Although the geometry of the calculations represents only a rough approximation of the actual assembly, refinements are probably not justified. Indications are that the uranium cubes were "as cast," so the actual volume available to the water cannot be known.

The characteristics of excursions of large masses of fissile metal in water are, at best, poorly known. A calculation by Hansen has shown that for a $68.5 \mathrm{~mm}$ radius ${ }^{235} \mathrm{U}$ sphere in water, $15 \%$ of the fissions occur in the outer $0.5 \mathrm{~mm}$ and the fission density in this region is six times that at the center. A spike of $3 \times 10^{15}$ fissions would then raise the surface temperature $130^{\circ} \mathrm{C}$, while the central regions would remain relatively cool with a temperature rise of only $19^{\circ} \mathrm{C}$. The initial spike must have been of this order of magnitude, with the majority of the fissions following at a much lower average power.

In this excursion, three people received radiation doses in the amounts of 66, 66, and 7.4 rep.* There was no contamination, and the active material was used again in 3 days.

*See Appendix A. 


\title{
2. Chalk River Laboratory, late 1940 s or early $1950 s^{63}$
}

\author{
ZEEP assembly; single excursion; three significant exposures.
}

The ZEEP assembly consisted of aluminum clad uranium metal rods in a heavy water moderator. The cylindrical aluminum reactor tank was reflected by graphite on the sides and bottom, shielded on the sides by 3 foot thick water tanks, and unshielded on the top. Reactivity was controlled by the level of the heavy water, which was supplied from a storage tank by an electrically driven pump. As a safety feature, the pump was controlled by a timer that required the pump to be restarted by a pushbutton switch every 10 seconds or so.

Cadmium coated plates suspended on cables between the reactor tank and the graphite reflector served as safety rods. The scram circuit was set to trip at a power of about 3 watts.

At the time of the accident, two physicists were working on the top of the reactor, inserting foils into reentrant tubes. A technician raising the water level in the reactor with the pump control had instructions to stop at a water level predetermined to be many minutes of pumping below predicted criticality.
One of the physicists asked the technician to bring a tool to the top of the reactor. Not wanting to lose time and in direct contravention of instructions, the technician inserted a chip of wood into the pump control button so the timer would reset each time it ran out. He then went to the reactor top and became involved in the work being done there, while the heavy water level continued to rise.

The reactor became critical and scrammed as designed. The pump was stopped automatically by an interlock in the scram circuit. The NRX reactor in the adjacent building was scrammed by skyshine radiation. Subsequent evaluations indicated that the ZEEP power level had coasted above the preset scram power level, perhaps by several factors of two.

The three people on the reactor top each received doses in excess of the quarterly permissible limit and, perhaps, above the annual limit.

\section{Argonne National Laboratory, 2 June $1952^{64}$}

\section{$U \mathrm{O}_{2}$ particles in plastic; water moderated; single excursion; 4 significant exposures.}

This accident occurred in a light water moderated core in which $6.8 \mathrm{~kg}$ of ${ }^{235} \mathrm{U}$ oxide were embedded in strips of polystyrene plastic. All but $0.5 \%$ of the oxide particles were $10 \mu \mathrm{m}$ in diameter or less, the remainder, up to $40 \mu \mathrm{m}$ in diameter. Seven strips of the plastic fastened to 6 zirconium strips $(0.91$ inches $x$ 0.110 inches $\times 43$ inches) formed 1 standard fuel element. The core was roughly cylindrical and contained 324 fuel elements. The zirconium, fuel strips, and water occupied $60 \%, 7.71 \%$, and $32.2 \%$, respectively. of the core volume.

The experiment in progress at the time of the accident consisted of making comparisons of the worth of central control rods of different design. The system became superprompt critical following an attempt (contrary to operating procedures) to replace the central control rod when the normal amount of water was in the core. Peripheral poison rods were in position but were inadequate to prevent criticality.
The quenching mechanism for the excursion of $1.22 \times 10^{17}$ fissions was the near uniform expansion of the plastic as the $10 \mu \mathrm{m}$ particles became hot and the bubble formation in the neighborhood of the $40 \mu \mathrm{m}$ particles. This forced most of the water out of the core, and the entire excursion was over about 0.6 seconds after the operator started raising the control rod. The maximum reciprocal period was nearly $100 \mathrm{~s}^{-1}$, the maximum power was $1.7 \times 10^{8}$ watts, and the halfwidth of the power spike was 18.5 milliseconds.

In this excursion, the core fuel elements were ruined, but no significant amount of fissile material was lost. The activity in the reactor room was above tolerance for about a day. The core elements were removed after 5 days, and decontamination was completed by a single application of detergent and warm water. Four persons received radiation doses of $136,127,60$, and 9 , rep.*

*See Appendix A. 


\title{
4. Chalk River Laboratory, Atomic Energy of Canada, Ltd., 12 December $1952^{63,65,66,67}$
}

\author{
NRX reactor; natural uranium rods; heavy water moderated; graphite reflected; multiple excursions; \\ insignificant exposures.
}

The NRX reactor was a natural uranium, heavy water moderated system with the uranium rods cooled by a thin sheath of light water flowing between the aluminum clad fuel rod and a slightly larger concentric aluminum cylinder. The heavy water moderator reduced the neutron energy enough that the light water coolant served as a poison.

Through a very complicated series of operator errors and electrical and mechanical safety circuit failures, the reactor was forced to be supercritical by about $60 \%$. Initially the power increased rapidly but, because of a slowly moving control rod, the reactor gave every indication of leveling off at a power of about 20 megawatts. Normally this would have been a high but tolerable power and, very likely the situation would have been controllable if the experiments underway had not required reduced the light water cooling flow for several of the fuel rods. At a power of about 17 megawatts, the cooling water commenced to boil in those channels with reduced flow. This autocatalytic action (the light water was effectively a poison) increased the reactivity by about $20 \notin$ and the power rose again with a period estimated to be between 10 and 15 seconds. When the power reached 60 to 90 megawatts, the heavy water moderator was dumped and the excursion stopped.

The reactor power was greater than 1 megawatts for no more than 70 seconds, and the total energy release has been estimated at 4,000 megajoules, or about $1.2 \times 10^{20}$ fissions. The core and calandria (fuel element support structure) were damaged beyond repair. Some $10^{4}$ Curies of long lived fission products were carried to the basement by a flood of $10^{6}$ gallons of cooling water. Personnel irradiations were apparently low; the reactor was restored to operation in slightly more than a year.

\section{National Reactor Testing Station, 22 July $1954^{69,70,71,72}$}

\section{BORAX reactor, aluminum-uranium alloy, water moderated; single excursion; insignificant exposures.}

The National Reactor Testing Station was located near Idaho Falls, Idaho in the United States. This excursion was an accident only in the sense that it was larger than expected. The BORAX-I reactor had been built as a temporary affair; steady state and transient studies were regarded as complete; and it was decided that the reactor should be forced onto a short period transient to obtain the maximum amount of experimental information before it was dismantled. The excess reactivity was chosen to produce a fission yield such that about $4 \%$ of the fuel plates would melt.

The BORAX-I reactor consisted of 28 MTR-type fuel elements moderated by light water. Each element contained 18 fuel plates 2.845 inches $x$

0.060 inches $\times 24.6$ inches consisting of aluminumuranium alloy clad with about 0.020 in. of aluminum. The total uranium inventory was $4.16 \mathrm{~kg}$, and the whole core was in a semi-buried tank 4 feet in diameter and 13 feet high.

It had been estimated from earlier controlled prompt excursions that about $4 \%$ excess $k$ would put the reactor on a period between 2.0 and 2.5 milliseconds and that the resulting excursion would release about 80 megajoules of fission energy. To perform this experiment a larger than usual fuel loading and a more effective central control rod were required.

The excursion and associated steam explosion following rapid ejection of the control rod completely disassembled the reactor core and ruptured the reactor tank (Figure 59). Very extensive melting of the fuel plates occurred; some elements remained in the tank and small pieces were found up to 200 feet away.

An example of the force of the explosion was the carrying away of the control rod mechanism. This mechanism, which weighed 2,200 pounds, sat on a base plate, about 8 feet above the top of the reactor tank. Except for the base plate, about 4 feet square, the top of the 10 foot shield tank was essentially unobstructed. The force of the explosion plus the impingement of water and debris on the base plate tore the plate loose from its coverage and, as revealed by high speed movies, tossed the mechanism about 30 feet into the air. ${ }^{71}$

The total energy release was 135 megajoules instead of the predicted 80 megajoules or, assuming $180 \mathrm{MeV}$ deposited per fission, $4.68 \times 10^{18}$ fissions. This energy is equivalent to that contained in about 70 pounds of high explosive, but it has been estimated that between 6 and 17 pounds of high explosives would produce comparable damage. The minimum period was 2.6 milliseconds, and the maximum power was about $1.9 \times 10^{10}$ watts. It is apparent that the nuclear excursion was completed before the steam explosion destroyed the system.

In this excursion, the reactor was destroyed but, because of the remote site, physical damage was limited to the reactor. No personnel were exposed to radiation. 


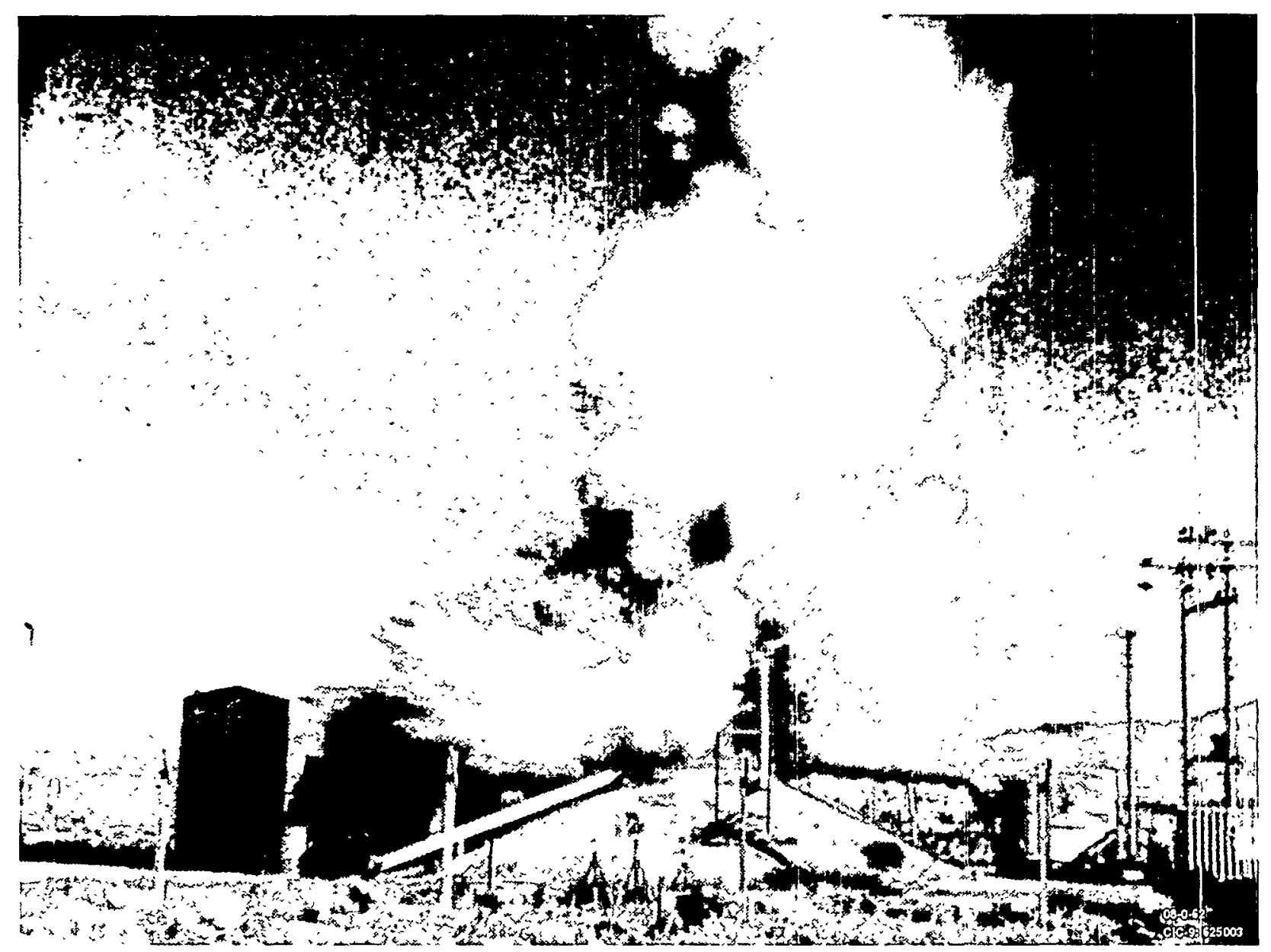

Figure 59. The destructive excursion in BORAX, 22 July 1954.

\section{Boris Kidrich Institute, 15 October $1958^{\star 73,74}$}

\section{Unreflected, $\mathrm{D}_{2} \mathrm{O}$-moderated, natural uranium assembly, unshielded.}

The Boris Kidrich Institute was located in Vinca, Yugoslavia. The accident occurred with an unreflected matrix of natural uranium rods moderated by heavy water. The aluminum clad rods were $25 \mathrm{~mm}$ in diameter and $2.1 \mathrm{~m}$ long; the total core uranium mass was $3,995 \mathrm{~kg}$ in a volume of $6.36 \mathrm{~m}^{3}$. Two cadmium safety rods were installed but not interlocked with the flux recorder. The liquid level was normally used to control the system reactivity (critical level, $1.78 \mathrm{~m}$ ).

At the time of the accident a subcritical foil counting experiment was in progress. To obtain as much activation of the foils as possible, it was desired to raise the multiplication to some high but still subcritical level. This was done by raising the heavy water in the tank in a series of steps. On the last step, two of the $\mathrm{BF}_{3}$ chambers performed as before-leveling off at a higher signal level, but the third behaved erratically and was disconnected. After the assembly had been at this $\mathrm{D}_{2} \mathrm{O}$ level about 5 to 8 minutes, one of the experimenters smelled ozone and realized that the system was supercritical at some unknown power level. The cadmium safety rods were used to stop the excursion.

Later investigation showed that both of the detecting chambers that were believed to be working properly had reached saturation and were reading a constant maximum value even though the power level was rising steadily.

Radiation doses were intense, being estimated at $205,320,410,415,422$, and $433 \mathrm{rem}^{74}$ Of the six persons present, one died and the other five recovered after severe cases of radiation sickness. The critical assembly withstood the energy release of 80 megajoules (about $2.6 \times 10^{18}$ fissions) with no reported damage.

\footnotetext{
${ }^{*}$ We are indebted to Dr. T. J. Thompson for first reporting the correct sequence of events. Some of the details of this incident are
} taken verbatim from his discussion. 


\section{Centre dÉtudes Nucleaires de Saclay, France, 15 March $1960^{26,27}$}

$U(1.5) O_{2}$ rods, water moderated and reflected, assembly; single excursion; insignificant exposures.

The Alize critical assembly was a water reflected and water moderated system using, in this case, $\mathrm{UO}_{2}$ rods as fuel in which the uranium was enriched to $1.5 \%$. The rods were $1 \mathrm{~m}$ long and $10 \mathrm{~mm}$ in diameter with the total $\mathrm{UO}_{2}$ mass equal to 2.2 tons.

The experiment in progress at the time of the accident required a stable positive period at a very low power. To accomplish this, the critical rod configuration was found experimentally and the rod position required for the necessary period was calculated. After allowing for the decay of delayed neutron precursors, the rods were withdrawn to the predetermined position. However, for reasons unknown, the operator then completely withdrew a rod that previously was not fully out. This placed the system on a period of about $1 / 4$ second.

The subsequent power excursion created $3 \times 10^{18}$ fissions, but the peak temperatures in the $\mathrm{UO}_{2}$ were less than $550^{\circ} \mathrm{C}$. The core was undamaged, and personnel radiation doses were trivial.

It was deduced that the quenching action must have been a result of the ${ }^{238} \mathrm{U}$ Doppler effect. This judgment was substantiated by the Spert experiments with a similar core in which the uranium was enriched to $4 \%$ (II-C.9).

\section{National Reactor Testing Station, 3 January $1961^{74,75}$}

$S L-1$ reactor; aluminum-uranium alloy; water moderated; single excursion; three fatalities.

The SL-1 reactor (originally known as the Argonne Low Power reactor) was a direct-cycle, boiling water reactor of 3 megawatts gross thermal power using enriched uranium fuel plates clad in aluminum, moderated, and cooled by water. Because the reactor was designed to operate for 3 years with little attention, the core was loaded with excess ${ }^{235} \mathrm{U}$. To counterbalance the excess of ${ }^{235} \mathrm{U}$, a burnable poison $\left({ }^{10} \mathrm{~B}\right)$ was added to some core elements as aluminum- ${ }^{10} \mathrm{~B}-$ nickel alloy. Because the boron plates had a tendency to bow (and, apparently, to corrode, increasing reactivity), some of them were replaced in November 1960 with cadmium strips welded between thin aluminum plates. At that time the shutdown margin was estimated to be $3 \%$ (about $4 \$$ ) compared to the initial value of $3.5 \%$ to $4 \%$. The cruciform control rods, which tended to stick, were large cadmium sheets sandwiched between aluminum plates. The nuclear accident was probably independent of the poor condition of the core.

After having been in operation for about 2 years, the SL-1 was shut down 23 December 1960 for routine maintenance; on 4 January 1961, it was again to be brought to power. The three man crew on duty the night of 3 January was assigned the task of reassembling the control rod drives and preparing the reactor for startup. Apparently, they were engaged in this task when the excursion occurred.

The best available evidence (circumstantial, but convincing) suggests that the central rod was manually pulled out as rapidly as the operator was able to do so. This rapid increase of reactivity placed the reactor on about a 4 millisecond period; the power continued to rise until thermal expansion and steam void formation quenched the excursion. The peak power was about $2 \times 10^{4}$ megawatts, and the total energy release was $133 \pm 10$ megajoules.

The subsequent steam explosion destroyed the reactor and killed 2 men instantly; the third died 2 hours later as a result of a head injury. The reactor building and especially the reactor room were very seriously contaminated by the reactor water, which carried fission products with it. Initial investigations were hindered by the high radiation field $(500$ to $1000 \mathrm{R} / \mathrm{h})$ in the reactor room. In spite of the large radioactivity release from the core, very little escaped from the building, which was not designed to be airtight.

In many respects this reactor excursion resembled that of the BORAX and Spert destructive experiments. Each of these, and especially Spert (II-C.9), was instrumented to follow just such an excursion. W. Nyer ${ }^{75}$ notes that the crucial parameter is the energy density in the core. This is larger for the SL-1, but not grossly so, being $12 \%$ more than BORAX and $60 \%$ more than Spert. The prompt alpha (reciprocal period) for SL-1 seems to have been slightly lower. The steam explosion caused considerable damage in all three power transients, especially in BORAX and SL-1. In SL-1 the core was enclosed and the water apparently was accelerated upward more or less as a single slug. The energy acquired by the water was sufficient to lift the entire reactor vessel some 9 feet before it fell back to its normal position.

In the Spert experiments, the steam explosion followed the nuclear power spike by 15 milliseconds. It is not known if such a delay occurred following the SL-1 power transient. 


\section{National Reactor Testing Station, 5 November $1962^{76}$}

\section{Assembly of Spert fuel elements; single non-nuclear excursion; insignificant exposures.}

The accident occurred with a small test assembly designed to investigate the transient behavior of water moderated and cooled plate type reactors. The Spert fuel consisted of plates of highly enriched uranium alloyed with aluminum and clad with the same material. Previous test programs had produced data for transients whose initial period exceeded 8 millisecond. These experiments were nondestructive, having resulted in only minor fuel plate distortion. However, some data of a destructive nature was obtained for a 2.6 millisecond period in the 1954 BORAX-I test that resulted in an explosion that destroyed the reactor. These experiments were therefore designed to investigate the transition from essentially non-damaging to destructive excursions.

After completion of a long experimental program, two tests were conducted resulting in periods of 5.0 and 4.6 milliseconds. These resulted in some plate distortion and some limited fuel melting. The transient behavior was regarded as a reasonable extrapolation of data from earlier experiments having longer periods. There was no indication that further extrapolation was not valid.

In the final test with a 3.2 milliseconds period (energy release $30.7 \mathrm{MJ}$ ) all 270 plates showed melting to some degree, with the average molten fraction about
$35 \%$. The performance of this test, from the nuclear point of view, was very close to predicted. Evidently the nuclear characteristics of the shutdown were essentially identical to the earlier transients and involved fuel and moderator thermal expansion and boiling of water. However, about 15 milliseconds after the nuclear transient was terminated, a violent pressure surge resulted in total destruction of the core. This is attributed to a steam explosion caused by rapid energy transfer from the molten fuel to the water moderator. Fuel, water, and core structure were violently ejected from the vessel in which the experiment took place.

This experiment was instrumented to measure the activity of any fission products that might be released, even though no violent excursion was expected. The measurements showed that about $7 \%$ of the noble gases produced during the transient escaped to the atmosphere. The roof and some of the siding of the reactor building had been removed prior to the test, so the building provided only limited confinement. Neither solid fission products nor any radioiodines were found in the atmosphere.

Based on the detection sensitivity of the instrumentation and the lack of any indicated presence of iodine, it was established that less than $0.01 \%$ of the radioiodines produced had escaped to the atmosphere.

\section{Mol, Belgium, 30 December $1965^{26,27}$}

VENUS assembly; $7 \%$ enriched $\mathrm{UO}_{2}$ rods in $\mathrm{H}_{2} \mathrm{O}_{-} \mathrm{D}_{2} \mathrm{O}$; single excursion; one serious exposure.

VENUS was a tank-type, water moderated, critical assembly machine used for experiments apropos of the Vulcan reactor. This was a "spectral shift" reactor, so called because the initial moderator of $\mathrm{D}_{2} \mathrm{O}$ could be diluted with $\mathrm{H}_{2} \mathrm{O}$ to soften the spectrum and maintain reactivity as the fissile material was consumed. For the experiments in progress, the composition of the moderator and reflector was $70 \% \mathrm{H}_{2} \mathrm{O}$ and $30 \% \mathrm{D}_{2} \mathrm{O}$; the reflector extended $0.3 \mathrm{~m}$ above the top of the core. The height and diameter of the core were about $1.6 \mathrm{~m}$. The fuel was $\mathrm{UO}_{2}$ in the form of pelleted rods, the total mass of $\mathrm{UO}_{2}$ was $1200 \mathrm{~kg}$, and the ${ }^{235} \mathrm{U}$ enrichment was $7 \%$.

The primary reactivity control was by motion of poison rods ( 8 safety rods and 2 control rods); 8 additional absorbing rods were available for manual positioning in the core. Just before the accident, all safety rods were in, a control rod was in, 7 manual rods were in, and a control rod was being inserted; the reactor was subcritical by 1 safety rod and 1 control rod.

To perform an experiment with a new rod pattern, the operator of the reactor decided to decrease reactivity by inserting the last manual rod, waiting until the second control rod was fully inserted. Then, as the reactor should have been subcritical by 1 safety rod, 2 control rods, and 1 manual rod, a different manual rod located near the last one inserted could be pulled out of the core and the reactor made critical again by lifting two safety rods.

Such a program required a person to insert I manual rod and extract another. The operator did not take into account a rule written into the safety report of the reactor, i.e., that no manipulation of a manual rod in the core should be performed without first emptying the vessel. He gave a written order to 
a technician prescribing the loading of a manual rod followed by the unloading of another one. The technician did not wait until the moving control rod reached its bottom position and started the manipulation in the wrong order. He first extracted a manual rod instead of first inserting the other.

During the extraction of the manual rod the reactor became critical. The technician had his left foot projecting over the edge of the tank and resting on a grating that was about $50 \mathrm{~mm}$ above the reflector; his right foot and leg were somewhat behind him and partly shielded. He noticed a glow in the bottom of the reactor, immediately dropped the control rod, and left the room.
The energy release was $4.3 \times 10^{17}$ fissions and, apparently, the excursion was stopped by the falling manual rod, although the scram may have been speeded up by a combination of the Doppler effect and emptying of the vessel, which was automatically "provoked." This is uncertain.

No steam was created, no damage was done to the fuel, and there was no contamination. The technician received a severe radiation dose, primarily gammarays. Eight days later and after 300 measurements in a phantom, rough estimates were that the dose to his head was 300 to $400 \mathrm{rem}$, to his chest $500 \mathrm{rem}$, and to his left ankle 1,750 rem. At the end of his foot the dose approached 4,000 rem. Medical treatment of the patient was successful, except that the left foot had to be amputated.

\section{Kurchatov Institute, 15 February $1971^{77}$}

\section{$U(20) \mathrm{O}_{2}$ fuel rod, iron and beryllium reflected, assembly; multiple excursions; two serious exposures.}

Experiments to evaluate the relative effectiveness of iron and metallic beryllium as a reflector on a power reactor core were in progress at the critical experiment facility, SF-7. The core measured $1,200 \mathrm{~mm}$ high and $1,000 \mathrm{~mm}$ in diameter and held 349 fuel rods. Criticality was obtained by adding water to the core and immersing the fuel rods. The safety rods consisted of a lattice of boron carbide rods that could be inserted throughout the core to compensate for the operative reactivity margin. The boron carbide lattice did not cover the three outer rows of fuel rods. The fuel rods were enriched to about $20 \%{ }^{235} \mathrm{U}$ (typical of icebreakers).

The first stage of the experiment consisted of a core configuration in which the neutron flux was nonuniformly distributed along the core radius. Measurements showed that the completely water flooded core with the boron carbide safety rod lattice inserted was deeply subcritical $(\sim 10 \%)$, and the reactivity increased only slightly $(+0.8 \%)$ after replacing the radial iron reflector with one of beryllium.

The second stage of the experiment consisted of a core configuration in which the neutron flux was uniformly distributed along the core radius. One hundred forty-seven fuel rods with the maximum loading of burnable neutron absorber were inserted into the central part of the core that was heavily poisoned by a safety rod lattice. Two surrounding rows of rods (118 rods) containing less absorber, in this case a burnable poison, were then added. The outermost row (84 rods) did not contain burnable neutron absorber material.
The second stage of the experiment, according to the plan, began with the beryllium reflector in place because it was in place at the end of the first stage. However, criticality calculations for this core configuration were performed only for an iron reflector. Based on results of the comparison between beryllium and iron reflectors for the first configuration, the supervisor of the experimental team determined that substituting iron for beryllium would not result in any considerable increase in reactivity. Therefore, additional calculations were not performed.

The core configuration with the beryllium reflector was assembled in the dry critical facility tank and left for the night. The next morning, the supervisor entered the facility control room (Figure 60) and without waiting for the arrival of the control console operator and the supervising physicist, switched on the pump, and began adding water to the critical assembly tank. The supervisor considered the system to be far from critical. The control equipment was switched on, but the neutron source had not been placed in the critical assembly, and the control rods were not actuated.

A scientist arrived from Gorky who was training at the SF-7 experimental facility and was standing near the critical assembly tank discussing the experiment with the supervisor. Suddenly they saw a blue luminescence reflecting from the ceiling and heard a rapidly increasing signal from an audible neutron flux indicator. They thought that something had happened in another facility and ran from the critical assembly room. Other workers who were in the room also left. The manager of the facility was informed of the event. The manager and a dosimetry technician tried to enter 


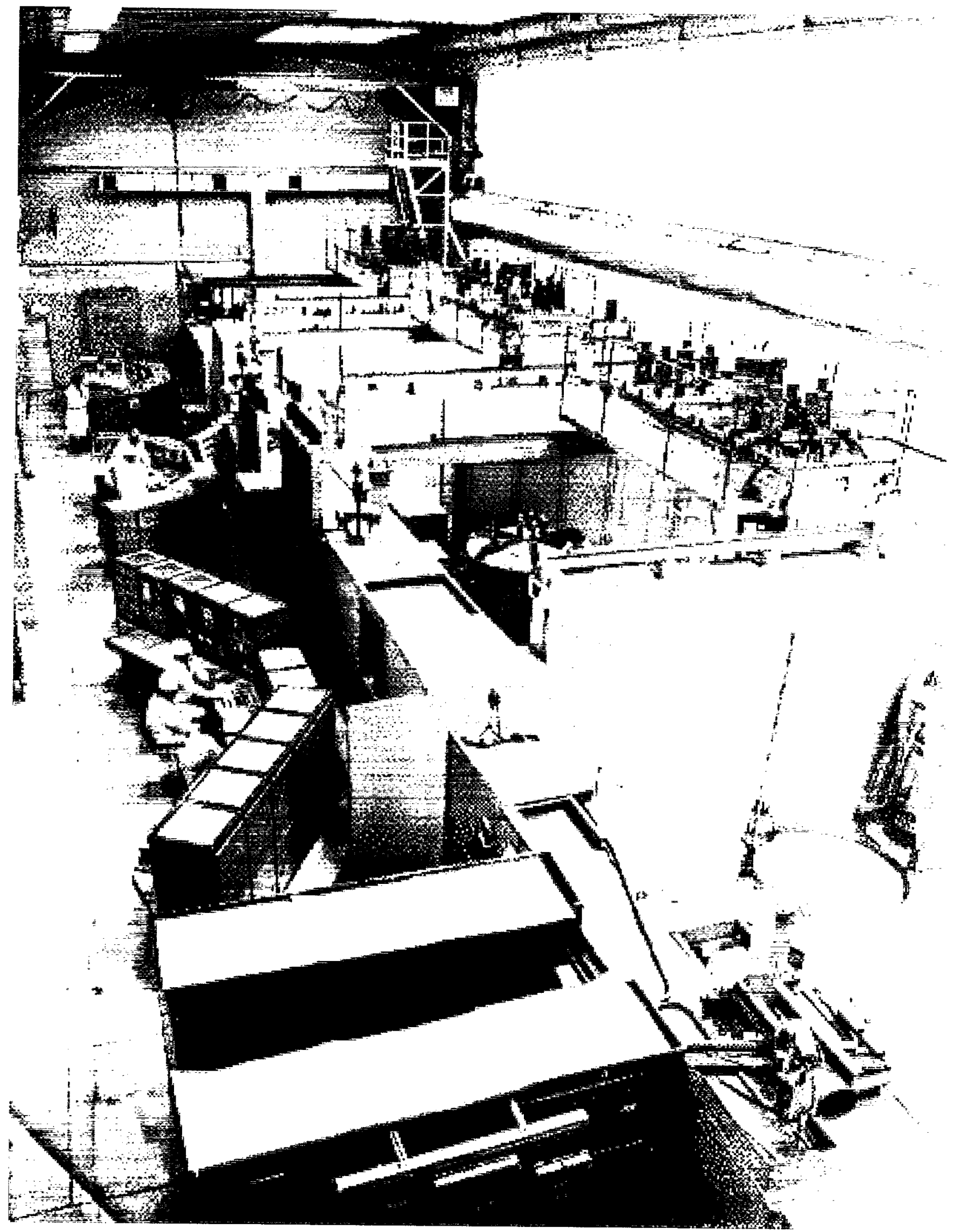

Figure 60. Photograph of the SF-7 control and experimental rooms where the first accident occurred. 
the room to drain the water out of the critical assembly tank but the radiation levels and the steam that filled the room made it impossible to approach the control console. The pump had continued adding water to the tank. After 5 to 7 minutes, the electricity supply was shut off at the substation and the pump ceased.

Later assessments showed that about 50 pulses occurred. Since the neutron source was not in the critical assembly the core reached critical on prompt neutrons, a fast pulse occurred, water boiled and splashed out of the tank, and the excursion terminated. When the water was pumped to the critical level the process was repeated. Total energy release was $\sim 2 \times 10^{19}$ fissions with each event averaging about $5 \times 10^{17}$ fissions. The rate of reactivity insertion was comparatively small ( $\sim 0.15 \beta_{\text {eff }}$ per second) so the fuel rod cladding did not rupture and the room was not contaminated.

Three days later the water level was measured and found to be $560 \mathrm{~mm}$ from the core bottom, and the lattice was flooded. The difference between excess reactivity margins for a core with iron and beryllium reflectors was $\sim 10 \%$.

The supervisor and the scientist were injured during the accident. They each received $\sim 1500$ rem to their feet. Other personnel in the room were behind shielding and received much smaller doses.
The two major causes of this accident were as follows:

1) It was incorrectly judged that the reactivity worth of the beryllium reflector (calculations had not been performed) was essentially the same as the iron reflector (calculations had been performed).

2) Serious violations of SF-7 operating requirements occurred:

a) Action that could change the core reactivity should have been considered an experiment. The addition of water was an obvious change to the core reactivity and should not have been initiated without a full operating crew (scientific leader, supervising physicist, and the control console operator).

b) Before initiating the experiment (adding water) all control equipment should have been tested, the neutron source should have been introduced into the core, and the safety rods should have been inserted.

c) Any reactivity addition should have been done step-by-step. The parameter $1 / \mathrm{M}$ should have been plotted and extrapolated to the critical value after each step.

\section{Kurchatov Institute, 26 May $1971^{78,79}$}

$U(90)$ fuel rod, water reflected, assembly; single excursion; two fatalities; two serious exposures.

This accident occurred in the SF -3 facility during an experimental program to measure critical masses formed by a certain type of highly enriched $(\sim 90 \% 235 \mathrm{U})$ fuel rods. These rods were very similar to those described in Reference 72 . The critical number of fuel rods at various hydrogen-to- ${ }^{235} \mathrm{U}$ atom ratios was being determined. This ratio was changed by varying the pitch of the fuel rods within the lattice while preserving the hexagonal form of the cell. Table 12 gives the lattice pitch value and the corresponding number of rods, $N$. This highlights the rather sharp decline in the critical number of fuel rods as the pitch increases in the $7-9 \mathrm{~mm}$ pitch range.

\begin{tabular}{|c|c|c|c|c|}
\hline Pitch, mm & 7.2 & 9.5 & 11.5 & 14.4 \\
\hline$N$ (rods) & 1,790 & 590 & 370 & 260 \\
\hline
\end{tabular}

Efforts were made to make the experiments as clean as possible with minimum perturbations in the system. The assembly consisted of a $20 \mathrm{~mm}$ thick Plexiglas base plate which supported the weight of a lattice of fuel rods, and $2 \mathrm{~mm}$ thick aluminum plates used to hold the end of the rods in position. Plexiglas was chosen since its hydrogen content is similar to water. The guiding devices for emergency protection and control rods were placed into the lateral reflector. The rod endings projected above the upper lattice about $2-3 \mathrm{~mm}$. The construction was quite delicate and fragile.

For each lattice pitch, a system containing considerably fewer rods than the estimated critical number was assembled in the dry critical assembly tank. This system was then flooded with water and reactivity measured until the water reflector above the rods was at least $200 \mathrm{~mm}$. Fuel rods were added, a few at a time, until the system became critical. Procedures were followed step-by-step and the parameter $1 / \mathrm{M}$ was plotted and extrapolated to the critical value after each step. 


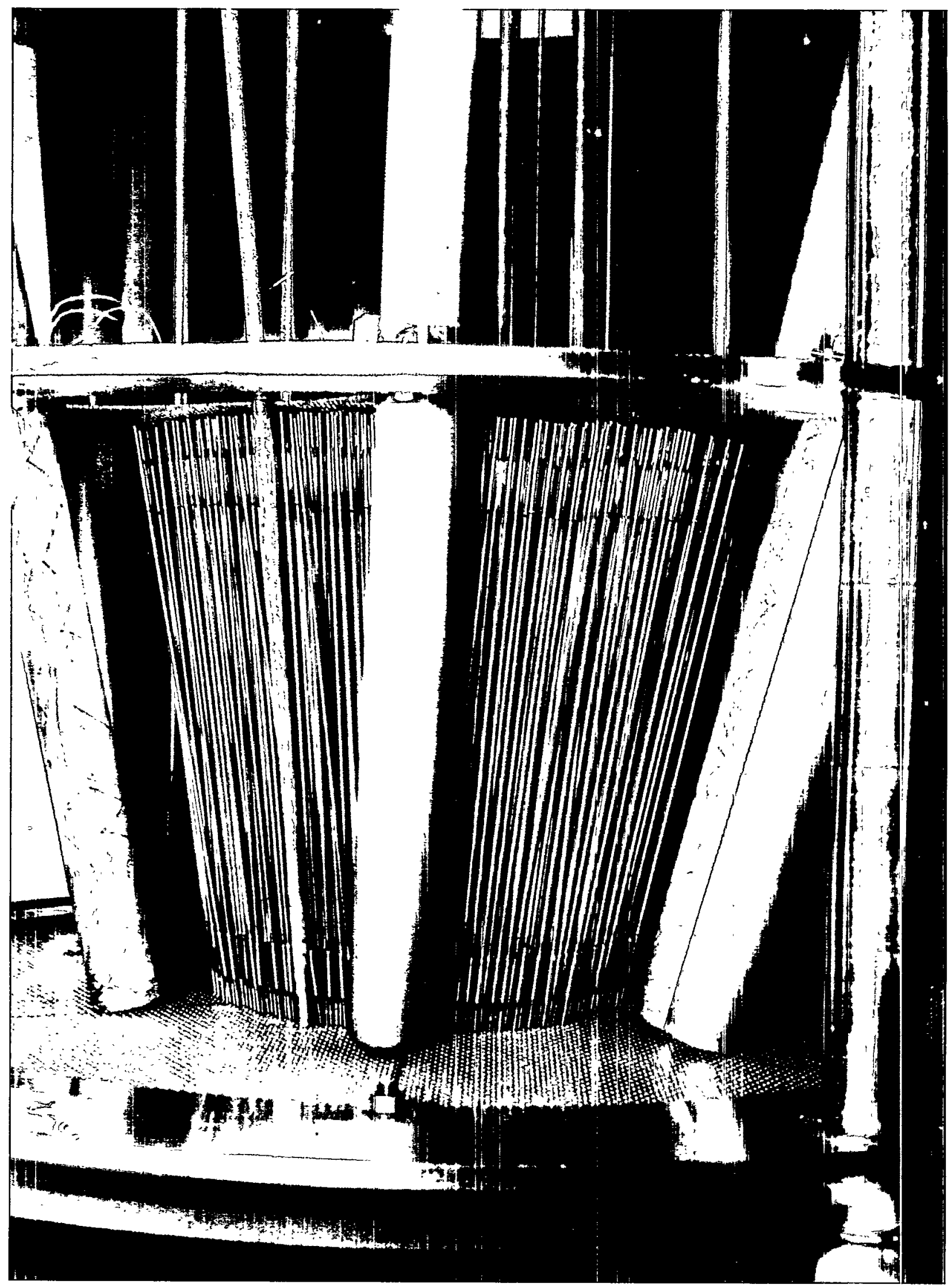

Figure 61. Mockup of the accident configuration for the 26 May 1971 accident. 
In the final experiment, the critical number of fuel rods with the smallest pitch $(7.2 \mathrm{~mm})$ was measured. This number was 1,790 and exceeded the minimum critical number of rods for an optimum pitch by approximately 7 times.

After the experiment was finished, the supervisor of the experimental team ordered the insertion of all control and emergency protection rods and the neutron source was removed from the core. Four staff members entered the critical assembly compartment for examination. The supervisor then ordered the water be removed through the fast dumping (emergency) valve.

The water from the critical assembly tank could have been drained through the slow dumping valve in 15 to 20 minutes or through the fast dumping valve in 20 to 30 seconds. After the previous experiments, the water had been drained through the slow dumping valve.

The plexiglas support plate almost completely covered the tank section, and the size of the gap between the plate edge and tank wall was less than the size of the fast dumping valve outlet. For this reason, upon initiating the fast dumping operation, the Plexiglas base plate sagged and the fuel rods fell out of the upper lattice plate (Figure 61). The fuel rods separated into a fan shaped array in which the pitch between the rods came close to optimum and the lattice went highly supercritical. The rate of reactivity insertion was calculated to have reached $\sim 2 \beta_{\mathrm{eff}} / \mathrm{s}$.
During the criticality accident, two peripheral rows of fuel rods were destroyed by the energy release. Fragments of these fuel rods resembled welding rod fragments. Water splashed out of the tank. The energy release in the burst, estimated from the core radioactivity, was $\sim 5 \times 10^{18}$ fissions. This value is, in all probability, universal for uranium-water systems in an open tank under conditions of rapid reactivity insertion. Excursions of this type are terminated due to fuel destruction or loss of water.

Radioactive contamination of the critical assembly room was minimal and there was no contamination of the outer premises; however, the accident consequences were tragic for the personnel involved. A technician, who was close to the tank when the pulse occurred received a radiation dose of $\sim 6,000$ rem and died 5 days after the accident. The supervisor received 2,000 rem and died in 15 days. Two other staff members inside the critical assembly room received doses of $700-800$ rem. Physicians managed to save their lives but both suffered long term health effects.

The construction of the critical assembly was the main cause of the accident. No calculations were performed for the components of the system and the construction as a whole. Improper and hasty actions by personnel during the final stage of the experiment also contributed to the cause of the accident.

\section{The RA-2 Facility, 23 September $1983^{79}$}

MTR-type fuel element, water reflected, assembly; single excursion; one fatality, two significant exposures.

The RA-2 Facility was located in Buenos Aires, Argentina. Control rods for this essentially zero power experimental reactor assembly were MTR elements in which 4 of the 19 fuel plates were removed and replaced by 2 cadmium plates. Just outside the fueled region (approximately $305 \mathrm{~mm} \times 380 \mathrm{~mm}$ ) was a graphite reflector approximately $75 \mathrm{~mm}$ thick. The large reactor vessel was filled with de-mineralized water during operations and was supposed to be drained during changes in fuel configurations when people were required to be present.

The technician, a qualified operator with 14 years experience, was alone in the reactor room making a change in the fuel configuration. The moderator had not been drained from the tank, though required by procedures. Two fuel elements had been placed just outside the graphite, instead of being removed completely from the tank. Two of the control elements, without the cadmium plates installed, were being placed in the fuel configuration. Apparently, criticality occurred as the second of these was being installed, since it was found only partially inserted.

The excursion consisted of 3 to $4.5 \times 10^{17}$ fissions; the operator received an absorbed dose of about $2000 \mathrm{rad}$ from gamma-rays and $1700 \mathrm{rad}$ from neutron. This exposure was highly non-uniform, with the upper right side of the body receiving the larger exposure. The operator survived for 2 days. Two people in the control room received doses of about $15 \mathrm{rad}$ from neutrons and 20 rad gamma-rays. Six others received lesser doses, down to $1 \mathrm{rad}$, and 9 received less than $1 \mathrm{rad}$. 


\section{MISCELLANEOUS SYSTEMS}

\section{Los Alamos Scientific Laboratory, 11 February $1945^{80,81}$}

\section{The Dragon assembly; $\mathrm{UH}_{3}$ pressed in styrex; single excursion; insignificant exposures.}

The Dragon assembly was the first fissile system designed to generate prompt power excursions and was probably the first reactor of any kind whose reactivity exceeded prompt criticality. 'This was accomplished by intent on 18 January 1945 ; the temperature rise is quoted as $0.001^{\circ} \mathrm{C}^{74}$ and the yield (not quoted) can be estimated to have been about $2 \times 10^{11}$ fissions.

The Dragon was made of enriched $\mathrm{UH}_{3}$ pressed with a special plastic, styrex, into small cubes of average chemical composition $\mathrm{UC}_{4} \mathrm{H}_{10}$. The configuration for the final experiments, containing only $5.4 \mathrm{~kg}$ of this material, was diluted with polyethylene and reflected by graphite and polyethylene.

The reactor was made prompt critical for about $1 /$ 100 of a second by dropping a slug of the active material through a vertical hole in the remaining portion, which was stacked on a $3 / 8$ inch steel table.
The falling slug of active material was contained in a steel box, its path closely defined by four guides.

Generally, the fission energy did not contribute to the quench of the excursion; the burst size was determined by the background fission rate and the stacking configuration on the table. Thus, the burst size could be varied by moving a reflector nearer the assembly or by increasing the background fission rate. Both techniques were often employed, and this may have been the case in the final experiment because the bursts were being made steadily larger. During the final excursion of about $6 \times 10^{15}$ fissions, the $\mathrm{UH}_{3}$ cubes became so hot that blistering and swelling occurred. The whole system had expanded about $1 / 8$ th of an inch.

In the final excursion, the core material was damaged but no active material was lost, there was no contamination, and no one received any radiation.

\section{National Reactor Testing Station, 29 November $1955^{82,83}$}

\section{EBR-1; enriched uranium fast breeder reactor; single excursion; insignificant exposures.}

Design of the EBR-1 fast neutron reactor was started in 1948 with the objectives of establishing possible breeding values and demonstrating the feasibility of cooling a metal fueled reactor with liquid metals. These objectives were met, and in early 1952, the plant furnished more than enough electrical power for the reactor and the reactor building; excess steam was blown to the condenser.

The reactor core consisted of cylindrical, highly enriched uranium rods slightly less than $1 / 2$ inch in diameter canned in stainless steel with a bonding of $\mathrm{NaK}$ between the rod and can. The total core mass of about $52 \mathrm{~kg}$ of uranium was bathed in a stream of $\mathrm{NaK}$, which served as a coolant.

The final experiment was designed to investigate coefficients of reactivity and, in particular, to study a prompt positive power coefficient without coolant flow. To do this, the system was placed on a period of 60 seconds at a power of 50 watts. About 3 seconds later the power was 1 megawatt, the period had decreased to 0.9 seconds, and core temperatures were rising significantly. The signal to scram the system was given, but by error the slow moving motor driven control rods were actuated instead of the fast acting scram-dropping part of the natural uranium blanket under gravity-as had been done to conclude similar experiments. This change in reactivity caused a momentary drop in power, but was inadequate to overcome the natural processes (very slight bowing inward of the fuel elements) adding reactivity to the system. After a delay of not more than 2 seconds, the fast scram was actuated, both manually and by instruments, and the experiment completed.

It was not immediately evident that the core had been damaged. Later examination disclosed that nearly one-half the core had melted and vaporized NaK had forced some of the molten alloy into the reflector. Theoretical analysis showed that the excursion was stopped by the falling reflector, after the power reached a maximum of 9 to 10 megawatt. The total energy release was close to $4.6 \times 10^{17}$ fissions. The theoretical analysis was carried further in an attempt to determine if the core would have shut itself off in a noncatastrophic manner. The conclusion was that the energy release could have been nearly 2.5 times the observed yield but would not have resulted in violent disassembly of the core.

During this accident no one received more than trivial radiation from airborne fission products, and direct exposure was essentially zero.

${ }^{*}$ R. Feynman pointed out the similarity of the procedures used in these experiments to tickling the tail of a dragon, thus it has been called the "Dragon Experiment." The name is often applied to the class of prompt-burst experiments where reactivity is added and subtracted mechanically and where quenching mechanisms dependent upon the fission energy released do not contribute significantly to the shutdown process. 


\section{Los Alamos Scientific Laboratory, 3 July $1956^{43,45}$}

\section{Honeycomb critical assembly; $U(93)$ metal foils moderated with graphite; single excursion; insignificant exposures.}

The machine in which this excursion occurred is typical of several then in existence. The Los Alamos machine consisted of a large matrix of 576 square aluminum tubes, 3 inches $\times 3$ inches $\times 6$ feet, split down the middle with one-half of the matrix moveable on tracks. The "honeycomb" in the disassembled state is shown in Figure 62. Generally, the facility had been used to simulate design features of complicated reactors because of the versatility in arrangements of uranium foil and various moderating materials. Inhomogeneous stackings in this and similar machines have the least inherent negative reactivity feedback of any critical assemblies in existence today. This conclusion stems from the apparent lack of any significant quenching mechanism, short of vaporizing the uranium foils, and the absence of a sufficiently fast acting scram mechanism.
The stacking on 3 July 1956 consisted of $58 \mathrm{~kg}$ of enriched $\left(93 \%{ }^{235} \mathrm{U}\right)$ uranium in the form of 2 and $5 \mathrm{mil}$ foils arranged between slabs of graphite with some beryllium reflector surrounding the core. The total mass of graphite was $1,139 \mathrm{~kg}$. At the time, some changes had been made in the reflector and graphite moderator, and criticality was being approached too rapidly for routine measurements. While the cart was moving at about 0.2 inch per second, the system became prompt critical, a burst occurred, and the scram system retracted beryllium control rods (reducing reactivity) and reversed the motion of the cart. The burst yield was $3.2 \times 10^{16}$ fissions.

Apparently this was a Dragon type excursion in that the excess reactivity was added and subtracted mechanically. There was no damage and no contamination. Because it was remotely controlled from a distance of $1 / 4$ of a mile, no one received any radiation.

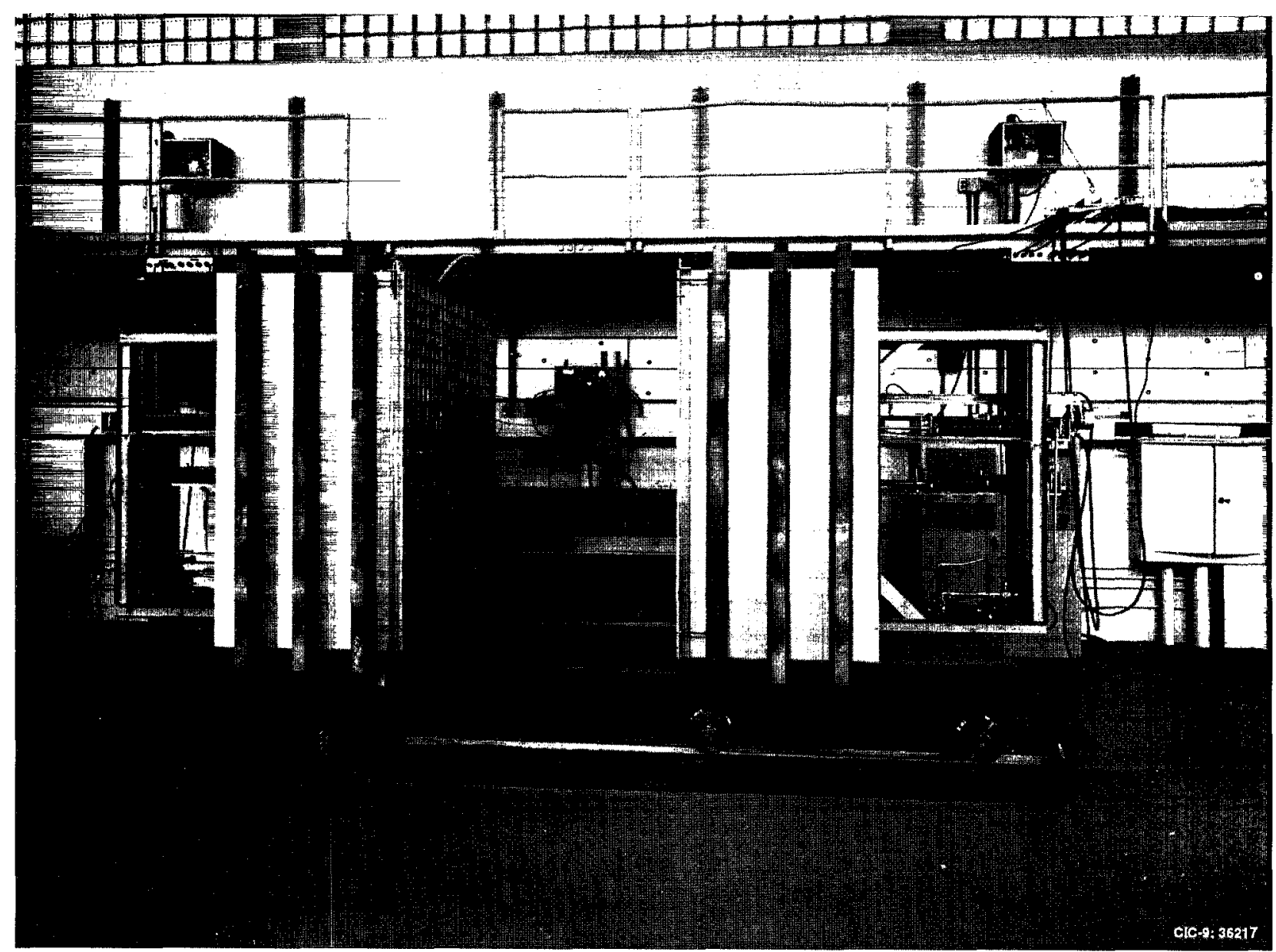

Figure 62. The LASL Honeycomb assembly machine. The movable section (right) is in the withdrawn position and the aluminum matrix is only partially loaded. 


\section{National Reactor Testing Station, 18 November $1958^{84}$}

HTRE Reactor; instrumentation failure; single excursion; insignificant exposures.

The High Temperature Reactor Experiment (HTRE No. 3) power plant assembly was a large reactor (core diameter 51 in.. length 43.5 in.) with nickelchromium- $\mathrm{UO}_{2}$ fuel elements, hydrided zirconium moderator, and beryllium reflector. The experimental objective was to raise the power to about 120 kilowatts, about twice that attained earlier in the day. This was done by manual control until about $10 \%$ of desired power was reached. At that point, control shifted to a servomechanism programmed to take the reactor power to 120 kilowatts on a 20 second period. When about $80 \%$ of full power was attained, the flux, as shown on the power level recorder, began to fall off rapidly and the servosystem further withdrew the control rods. The power indication, however, did not increase but continued to drop. This situation existed for about 20 seconds when the reactor scrammed automatically; within 3 seconds the operator took action that also activated the scram circuit. It is thought that the automatic scram was triggered by melting thermocouple wires. The primary cause of the accident was a drop in the ion collecting voltage across the detection chamber of the servosystem with increasing neutron flux. This behavior was, in turn, caused by the addition to the wiring of a filter circuit designed to reduce electronic noise from the high voltage supply or its connecting cable. Thus, this accident appears to be unique, as it was due solely to instrumentation.

In the nonviolent power excursion of about $2.5 \times 10^{19}$ fissions, all core fuel elements experienced some melting; only a few of the zirconium hydride moderator pieces were ruined. The melting of fuel elements allowed a minor redistribution of fuel, decreasing the reactivity by about $2 \%$. Some fission product activity was released downwind, but personnel radiation doses apparently were negligible.

\section{Los Alamos Scientific Laboratory, 11 December 1962}

Zepo critical assembly; ${ }^{235}$ U foils, graphite moderated; single excursion; insignificant expostures.

The critical assembly consisted of a large cylindrical enriched uranium-graphite core on a lift device and a stationary platform holding a reflector of graphite and beryllium into which the core was raised. Most of the ${ }^{235} \mathrm{U}$ was placed in the graphite in the form of thin foils, therefore the excursion characteristics should be similar to those of the honeycomb assembly. The experiment was concerned with measurements of the axial fission distribution, which was perturbed from its normal value by an end reflector of layers of graphite and polyethylene. For this reason, some fresh ${ }^{235} \mathrm{U}$ foils had been placed in the assembly to obtain a reasonably precise value of the fission energy release.
The crew assumed the assembly had been run and checked the previous day; however, this was not the case. The system became critical with the core in motion upward. The instrumentation scrammed the assembly when the power was about 200 watts. Before the lift could coast to a stop and start down, the system reactivity exceeded prompt criticality by about $12 \notin$. Peak power was about 1 megawatt; maximum alpha was $40 \mathrm{~s}^{-1}$; and the yield was $3 \times 10^{16}$ fissions. No damage was done and personnel radiation doses were not measurable. The laboratory was entered within 30 minutes. 


\section{POWER EXCURSIONS AND QUENCHING MECHANISMS}

The study and understanding of initiating events and shutdown mechanisms associated with criticality accidents offer potential for limiting the frequency and consequences of such untoward events. Although more fatalities have been associated with critical experiment and small reactor accidents (12) than with processing of fissile material (9), greater visibility seems to be associated with the safety of processing activities. Perhaps this is because of the larger number of individuals exposed in processing plants, the larger economic impact of facility shutdown, and the recognition of a degree of assumed risk for systems operated at or near the critical state.

The most obvious and significant characteristic of the criticality accidents that have occurred in process operations is that all but one of them involved solutions or slurries. This is attributable to several factors: the relatively small quantity of fissile material required for criticality when well moderated; the high mobility of solutions; the ease with which they adapt to changes in vessel shape; the potential for changes in concentration; and, in several cases, the exchange of fissile material between aqueous and organic phases. Fortunately, along with the frequency of solution accidents, there is a good understanding of quenching mechanisms and of an inherent limitation to the fission power density in solutions.

While there must be no implication of neglecting concern with solid fissile materials, safety interests may well concentrate on the behavior of solutions for which criticality control is more subtle. While today's practices strongly encourage reliance on criticality safety features that are built into the process equipment, complete independence from administrative controls is extremely difficult to achieve. Studies of real and simulated accident mechanisms offer insight into features that can mitigate the consequences of the unlikely accident, should it occur. One such feature might involve the inclusion of an appropriately strong neutron source internal to a necessary, unfavorable geometry vessel that is to receive solution normally too lean to support criticality and not having a significant inherent neutron source. The CRAC 5 experiments clearly demonstrate the efficacy of such a source for limiting the size of first peaks of power excursions.

In addition to the understanding gained from studying the process accidents and the reactor and critical assembly excursions involving solution systems, we derive much information from several series of experiments with controlled excursions in solutions. In the U.S. the KEWB ${ }^{85,86,87}$ (Kinetic Experiments on Water Boilers) series is of interest, while the CRAC experiments performed by the Service
d'Études de Criticité of the Commissariat a l'Énergie Atomique have direct applicability to estimates of accident consequences. These programs, which involved solutions of highly enriched uranium, are supplemented by a series of measurements at Los Alamos using the SHEBA assembly. This assembly is fueled with a $5 \%$ enriched uranium solution, that provides information on dose rates near excursions in systems of lower enrichment. ${ }^{88}$ Analysis of data from KEWB and CRAC has led to relatively simple computer codes that follow the early transient behavior well and rely on thermal expansion and the formation of radiolytic gas for the shutdown mechanisms.

Transient behavior in moderated solid cores has been studied in the SPERT ${ }^{89,90,91}$ and TRIGA ${ }^{92,93}$ experimental programs, while the very fast transients in simple, unmoderated metal systems are well understood as a result of studies of Godiva and similar fast burst reactors.

The quenching actions manifest in the above mentioned experimental studies and which have terminated many of the accidental excursions, inçlude thermal expansion, boiling, ${ }^{238} \mathrm{U}$ Doppler effect ${ }^{95}$, and radiolytic gas bubble formation. The order here is of no importance, and not all are independent. In addition, in some situations, more than one mechanism contributes to quench or shutdown the excursion; in many cases, additional quenching actions set in when energy densities or temperatures reach some threshold value. The ramifications of this subject are varied and numerous, but the simplest and most generally applicable case is that of the energy model ${ }^{95,96,97}$ in which the change of reactivity is proportional to the release of fission energy.

For the special case of a step increase in reactivity, $\Delta k_{0}$, we can write

$$
\Delta k(t)=\Delta k_{0}-b E(t)
$$

where $E(t)$ is the fission energy released to time $t$ and $b$ is a constant characteristic of the system. With this assumption, the reactor kinetic equations have been coded for numerical solution by use of digital computers. Such codes exist in many laboratories; the results quoted here are from the Los Alamos RTS Code. ${ }^{98,99}$ Figure 63 illustrates a series of computations for hypothetical systems in which the step increase of $\Delta k$ is $1.20 \$$ relative to delayed criticality, the value of $b$ is constant, and the neutron lifetime, $l$, is varied from $10^{-8}$ to $10^{-4}$ seconds. The power and reactivity traces for the short neutron lifetime cases are characteristic of prompt excursions in fast reactors. The very sharp rise and fall in power is called the spike, and the relatively 

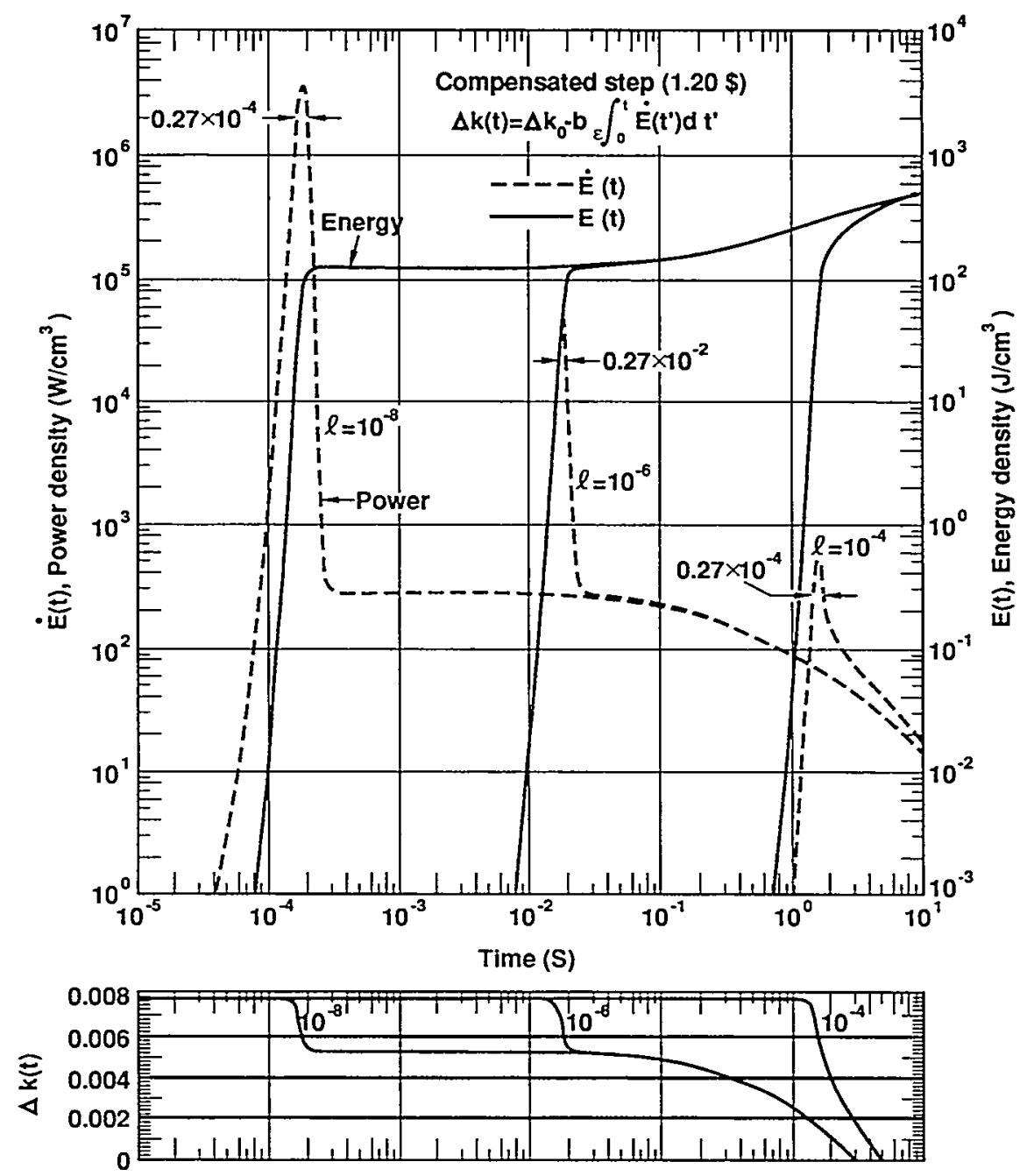

Figure 63. Energy model computation of power and energy release vs time. The initial reactivity is $1.2 \$$ above delayed critical. Neutron lifetime values are $10^{-8}, 10^{-6}$, and $10^{-4}$ seconds. The bottom panel shows the corresponding curves of reactivity vs time.

constant power following the spike is the plateau. During the spike. the reactivity changes by $2 \Delta k_{0}$-that is. it reflects about prompt criticality. The characteristics of such spikes are established almost entirely by the prompt neutrons. The traces for $l=10^{-4}$ (simulating a solution system or a moderated reactor) do not show the reflection about prompt criticality, and there is no well-defined plateau following the spike. The time scale is of the order of the decay times of the shorter delayed neutron precursor: the effects of these neutrons cannot be ignored.

Figure 64 illustrates comparable data for a step increase in reactivity of $1.0 \$$. The time history of the reactivity and power in this case is quite different and is typical of excursions in the delayed critical region. The time scale is much extended, allowing the possibility of mechanical devices shutting off the transient; power excursion peaks are broader; and the reactivity now attempts to reflect about delayed criticality. It should be noted that the implicit assumption of no heat loss from the system cannot be realized in practice. Any such loss of energy would result in power values greater than those plotted.

Some of the results shown in Figures 63 and 64 can be obtained analytically. For sufficiently large step increases in reactivity above prompt criticality, the delayed neutrons may be ignored and the kinetic equations integrated to give the total excursion yield.

$$
d E / d t=2 \Delta k_{p} / b
$$

where $\Delta k_{p}$ is the step increase relative to prompt criticality. The half-width of the spike is given by

× A similar result can be obtained for the delayed critical region, but the nonadiabatic behavior vitiates the result. 


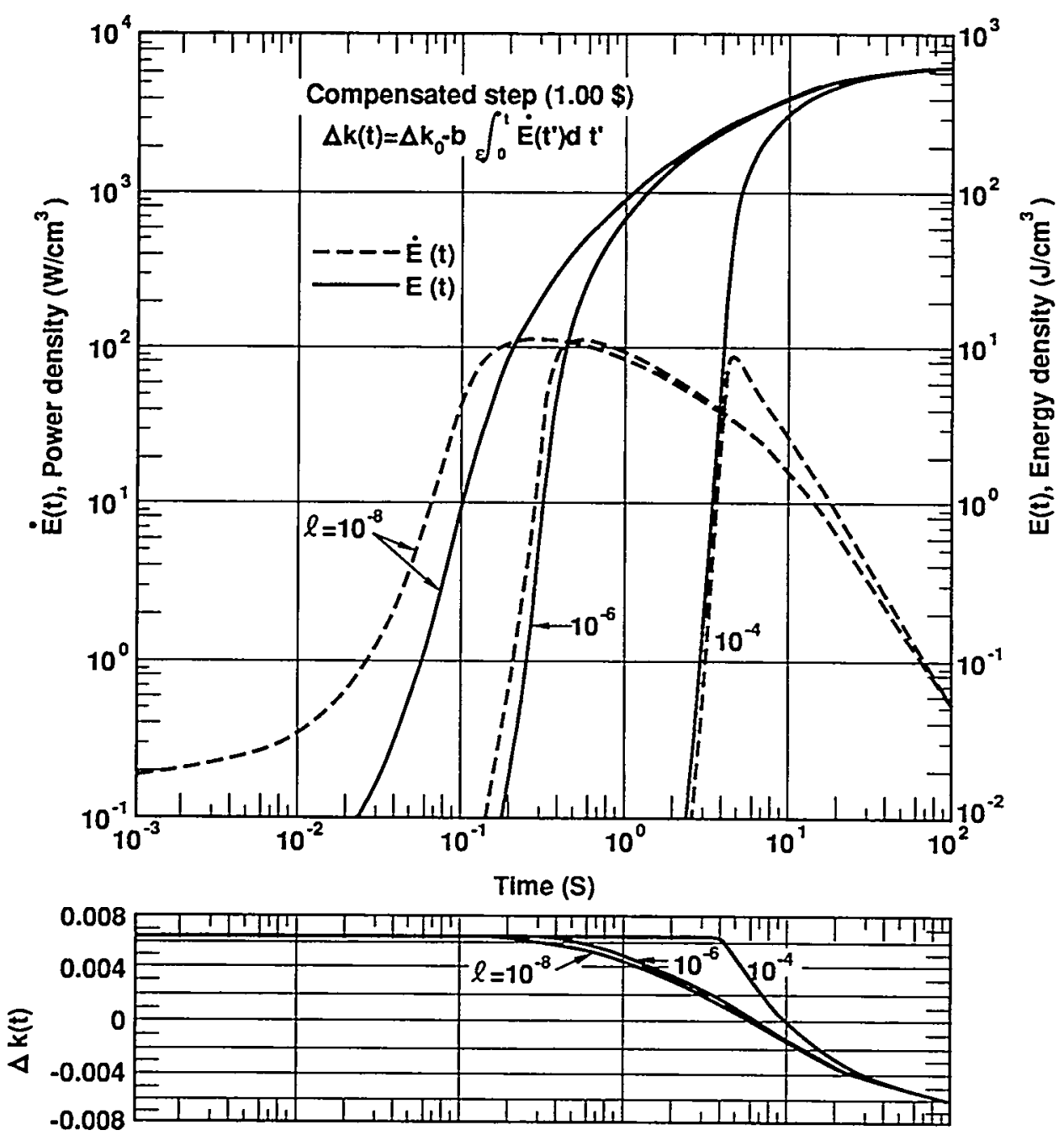

Figure 64. Energy model computation of power vs time. The initial reactivity is $1.0 \$$ above delayed critical. Neutron lifetime values are $10^{-8}, 10^{-6}$, and $10^{-4}$ seconds. The bottom panel shows the corresponding curves of reactivity vs time.

$$
t_{1 / 2}=3.52 l / \Delta k_{p}
$$

where $l=$ the neutron lifetime and the maximum power is

$$
d E / d t_{\text {max }} \approx 2 \Delta k_{p}^{2} / 3.5 \mathrm{bl}
$$

The experimental systems that have been intensively studied and that exemplify the data in Figures 63 and 64 are the Godiva, KEWB, and SPERT reactors, and the CRAC experiments.

Godiva I and II were near solid uranium $\left(93 \%{ }^{235} \mathrm{U}\right)$ metal critical assemblies, pressed into service as irradiation facilities. At a few cents above prompt criticality, controlled prompt excursions provide an excellent experimental picture to complement the curves of Figures 63 and 64 . The prompt negative temperature coefficient of reactivity of about $4.3 \times 10^{3} \$ /^{\circ} \mathrm{C}$ (depending on the model) arises from thermal expansion and is directly related to the deposition of fission energy. The transient proceeds so rapidly that no heat is lost from the system. When the step change of reactivity is increased to 4 or $5 \notin$ above prompt criticality, a new effect sets in. The power rises to such high values that the thermal expansion lags the energy deposition and the simple ratio of $E$ and $\Delta k_{p}$ in Eq. (2) is no longer true. At still higher step changes, the energy release becomes proportional to the square and eventually to the cube of the initial excess reactivity. Structural damage from shocks commences at 10 or $11 \not$, thus providing a limit for planned repetitive bursts.

The transient behavior of solution systems has been studied with the two KEWB reactors. The KEWB-A core was a $13.6 \ell$ stainless steel sphere containing $11.5 \ell$ of highly enriched $\mathrm{UO}_{2} \mathrm{SO}_{4}$ solution; the reflector was thick graphite. This reactor provided a means of studying transients in solution systems during which the period was as short as 2 milliseconds. The 
KEWB-B core was designed specifically to extend these measurements to a period of 1 millisecond. It was cylindrical and, during the transient experiments (up to about $5.2 \$$ above prompt criticality), contained 181 of $\mathrm{UO}_{2} \mathrm{SO}_{4}$ solution.

In the KEWB systems, two quenching mechanisms seem to be dominant over a wide range of excursions. The first of these is the rise in neutron temperature and thermal expansion as the core temperature rises, resulting in a prompt temperature coefficient equal to $-2 \notin /{ }^{\circ} \mathrm{C}$ at $30^{\circ} \mathrm{C}$. This effect is sufficient to account for the observed yield of excursions starting near prompt criticality, but is inadequate for more violent transient experiments. The second quenching mechanism is bubble formation. ${ }^{100}$ The available evidence supports the contention that during the spike, void space, consisting of many very small bubbles (microbubbles) with internal pressures of from 10 to 1000 atmospheres, is created by the fission process. The bubbles later coalesce and leave the system, giving the observed gas production coefficient of about $4.4 \mathrm{l} / \mathrm{MJ}$.

Growth of these microbubbles seems to involve the repeated interaction between fission fragments and existing microbubbles from earlier fissions. Thus, a quenching mechanism proportional to the square of the energy release can be invoked. This model is successful in describing the solution transients, notwithstanding imprecise knowledge of the manner in which the bubbles form and grow.

While the KEWB, SPERT, and TRIGA programs were largely oriented toward reactor safety, the CRAC studies were conceived and conducted to further an understanding of process accidents. Transients were stimulated in cylindrical vessels of 300 and $800 \mathrm{~mm}$ diameter with highly enriched uranium solutions having concentrations from $48.2 \mathrm{~g} / /$ to $298 \mathrm{~g} / \ell$. In most experiments, solution was added to a cylinder at a constant rate until the height required for criticality was substantially exceeded. Some experiments used a neutron source of sufficient size to initiate the excursion as soon as the system achieved criticality, while the absence of such a source in others permitted the system to become superprompt critical prior to initiation and resulted in higher spike yields.

The magnitude of the spike yield correlated well with the rate of reactivity addition when a source was present. For periods shorter than 10 milliseconds, the specific peak power was found to vary as the reciprocal period to the $3 / 2$ power, which is in agreement with predictions based on the KEWB results.
The CRAC program also provides helpful guidance regarding dose rates to be expected near unshielded solution excursions. For the $300 \mathrm{~mm}$ cylinder the exposure at $4 \mathrm{~m}$ from the surface of the vessel was about $2 \times 10^{-15} \mathrm{R} /$ fission and for the $800 \mathrm{~mm}$ cylinder about $5 \times 10^{-16} \mathrm{R} /$ fission.

SPERT-1 reactor cores (heterogeneous, moderated, and reflected by water ${ }^{99}$ were of two general types. The first had fuel in the form of MTR type aluminumuranium plates and cores designed to include the range from under moderation to the more hazardous region of over moderation. The second was composed of canned $\mathrm{UO}_{2}$ rods about $10 \mathrm{~mm}$ in diameter. The uranium enrichment in these rods was $4 \%$.

Transients of the plate type reactors have been extensively studied since 1957 in an effort to solve core design problems and to find the limitations of such reactors. In particular, the period and energy release that can cause damage have been carefully determined. The shutdown of a power transient in the SPERT systems is more complicated than in simpler reactors. The model developed includes heating and density change of the water; heating of the core structure, including its own geometry changes and moderator expulsion from such changes; and finally, the boiling of water next to the plates and loss of moderator when water is expelled from the core. When the plate type core was destroyed, the reactivity, period, peak power, and fission energy release were essentially as predicted. The destructive steam pressure pulse starting some 15 milliseconds after completion of the nuclear phase was not foreseen and is thought to have been caused by very rapid transfer of energy from the near molten aluminum plates to the thin layer of water between the plates. The transfer, occurring before any significant volume change took place, and the resulting high pressure destroyed the core. This effect seems to have been involved in the destruction of BORAX, SPERT, and SL-1.

The second type of SPERT- 1 core $^{89}$ (4\% enriched $\mathrm{UO}_{2}$ rods in water) was tested during 1963 and 1964. Transient experiments with this core demonstrated the effectiveness of the Doppler mode of self shutdown and provide a basis for analysis of accidents in similar power reactor systems. Two attempts to destroy the core by placing the reactor on very short periods (2.2 and 1.55 milliseconds) failed. In each case, the Doppler effect was operative and additional quenching developed because one or two fuel pins (out of several hundred) cracked and caused local boiling. The pins were thought to have been saturated with water before the test. 


\section{References}

1. Stratton, W. R. A Review of Criticality Accidents. Los Alamos Scientific Laboratory, Los Alamos, NM., LA-3611, (1967).

2. Stratton W. R., revised by D. R. Smith. A Review of Criticality Accidents.Lawrence Livermore National Laboratory, Livermore, CA, DOE/NCT-04, (March 1989)

3. Paxton, Hugh C. Glossary of Nuclear Criticality Terms. Los Alamos National Laboratory report LA-11627-MS, Los Alamos, NM, (October 1989).

4. Barbry, F. SILENE Reactor: Results of Selected Typical Experiments. Report SRSC n223, CEA Institute de Protectionet de Surete Nucleaire, Department de Recherches en Securite, Service de Recherches en Surete et Criticite, Centre d'Etudes de VALDUC - SRSC 21120 Is-sur-Tille, France, (September 1994).

5. Lecorche, P., and R. L. Seale. Review of the Experiments Performed to Determine the Radiological Consequences of a Criticality Accident. Y-12 Plant, Oak Ridge, TN., Y-CDC-12, (1973).

6. Dunenfeld, M.S., and R. K. Stitt. Summary Review of the Kinetics Experiments on Water Boilers. NAA-SR-7087, (1963). This report is proprietary information of North American Aviation Co.

7. Accidental Radiation Excursion at the Y-12 Plant June 16, 1958. Union Carbide Nuclear Company, Y-12 Plant, Oak Ridge, TN., Y-1234, (1958).

8. Callihan, D., and J. T. Thomas. “Accidental Radiation Excursion at the Oak Ridge Y-12 Plant-I, Description and Physics of the Accident." Health Phys., 1, 363-372, (1959).

9. "Oak Ridge Y-12 Accidental Excursion, June 16, 1958." Nucleonics, 16, Nov., pp. 138-140, 200-203, (1958).

10. Hurst, G. S., R. S. Ritchie, and R. L. Emerson. "Accidental Radiation Excursion at the Oak Ridge Y-12 Plant, Part II, Determination of Doses." Health Physics, 2, p. 121 (1959).

11. Paxton, H. C., R. D. Baker, W. T. Maraman, and R. Reider. Nuclear-Critical Accident at the Los Alamos Scientific Laboratory on December 30 , 1958. Los Alamos Scientific Laboratory, Los Alamos, NM, LAMS-2293 (1959).

12. Paxton, H. C., R. D. Baker, W. J. Maraman, and R. Reider. "Los Alamos Criticality Accident, December 30, 1958." Nucleonics, 17(4), pp. 107-108, 151 (1959).
13. Ginkel, W. L., C. W. Bills, A. O. Dodd, K. K. Kennedy, and F. H. Tingey. Nuclear Incident at the Idaho Chemical Processing Plant on October 16, 1959. Phillips Petroleum Co., Atomic Energy Div., Idaho Falls, ID, IDO-10035 (1960).

14. Paulus, P. C., A. O. Dodd, K. K. Kennedy, F. H. Tingey, and F. M. Warzel. Nuclear Incident at the Idaho Chemical Processing Plant on January 25, 1961. Phillips Petroleum Company, Atomic Energy Div., Idaho Falls, ID, IDO-10036 (1961).

15. Latchum J. W., F. C. Haas, W. M. Hawkins, and F. M. Warzel. Nuclear Incident at the Idaho Chemical Processing Plant of January 25, 1961. La-54-61A, Phillips Petroleum Co., (4 April 1961).

16. Olsen A. R., R. L. Hooper, V. O. Uotinen, and C. L. Brown. "Empirical Model to Estimate Energy Release from Accidental Criticality." Trans. Am. Nuc. Soc., 19, pp. 189-191, (October 1974).

17. Hetrick, D. L. Letter to Thomas P. McLaughlin, (14 July 1999).

18. Callihan, D. "Accidental Nuclear Excursion in Recuplex Operation at Hanford in April 1962." Nucl. Safety, 4(4), pp. 136-144, (1963).

19. Clayton, E. D. Further Considerations of Criticality in Recuplex and Possible Shutdown Mechanism. Hanford Atomic Products Operation, Hanford, Wash. HW-77780 (1963).

20. Zangar, C. N. Summary Report of Accidental Nuclear Excursion Recuplex Operation 234-5 Facility. HW74723, Richland Operations Office, AEC, TID-18431 (1962).

21. Investigation Committee. Final Report of Accidental Nuclear Excursion Recuplex Operation 234-5 Facility. Hanford Operations Office, HW-74723, (August, 1962).

22. Clayton, E. D. "The Hanford Pulser Accident." Transactions of the American Nuclear Society, 46, pp. 463-464, (June 1984).

23. Nakache, F. R., and M. M. Shapiro. The Nuclear Aspects of the Accidental Criticality at Wood River Junction, Rhode Island, July 24, 1964. Supplemental Report, United Nuclear Corp., New Haven, Conn., Fuels Div., TID-21995 (1964).

24. Kouts, H., et al. Report of the AEC Technical Review Committee, (Nov. 6, 1964).

25. Daniels, J. T., H. Howells, and T. G. Hughes. "Criticality Incident-Aug 24, 1970, Windscale Works." Trans. Am. Nuc. Sec., 14, pp. 35-36 (1971). 
26. Evans, M. C. "A Review of Criticality Accidents Within the European Community." Trans. Am. Nuc. Sec., 46, pp. 462-463 (1984).

27. Evans, M.C., "A Review of Criticality Accidents Within the European Community." Notes from oral presentation at the Summer Meeting of the American Nuclear Society, New Orleans, (June 1984).

28. Recovery of ICPP from Criticality Event of October 17, 1978 - Part II (Support and Safety Justification of the Specific Approach to Emptying H-100). Allied Chemical, ACI-366, (January 1979).

29. Casto, W. R. (ed.). "ICPP Criticality Event of October 17, 1978." Nuclear Safety, vol. 21, No. 5, (October 1980).

30. Report of the Accident Investigation Committee on a Critical Accident in Uranium Fuel Fabrication Plant. The Nuclear Safety Commission, Japan (December 42, 1999).

31. Report No. 3 in the $5^{\text {th }}$ Meeting in 2000 of the Nuclear Safety Commission: "Scope of Radiation Dose to Persons by the Critical Accident in JCO Co.. Lid. Tokai Site and Its Follow-up." Nuclear Safety Bureau of Science and Technology Agency, Japan, (January 2000).

32. McCoy, F. R. III, T.P. McLaughlin, and L.C. Lewis. U.S. Department of Energy Trip Report of Visit to Tokyo and Tokai-Mura, Japan on October 18-19. 1999 for Information Exchange with Government of Japan Concerning the September 30, 1999 Tokai-Mura Criticality Accident. U.S. Department of Energy.

33. NEA Nuclear Science Committee. International Handbook of Evaluated Criticality Safety Benchmark Experiments. NEA/NSC/DOC-(95)-03. (September 1998).

34. Paxton, H. C., and N. L. Pruvost. Critical Dimensions of Systems Containing ${ }^{235} U,{ }^{239} \mathrm{Pu}$. and ${ }^{233}$ U. 1986 Revision. LA-10860-MS, Figure 4, p. 14, (July 1987).

35. Taylor. E. F., and J. A. Wheeler. Spacetime Physics. W. H. Freeman and Co., p. 60, San Francisco, p. 60, (1966).

36. Callihan, D., W. Ozeroff, H. Paxton, and C. Schuske. Nuclear Safety Guide. U. S. Atomic Energy Commission report TID-7016, (1957).

37. Hayes, D. F. A Summary of Accidents and Incidents Involving Radiation in Atomic Energy Activities, June 1945 through December 1955.
U. S. Atomic Energy Commission TID-5360, (1956).

38. King, L. D. P. "Design and Description of Water Boiler Reactors." Proc. Intern. Conf. Peaceful Uses At. Energy, Geneva 1955, vol. 2, pp. 372 391, (1955).

39. Leonard, Jr., B. R. A Study of the Radiation Burst in the Hanford Homogeneous Reactor. Hanford Works, Richland, WA. HW-24327, (1952).

40. Thomas, J. T., and A. D. Callihan. Radiation Excursions at the ORNL Critical Experiments Laboratory. I. May 26, 1954. II. February I, 1956. Oak Ridge National Laboratory, Oak Ridge, TN, ORNL-2452, (1958).

41. Callihan, D. Excursion at the Oak Ridge Critical Experiments Facility, January 30, 1968. Oak Ridge National Laboratory, Oak Ridge, TN, ORNL-TM-2207, (1968).

42. Paxton, H. C. "Critical-Assembly Booby Traps." Nucleonics 16, Mar., pp. 80-81, (1958).

43. Paine, Jr., R. W., R. S. Dike, J. D. Orndoff, and D. P. Wood. A Study of an Accidental Radiation Burst. Los Alamos Scientific Laboratory, Los Alamos, NM, LA-1289, (1951).

44. Paxton, H. C. Booby Traps. Los Alamos Scientific Laboratory, Los Alamos, NM, AECD-4240, (1957). This reference has been carried over from a previous edition of the document. As of the time of printing it was not possible to locate a copy of the reference.

45. Mallary, E. C., G. E. Hansen, G. A. Linenberger, and D. P. Wood. Neutron Burst from a Cylindrical Untamped Oy (Enriched U) Assembly. Los Alamos Scientific Laboratory, Los Alamos, NM, LA-1477, (1952).

46. Peterson, R. E., and G. A. Newby. "An Unreflected U-235 Critical Assembly." Nucl. Sci. Eng. 1, 112-125, (1956).

47. Wimett, T. F., L. B. Engle, G. A. Graves, G. R. Keepin, Jr., and J. D. Orndoff. Time Behavior of Godiva Through Prompt Critical. Los Alamos Scientific Laboratory, Los Alamos, NM. LA-2029, (1956).

48. Paxton, H. C. "Godiva, Topsy, Jezebel-Critical Assemblies at Los Alamos." Nucleonics 13, Oct., 48-50, (1955).

49. A. M. Voinov, V. P. Egorov, A. E. Zapolsky, et al. "Facility for neutronics testing of simple critical assemblies." VANT, section Nuclear Reactor Physics, 2, pp. 21-29, (1992). 
50. Paxton, H. C. "Godiva Wrecked at Los Alamos." Nucleonics 15, Apr., p. 104, (1957).

51. Stratton, W. R., T. H. Colvin, and R. B. Lazarus. "Analyses of Prompt Excursions in Simple Systems and Idealized Fast Reactors." In Proc. UN Intern. Conf. Peaceful Uses At. Energy, 2nd, Geneva, 1958 (United Nations, Geneva), vol. 12, pp. 196-206, (1958).

52. Wimett, T. F., and J. D. Orndoff. "Applications of Godiva II Neutron Pulses." In Proc. UN Intern.

Conf. Peaceful Uses At. Energy, 2nd, Geneva, 1958 (United Nations, Geneva), vol. 10, pp. 449-460, (1958).

53. Callihan, D., Criticality Excursion of November 10, 1961. Oak Ridge National Laboratory, Oak Ridge, TN, ORNL-TM-139, (1962).

54. Kuvshinov M. I., P. F. Cherednic, I. I. Ignatov, et al. "Experimental research of coupled systems including BIR pulse reactor and a subcritical assembly." VANT, Section: Pulse reactors and simple critical assemblies, 2, pp. 3-15, (1988).

55. Kathren, R. L., W. C. Day, D. H. Denham, and J. L. Brown. Health Physics Following a Nuclear Excursion: The LRL Incident of March 26, 1963. Lawrence Livermore National Laboratory, Livermore, CA, UCRL-7345, (1963).

56. Fast Burst Reactor Facility Operations report Number 2. White Sands Missile Range, White Sands, NM, (1965). This reference has been carried over from a previous edition of the document. At the time of printing it was not possible to locate a copy of the reference.

57. Teryokhin, V. A., V. D. Perezhogin, and Y. A. Sokolov. "Criticality Measurements at VNIITF Review." In Proc. of the Fifth International Conference on Nuclear Criticality Safety, September 17-21, 1995, pp. 4.44-4.47, (1995).

58. Voloshin, N. P., I. S. Pogrebov, and V. A. Teryokhin. "RFNC-VNIITF Physical Experimental Division and a Short Historical Sketch of Critical Mass Measurements." In Proc. of the Fifth International Conference on Nuclear Criticality Safety, September 17-21, 1995, pp. P-31- P-36, (1995).

59. Kazi, A. H., H. G. Dubyoski, and E. W. Dickinson. "Preoperational Test Experience with the Army Pulse Radiation Facility Reactor." In Proc. of the National Topical Meeting on Fast Burst Reactors, Albuquerque, NM (U. S. Atomic Energy Commission), pp. 353-371, (1969).
60. Voloshin, N. P. "Summary of the Expert Findings about the Causes of the Nuclear Accident at RFNC-VNIIEF." Sarov. Atompressa, 26 (262), (July 1997).

61. Punin, V. T., I. G. Smirnov, and S. A. Zykov. "The Accident of the RFNC-VNIIEF Criticality Test Facility." Atomnaya energia, 83.2, pp. 154-156, (1997).

62. Khodalev, G. F., E. Yu. Tarasova, A. K. Zhitnik, et al. "An exposure dose for the experimentalist during the criticality accident at RFNC-VNIIEF." Atomnaya energia, 85.2, pp. 153-158 (1998).

63. Argonne National Laboratory. Controlled Nuclear Chain Reaction: The First 50 Years. American Nuclear Society, La Grange Park, IL, pp. $52-54$ (1992).

64. Brittan, R. O., R. J. Hasterlik, L. D. Marinelli, and F. W. Thalgott. Technical Review of ZPR-I Accidental Transient-The Power Excursion, Exposures, and Clinical Data. Argonne National Laboratory, Argonne, IL, ANL-4971, (1953).

65. Lewis, W. B. The Accident to the NRX Reactor on December 12, 1952. Atomic Energy of Canada, Ltd., Chalk River Project, Chalk River, Ontario, Canada, DR-32, (1953).

66. Hurst, D. C., and A. G. Ward. "Canadian Research Reactors." In Progress in Nuclear Energy, Series II, Reactors, vol. I. R. A. Charpie, D. J. Hughes, D. J. Littler, and M. Trocheris, Eds. Pergamon Press, London, pp. 1-48, (1956).

67. Henderson, W. J., A.C. Johnson, and P. R. Tunnicliffe. "An Investigation of Some of the Circumstances Pertinent to the Accident to the NRX Reactor of December 12, 1952. Atomic Energy of Canada Limited, Chalk River Ontario, NEI-26, (March 31, 1953).

68. Dietrich, J. R. Experimental Investigation of the Self-Limitation of Power During Reactivity Transients in a Subcooled, Water-Moderated Reactor. Argonne National Laboratory, Argonne, IL, ANL-5323, (1954).

69. "Reactors." Nucleonics, 13, Sept., 40-45, (1955).

70. Dietrich, J. R. "Experimental Determinations of the Self-Regulation and Safety of Operating Water-Moderated Reactors." In Proc. Intern. Conf. Peaceful Uses At. Energy, Geneva, 1955, United Nations, New York, vol. 13, pp. 88-101, (1956). 
71. Dietrich, J. R., and D. C. Layman. Transient and Steady State Characteristics of a Boiling Reactor: The Borax Experiments, 1953. Argonne National Laboratory, Argonne, IL, AECD-3840, (1954).

72. Thompson, T. J., and J. G. Beckerley, Eds. The Technology of Nuclear Reactor Safety, vol. 1 (The M.I.T. Press, Cambridge, MA, 1964).

73. Lushbaugh, C. C. "Reflections on Some Recent Progress in Human Radiobiology." In Advances in Radiation Biology, vol. 3, L. G. Augenstein, R. Mason, and M. Zelle, Eds. (Academic Press Inc.. pp 277-314., (1969).

74. Tardiff, A. N. "Some Aspects of the WTR and SL-1 Accidents." In Proc. Symp. Reactor Safety and Hazards Evaluation Techniques. vol. 1, International Atomic Energy Agency, Vienna, pp. 43-88, (1962).

75. Nyer, W. E., G. O. Bright, and R. J. McWhorter. "Reactor Excursion Behavior." In Proc. UN Intern. Conf. Peaceful Uses At. Energy, 3rd, Geneva, 1964, vol. 13, United Nations, Geneva, pp. 13-25. (1965).

76. Miller, R. W., A. Sola, and R. K. McCardell, "Report of the SPERT-1 Destructive Test Program on an Aluminum, Plate-type, Water-Moderated Reactor,' Phillips Petroleum Company, IDO-16883. (June 1964).

77. Parfanovich, D. M. Summary of Two Criticality Accidents at the Russian Research Center "Kurchatov Institute." INEEL/EXT-98-00409, Idaho National Engineering and Environmental Laboratory, J. Blair Briggs, ed., (August 1998).

78. "Water-Moderated Hexagonally Pitched Lattices of $\mathrm{U}(9 \mathrm{O} \%) \mathrm{O}_{2}+\mathrm{Cu}$ Fuel Rods with GD or SM Rods." HEU-COMP-THERM-004, International Handbook of Evaluated Criticality Safety Benchmark Experiments, NEA/N S C/DOC(95)03/II, 1996 Version or Later.

79. US NRC Information Notice No. 83-66, Supplement 1: Fatality at Argentine Critical Facility, (May 25, 1984).

80. Frisch, O. R. Controlled Production of an Explosive Nuclear Chain Reaction. Los Alamos Scientific Laboratory, Los Alamos, NM, LA-397, (1945).

81. De Hoffman, F., B. T. Feld, and P. R. Stein. "Delayed Neutrons from ${ }^{235} \mathrm{U}$ After Short Irradiation." Phys. Rev., 74, (10) 1330-1337, (1948).
82. Brittan, R. O. "Analysis of the EBR-1 Core Meltdown." In Proc. UN Intern. Conf. Peaceful Uses At. Energy, 2nd Geneva, 1958, vol. 12, United Nations, Geneva, pp. 267-272, (1958).

83. Kittel, J. H., M. Novick, and R. F. Buchanan. The EBR-I Meltdown-Physical and Metallurgical Changes in the Core. Argonne National Laboratory, Argonne, IL, ANL-5731, (1957).

84. Summary Report of HTRE No. 3 Nuclear Excursion. General Electric Co., Aircraft Nuclear Propulsion Dept., Cincinnati, OH, APEX-509, (1959).

85 Remley, M. E., J. W. Flora, D. L. Hetrick, D. R. Muller, E. L. Gardner, R. E. Wimmer, R. K. Stitt, and D. P. Gamble. "Experimental Studies on the Kinetic Behavior of Water Boiler Type Reactors." In Proc. UN Intern. Conf. Peaceful Uses At. Energy, 2nd, Geneva 1958. vol. 11, United Nations, Geneva, pp. 447-456 (1958).

86. Stitt, R. K. “A Summary of Experimental Results of the Spherical Core Investigations in the Kewb Program.” Nucl. Sci. Eng., 2 (1), Suppl., 212-213, (1959).

87. Hetrick, D. L., J. W. Flora, E.L. Garner, et.al. "Preliminary Results on the Kinetic Behavior of Water Boiler Reactors." Atomics International, North American Aviation, NAA-SR-1896, (April 15, 1987).

88. Malenfant, R. E., H. M. Forehand, and J. J. Koelling. "SHEBA: A Solution Critical Assembly." Trans. Amer: Nucl. Sec. 35 p. 279 , (1980).

89. Forbes, S. G., F. L. Bentzen, P. French, J. E. Grund, I. C. Haire, W. E. Nyer, and R. F. Walker. Analysis of Self-Shutdown Behavior in the SPERT-1 Reactor. Phillips Petroleum Company, Atomic Energy Div., Idaho Falls, Idaho, IDO-16528, (1959). This reference has been carried over from a previous edition of the document. At the time of printing it was not possible to locate a copy of the document.

90. Nyer, W. E., and S. G. Forbes. "SPERT-1 Reactor Safety Studies." In Proc. UN Intern. Conf. Peaceful Uses At. Energy, 2nd, Geneva, 1958, vol. 11, United Nations, Geneva, pp. 470-480, (1958).

91. Schroeder, F., S. G. Forbes, W. E. Nyer, F. L. Bentzen, and G. O. Bright. "Experimental Study of Transient Behavior in a Subcooled, Water-Moderated Reactor." Nucl. Sci. Eng. 2, 96-115, (1957). 
92. Stone, R. S., H. P. Sleeper, Jr., R. H. Stahl, and G. West. "Transient Behavior of TRIGA, a Zirconium-Hydride, Water-Moderated Reactor." Nucl. Sci. Eng., 6, 255-259, (1959).

93. Koutz, S. L., T. Taylor, A. McReynolds, F. Dyson, R. S. Stolne, H. P. Sleeper, Jr., and R. B. Duffield. "Design of a 10-kw Reactor for Isotope Production, Research and Training Purposes." In Proc. UN Intern. Conf. Peaceful Uses At. Energy, 2nd, Geneva, 1958, vol. 10, United Nations, Geneva, pp. 282-286, (1958).

94. Knief, R. A., Nuclear Criticality Safety: Theory and Practice. American Nuclear Society, LaGrange Park, IL, p. 11, (1985).

95. Hansen, G. E. Burst Characteristics Associated with the Slow Assembly of Fissionable Materials. Los Alamos Scientific Laboratory, Los Alamos, NM, LA-1441, (1952).

96. Fuchs, K. Efficiency for Very Slow Assembly. Los Alamos Scientific Laboratory, Los Alamos, NM, LA-596, (1946).

97. Hansen, G. E. "Assembly of Fissionable Material in the Presence of a Weak Neutron Source." Nucl. Sci. Eng., 8, 709-719, (1960).

98. Keepin, G. R. Physics of Nuclear Kinetics. Addison Wesley Pub. Co., Reading, MA, p. 287, (1965).

99. Keepin, G. R, and C. W. Cox. "General Solution of the Reactor Kinetics Equations." Nucl. Sci. Eng., 8, 670-690, (1960).

100. Gamble, D. P. "A Proposed Model of Bubble Growth During Fast Transients in the Kewb Reactor." Nucl. Sci. Eng., 2 (1), Suppl., 213-214, (1959).

101. Wilson, Robert E., and Jensen, William D., "Reflections on the 1978 ICPP Criticality Accident," Proceedings of the Sixth International Conference on Nuclear Criticality Safety, Vol. IV, 1540-1544, (1999). 


\section{APPENDIX A GLOSSARY OF NUCLEAR CRITICALITY TERMS}

An excellent glossary of nuclear criticality terms has been available for several years. Rather than reproduce this document in part in an attempt to focus on terminology specific to criticality accidents, we decided to reproduce the entire document in this appendix. In this way it is hoped that this accident report will also serve to further standardize the definitions that practitioners use.

The following is a reproduction of Glossary of Nuclear Criticality Terms by Hugh Paxton, LA-1 1627-MS. ${ }^{3}$ For additional reference material cited in this document, please see Reference 94.

This is a glossary of terms generally encountered in the literature of nuclear criticality and criticality safety. Terms sometimes misused are emphasized.

The following two terms are so basic and so intertwined that they call for special consideration inconsistent with the body of this glossary. Consequently, they are given this introductory position.

critical, criticality: Proper use is generally consistent with the following definition from Webster's New International Dictionary, Second Edition, Unabridged:

-ity. A suffix denoting state, condition, quality, or degree, used to form abstract nouns from adjectives, as in acidity, calamity.

Thus, "delayed criticality" and "delayed critical state" are equivalent. "Critical" is not used as a noun but may seem so by implying "critical state" in legends of graphs or charts where space is at a premium. When the meaning of "critical" as an adjective may be misinterpreted, as in "critical terms" or "critical accidents," "criticality" may be substituted for clarification. Use of "a criticality" for "a critical condition" or simply for "criticality," as is sometimes heard, is unacceptable. See delayed criticality, prompt criticality.

albedo, neutron: The probability under specified conditions that a neutron entering into a region through a surface will return through that surface.

absorbed dose: The energy imparted to matter by directly or indirectly ionizing radiation per unit mass of irradiated material at the point of interest; unit of absorbed dose has been the rad and now in the International System of Units (SI) is the gray (Gy). $100 \mathrm{rad}=1$ Gy. See rad, gray.

absorption, neutron: A neutron-induced reaction, including fission, in which the neutron disappears as a free particle. The absorption cross section is designated $\sigma_{a}$. See capture, neutron; cross section, neutron.

alarm system, criticality accident: A system capable of sounding an audible alarm after detecting neutron or gamma radiation from a criticality accident. See criticality accident.

alpha particle: A helium-4 nucleus emitted during a nuclear transformation.

beta particle: An electron of either positive or negative charge that has been emitted in a nuclear transformation.

buckling: For our purposes, algebraic expressions that relate critical dimensions of various simple shapes (sphere, cylinder, or cuboid) of cores of the same composition and similar reflectors. For example, the known radius of a critical sphere may be used to obtain the radius and length of a corresponding critical cylinder. See core, reflector:

burst, prompt: Usually refers to the pulse of energy from fissions produced by a prompt burst reactor. See prompt burst reactor; spike (in a prompt power excursion).

capture, neutron: Neutron absorption not leading to fission or other neutron production. The capture cross section is designated $\sigma_{\mathrm{a}}$. See absorption, neutron; cross section, neutron.

cent: A unit of reactivity equal to one-hundredth of the increment between delayed criticality and prompt criticality (a dollar). See dollar, reactivity.

chain reaction, fission: A sequence of nuclear fission reactions in which fissions are induced by neutrons emerging from preceding fissions. Depending on whether the number of fissions directly induced by neutrons from one fission is on the average less than, equal to. or greater than unity, the chain reaction is convergent (subcritical), self-sustaining (critical), or divergent (supercritical).

core: That part of a fissile system containing most or all of the fissile material, as distinguished from an external reflector. See fissile system, reflector:

critical infinite cylinder: For specified fissile medium and surrounding reflector, the infinitely long cylinder with a diameter that would be critical.

critical infinite slab: For specified fissile medium and reflector on each surface, the slab of infinite lateral dimensions with a thickness that would be critical. 
criticality accident: The release of energy as a result of accidentally producing a self-sustaining or divergent fission chain reaction. See reaction, fission.

criticality safety: Protection from the consequences of a criticality accident, preferably by prevention of the accident. Encompasses procedures, training, and other precautions in addition to physical protection. See criticality accident.

criticality safety standards: These standards describe criticality control practices for which there is industry-wide consensus. Consensus is established through procedures of the American National Standards Institute.

cross section $(\sigma)$, neutron: The proportionality factor that relates the rate of a specified reaction (such as capture or fission) to the product of the number of neutrons per second impinging normally onto a unit area of a thin target and the number of target nuclei per unit area. It may be considered a small area assigned to each target nucleus, usually expressed in barns, i.e., $10^{-24} \mathrm{~cm}^{2}$. See absorption, neutron; capture, neutron; fission, nuclear:

decay, radioactive: A spontaneous nuclear transformation in which particles or gamma radiation is emitted, in which $\mathrm{x}$-radiation is emitted following orbital electron capture, or in which the nucleus undergoes spontaneous fission. See fission, nuclear; gamma radiation.

delayed criticality: State of a fissile system such that $\mathrm{k}_{\text {eff }}=1$, the steady-state condition. See multiplication factor:

delayed neutrons: Neutrons from nuclei produced by beta decay following fission. They follow fission by intervals of seconds to minutes. See prompt neutrons.

dollar: A unit of reactivity equal to the increment between delayed criticality and prompt criticality for a fixed chain-reacting system. See reactivity.

dose equivalent: The absorbed dose multiplied by the quality factor and other less significant modifying factors, so that doses from different radiations (alpha, beta, gamma, slow neutron, fast neutron) can be summed to provide an effective total dose at the point of interest. The conventional unit of dose equivalent has been the rem, and now in the International System of Units (SI) is the sievert (Sv), $100 \mathrm{rem}=1$ Sv. See rem, sievert.

dose rate: Absorbed dose delivered per unit time. See absorbed dose.

excursion, nuclear: An episode during which the fission rate of a supercritical system increases, peaks, and then decreases to a low value. excursion, prompt-power: A nuclear excursion as the result of a prompt-critical configuration of fissile material. In general, a sharp power spike followed by a plateau that may be interrupted by smaller spikes. See excursion, nuclear; spike (in a prompt power excursion).

excursion period $(T)$ : The reciprocal coefficient of $t$, where fission power in a nuclear excursion increases as $\mathrm{e}^{\mathrm{l} / \mathrm{T}}$ before a quenching mechanism becomes effective. See excursion, nuclear; quenching mechanism.

exponential column: A subcritical block or cylinder of fissile material with an independent neutron source at one end. Under appropriate conditions, the response of a neutron detector decreases exponentially with distance from the source. From the logarithmic rate of this decrease and lateral dimensions of the column, critical dimensions of an unreflected assembly of the material may be deduced.

exposure: A measure of the ionization produced in air by $x$-rays or gamma radiation; the sum of electric charges on all ions of one sign in a small volume of air when all electrons liberated by photons are completely stopped, per unit mass of the air. Note that exposure refers to the environment, not absorbing material. The unit of exposure is the roentgen. See gamma radiation, roentgen. Alternatively, exposure is the incidence of radiation on living or inanimate material.

favorable geometry: Geometric constraint of fissile material in which subcriticality is maintained under anticipated conditions. Examples are limited diameter of pipes intended to contain fissile solution or limited volumes of solution containers.

fissile nucleus: A nucleus capable of fission by thermal neutrons, provided the effective neutron production cross section, $\overline{v \sigma_{f}}$ exceeds the effective absorption cross section, $\overline{\sigma_{a}}$. The common fissile nuclei are ${ }^{235} \mathrm{U},{ }^{239} \mathrm{Pu}$, and ${ }^{233} \mathrm{U}$. See absorption, neutron; fission, nuclear.

fissile system: A system containing ${ }^{235} \mathrm{U},{ }^{239} \mathrm{Pu}$, or ${ }^{233} \mathrm{U}$ nuclei and capable of significant neutron multiplication. See fissile nucleus; multiplication, subcritical.

fission, nuclear: Disintegration of a nucleus (usually $\mathrm{Th}, \mathrm{U}, \mathrm{Pu}$, or heavier) into two (rarely more) masses of similar order of magnitude accompanied by a large release of energy and the emission of neutrons. Although some fissions take place spontaneously, neutron-induced fissions are of major interest in criticality safety. The fission cross section is 
designated $\sigma_{f}$, and $v$ is the number of neutrons emitted per fission. See cross section, neutron.

fission products: Nuclides produced by fission or by the subsequent radioactive decay of nuclides formed in this manner. See fission, nuclear; nuclide.

fission yield, excursion: The total number of fissions in a nuclear excursion. See excursion, nuclear.

fissionable nucleus: A nucleus capable of fission by neutrons of some energy. Fissionable nuclei include ${ }^{238} \mathrm{U},{ }^{240} \mathrm{Pu}$, and others with neutron-energy fission thresholds, in addition to those that are fissile. See fissile nucleus.

gamma radiation: Short-wavelength electromagnetic radiation emitted in the process of nuclear transition or particle annihilation.

gray (Gy): A unit of absorbed dose; $1 \mathrm{~Gy}=1$ $\mathrm{J} / \mathrm{kg}=100 \mathrm{rad}$. Adopted in 1976 by the International Conference on Weights and Measures to replace the rad. See rad.

hazard: A potential danger. "Potentially hazardous" is redundant. Note that a hazardous facility is not necessarily a high-risk facility. See risk.

$\mathrm{H} / \mathrm{X}$ : Conventionally, the atomic ratio of hydrogen to ${ }^{235} \mathrm{U},{ }^{239} \mathrm{Pu}$, or ${ }^{233} \mathrm{U}$ in a solution or hydrogenous mixture. Where there is more than one fissile species, the ratios must be specified separately.

inhour: $A$ unit of reactivity that when added to a delayed-critical system would produce a period of one hour; now seldom used. See reactivity.

ionizing radiation: Any radiation consisting of directly or indirectly ionizing particles, photons, or a mixture of both. $X$-rays and the radiations emitted in radioactive decay are examples. See decay, radioactive.

irradiation: Exposure to ionizing radiation. See exposure (alternative definition).

isotopic code: Combined final digits of atomic number and atomic weight, such that ${ }^{235} \mathrm{U},{ }^{239} \mathrm{Pu}$, and ${ }^{233} \mathrm{U}$ are represented " 25 ," "49," and " 23 ;" ${ }^{240} \mathrm{Pu}$, however, is called " 410 ;" these appear in some documents but now are seldom used.

linear energy transfer (LET): The average energy lost by an ionizing radiation per unit distance of its travel in a medium. A high LET is generally associated with protons, alpha particles, and neutrons, whereas a low LET is associated with $\mathrm{x}$ rays, electrons, and gamma rays. See ionizing radiation.

monitor, radiation: A detector to measure the level of ionizing radiation. A purpose may be to give information about dose or dose rate. See ionizing radiation.

multiplication, subcritical: In a subcritical fissile system containing a neutron source, the equilibrium ratio of the total number of neutrons resulting from fission and the source to the total number of neutrons from the source alone.

multiplication factor $\left(\mathrm{k}_{\mathrm{eff}}\right)$ : For a chain-reacting system, the mean number of fission neutrons produced by a neutron during its life within the system. It follows that $k_{\text {eff }}=1$, if the system is critical; $k_{\text {eff }}<1$, if the system is subcritical; and $\mathrm{k}_{\mathrm{eff}}>1$, if the system is supercritical.

neutron: An elementary particle having no electric charge, a rest mass of $1.67495 \times 10^{-24}$ grams, and a mean life of about 10 minutes.

neutron poison: A nonfissionable neutron absorber, generally used for criticality control. See absorption, neutron; capture, neutron.

neutrons, epithermal: Neutrons of kinetic energy greater than that of thermal agitation, often restricted to energies comparable with those of chemical bonds.

neutrons, fast: Neutrons of kinetic energy greater than some specified value, often chosen to be $0.1 \mathrm{MeV}$ (million electron volts).

neutrons, thermal: Neutrons in thermal equilibrium with the medium in which they exist. At room temperature, the mean energy of thermal neutrons is about $0.025 \mathrm{eV}$ (electron volt).

nonfavorable geometry: See favorable geometry.

nuclide: A species of atom characterized by its mass number, atomic number, and a possible elevated nuclear energy state if prolonged.

oralloy (Oy): Introduced in early Los Alamos documents to mean enriched uranium (aa $\underline{\text { Ridge }}$ alloy); now uncommon except to signify highly enriched uranium. See tuballoy.

personnel monitor (radiation): A device for measuring a person's exposure to radiation. Information on the dose equivalent of ionizing radiation to biological tissue is derived from exposures recorded by film badges, ionization chambers, and thermoluminescent devices; from whole-body counting and analysis of biological specimens; and from area monitoring and special surveys.

photon: A quantum of electromagnetic radiation.

prompt burst reactor: A device for producing nondestructive super-prompt-critical nuclear excursions. See burst, prompt; excursion, nuclear. 
prompt criticality: State of a fissile system such that the prompt-neutron contribution to $\mathrm{k}_{\mathrm{eff}}$ equals unity. See multiplication factor:

prompt neutrons: Neutrons emitted immediately during the fission process. See delayed neutrons.

quality factor $(\mathrm{QF})$ : The linear energy-transfer-dependent factor by which absorbed doses are multiplied to obtain, for radiation-protection purposes, a quantity that expresses on a common scale the biological effectiveness of the absorbed dose derived from various radiation sources. Approximately the ratio of dose equivalent and absorbed dose. See absorbed dose, dose equivalent, linear energy transfer:

quenching mechanism: Physical process other than mechanical damage that limits an excursion spike. Examples are thermal expansion, or microbubble formation in a solution. See spike (in a prompt power excursion).

rad: A unit of absorbed dose; $1 \mathrm{rad}=10^{-2} \mathrm{~J} / \mathrm{kg}$ of the medium. In 1976, the International Conference on Weights and Measures adopted the gray $(1 \mathrm{~Gy}=1 \mathrm{~J} / \mathrm{kg})$ as the preferred unit of absorbed dose, but the gray has not appeared in the criticality-accident literature, which was essentially complete before that date. See absorbed dose, gray, and discussion under personnel monitor:

radiation: In context of criticality safety, alpha particles, beta particles, neutrons, gamma rays, and combinations thereof. See alpha particle, beta particle, neutron, $x$-ray.

reactivity: A parameter of a fissile system that is proportional to $1-1 / \mathrm{k}_{\text {eff }}$ Thus, it is zero if the system is critical, positive if the system is supercritical, negative if the system is subcritical. See dollar, cent, and inhour, which are various units of reactivity; multiplication factor:

reactivity, uncompensated: The reactivity that would pertain to a fissile system if the state of the system were not altered by its power. ${ }^{*}$

reflector: Material outside the core of a fissile system capable of scattering back to the core some neutrons that would otherwise escape. See core, fissile system.

reflector savings: The absolute difference between a dimension of the reflected core of a critical system and the corresponding dimension of a similar core that would be critical if no reflector were present. See core, fissile system, reflector:

relative biological effectiveness ( $\mathrm{RBE})$ : A factor used to compare the biological effectiveness of absorbed

\footnotetext{
*Not a part of the original glossary, LA-1 1627-MS. ${ }^{101}$
}

radiation doses (rads or grays) because of different types of ionizing radiation; more specifically, it is the experimentally determined ratio of an absorbed dose of a radiation in question to the absorbed dose of a reference radiation required to produce an identical biological effect in a particular experimental organism or tissue. This term should be used only in radiobiology, not instead of quality factor in radiation protection. See quality factor:

rem: A unit of dose equivalent (roentgen equivalent, man), replaced by the sievert, which was adopted in 1980 by the International Conference on Weights and Measures. The sievert, however, has not appeared in the criticality-accident literature. See dose equivalent, sievert.

rep: An obsolete term for absorbed dose in human tissue, replaced by rad. Originally derived from roentgen equivalent, physical.

risk: The cost of a class of accidents over a given period, usually expressed as dollars or fatalities, per year or during plant lifetime. Unless established by experience, risk is estimated as the product of the probability of occurrence and the consequence of the accident type. Not to be confused with hazard. See hazard.

roentgen (R): A unit of exposure; $1 \mathrm{R}=2.58 \times 10-4$ coulombs/kg in air. Strictly, the roentgen applies to $\mathrm{x}$-rays or gamma radiation, although in one report of a criticality accident beta "dosages" were expressed in units of R. See exposure.

scram: An alternative term for reactor trip.

shutdown mechanism: Quenching mechanism and mechanical damage, if any, that limits a prompt-power excursion spike. See excursion, prompt power; quenching mechanism; spike.

sievert (Sv): A unit of dose equivalent; $1 \mathrm{~Sv}=1 \mathrm{~J} / \mathrm{kg}=100 \mathrm{rem}$. Adopted in 1980 by the International Conference on Weights and Measures to replace the rem. See dose equivalent, rem.

spike (in a prompt-power excursion): The initial power pulse of a prompt-power excursion, limited by the shutdown mechanism. See excursion, prompt power; shutdown mechanism.

tuballoy (Tu): A wartime term for natural uranium, originating in England; now obsolete. See oralloy.

uranium enrichment (enrichment): The weight percentage of ${ }^{235} \mathrm{U}$ in uranium, provided that percentage exceeds its natural value; if the reference is to enhanced ${ }^{233} \mathrm{U}$ content, then " $233 \mathrm{U}$ enrichment" should be specified.

x-ray: Electromagnetic radiation of wavelength in the range $10^{-10} \mathrm{~cm}$ to $10^{-6} \mathrm{~cm}$. 


\section{APPENDIX B \\ EQUIPMENT DIAGRAMS AND TABULAR PHYSICAL AND YIELD DATA FOR THE 22 PROCESS ACCIDENTS}

Part I contains a section immediately following the description of the $22^{\text {nd }}$ accident entitled, "Physical and Neutronic Characteristics for the Process Facility Criticality Accidents." Therein are described the many unknowns, approximations, and uncertainties associated with the simplified re-constructions and data tabulations. The yield and specific yield values in the tables of this appendix are reported in units of fissions and fissions per liter, respectively.

This same information is presented here in a new format to facilitate an understanding of the approximate geometry and yield data associated with each process accident. While this information would never qualify as benchmark data (computations could be performed, but the value of the answers would be highly questionable), it may prove useful to students and teachers at universities and to criticality staff as they provide (training) lectures to operating personnel. 


\section{Mayak Production Association, 15 March 1953}

Plutonium nitrate solution in an interim storage vessel; single excursion; one serious exposure, one significant exposure.

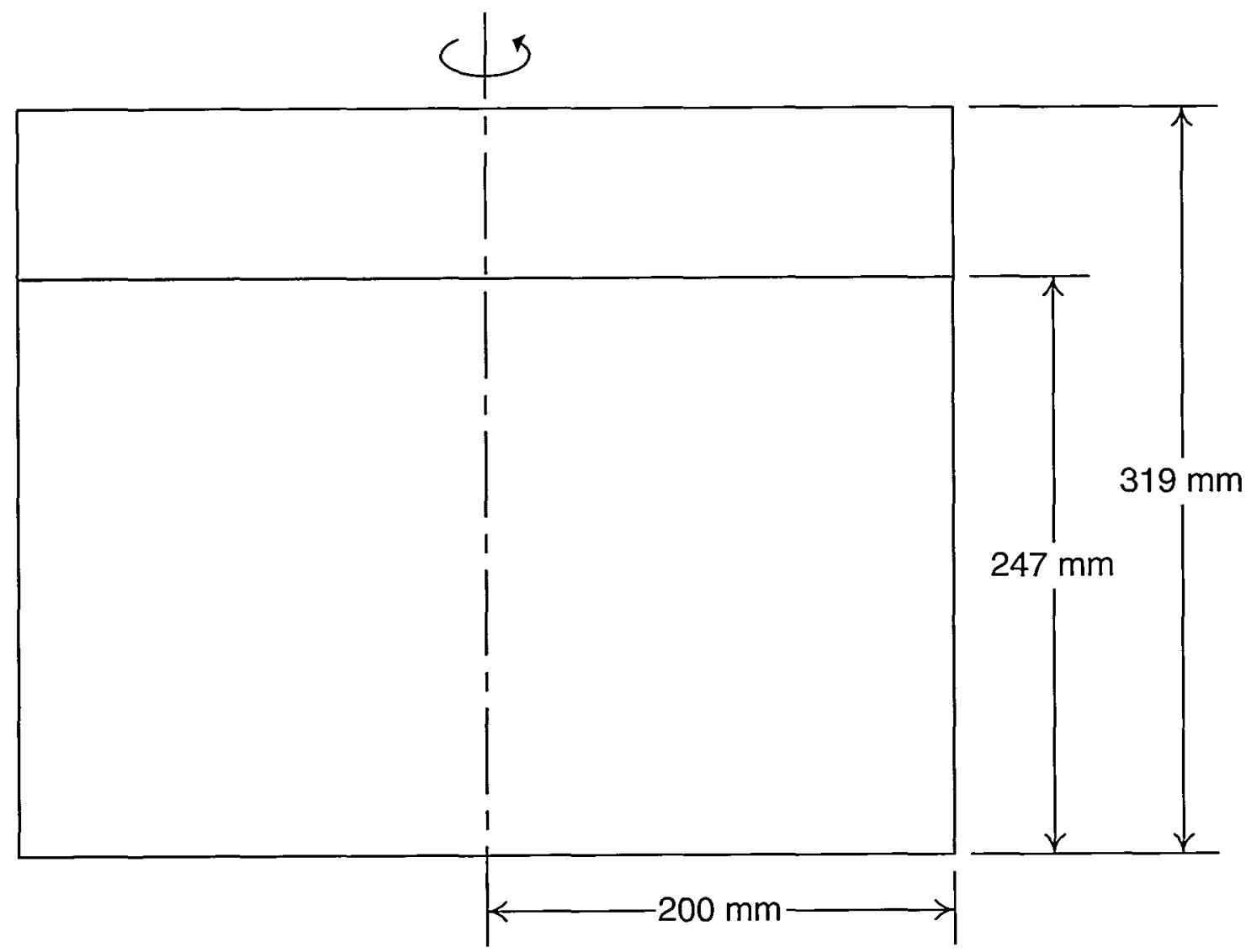

\begin{tabular}{|l|r|}
\hline Vessel Volume & $40.0 \ell$ \\
\hline Fissile Volume & $31.0 \ell$ \\
\hline Fissile Mass & $0.81 \mathrm{~kg}$ \\
\hline Fissile Density & $26.1 \mathrm{~g} / \ell$ \\
\hline
\end{tabular}

\begin{tabular}{|l|r|}
\hline $\begin{array}{l}\text { Estimated Spherical } \\
\text { Critical Mass }\end{array}$ & $0.67 \mathrm{~kg}$ \\
\hline First Spike Yield & unknown \\
\hline Specific Spike Yield & unknown \\
\hline Total Yield & $\sim 2.0 \times 10^{17}$ \\
\hline
\end{tabular}




\section{Mayak Production Association, 21 April 1957}

Uranium precipitate, $U(90)$, buildup in a filtrate receiving vessel; excursion history unknown; one fatality; five other significant exposures.
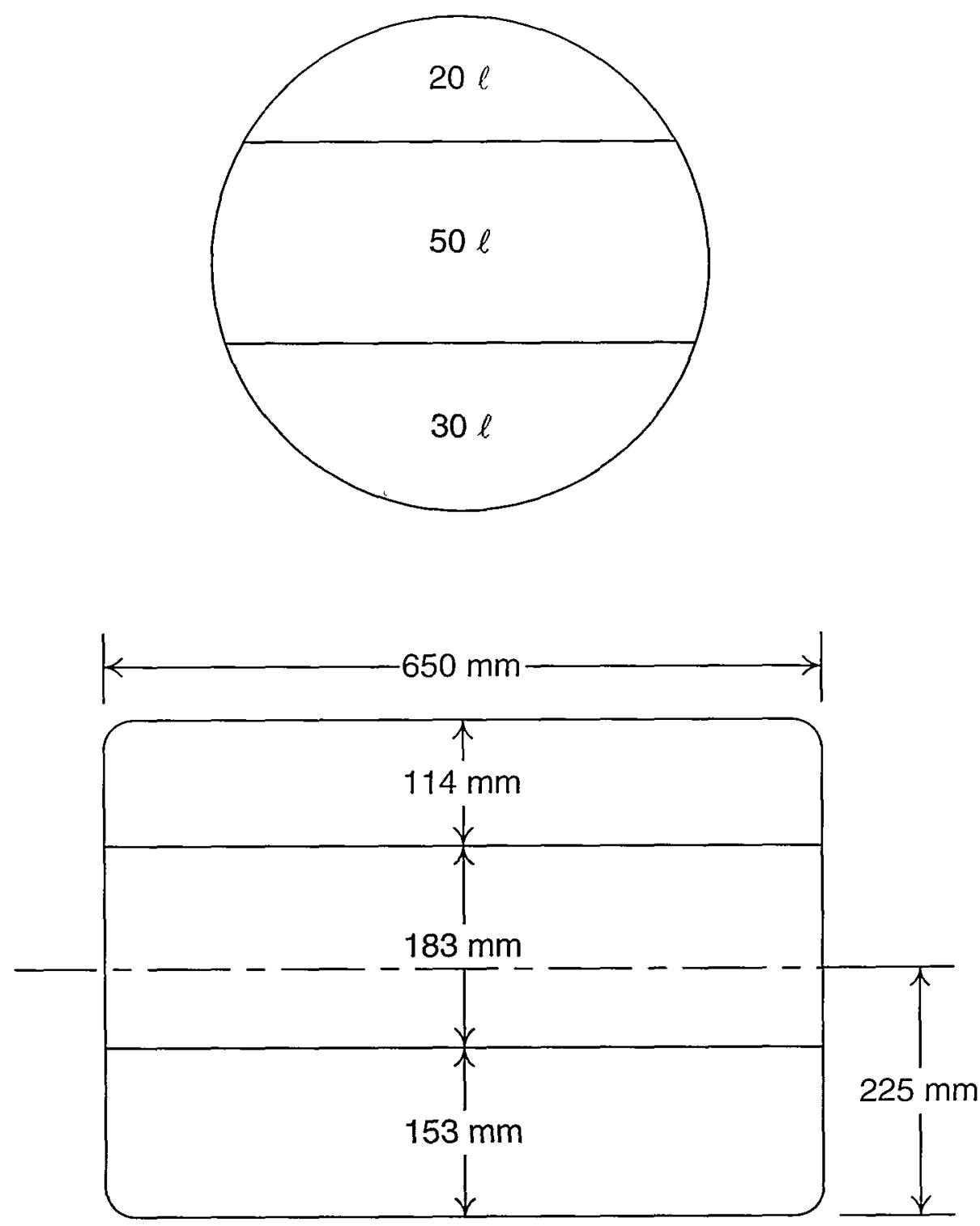

\begin{tabular}{|l|r|}
\hline Vessel Volume & $100.0 \ell$ \\
\hline Fissile Volume & $30.0 \ell$ \\
\hline Fissile Mass & $3.06 \mathrm{~kg}$ \\
\hline Fissile Density & $102.0 \mathrm{~g} / \ell$ \\
\hline
\end{tabular}

\begin{tabular}{|l|r|}
\hline $\begin{array}{l}\text { Estimated Spherical } \\
\text { Critical Mass }\end{array}$ & $1.09 \mathrm{~kg}$ \\
\hline First Spike Yield & unknown \\
\hline Specific Spike Yield & unknown \\
\hline Total Yield & $\sim 1.0 \times 10^{17}$ \\
\hline
\end{tabular}




\section{Mayak Production Association, 2 January 1958}

Uranyl nitrate solution, U(90), in an experiment vessel; one prompt critical burst; three fatalities; one serious exposure.

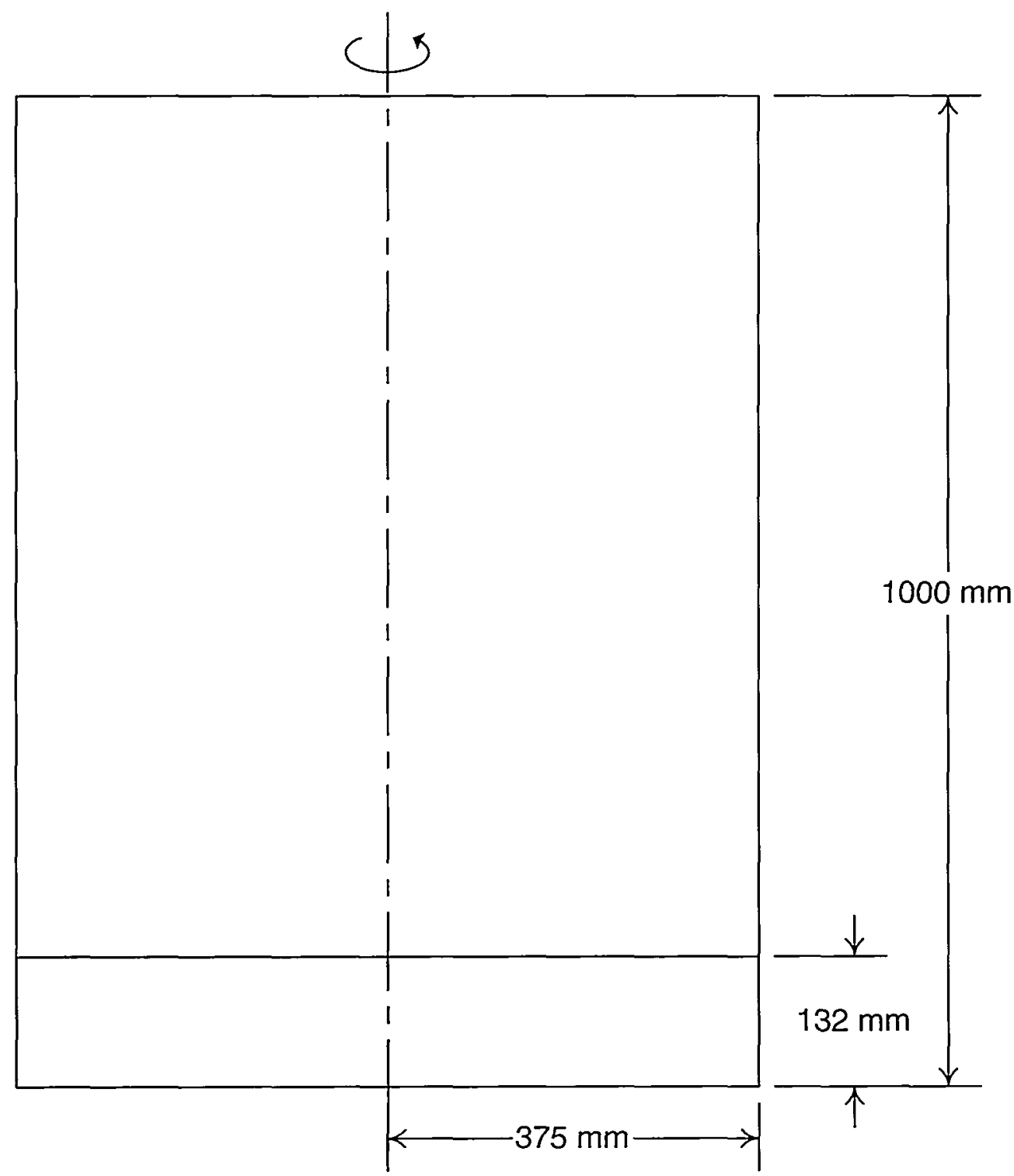

\begin{tabular}{|l|r|}
\hline Vessel Volume & $442.0 \ell$ \\
\hline Fissile Volume & $58.4 \ell$ \\
\hline Fissile Mass & $22.0 \mathrm{~kg}$ \\
\hline Fissile Density & $376.7 \mathrm{~g} / \ell$ \\
\hline
\end{tabular}

\begin{tabular}{|l|r|}
\hline $\begin{array}{l}\text { Estimated Spherical } \\
\text { Critical Mass }\end{array}$ & $5.24 \mathrm{~kg}$ \\
\hline First Spike Yield & $\sim 2.0 \times 10^{17}$ \\
\hline Specific Spike Yield & $3.4 \times 10^{15}$ \\
\hline Total Yield & $\sim 2.0 \times 10^{17}$ \\
\hline
\end{tabular}




\section{Oak Ridge Y-12 Plant, 16 June 1958}

Uranyl nitrate solution, U(93), in a water collection drum; multiple excursions; seven significant exposures.

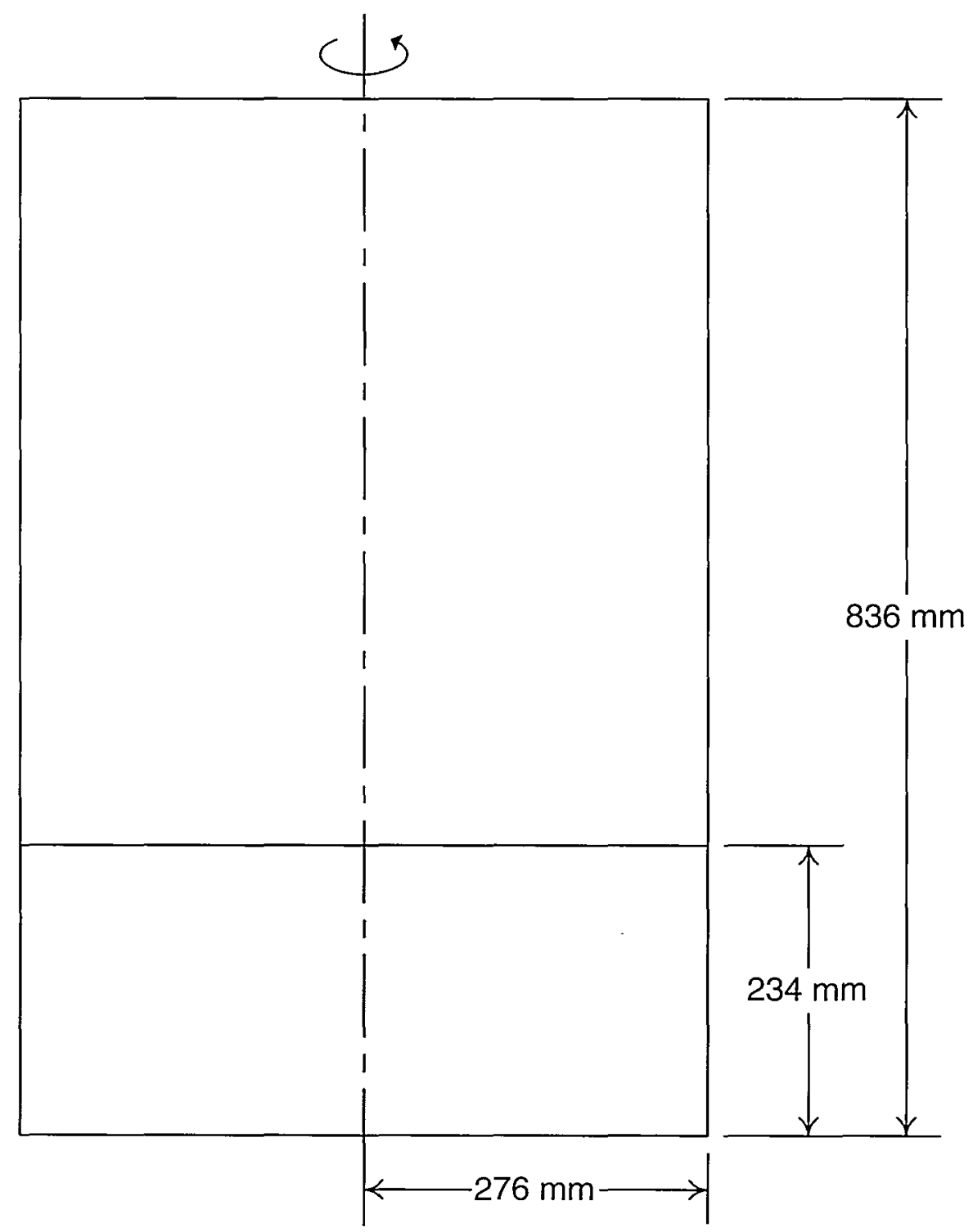

\begin{tabular}{|l|r|}
\hline Vessel Volume & $208.0 \ell$ \\
\hline Fissile Volume & $56.0 \ell$ \\
\hline Fissile Mass & $2.10 \mathrm{~kg}$ \\
\hline Fissile Density & $37.5 \mathrm{~g} / \ell$ \\
\hline
\end{tabular}

\begin{tabular}{|l|r|}
\hline $\begin{array}{l}\text { Estimated Spherical } \\
\text { Critical Mass }\end{array}$ & $1.50 \mathrm{~kg}$ \\
\hline First Spike Yield & $\sim 0.1 \times 10^{17}$ \\
\hline Specific Spike Yield & $0.2 \times 10^{15}$ \\
\hline Total Yield & $13.0 \times 10^{17}$ \\
\hline
\end{tabular}




\section{Los Alamos Scientific Laboratory, 30 December 1958}

Plutonium organic solution in an organic treatment tank; single excursion; one fatality, two significant exposures.

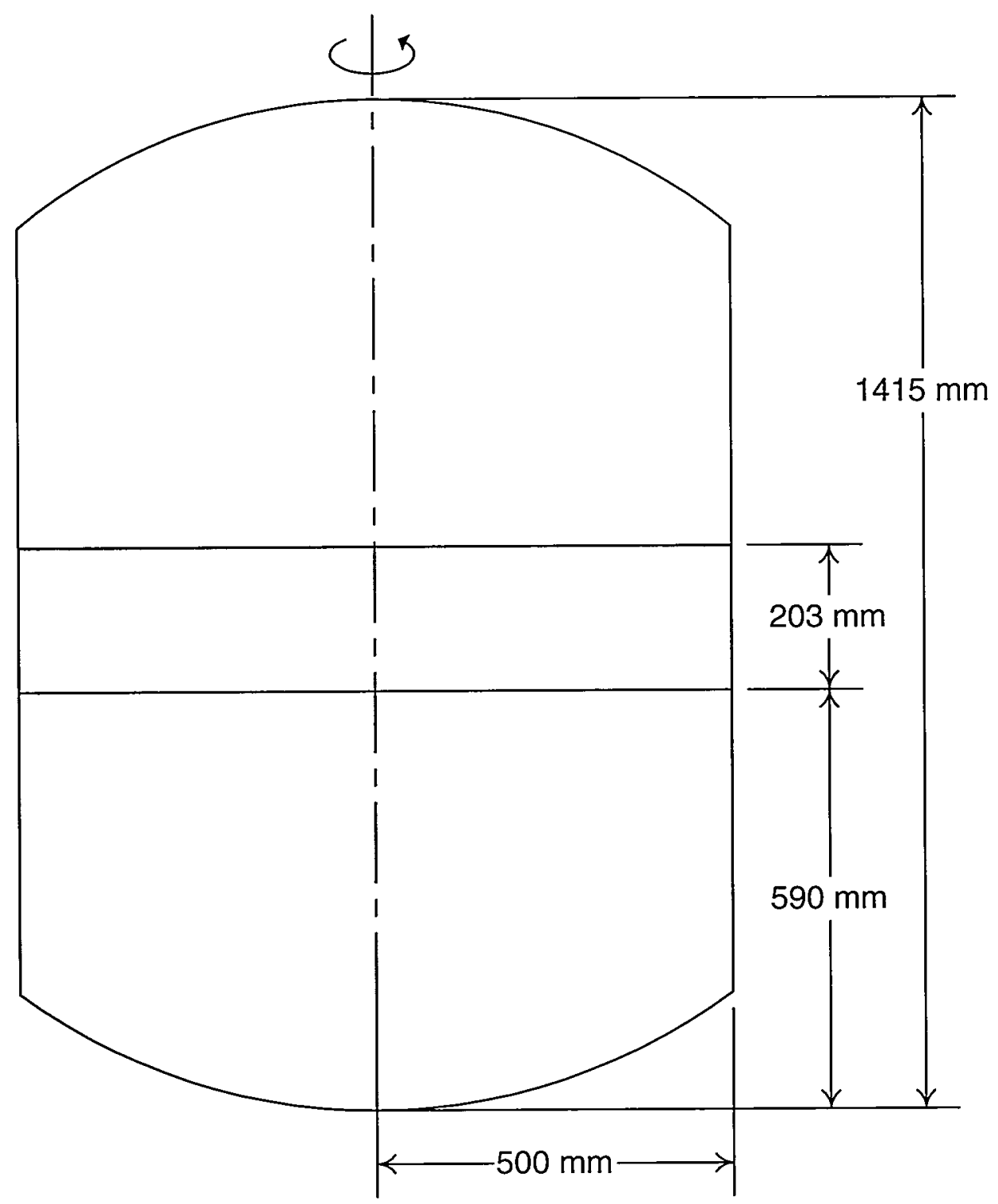

\begin{tabular}{|l|r|}
\hline Vessel Volume & $982.0 \ell$ \\
\hline Fissile Volume & $160.0 \ell$ \\
\hline Fissile Mass & $2.94 \mathrm{~kg}$ \\
\hline Fissile Density & $18.4 \mathrm{~g} / \ell$ \\
\hline
\end{tabular}

\begin{tabular}{|l|c|}
\hline $\begin{array}{l}\text { Estimated Spherical } \\
\text { Critical Mass }\end{array}$ & $0.84 \mathrm{~kg}$ \\
\hline First Spike Yield & $1.5 \times 10^{17}$ \\
\hline Specific Spike Yield & $0.94 \times 10^{15}$ \\
\hline Total Yield & $1.5 \times 10^{17}$ \\
\hline
\end{tabular}




\section{Idaho Chemical Processing Plant, 16 October 1959}

Uranyl nitrate solution, $U(91)$, in a waste receiving tank; multiple excursions; tw'o significant exposures.

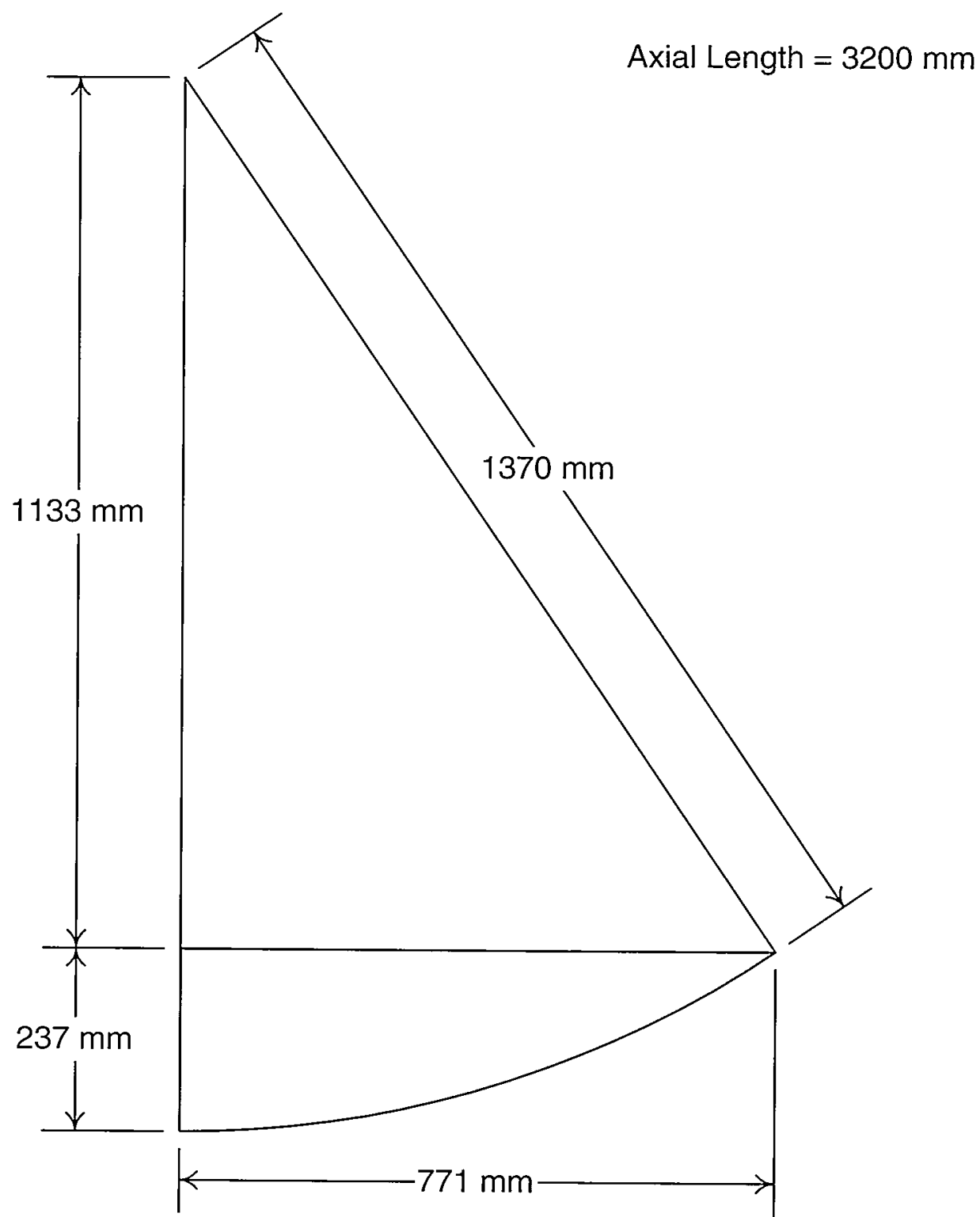

\begin{tabular}{|l|r|}
\hline Vessel Volume & $18,900 \ell$ \\
\hline Fissile Volume & $800.0 \ell$ \\
\hline Fissile Mass & $30.9 \mathrm{~kg}$ \\
\hline Fissile Density & $38.6 \mathrm{~g} / \ell$ \\
\hline
\end{tabular}

\begin{tabular}{|l|c|}
\hline $\begin{array}{l}\text { Estimated Spherical } \\
\text { Critical Mass }\end{array}$ & $1.24 \mathrm{~kg}$ \\
\hline First Spike Yield & $\sim 1.0 \times 10^{17}$ \\
\hline Specific Spike Yield & $\sim 0.1 \times 10^{15}$ \\
\hline Total Yield & $400 \times 10^{17}$ \\
\hline
\end{tabular}




\section{Mayak Production Association, 5 December 1960}

Plutonium carbonate solution in a holding vessel; multiple excursions; insignificant exposures.

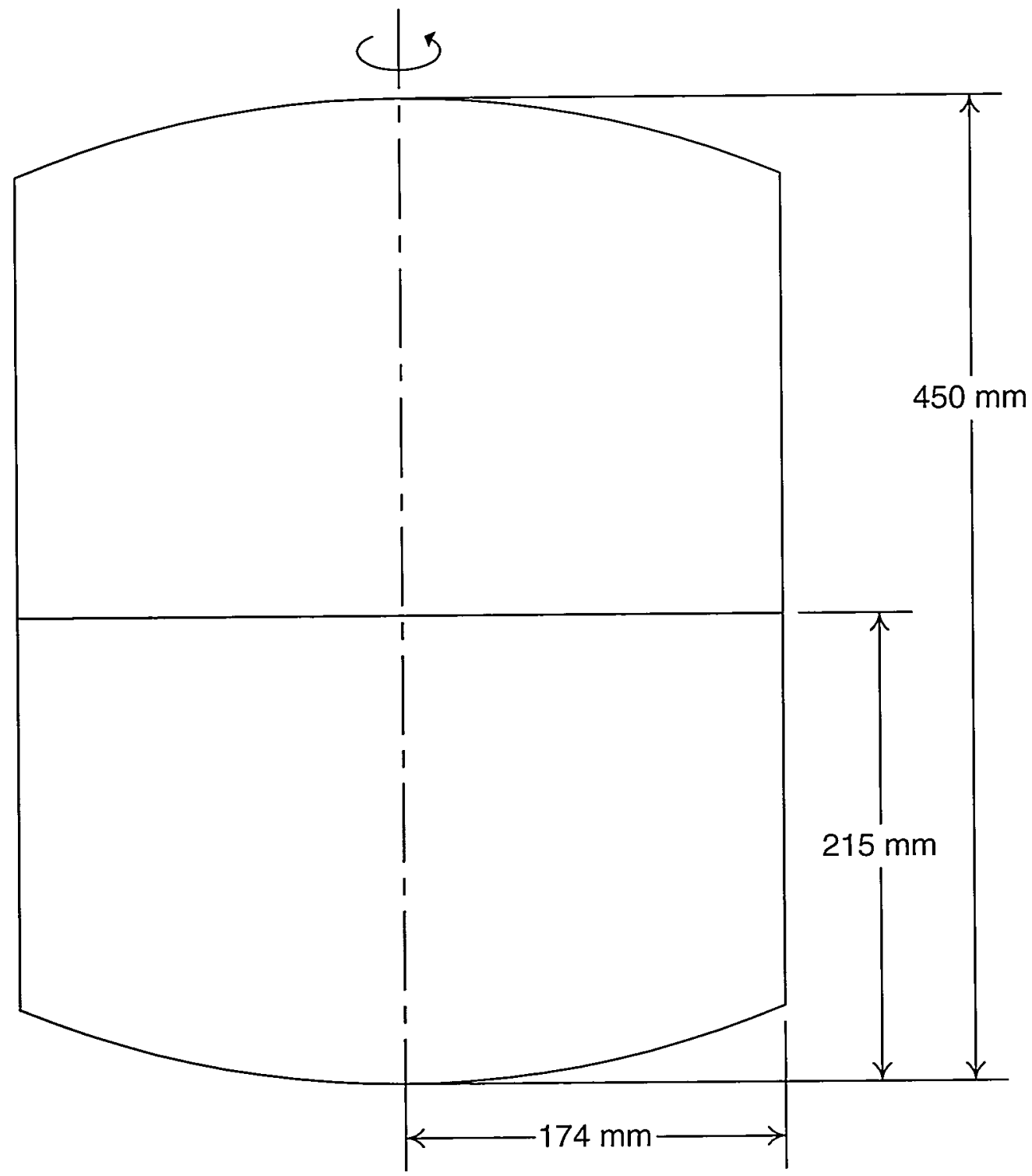

\begin{tabular}{|l|r|}
\hline Vessel Volume & $40.0 \ell$ \\
\hline Fissile Volume & $19.0 \ell$ \\
\hline Fissile Mass & $0.85 \mathrm{~kg}$ \\
\hline Fissile Density & $44.7 \mathrm{~g} / \ell$ \\
\hline
\end{tabular}

\begin{tabular}{|l|r|}
\hline $\begin{array}{l}\text { Estimated Spherical } \\
\text { Critical Mass }\end{array}$ & $0.71 \mathrm{~kg}$ \\
\hline First Spike Yield & unknown \\
\hline Specific Spike Yield & unknown \\
\hline Total Yield & $\sim 2.5 \times 10^{17}$ \\
\hline
\end{tabular}




\section{Idaho Chemical Processing Plant, 25 January 1961}

Uranyl nitrate solution, $U(90)$, in a vapor disengagement vessel; multiple excursions; insignificant exposures.

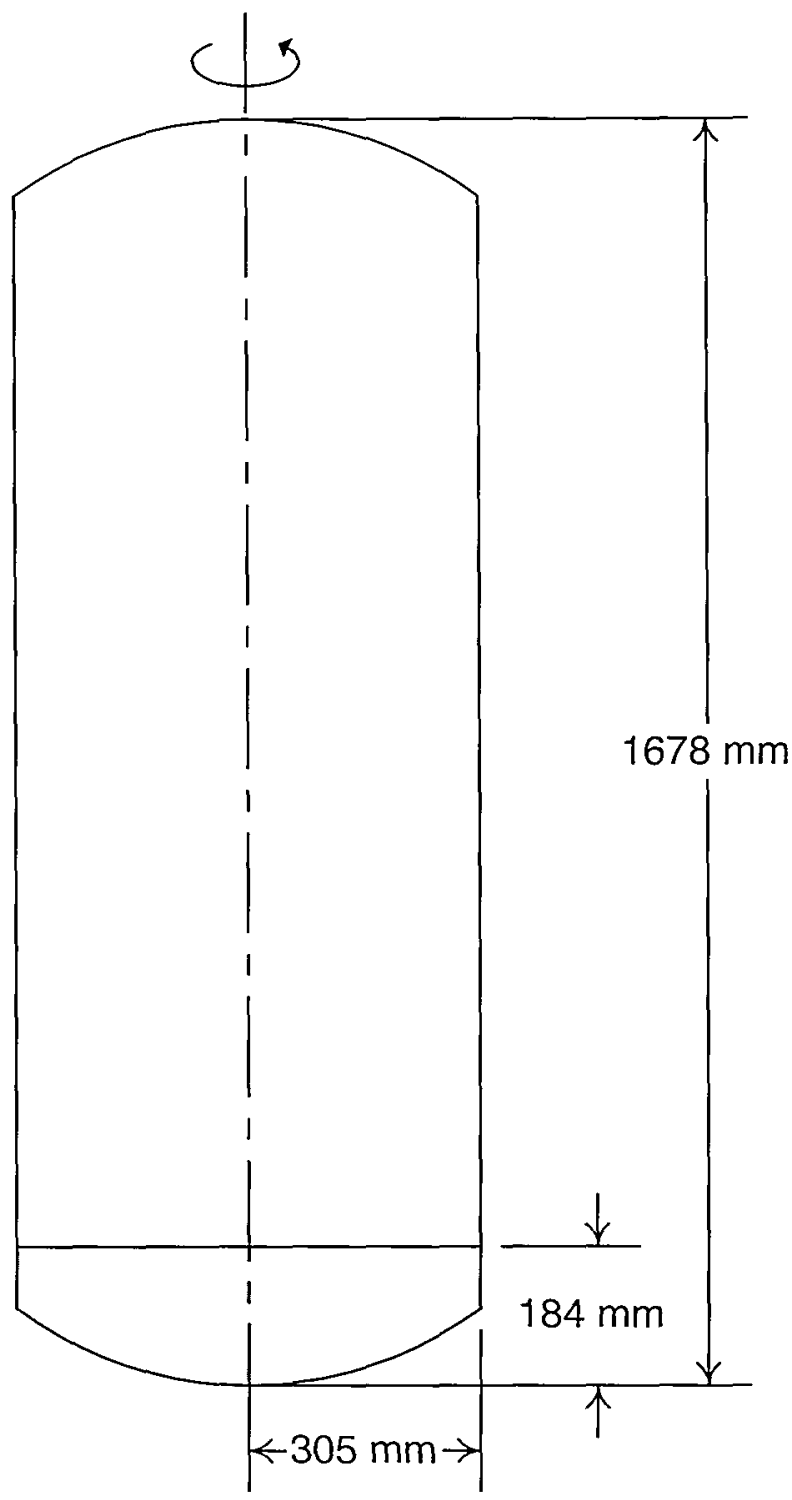

\begin{tabular}{|l|r|}
\hline Vessel Volume & $461.0 \ell$ \\
\hline Fissile Volume & $40.0 \ell$ \\
\hline Fissile Mass & $7.20 \mathrm{~kg}$ \\
\hline Fissile Density & $180.0 \mathrm{~g} / \ell$ \\
\hline
\end{tabular}

\begin{tabular}{|l|c|}
\hline $\begin{array}{l}\text { Estimated Spherical } \\
\text { Critical Mass }\end{array}$ & $2.48 \mathrm{~kg}$ \\
\hline First Spike Yield & $\sim 0.6 \times 10^{17}$ \\
\hline Specific Spike Yield & $1.5 \times 10^{15}$ \\
\hline Total Yield & $6.0 \times 10^{17}$ \\
\hline
\end{tabular}




\section{Siberian Chemical Combine (Tomsk), 14 July 1961}

Uranium hexafluoride, $U(22.6)$, accumulation in a vacuum pump oil reservoir; two excursions; one significant exposure.

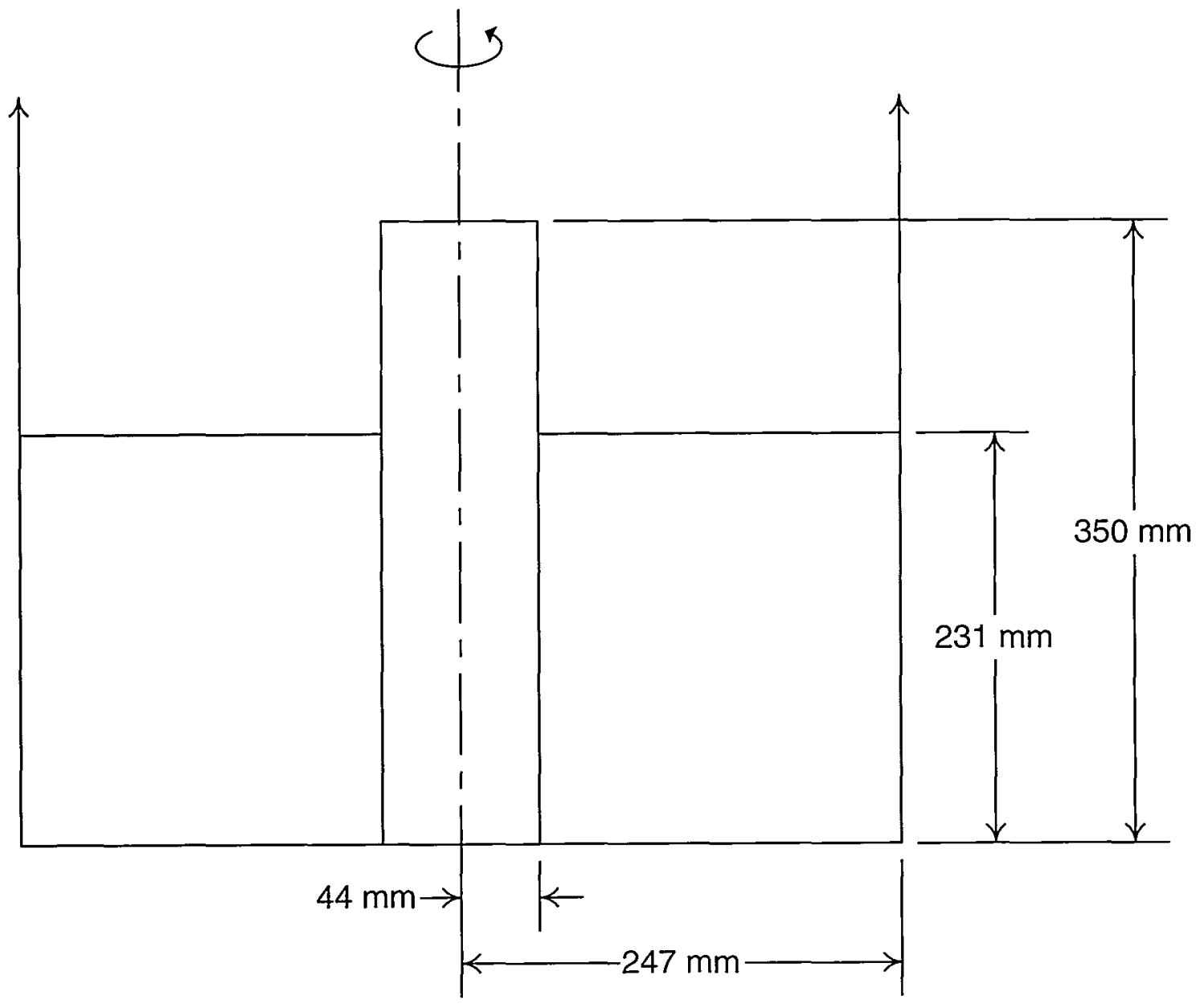

\begin{tabular}{|l|r|}
\hline Vessel Volume & $65.0 \ell$ \\
\hline Fissile Volume & $42.9 \ell$ \\
\hline Fissile Mass & $1.68 \mathrm{~kg}$ \\
\hline Fissile Density & $39.2 \mathrm{~g} / \ell$ \\
\hline
\end{tabular}

\begin{tabular}{|l|r|}
\hline $\begin{array}{l}\text { Estimated Spherical } \\
\text { Critical Mass }\end{array}$ & $0.9 \mathrm{~kg}$ \\
\hline First Spike Yield & none \\
\hline Specific Spike Yield & none \\
\hline Total Yield & $0.12 \times 10^{17}$ \\
\hline
\end{tabular}




\section{Hanford Works, 7 April 1962}

Plutonium solution in a transfer vessel; multiple excursions; three significant exposures.

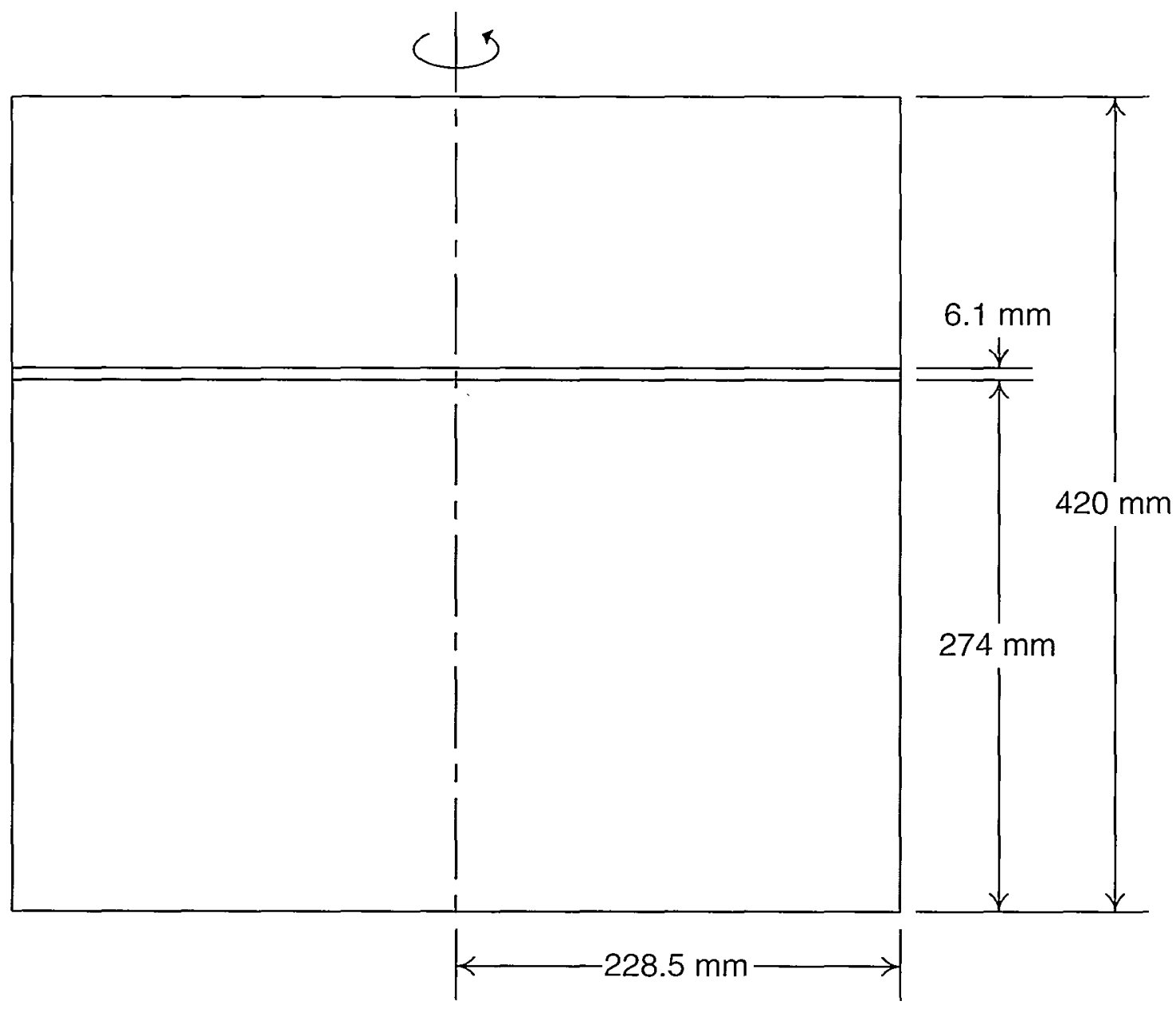

\begin{tabular}{|l|r|}
\hline Vessel Volume & $69.0 \ell$ \\
\hline Fissile Volume & $45.0 \ell$ \\
\hline Fissile Mass & $1.29 \mathrm{~kg}$ \\
\hline Fissile Density & $28.7 \mathrm{~g} / \ell$ \\
\hline
\end{tabular}

\begin{tabular}{|l|c|}
\hline $\begin{array}{l}\text { Estimated Spherical } \\
\text { Critical Mass }\end{array}$ & $1.07 \mathrm{~kg}$ \\
\hline First Spike Yield & $\sim 0.1 \times 10^{17}$ \\
\hline Specific Spike Yield & $0.2 \times 10^{15}$ \\
\hline Total Yield & $8.0 \times 10^{17}$ \\
\hline
\end{tabular}


11. Mayak Production Association, 7 September 1962

Plutonium nitrate in a dissolution vessel; three excursions; insignificant exposures.

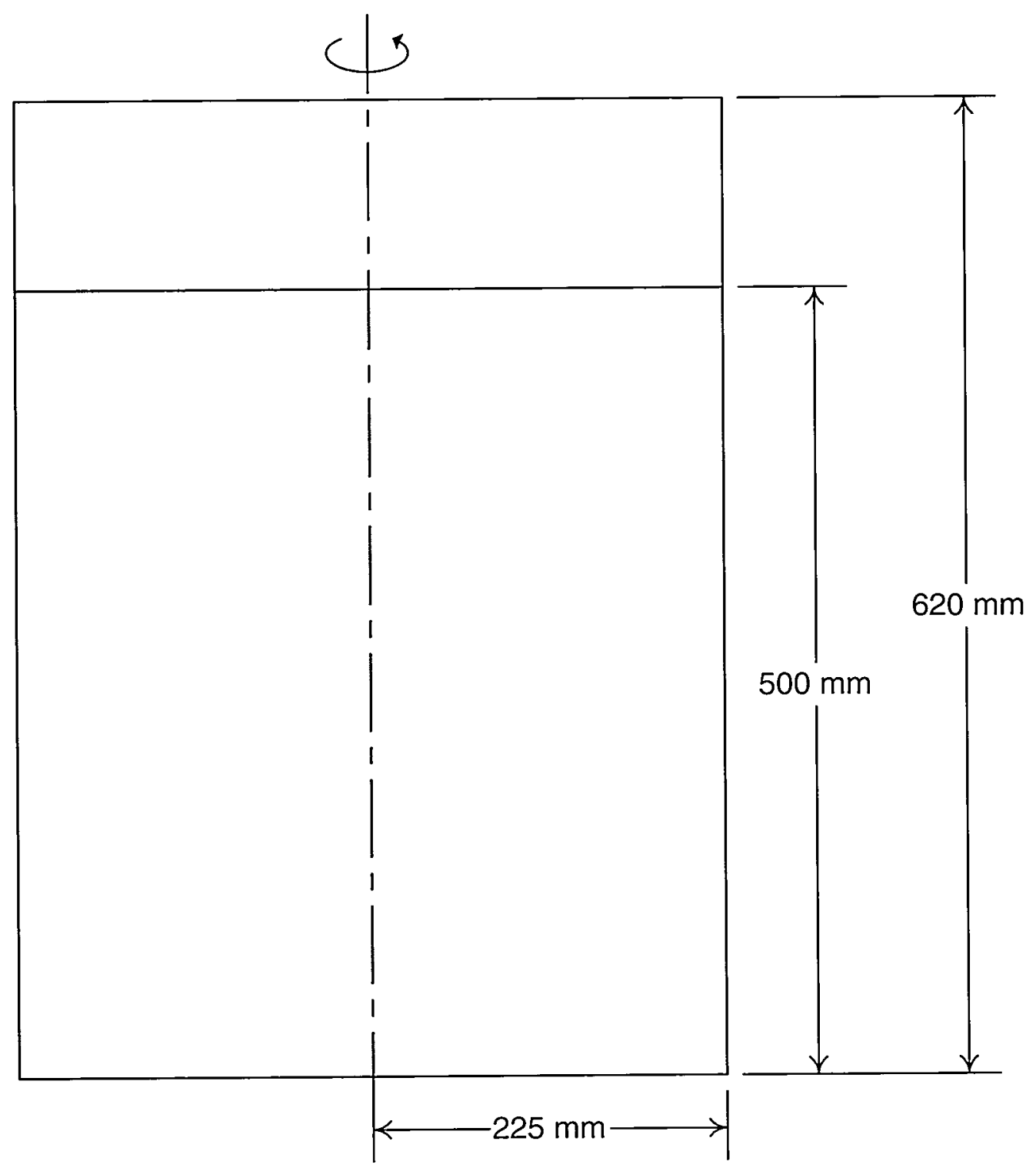

\begin{tabular}{|l|c|}
\hline Vessel Volume & $100.0 \ell$ \\
\hline Fissile Volume & $80.0 \ell$ \\
\hline Fissile Mass & $1.26 \mathrm{~kg}$ \\
\hline Fissile Density & $15.8 \mathrm{~g} / \ell$ \\
\hline
\end{tabular}

\begin{tabular}{|l|r|}
\hline $\begin{array}{l}\text { Estimated Spherical } \\
\text { Critical Mass }\end{array}$ & $1.05 \mathrm{~kg}$ \\
\hline First Spike Yield & none \\
\hline Specific Spike Yield & none \\
\hline Total Yield & $\sim 2.0 \times 10^{17}$ \\
\hline
\end{tabular}




\section{Siberian Chemical Combine (Tomsk), 30 January 1963}

Uranyl nitrate solution, $U(90)$, in a collection vessel; multiple excursions; insignificant exposures.

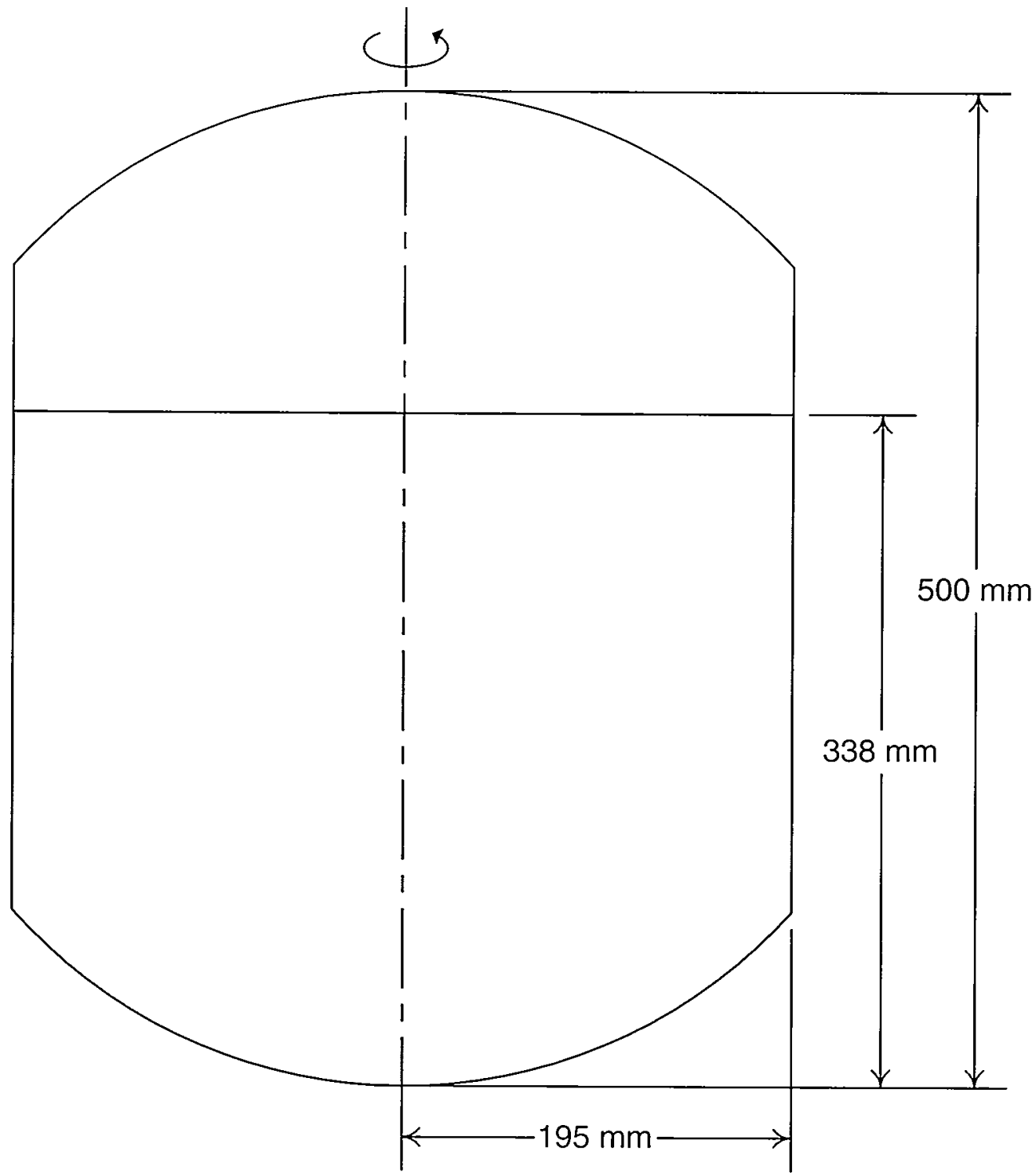

\begin{tabular}{|l|r|}
\hline Vessel Volume & $49.9 \ell$ \\
\hline Fissile Volume & $35.5 \ell$ \\
\hline Fissile Mass & $2.27 \mathrm{~kg}$ \\
\hline Fissile Density & $63.9 \mathrm{~g} / \ell$ \\
\hline
\end{tabular}

\begin{tabular}{|l|r|}
\hline $\begin{array}{l}\text { Estimated Spherical } \\
\text { Critical Mass }\end{array}$ & $2.06 \mathrm{~kg}$ \\
\hline First Spike Yield & unknown \\
\hline Specific Spike Yield & unknown \\
\hline Total Yield & $7.9 \times 10^{17}$ \\
\hline
\end{tabular}




\section{Siberian Chemical Combine, 2 December 1963}

Uranium organic solution, $U(90)$, in a vacuum system holding vessel; multiple excursions; insignificant exposures.

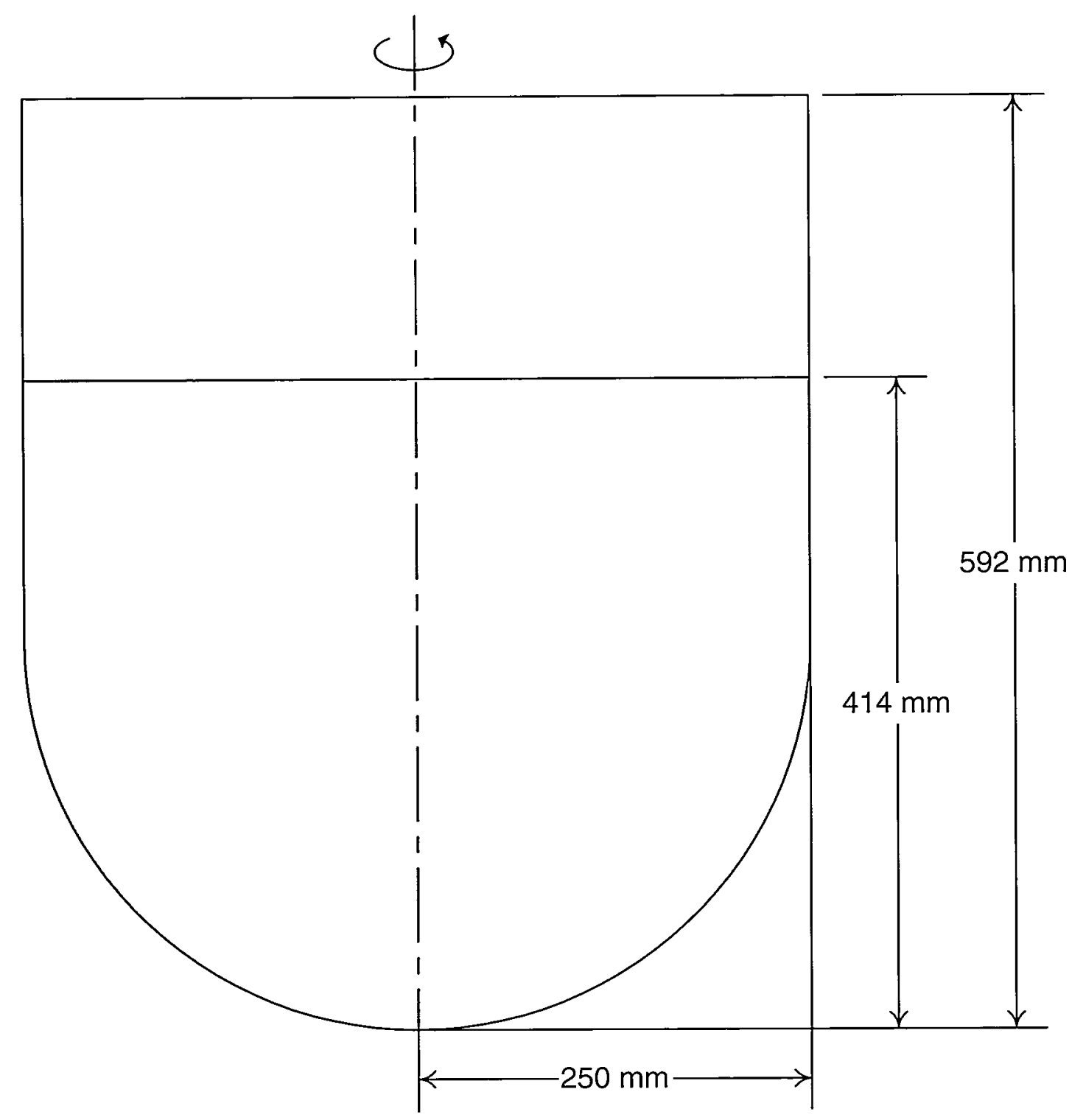

\begin{tabular}{|l|r|}
\hline Vessel Volume & $100.0 \ell$ \\
\hline Fissile Volume & $64.8 \ell$ \\
\hline Fissile Mass & $1.93 \mathrm{~kg}$ \\
\hline Fissile Density & $29.8 \mathrm{~g} / \ell$ \\
\hline
\end{tabular}

\begin{tabular}{|l|r|}
\hline $\begin{array}{l}\text { Estimated Spherical } \\
\text { Critical Mass }\end{array}$ & $1.38 \mathrm{~kg}$ \\
\hline First Spike Yield & none \\
\hline Specific Spike Yield & none \\
\hline Total Yield & $0.16 \times 10^{17}$ \\
\hline
\end{tabular}




\section{United Nuclear Fuels Recovery Plant, 24 July 1964}

Uranyl nitrate solution, $U(93)$, in a carbonate reagent makeup vessel; tw'o excursions; one fatality, two significant exposures.

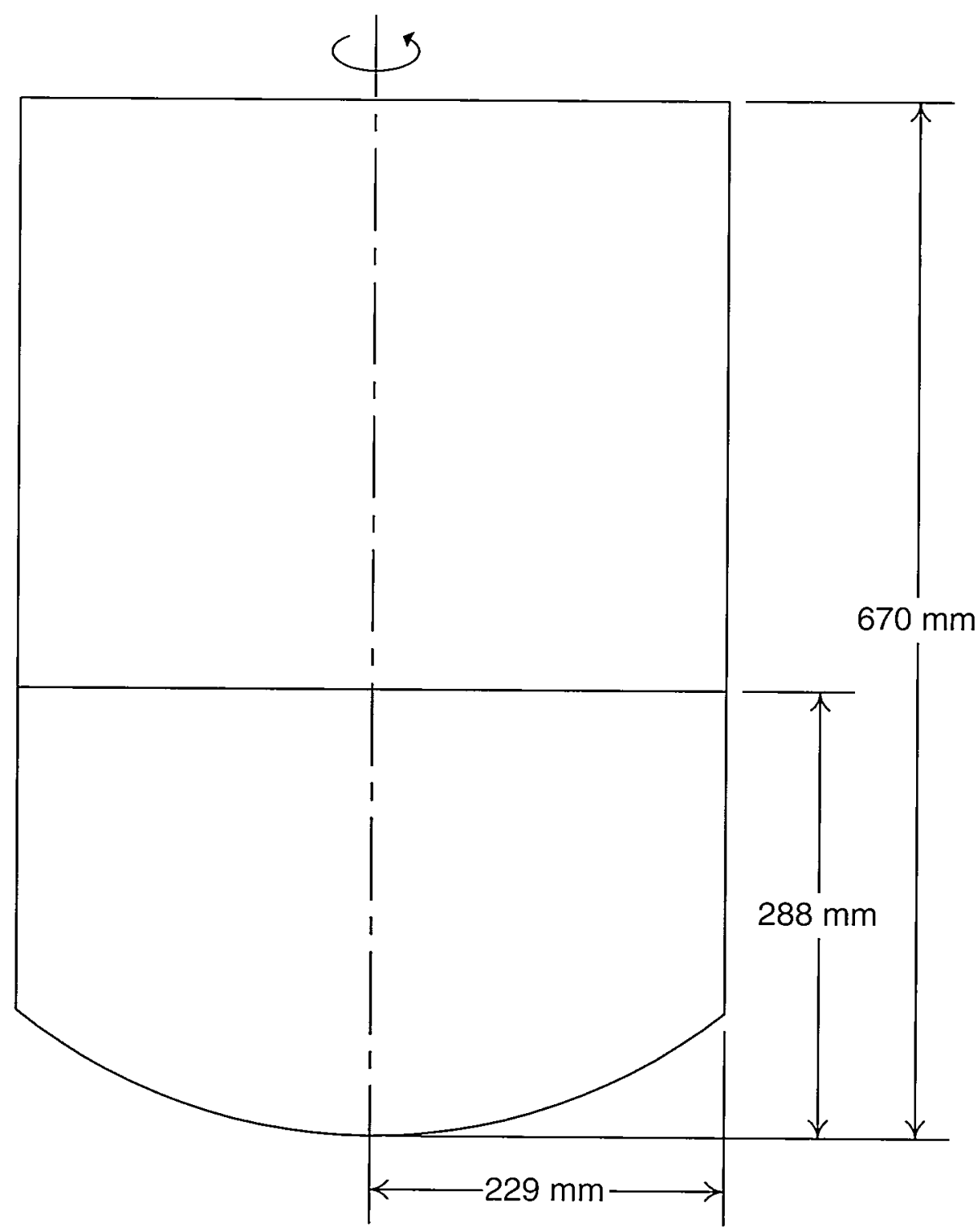

\begin{tabular}{|l|r|}
\hline Vessel Volume & $103.7 \ell$ \\
\hline Fissile Volume & $41.0 \ell$ \\
\hline Fissile Mass & $2.07 \mathrm{~kg}$ \\
\hline Fissile Density & $50.5 \mathrm{~g} / \ell$ \\
\hline
\end{tabular}

\begin{tabular}{|l|c|}
\hline $\begin{array}{l}\text { Estimated Spherical } \\
\text { Critical Mass }\end{array}$ & $1.72 \mathrm{~kg}$ \\
\hline First Spike Yield & $\sim 1.0 \times 10^{17}$ \\
\hline Specific Spike Yield & $2.4 \times 10^{15}$ \\
\hline Total Yield & $\sim 1.3 \times 10^{17}$ \\
\hline
\end{tabular}




\section{Electrostal Machine Building Plant, 3 November 1965}

Uranium oxide slurry, $U(6.5)$, in a vacuum system vessel; single excursion; insignificant exposures.

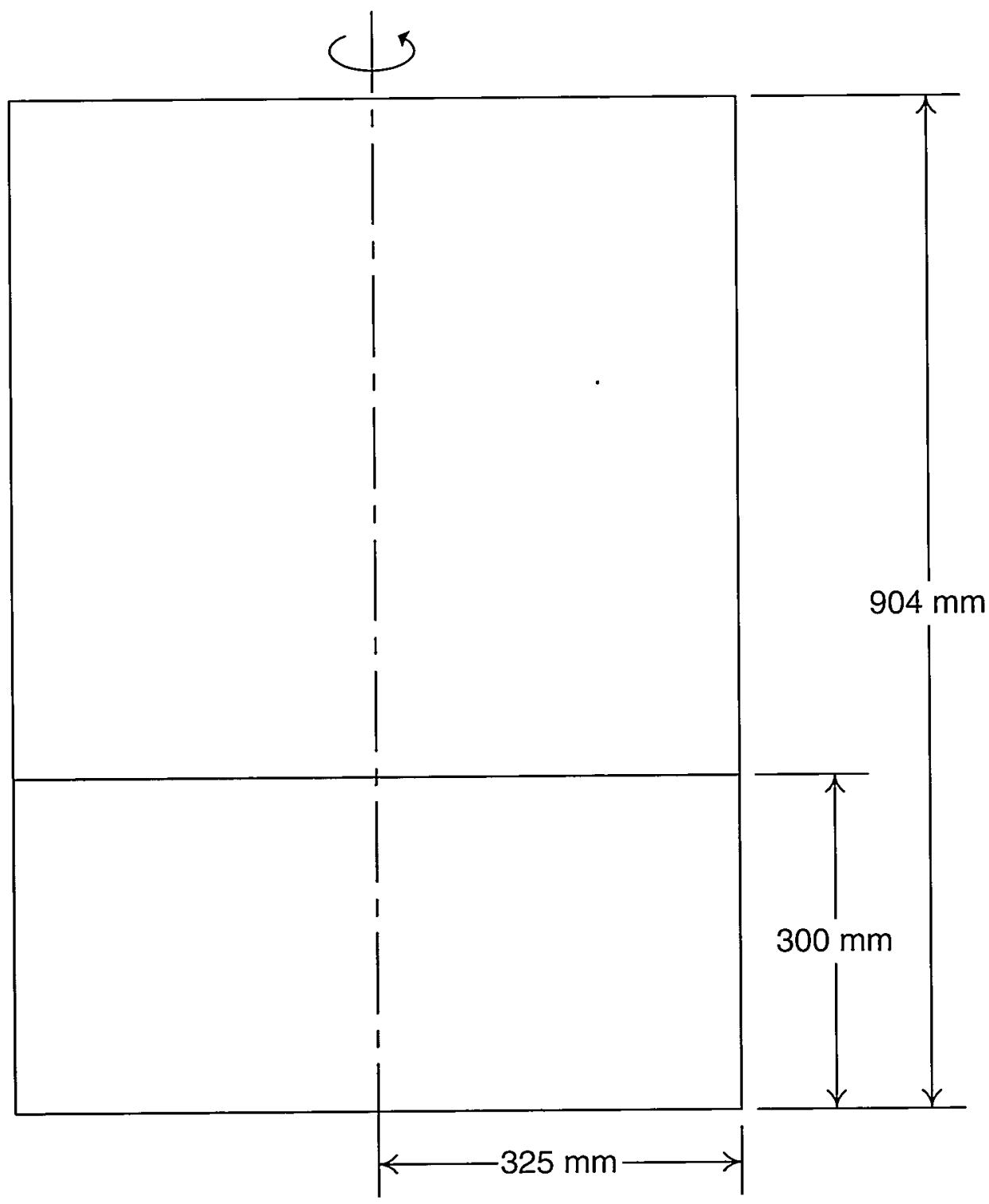

\begin{tabular}{|l|c|}
\hline Vessel Volume & $300.0 \ell$ \\
\hline Fissile Volume & $100.0 \ell$ \\
\hline Fissile Mass & $3.65 \mathrm{~kg}$ \\
\hline Fissile Density & $36.5 \mathrm{~g} / \ell$ \\
\hline
\end{tabular}

\begin{tabular}{|l|r|}
\hline $\begin{array}{l}\text { Estimated Spherical } \\
\text { Critical Mass }\end{array}$ & $1.6 \mathrm{~kg}$ \\
\hline First Spike Yield & none \\
\hline Specific Spike Yield & none \\
\hline Total Yield & $\sim 0.08 \times 10^{17}$ \\
\hline
\end{tabular}




\section{Mayak Production Association, 16 December 1965}

Uranyl nitrate solution, U(90), in a dissolution vessel; multiple excursions; insignificant exposures.

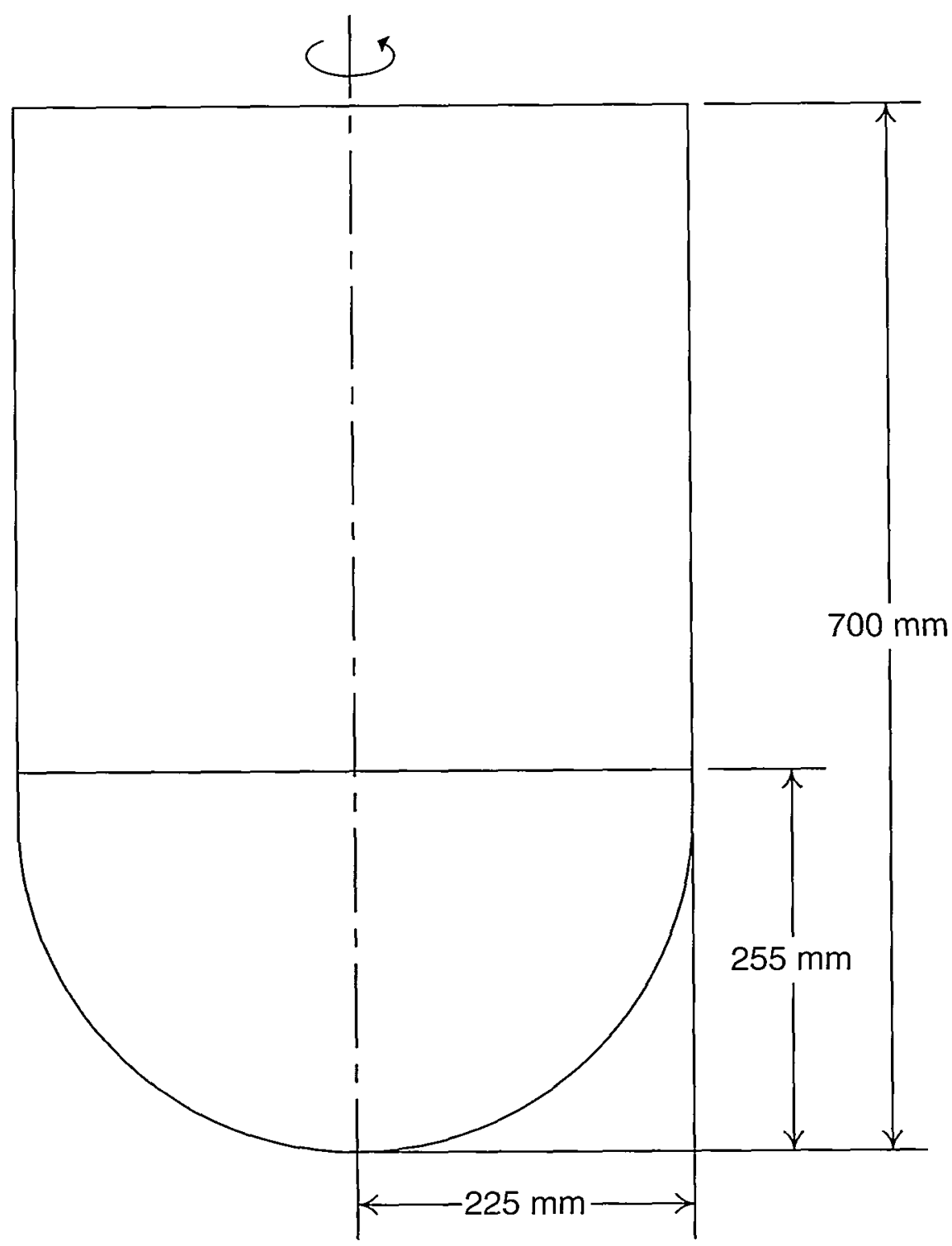

\begin{tabular}{|l|r|}
\hline Vessel Volume & $100.0 \ell$ \\
\hline Fissile Volume & $28.6 \ell$ \\
\hline Fissile Mass & $1.98 \mathrm{~kg}$ \\
\hline Fissile Density & $69.2 \mathrm{~g} / \ell$ \\
\hline
\end{tabular}

\begin{tabular}{|l|r|}
\hline $\begin{array}{l}\text { Estimated Spherical } \\
\text { Critical Mass }\end{array}$ & $1.65 \mathrm{~kg}$ \\
\hline First Spike Yield & none \\
\hline Specific Spike Yield & none \\
\hline Total Yield & $\sim 5.5 \times 10^{17}$ \\
\hline
\end{tabular}


17. Mayak Production Association, 10 December 1968

Plutonium solutions (aqueous and organic) in a 60 liter vessel; three excursions; one fatality, one serious exposure.

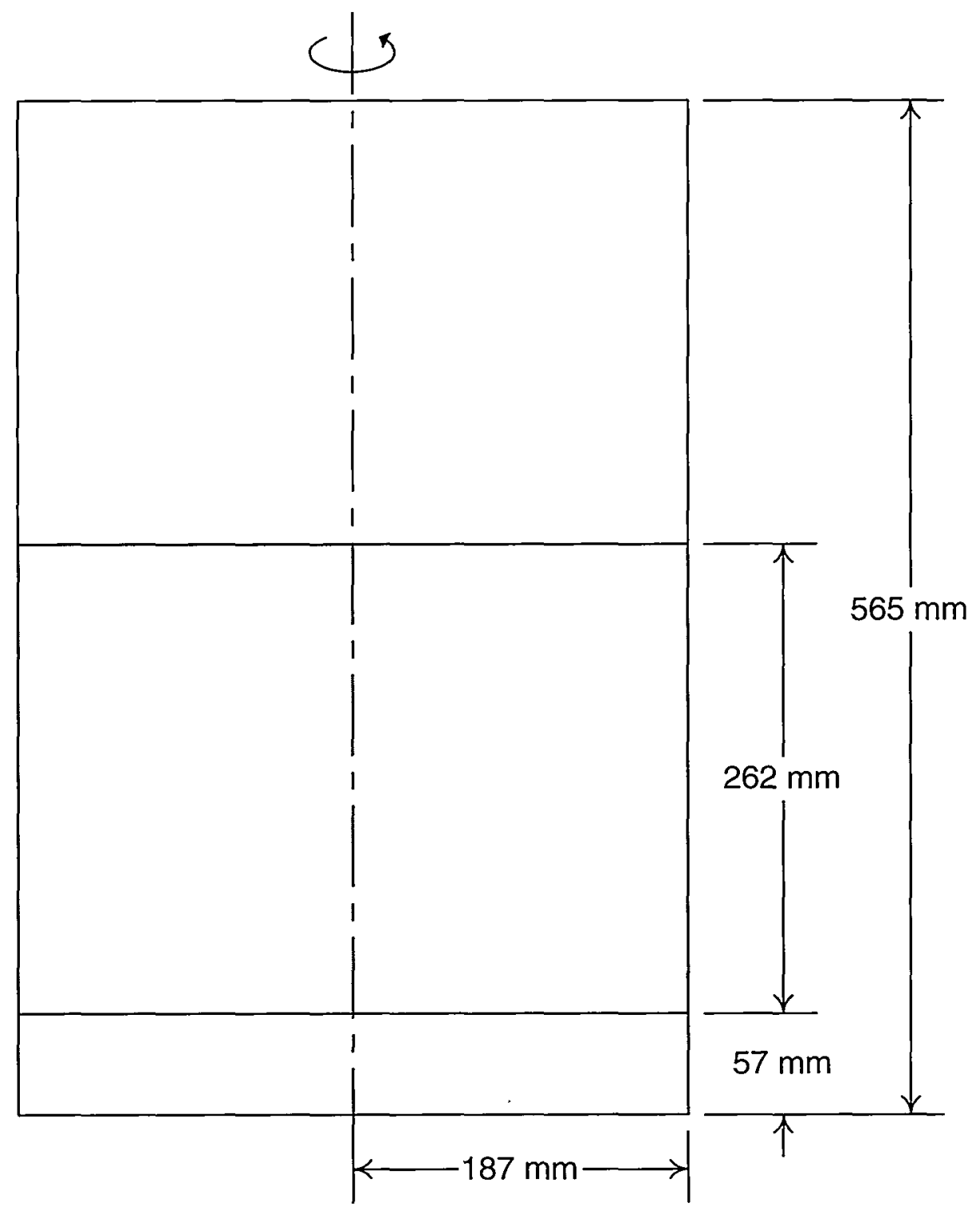

\begin{tabular}{|l|r|l|r|}
\hline Vessel Volume & $62.1 \ell$ & $\begin{array}{l}\text { Estimated Spherical } \\
\text { Critical Mass }\end{array}$ & $1.36 \mathrm{~kg}$ \\
\hline Fissile Volume & $28.8 \ell$ \\
\hline Fissile Mass & $1.50 \mathrm{~kg}$ \\
\hline Fissile Density & $52.1 \mathrm{~g} / \ell$ \\
\cline { 1 - 3 } & Specific Spike Yield & $1.0 \times 10^{15}$ \\
\hline Total Yield & $\sim 1.3 \times 10^{17}$ \\
\hline
\end{tabular}


18. Windscale Works, 24 August 1970

Plutonium organic solution in a transfer vessel; one excursion; insignificant exposures.

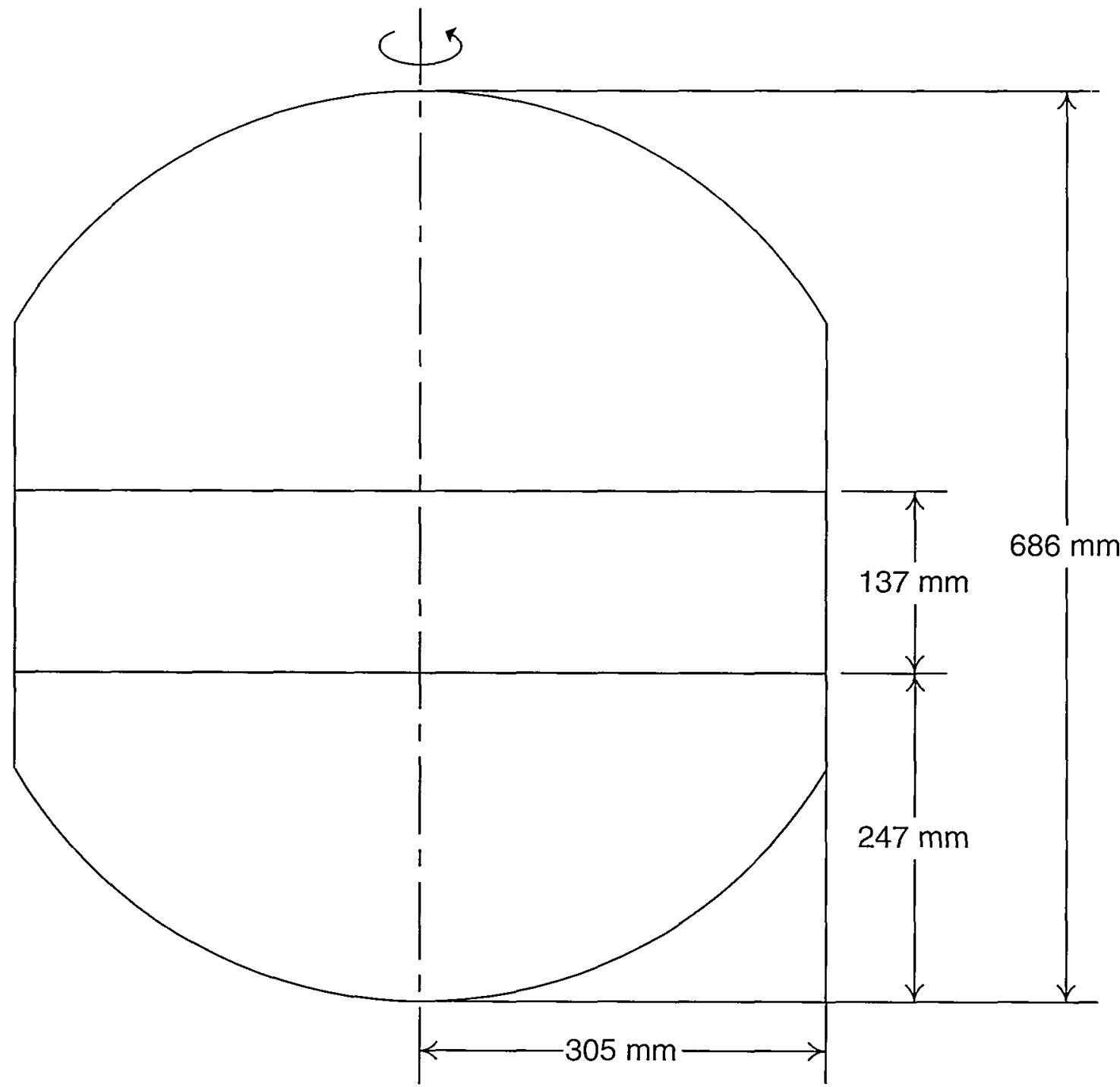

\begin{tabular}{|l|r|}
\hline Vessel Volume & $156.0 \ell$ \\
\hline Fissile Volume & $40.0 \ell$ \\
\hline Fissile Mass & $2.07 \mathrm{~kg}$ \\
\hline Fissile Density & $51.8 \mathrm{~g} / \ell$ \\
\hline
\end{tabular}

\begin{tabular}{|l|r|}
\hline $\begin{array}{l}\text { Estimated Spherical } \\
\text { Critical Mass }\end{array}$ & $0.69 \mathrm{~kg}$ \\
\hline First Spike Yield & none \\
\hline Specific Spike Yield & none \\
\hline Total Yield & $0.01 \times 10^{17}$ \\
\hline
\end{tabular}




\section{Idaho Chemical Processing Plant, 17 October 1978}

Uranyl nitrate solution, $U(82)$, in a lower disengagement section of a scrubbing column; excursion history unknown; insignificant exposures.

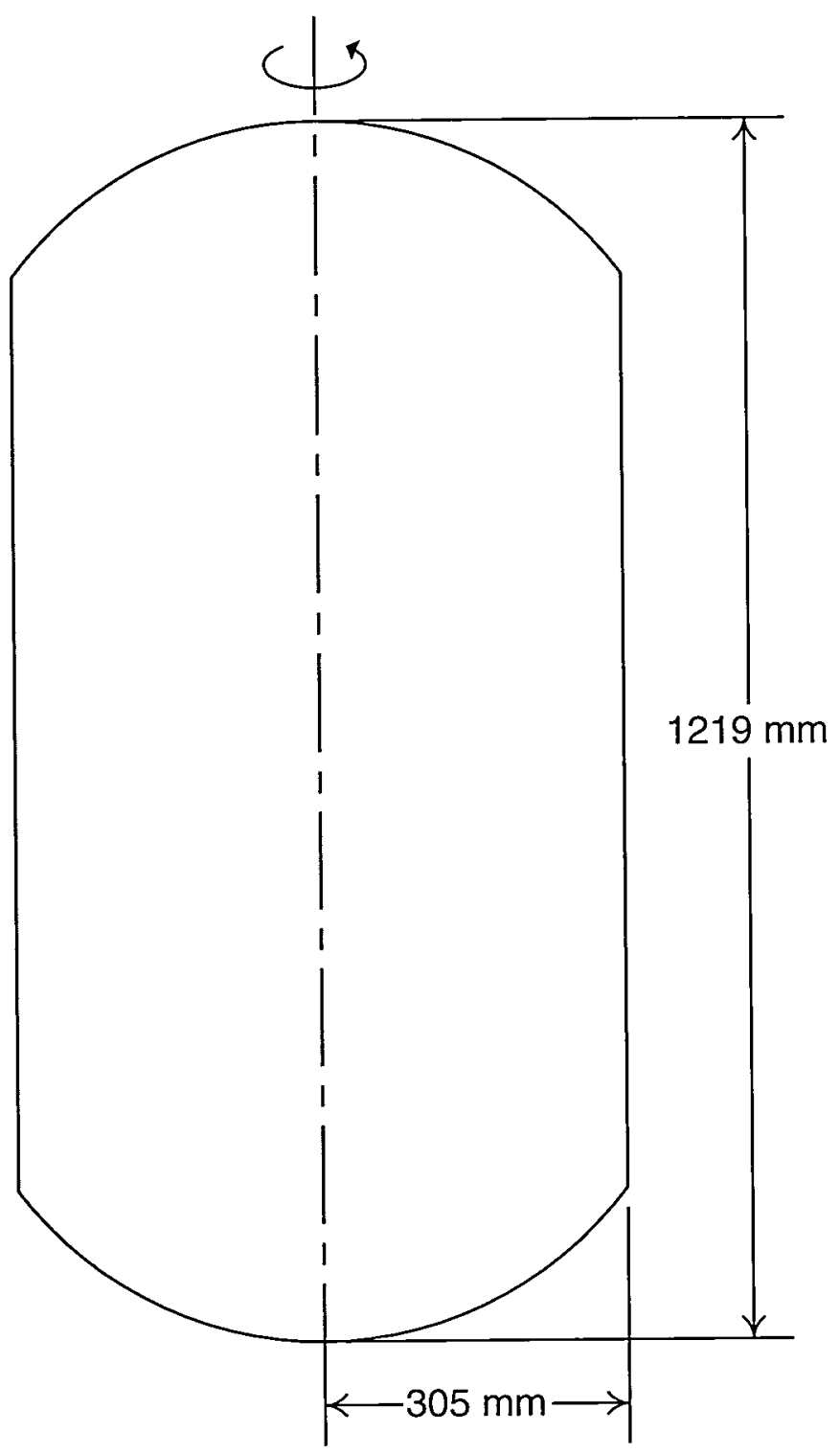

\begin{tabular}{|l|r|}
\hline Vessel Volume & $315.5 \ell$ \\
\hline Fissile Volume & $315.5 \ell$ \\
\hline Fissile Mass & $6.08 \mathrm{~kg}$ \\
\hline Fissile Density & $19.3 \mathrm{~g} / \ell$ \\
\hline
\end{tabular}

\begin{tabular}{|l|r|}
\hline $\begin{array}{l}\text { Estimated Spherical } \\
\text { Critical Mass }\end{array}$ & $4.34 \mathrm{~kg}$ \\
\hline First Spike Yield & unknown \\
\hline Specific Spike Yield & unknown \\
\hline Total Yield & $27.0 \times 10^{17}$ \\
\hline
\end{tabular}


20. Siberian Chemical Combine (Tomsk), 13 December 1978

Plutonium metal ingots in a storage container; single excursion; one serious exposure, seven significant exposures.

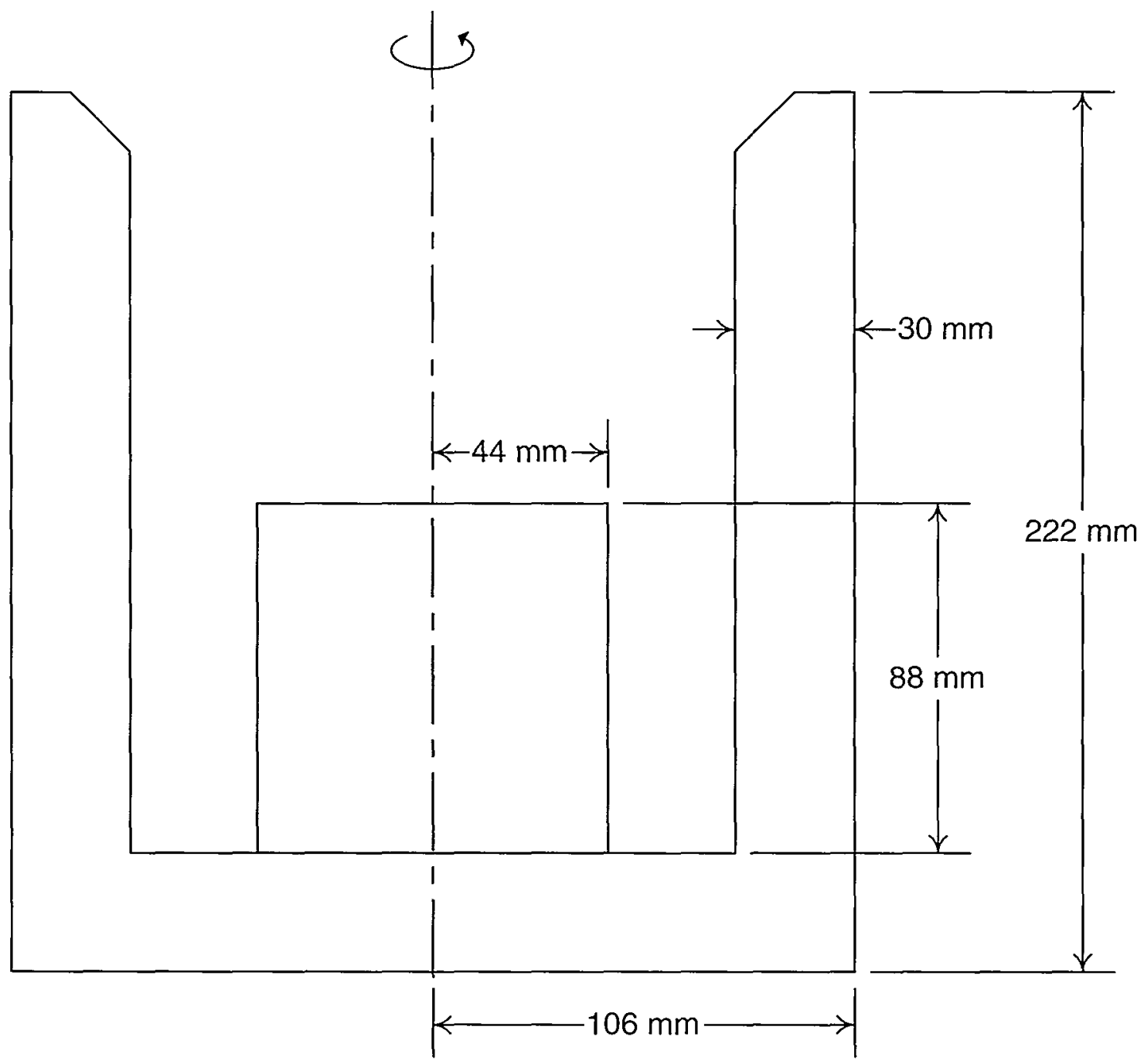

\begin{tabular}{|l|r|}
\hline Vessel Volume & $3.2 \ell$ \\
\hline Fissile Volume & $0.54 \ell$ \\
\hline Fissile Mass & $10.1 \mathrm{~kg}$ \\
\hline Fissile Density & $18,700 \mathrm{~g} / \ell$ \\
\hline
\end{tabular}

\begin{tabular}{|l|r|}
\hline $\begin{array}{l}\text { Estimated Spherical } \\
\text { Critical Mass }\end{array}$ & $9.18 \mathrm{~kg}$ \\
\hline First Spike Yield & $0.03 \times 10^{17}$ \\
\hline Specific Spike Yield & $5.6 \times 10^{15}$ \\
\hline Total Yield & $0.03 \times 10^{17}$ \\
\hline
\end{tabular}


Uranium oxide slurry and crust, $U(70)$, in the lower regions of two parallel vessels; multiple excursions; insignificant exposures.

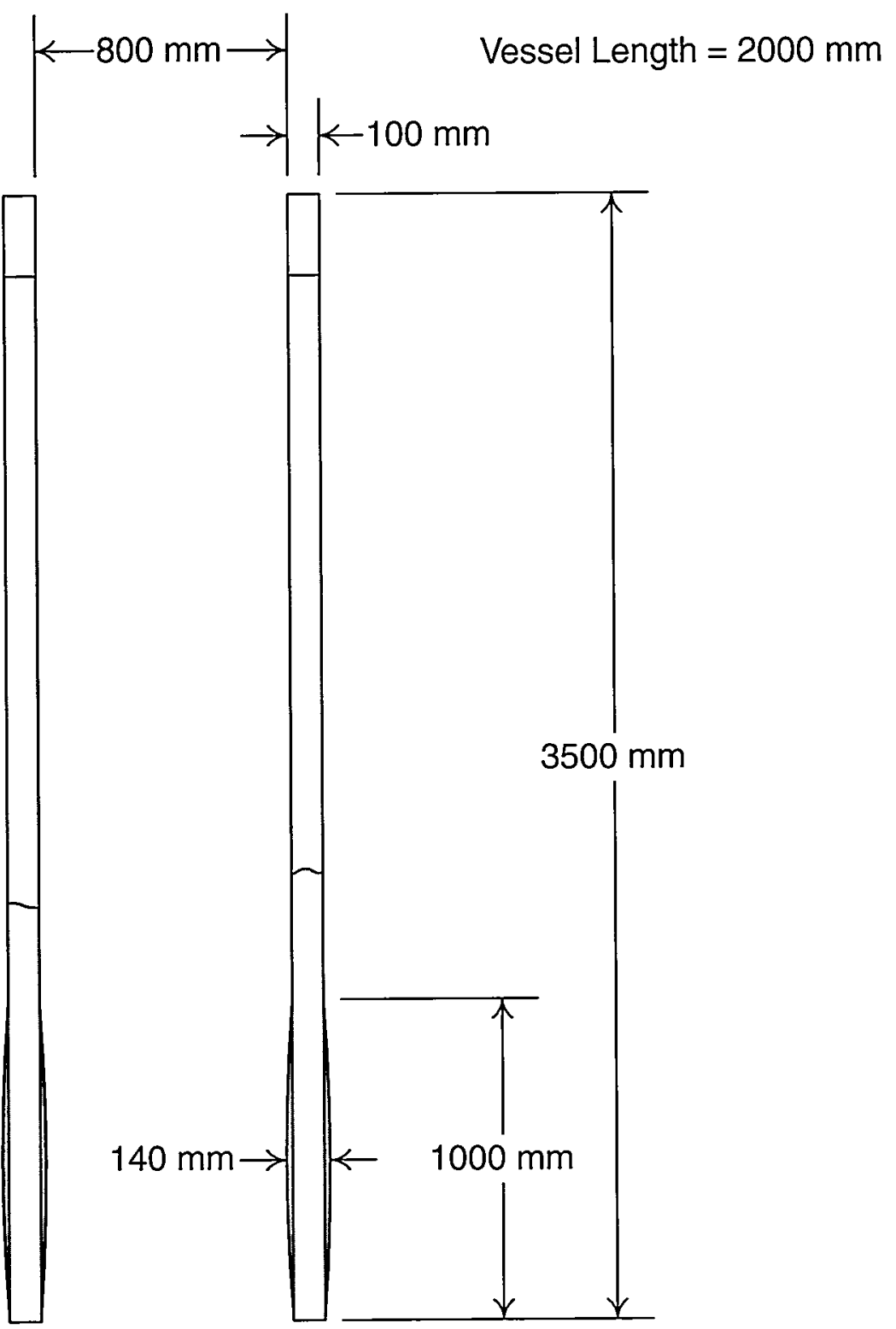

\begin{tabular}{|l|c|}
\hline Vessel Volume & $\begin{array}{r}700.0 \ell \\
\text { per vessel }\end{array}$ \\
\hline Fissile Volume & $*$ \\
\hline Fissile Mass & $17.1 \mathrm{~kg}$ \\
\hline Fissile Density & $*$ \\
\hline
\end{tabular}

\begin{tabular}{|l|r|}
\hline $\begin{array}{l}\text { Estimated Spherical } \\
\text { Critical Mass }\end{array}$ & \multicolumn{1}{|c|}{ * } \\
\hline First Spike Yield & none \\
\hline Specific Spike Yield & $0.055 \times 10^{17}$ \\
\hline Total Yield & \\
\hline
\end{tabular}

* System description was not adequate to estimate parameter. 


\section{JCO Fuel Fabrication Plant, 30 September 1999}

Uranyl nitrate solution, U(18.8), in a precipitation vessel; multiple excursions; two fatalities, one significant exposure.

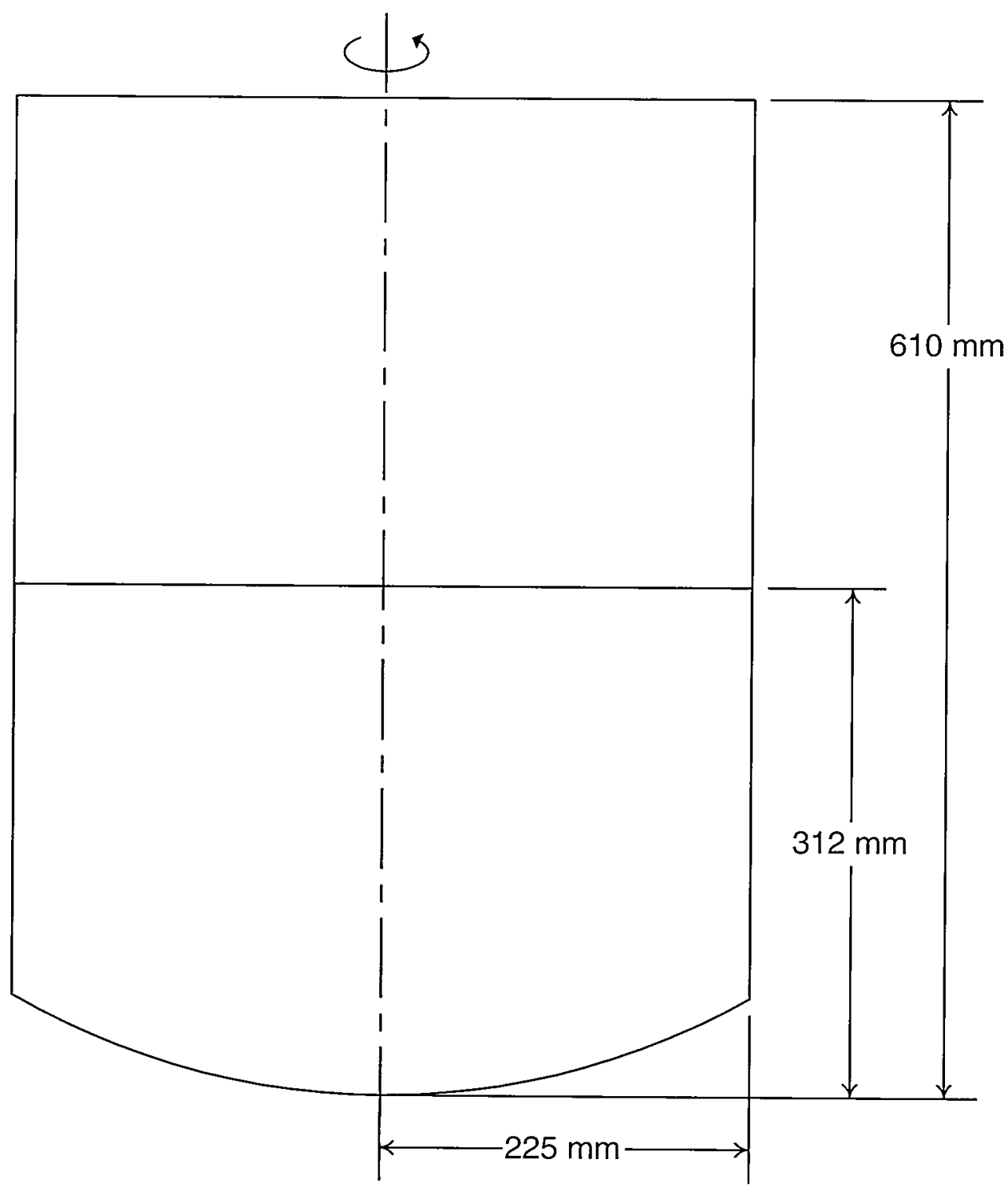

\begin{tabular}{|l|r|}
\hline Vessel Volume & $100.0 \ell$ \\
\hline Fissile Volume & $45.0 \ell$ \\
\hline Fissile Mass & $3.12 \mathrm{~kg}$ \\
\hline Fissile Density & $69.3 \mathrm{~g} / \ell$ \\
\hline
\end{tabular}

\begin{tabular}{|l|r|}
\hline $\begin{array}{l}\text { Estimated Spherical } \\
\text { Critical Mass }\end{array}$ & $1.9 \mathrm{~kg}$ \\
\hline First Spike Yield & $\sim 0.5 \times 10^{17}$ \\
\hline Specific Spike Yield & $1.1 \times 10^{15}$ \\
\hline Total Yield & $25 \times 10^{17}$ \\
\hline
\end{tabular}

